\title{
MODELO MATEMÁTICO PARA PREVISÃO DA MACROESTRUTURA BRUTA DE SOLIDIFICAÇÃO SOB EFEITO DA DECANTAÇÃO DE GRÃOS EQUIAXIAIS
}

Dissertação apresentada à Escola Politécnica da Universidade de São Paulo para obtenção do título de

Mestre em Engenharia de Materiais 


\title{
MODELO MATEMÁTICO PARA PREVISÃO DA MACROESTRUTURA BRUTA DE SOLIDIFICAÇÃO SOB EFEITO DA DECANTAÇÃO DE GRÃOS EQUIAXIAIS
}

\author{
Dissertação apresentada à Escola \\ Politécnica da Universidade de São \\ Paulo para obtenção do título de \\ Mestre em Engenharia de Materiais
}

Área de Concentração:

Engenharia de Metalúrgica e de Materiais

Orientador: Prof. Dr. Marcelo de Aquino Martorano 


\section{AGRADECIMENTOS}

Ao professor e orientador Marcelo de Aquino Martorano pelo incentivo, pela precisa orientação neste início da minha carreira acadêmica e pelo tempo pacientemente despendido.

Aos professores Marcelo Breda Mourão, Ivan Gilberto Sandoval Falleiros, Neusa Alonso Falleiros, Ângelo Fernando Padilha, César R. F. Azevedo, Tah Wung Son e José Luiz de Paiva pela formação proporcionada.

À CAPES e aoCNPq pelo auxílio oferecido durante a realização deste trabalho.

À minha namorada Daniele Honda Gerage, pelo apoio, compreensão e amor incondicional. Aos meus amigos e colegas Rafael Bechelli Paviato, Gustavo Russo Blazek, Pedro Garcia Lins, Hugo Hashimoto por inúmeras ajudas técnicas e pelos momentos de descontração. Aos amigos Ana Beatriz, Daniela Ortega, Thiago Ricarte, Thiago Hila, Bruno Chies, Felipe Bregalda, Diego Caleiro e Leo Arruda cujas presenças elimininam qualquer stress de um fim de dia de intenso trabalho.

Aos meus pais Leila Solange D'Amelio Briquet Caradec e Jean Pierre Alexis Briquet Caradec, por tudo. Tomaria páginas e páginas para descrever todo o apoio incalculável que recebi deles. 


\section{RESUMO}

Durante a solidificação de ligas metálicas, a decantação de grãos equiaxiais pode causar: macrossegregação, mudança na posição da transição colunar-equiaxial e alteração no tamanho de grão equiaxial. O objetivo do presente trabalho é a implementação e análise de um modelo matemático para simular a solidificação sob efeito da decantação de grãos. Este modelo combina: (a) a técnica do autômato celular bi-dimensional em escala microscópica considerando a decantação de grãos,(b) um submodelo microscópico baseado em equações de conservação para simular os processos internos aos grãos e (c) um submodelo macroscópico também baseado em equações de conservação para simular os processos importantes da escala de tamanho macroscópica. Os submodelos macroscópico e microscópico compartilham informações correspondentes às suas escalas características de tamanho através de um método de acoplamento. O modelo matemático completo foi examinado inicialmente através da simulação de diversas situações idealizadas como: a decantação de uma esfera sólida, a decantação de um conjunto de esferas porosas e a decantação e solidificação simultânea de um grão dendrítico isolado e imerso em um líquido super-resfriado. Posteriormente, compararam-se os resultados do modelo para a solidificação isotérmica e para a solidificação unidirecional com resultados disponíveis na literatura obtidos por outros modelos numéricos e por técnicas experimentais. Os resultados do modelo mostraram que a decantação de grãos resulta nos seguintes efeitos no caso da solidificação unidirecional: variação de tamanho médio de grãos e macrossegregação ao longo do lingote e alteração ou até eliminação na posição da transição colunar-equiaxial.

Palavras-chave: Solidificação, Modelos Matemáticos, Decantação, Autômato Celular. 


\begin{abstract}
During solidification of metallic alloys, the settling of equiaxed grains can cause macrosegregation, change the position of the columnar-to-equiaxed transition, and change the grain size of equiaxed grains. The objective of the present work is to implement and analyze a mathematical model to simulate the solidification under the effect of grain settling. The present model combines: (a) the cellular automaton technique in two dimensions applied in the microscopic lengthscale to account for the movement of grains; (b) a microscopic submodel based on conservation equations to simulate important phenomena occurring within the grains, and (c) a macroscopic submodel, also based on conservation equations, to simulate important phenomena of the macroscopic lengthscale. Using a strong coupling scheme, the macroscopic and microscopic submodels share important information specific to their typical lengthscales. The complete mathematical model was initially examined in several idealized conditions: the settling of a single solid sphere; the settling of a group of porous spheres; and the growth of a single dendritic grain settling in an undercooled liquid. The model was also used to simulate the isothermal solidification and the unidirectional solidification. For these cases, the outcome of the model was compared with experimental and calculated results available in the literature. For the unidirectional solidification, the model results showed that the settling of grains can cause a variation in the macrosegregation and grain size along the ingot and can change the position or even eliminate the columnar-to-equiaxed transition region.
\end{abstract}

Keywords: Solidification, Mathematical Modelling, Settling, Cellular Automaton 


\section{LISTA DE ABREVIAÇÕES}

VER Volume representativo elementar

$\begin{array}{ll}\text { CA } & \text { Autômato celular } \\ \text { VF } & \text { Volume finito } \\ \text { CET } & \text { Transição colunar-equiaxial } \\ \text { MC } & \text { Monte Carlo } \\ \text { Eq. } & \text { Equação }\end{array}$

Subscritos e sobrescritos:$$
\mathrm{S}
$$

Fase sólida primária

e Fase eutética / Envelope (dependendo do contexto)

d Fase líquida interdendrítica

I Fase líquida extradendrítica

g Grão

C Aglomerado ("Cluster")

M Submodelo macroscópico

m Submodelo microscópico

VF Relativo a um volume finito

CA Relativo a uma célula

$\Gamma \quad$ Relativo à movimentação de interfaces

D Relativo à difusão

t Relativo ao Instante de tempo "t"

sh Relativo à forma

sph Relativa à esfera equivalente

$\vec{\psi}^{\prime} \quad$ Grandeza $\vec{\psi}$ relativa a um referencial móvel

* $\quad$ Efetiva / Adimensional (dependendo do contexto)

$0 \quad$ Inicial

N Nucleação 


\section{LISTA DE SÍMBOLOS}

$a_{2}$ Constante para o crescimento dendrítico. $\left(\mathrm{m} / \mathrm{s} / \mathrm{K}^{-2}\right)$

$a_{3}$ Constante para o crescimento dendrítico. $\left(\mathrm{m} / \mathrm{s} / \mathrm{K}^{-3}\right)$

$A_{C} \quad$ Área equivalente de um "cluster". $\left(\mathrm{m}^{2}\right)$

$A_{C_{0}} \quad$ Constante de crescimento $\left(\mathrm{m}^{2}\right)$

$A_{\mathrm{N}} \quad$ Constante para taxa de nucleação

$A_{k} \quad$ Área de interface de uma fase "k" no VER.

$A_{k j} \quad$ Área de interface comum entre as fases " $k$ " e "j" no VER. $\left(m^{2}\right)$

$A_{\text {proj }}$ Área projetada de um sólido. $\left(\mathrm{m}^{2}\right)$

$C_{k} \quad$ Concentração de soluto em uma fase "k". (\%)

$C_{0} \quad$ Concentração média de soluto na liga. (\%)

$C_{s} \quad$ Concentração da fase sólida. (\%massa)

$C_{l} \quad$ Concentração da fase líquida (\%massa)

$C_{D} \quad$ Coeficiente de arraste. (-)

$C_{P} \quad$ Calor específico. $\left(\mathrm{J} \cdot \mathrm{kg}^{-1} \cdot \mathrm{K}^{-1}\right)$

$C_{s h} \quad$ Coeficiente de forma na força de arraste (-)

$\Delta \vec{C}_{\mu} \quad$ Vetor descentralização de um polígono de crescimento da célula $\mu(\mathrm{m})$

$d_{g} \quad$ Diâmetro equivalente de um grão $(\mathrm{m})$

$d_{s p h} \quad$ Diâmetro de uma esfera de volume equivalente $(\mathrm{m})$

$d^{*} \quad$ Diâmetro adimensional (-)

$D \quad$ Difusividade de soluto. $\left(\mathrm{m}^{2} / \mathrm{s}\right)$

$E_{1} \quad$ Função Exponencial Integral

$\vec{F}_{D} \quad$ Força de arraste (N)

$\vec{g} \quad$ Vetor gravidade $\left(\mathrm{m} / \mathrm{s}^{2}\right)$

$G \quad$ Gradiente de temperatura $(\mathrm{K} / \mathrm{m})$

$G_{y} \quad$ Gradiente de temperatura no eixo vertical $(\mathrm{K} / \mathrm{m})$ 
$\Delta G_{s l} \quad$ Variação de energia livre de Gibbs de transformação de líquido para sólido $\left(\mathrm{J} / \mathrm{m}^{3}\right)$

h Coeficiente de transferência de calor. (W. $\mathrm{m}^{-2} \cdot \mathrm{K}^{-1}$ )

Iv Função de Ivantsov

$\vec{j}_{k j} \quad$ Fluxo difusivo na interface entre a fase "k" e "j". (kg.\%.s.-1.m $\left.{ }^{-2}\right)$

$J_{k j} \quad \Theta_{k j}$ para a massa de soluto. $\left(\mathrm{kg} . \% \cdot \mathrm{s}^{-1} \cdot \mathrm{m}^{-3}\right)$

$k \quad$ Coeficiente de partição de soluto. (-)

$k_{p} \quad$ Permeabilidade de um meio isotrópico. $\left(\mathrm{m}^{2}\right)$

$K \quad$ Condutividade Térmica. $(\mathrm{W} / \mathrm{m} / \mathrm{K})$

$\bar{K} \quad$ Condutividade Térmica de Mistura. $(\mathrm{W} / \mathrm{m} / \mathrm{K})$

$K_{1}, K_{2}$ Constantes para cálculo da velocidade terminal.

$L_{f} \quad$ Calor latente de fusão. $(\mathrm{J} / \mathrm{kg})$

$L_{l d} \quad$ Contorno de grãos por área. $\left(\mathrm{m}^{-1}\right)$

$L_{x} \quad$ Largura do molde $(\mathrm{m})$

$L_{y} \quad$ Altura do molde $(\mathrm{m})$

$\vec{L}_{\mu[10]}$ Vetor diagonal de um polígono de crescimento da célula $\mu(\mathrm{m})$

$m_{l} \quad$ Inclinação da curva liquidus (K/\%)

$M_{\mathrm{TiB}_{2}} \quad$ Massa total de inoculante $(\mathrm{kg})$

$n \quad$ Densidade de número de núcleos $\left(\mathrm{m}^{-3}\right)$

$n_{g} \quad$ Densidade de número de grãos $\left(\mathrm{m}^{-3}\right)$

$n_{S}^{*} \quad$ Quantidade de substratos por superfície do molde (unid. $/ \mathrm{m}^{2}$ )

$n_{V}^{*} \quad$ Quantidade de substratos por volume (unid. $/ \mathrm{m}^{3}$ )

$n_{A} \quad$ Quantidade equivalente de substratos por área de domínio bidimensional. (unid. $/ \mathrm{m}^{2}$ )

$n_{L} \quad$ Quantidade equivalente de substratos por contorno de domínio bidimensional. (unid./m)

$n_{\max } \quad$ Densidade máxima de número de grãos (unid. $/ \mathrm{m}^{3}$ )

$\vec{n}_{k} \quad$ Versor normal à interface de uma fase "k".

$\vec{n}_{x} \quad$ Versor na direção horizontal. 
$\vec{n}_{y} \quad$ Versor na direção vertical.

$P \quad$ Adimensional para efeito da composição da CET (-)

$r \quad$ Raio de curvatura da ponta de uma dendrita $(\mathrm{m})$

$r^{*} \quad$ Raio crítico para a nucleação de um embrião $(\mathrm{m})$

$\Delta \vec{r}_{\mu}^{v} \quad$ Vetor distância entre o centro do polígono de crescimento da célula $\mu \mathrm{e}$ o centro da célula $v(\mathrm{~m})$

$R_{e} \quad$ Raio do envelope médio (m)

$R_{f} \quad$ Raio de referência $(\mathrm{m})$

Re Número de Reynolds. (-)

$S_{l d} \quad$ Área de grãos por volume. $\left.\left(\mathrm{m}^{-1}\right)\right)$

Sc $\quad$ Número de Schmidt. (-)

Pe Número de Peclet. (-)

$P e_{T} \quad$ Peclet térmico. (-)

$t \quad$ Tempo. (s)

$\Delta t \quad$ Passo de tempo. (s)

St Passo de tempo para a estabilidade do modelo. (s)

$T$ Temperatura (K)

$T_{k} \quad$ Temperatura em uma fase " $\mathrm{k}$ " (\%)

$T_{f} \quad$ Temperatura de fusão $(\mathrm{K})$

$T_{\text {liq }} \quad$ Temperatura líquidus (K)

$\dot{T} \quad$ Taxa de resfriamento $(\mathrm{K} / \mathrm{s})$

$\Delta T \quad$ Super-resfriamento (K)

$\Delta T_{C} \quad$ Super-resfriamento na frente colunar $(\mathrm{K})$

$\Delta T_{N} \quad$ Super-resfriamento de nucleação (K)

$\overline{\Delta T_{N}} \quad$ Super-resfriamento médio $(\mathrm{K})$

$\Delta T_{\sigma} \quad$ Desvio-padrão de super-resfriamentos. (K)

$\Delta T_{0} \quad$ Super-resfriamento/superaquecimento inicial. (K)

$\vec{w}_{k} \quad$ Velocidade da interface de uma fase " $\mathrm{k}$ " $(\mathrm{m} / \mathrm{s})$

$\vec{w}_{e}^{\prime} \quad$ Velocidade de crescimento do envelope dendrítico $(\mathrm{m} / \mathrm{s})$ 
$\vec{v}_{k} \quad$ Velocidade de uma fase " $\mathrm{k}$ " $(\mathrm{m} / \mathrm{s})$

$v_{f} \quad$ Velocidade do fluido ao longe $(\mathrm{m} / \mathrm{s})$

$v_{\text {iso }} \quad$ Velocidade das isotermas $(\mathrm{m} / \mathrm{s})$

$v_{t i p} \quad$ Velocidade de crescimento da ponta dendrítica $(\mathrm{m} / \mathrm{s})$

$v^{*} \quad$ Velocidade adimensional (-)

$V \quad$ Volume. $\left(\mathrm{m}^{3}\right)$

$V_{0} \quad$ Volume elementar representativo (VER). $\left(\mathrm{m}^{3}\right)$

$V_{k} \quad$ Volume de uma fase "k" no VER. $\left(\mathrm{m}^{3}\right)$

$\Delta x, \Delta y$ Dimensão de um volume finito. (m)

$\alpha_{l} \quad$ Difusividade de calor da fase líquida $\left(\mathrm{m}^{2} / \mathrm{s}\right)$

$\alpha_{\text {mov }}$ Coeficiente de segurança para a movimentação de grãos. (-)

$\beta \quad$ Raio adimensional de uma esfera porosa (-)

$\gamma_{s l} \quad$ Tensão da interface sólido-líquido $\left(\mathrm{J} / \mathrm{m}^{2}\right)$

$\Gamma \quad$ Coeficiente de Gibbs-Thompson (m.K)

$\Gamma_{k} \quad$ Taxa de transformação de fase de uma fase "k". $\left(\mathrm{kg} \cdot \mathrm{m}^{-3} \cdot \mathrm{s}^{-1}\right)$

$\Gamma_{k j} \quad$ Taxa de transformação de fase de uma fase "k" sobre uma fase "j".

$\delta_{l d} \quad$ Espessura efetiva de difusão $(\mathrm{m})$

$\delta_{C} \quad$ Espessura de estagnação $(\mathrm{m})$

$\theta \quad$ Ângulo de orientação do polígono de crescimento. (rad)

$\Theta_{k j} \quad$ Fluxo total de uma grandeza $\Psi$ de uma fase "k" para uma fase "j"

$\Theta_{k j}^{\Gamma} \quad$ Fluxo de uma grandeza $\Psi$ de uma fase " $k$ " para uma fase "j" por movimentação de interface.

$\Theta_{k j}^{D} \quad$ Fluxo de uma grandeza $\Psi$ de uma fase "k" para uma fase "j" por difusão

$\varepsilon_{k} \quad$ Fração de fase para uma fase "k" (-)

$\kappa_{v} \quad$ Coeficiente de partição de escoamento (-)

$\mu \quad$ Viscosidade (Pa.s)

$\rho \quad$ Densidade $\left(\mathrm{kg} / \mathrm{m}^{3}\right)$ 
$\sigma^{*} \quad$ Constante de estabilidade (-)

$\sigma_{\phi} \quad$ Parâmetro da curva de distribuição log-normal (-)

$\phi \quad$ Diâmetro de partícula $(\mathrm{m})$

$\bar{\phi} \quad$ Diâmetro médio de partícula $(\mathrm{m})$

$\Phi_{k} \quad$ Fluxo macroscópico por difusão microscópica de uma grandeza $\Psi$ numa fase " $k$ "

$\left\langle\Phi_{k}\right\rangle^{t}$ Fluxo dispersivo de uma grandeza $\Psi$

$\psi \quad$ Fator de forma (-)

$\psi_{e} \quad$ Fator de forma de um envelope (-)

$\Psi \quad$ Grandeza por unidade de volume

$\Omega \quad$ Razão entre coeficiente de arraste para uma esfera porosa e uma esfera rígida de mesmo raio. (-)

$\Omega_{C} \quad$ Supersaturação de soluto (-)

$\Omega_{T} \quad$ Super-resfriamento adimensional térmico (-)

〈 $\rangle$ Operação de média sobre um volume microscópico

\langle\rangle$^{k}$ Operação de média intrínseca sobre um volume microscópico

\langle\rangle$_{M}$ Operação de média sobre um volume macroscópico

\langle\rangle$_{M}^{k}$ Operação de média intrínseca sobre um volume macroscópico 


\section{LISTA DE TABELAS}

Tabela 1 - Parâmetros $K_{1}$ e $K_{2}$ calculados para as formas de esfera e de octaedro regular (HAIDER; LEVENSPIEL, 1989). 66

Tabela 2 - Equações Diferenciais solucionadas no submodelo microscópico e suas respectivas condições iniciais e de contorno.

Tabela 3 - Equações Diferenciais solucionadas no submodelo macroscópico com suas respectivas condições iniciais e de contorno.

Tabela 4 - Dados de entrada para as simulações A, B e C …........................85

Tabela 5 - Parâmetros da liga Al- $7 \% \mathrm{Si}$. .89

Tabela 6 - Parâmetros de entrada para simulação de decantação de grãos. 89

Tabela 7 - Parâmetros da liga Al-5\%Si 106

Tabela 8 - Parâmetros de entrada para a simulação do caso isotérmico com grãos fixos 106

Tabela 9 - Parâmetros da liga Al-5\%Si.

Tabela 10 - Parâmetros de entrada para a simulação do caso isotérmico com referencial móvel

Tabela 11 - Parâmetros da liga Al-3\%Cu.

Tabela 12 - Parâmetros de entrada para a simulação do caso de solidificação unidirecional

Tabela 13 - Parâmetros da liga Al-7\%Si utilizados 123

Tabela 14 - Parâmetros de entrada para a simulação do caso de solidificação unidirecional

Tabela 15 - Parâmetros da liga Al-10\%Cu. 129

Tabela 16 - Parâmetros de entrada para a simulação do caso de solidificação unidirecional 129 


\section{LISTA DE FIGURAS}

Figura 1 - Imagem de braços primários (com espaçamento $\lambda_{1}$ ) e secundários (espaçamento $\lambda_{2}^{\prime}$ ) em uma dendrita. (KURZ; FISHER, 1998) .24

Figura 2 - Macroestruturas brutas de solidificação (a) esquemática de fundição por gravidade (OHNO, 1987); (b) experimento de solidificação unidirecional ascendente com a liga Al-3\%Si (ARANGO, 2009) 28

Figura 3 - Macroestrutura da liga $\mathrm{Al}-0,1 \% \mathrm{Cu}$ com as zonas colunares e de grãos equiaxiais sedimentados com formatos de gotas, originados na interface superior do metal líquido.

Figura 4 - Resultados de McFadden e Browne (2006) para o campo de temperatura no sólido e no líquido para os casos de um grão isolado e três grãos. .35

Figura 5 - Esquema de um envelope a partir de um sólido dendrítico equiaxial e as esferas equivalentes em volume do envelope e do sólido.(Ahuja, 1992) 37

Figura 6 - Estrela do trabalho de de Groh III (1993) com seus parâmetros de medida: $L$, a distância entre a ponta de um braço e o centro do envelope, diâmetro equivalente $d_{e}$ e ângulo da ponta $\alpha$.

Figura 7 - Padrões de macrossegregação encontrados em lingotes. O sinal indica se a segregação é positiva ou negativa. (BECKERMANN, 2002).

Figura 8 - Curvas para os modelos de nucleação contínua da densidade de núcleos $n$ para um super-resfriamento $\Delta T$. (a) curva de resfriamento (b) distribuição normal da equação [26] (THEVOZ et al, 1989) (c) população de núcleos pela integral da curva (b).

Figura 9 - Desenho esquemático de volumes elementares representativos (VER) na zona colunar e na zona equiaxial, distinguindo cada fase constituinte: sólido (s), líquido interdendrítico (d) e líquido extradendrítico (I). (Wang e

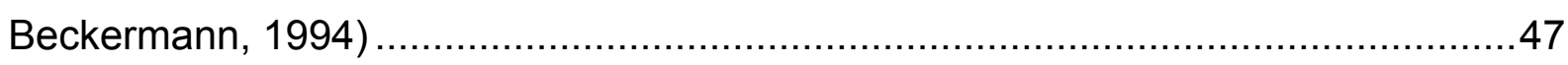

Figura 10- Representação dos envelopes dendríticos com a técnica do autômato celular. 49

Figura 11 - Domínio onde será utilizado cada modelo. O contorno do molde ( $L_{x}$ e $L_{y}$ ) delimita o domínio do modelo macroscópico, enquanto cada conjunto de grãos (destacados com cores diferentes) que se tocam define um domínio onde será 
solucionado o conjunto de equações do modelo microscópico. As linhas cinzas tracejadas representam o contorno dos volumes finitos que discretizam o domínio macroscópico, enquanto a malha quadriculada representa a discretização do domínio microscópico em células do autômato celular. .53

Figura 12 - Representação de um envelope dendrítico na malha de células do modelo de autômato celular com a definição do estado de suas células (ativo ou inativo) e das células líquidas ao redor.

Figura 13 - Exemplo de um quadrado de crescimento descentrado em uma célula de CA.

Figura 14 - Exemplo da captura de uma célula líquida $v$ (célula branca superior) pelo polígono de crescimento de sua célula vizinha $\mu$ (célula cinza ao centro). $\mathrm{O}$ polígono descentrado da célula ativa $\mu$ é definido no instante $t$ pelas quatro diagonais $\vec{L}_{\mu}^{t}$, e no instante $t+\Delta t$ (após crescimento) pelas diagonais $\vec{L}_{\mu}^{t+\Delta t}$, e pela descentralização $\Delta \vec{C}_{\mu}$. No instante de captura $(t+\Delta t)$, o vetor $\Delta \vec{r}_{\mu}^{v}$ está contido no triângulo formado pelas diagonais $\vec{L}_{\mu[01]}^{t+\Delta t}$ e $\vec{L}_{\mu[\overline{1} 0]}^{t+\Delta t}$

Figura 15 - Definição dos vetores para o cálculo do novo polígono de crescimento.

Figura 16 - Esquema do cálculo do volume da esfera equivalente, obtendo-se a área com o número de células ativas para calcular o octaedro correspondente ao grão. $N_{C}$ é o número de células que pertencem ao grão, $A_{C}$ é a área do quadrado interno ao octaedro e $d_{g}$ o diâmetro da esfera equivalente.

Figura 17 - Representação da migração de um envelope durante três instantes diferentes; onde $\vec{C}_{1}, \vec{C}_{2}$ e $\vec{C}_{3}$ são os centros do envelope nos instantes $t$ (azul), $t+\Delta t$ (verde) e $t+2 \Delta t$ (laranja) respectivamente; $\vec{d}$ indica o deslocamento do centro do envelope em relação ao centro da célula de CA que este estiver contido e $\Delta \vec{d}$ a variação de deslocamento dado pela Eq. [58].

Figura 18 - Simulação de um único grão sob a condição $A$ : (a) formato de posição do envelope para vários instantes de tempo dados em segundos; (b) formatos apresentados por Gandin e Rappaz (1994) para os mesmos instantes, sem considerar a translação. 
Figura 19 - Simulação de um único grão sob a condição B: (a) formato de posição do envelope para vários instantes de tempo dados em segundos; (b) formatos apresentados por Gandin e Rappaz (1994) para os mesmos instantes, sem considerar a translação

Figura 20 - Simulação de um único grão sob a condição C: (a) formato de posição do envelope para vários instantes de tempo dados em segundos; (b) formatos apresentados por Gandin e Rappaz (1994) para os mesmos instantes, sem considerar a translação

Figura 21 - Esfera sólida decantando e com sua posição ilutrada nos instantes 0,0s, 0,075s, 0,15s, 0,225s.

Figura 22 - Perfis de velocidade média do líquido extradendrítico em função da altura em quatro instantes de tempo diferentes.

Figura 23 - Perfis de concentração de Si no líquido extradendrítico em função da altura em dois instantes de tempo diferentes.

Figura 24 - Macroestrutura da esfera porosa decantando em diferentes instantes de tempo.

Figura 25 - Perfis de velocidade média do líquido extradendrítico em função da altura em quatro instantes de tempo diferentes para o caso de decantação da esfera porosa.

Figura 26 - Perfis de concentração de Si no líquido extradendrítico em função da altura em quatro instantes de tempo diferentes no caso de decantação da esfera porosa.

Figura 27 - Macroestrutura de um grão dendrítico decantando em um liquido super-resfriado em $5 \mathrm{~K}$ em relação a temperatura liquidus em diferentes instantes. .96

Figura 28 - Perfis de temperatura em função da altura em quatro instantes de tempo diferentes para o caso de decantação do grão dendrítico.

Figura 29 - Perfis de velocidade média do líquido extradendrítico em função da altura em dois instantes de tempo diferentes para o caso de decantação do grão dendrítico.

Figura 30 - Perfis de concentração média do líquido extradendrítico em função da altura em quatro instantes de tempo diferentes para o caso de decantação do grão dendrítico. 
Figura 31 - Campos internos ao grão dendrítico em decantação apresentado na Figura 27 para o instante de tempo 2,1s: (a) campo de fração de sólido $\varepsilon_{s}$ e velocidade do líquido interdendrítico $\left\langle v_{d}\right\rangle^{d}$; (b) campo de concentração do líquido interdendrítico $\left\langle C_{d}\right\rangle^{d}$. 100

Figura 32 - Conjunto de esferas com fração de sólido interna igual a 0.1 decantando em dois instantes de tempo. 102

Figura 33 - Perfis de velocidade média do líquido extradendrítico em função da altura em quatro instantes de tempo diferentes para o caso da decantação de um conjunto de esferas porosas. 103

Figura 34 - Perfis de concentração de Si no líquido extradendrítico em função da altura em quatro instantes de tempo diferentes no problema da decantação de um conjunto de esferas porosas. 104

Figura 35 - Macroestrutura de grãos nos instantes $(a) t=0,5 s(b) t=1,5 \mathrm{~s}$ e (c) $\mathrm{t}=4,0 \mathrm{~s}$

Figura 36 - Evolução da temperatura macroscópica nos modelos examinados. 107

Figura 37 - Evolução da área específica de grãos no modelo atual e no modelo de Wang e Beckermann (1993) com a correção de Avrami. No modelo de Rappaz e Gandin (1993) não há cálculo para $S_{l d}$ 108

Figura 38 - Evolução fração de fase sólida nos modelos examinados. 109

Figura 39 - Evolução da concentração de soluto no líquido extradendrítico para modelos examinados 109

Figura 40 - Evolução da fração de grão $\left(\varepsilon_{g}=1-\varepsilon_{l}\right)$ nos diferentes modelos.

Figura 41 - Macrosestrutura final da simulação do modelo para o caso isotérmico com referencial móvel.

Figura 42 - Comparação da evolução da temperatura do submodelo macroscópico entre o modelo com movimentação, o modelo sem movimentação e o modelo determinístico de envelope com correção de Avrami.

Figura 43 - Comparação da evolução da fração de sólido dos três modelos analisados 
Figura 44 - Comparação da evolução da concentração de soluto na fase líquida extradendrítica para os diferentes modelos.

Figura 45 - Comparação da evolução da área específica de grãos $S_{l d}$ dos três modelos analisados

Figura 46 - Comparação da evolução da fração de grão $\varepsilon_{g_{M}}$ 115

Figura 47 - Evolução da velocidade do referencial $\left\langle v_{s}\right\rangle_{M}^{s}$ e velocidade da fase líquida interdendrítica $\left\langle v_{d}\right\rangle_{M}^{d}$ para o modelo com referencial móvel. 116

Figura 48 - Macroestruturas finais para o caso de solidificação unidirecional ascendente com diferentes malhas: (a) $\Delta x_{C A}=10^{-3} \mathrm{~m}$ (b) $\Delta x_{C A}=5 \times 10^{-4} \mathrm{~m}$ (c) $\Delta x_{C A}=10^{-4} \mathrm{~m}$

Figura 49 - Macroestrutura de grãos calculada para a solidificação unidirecional da liga Al-3\%Cu: (a) considerando o efeito de decantação de grãos; (b) efeito de decantação dos grãos não foi considerado. A linha vermelha horizontal é a posição da transição colunar-equiaxial prevista pelo modelo de Wang e Beckermann (1994) para o caso sem decantação

Figura 50 - (a) Macroestrutura de grãos calculada para a solidificação unidirecional ascendente da liga $\mathrm{Al}-3 \% \mathrm{Cu}$ no instante $\mathrm{t}=450,0$ s considerando $\mathrm{o}$ efeito de decantação de grãos. À direita, os perfis de (b) temperatura, (c) fração de sólido e (d) fração de grãos correspondente à macroestrutura à esquerda. 120

Figura 51 - Macroestrutura final de grãos calculada para a solidificação unidirecional descendente da liga $\mathrm{Al}-3 \% \mathrm{Cu}$.

Figura 52 - (a) Macroestrutura de grãos calculada para a solidificação unidirecional descendente da liga Al-3\%Cu no instante $t=450,0$ s considerando o efeito de decantação de grãos. À direita, os perfis de (b) temperatura, (c) fração de sólido e (d) fração de grãos correspondente à macroestrutura à esquerda 122

Figura 53 - Comparação entre as macroestruturas fornecidas no trabalho de Martorano e Biscuola (2009) (sequência acima) e as calculadas pelo presente modelo (seqüência abaixo) para $\overline{\Delta T_{N}}=2 \mathrm{~K}$, com o desvio-padrão $\Delta T_{\sigma}$ variando entre $0,0 \mathrm{Ke} 3,0 \mathrm{~K}$

Figura 54 - Comparação entre as macroestruturas fornecidas no trabalho de Martorano e Biscuola (2009) (sequência acima) e as calculadas pelo modelo para $\overline{\Delta T_{N}}=5 \mathrm{~K}$, com o desvio-padrão $\Delta T_{\sigma}$ variando entre $0,0 \mathrm{~K} \mathrm{e} 3,0 \mathrm{~K}$. 
Figura 55 - Curvas de temperatura do modelo interpolada nas posições dos termopares do experimento de Rerko et al. (2003), e as curvas fornecidas no próprio experimento.

Figura 56 - Macroestrutura obtida no trabalho experimental de Rerko et al. (2003) à esquerda e macroestrutura calculada pelo modelo à direita. 131

Figura 57 - População de grãos $(\mathrm{N})$ para determinadas distâncias percorridas por decantação (d) 132

Figura 58 - Densidade de número de grãos por volume $n_{V}^{*}$ calculada pelo modelo ao longo do lingote a partir de sua base e no experimento de Rerko et al. (2003). 132

Figura 59 - Concentração média de soluto $\langle C\rangle_{M}$ no eixo vertical calculado pelo modelo e obtido experimentalmente por Rerko et al. (2003) 133 


\section{SUMÁRIO}

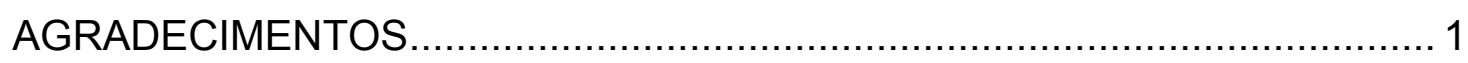

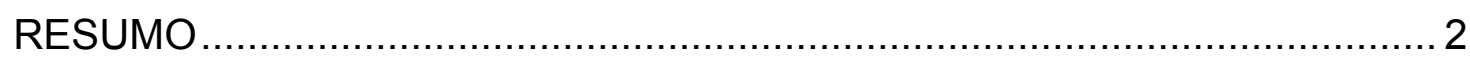

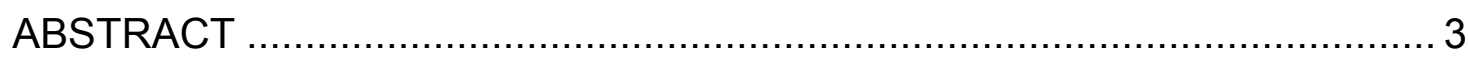

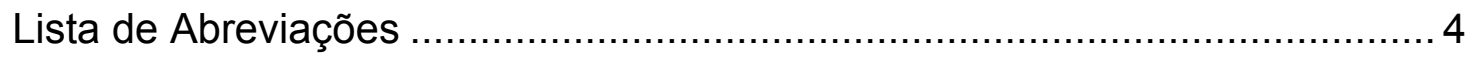

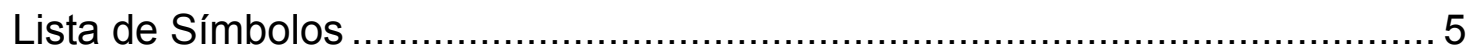

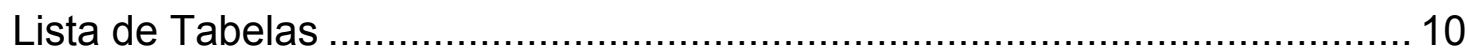

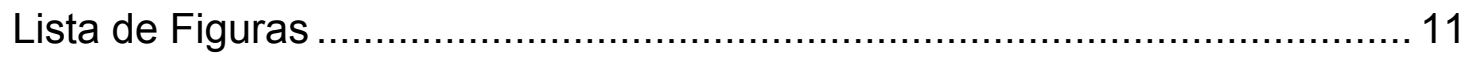

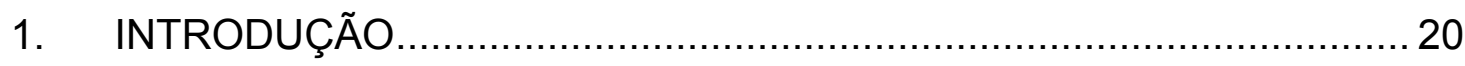

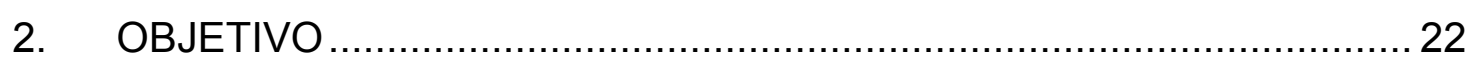

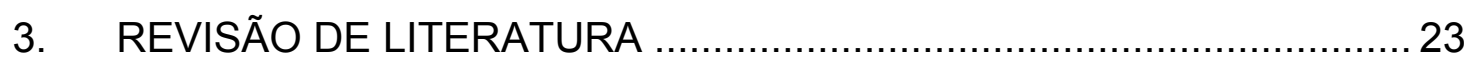

3.1 Solidificação de Ligas Binárias - Considerações Gerais ..................23

3.2 Crescimento Dendrítico .................................................... 24

3.3 Macroestrutura Bruta de Solidificação........................................27

3.3.1 Zona Coquilhada ....................................................... 28

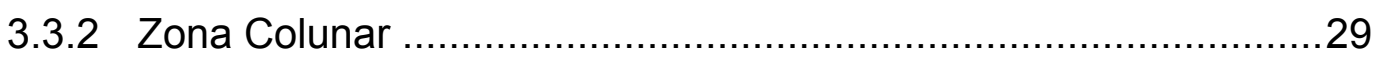

3.3.3 Zona Equiaxial ....................................................... 29

3.3.4 Transição Colunar-Equiaxial ......................................... 31

3.4 Mecanismo de Ocorrência da Transição Colunar-Equiaxial ................33

3.5 Decantação de Envelopes Dendríticos...........................................35

3.6 Macrossegregação .......................................................... 40

3.7 Modelos de Nucleação ..................................................... 43

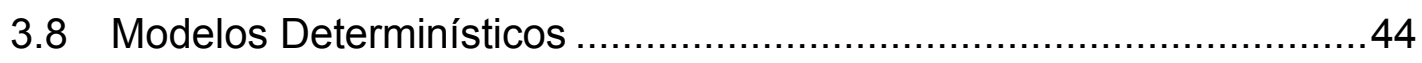

3.9 Técnica do Autômato Celular ..............................................48

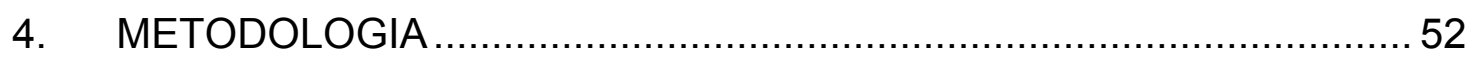

4.1 Aspectos Gerais do Modelo Matemático ........................................52

4.2 Técnica do Autômato Celular ......................................................56

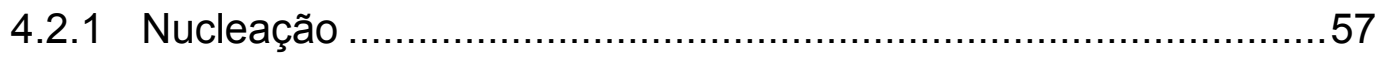

4.2.2 Crescimento de Grãos ................................................59

4.2 .3 Translação de Grãos......................................................63

4.3 Submodelo Microscópico ...................................................69

4.3.1 Conservação de Massa................................................... 70 
4.3.2 Cálculo do Coeficiente de Partição de Escoamento ...................71

4.3.3 Conservação de Energia ................................................... 73

4.3.4 Conservação das Espécies Químicas ...................................73

4.3.5 Sistema de Equações para o Submodelo Microscópico ..............77

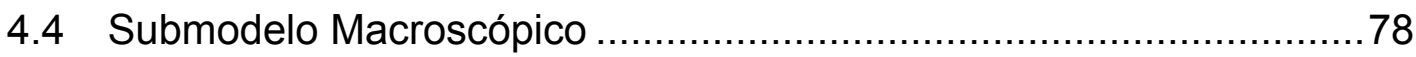

4.4.1 Conservação de Energia ................................................. 78

4.4.2 Conservação de Massa..........................................................79

4.4.3 Conservação de Soluto ................................................... 80

4.4.4 Sistema de Equações para o Submodelo Macroscópico .............82

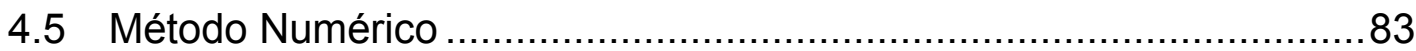

5. RESULTADOS E DISCUSSÃO ............................................... 84

5.1 Aferição do Cálculo do Crescimento de Grão ..................................84

5.2 Decantação de Grãos............................................................ 88

5.2.1 Decantação de um Grão Esférico ..........................................89

5.2.2 Decantação de um Grão Esférico Poroso ..................................92

5.2.3 Decantação de um Grão Dendrítico ..........................................95

5.2.4 Decantação de um Conjunto de Esferas Porosas.......................101

5.3 Simulação da Solidificação Isotérmica ........................................104

5.3.1 Solidificação Isotérmica com Grãos Fixos................................105

5.3.2 Solidificação Isotérmica com Grãos em Decantação .................110

5.4 Solidificação Unidirecional ..........................................................116

5.4.1 Análise da Malha Numérica ................................................117

5.4.2 Solidificação Unidirecional Ascendente...................................118

5.4.3 Solidificação Unidirecional Descendente ................................120

5.5 Efeito da Distribuição de Super-resfriamentos ..............................123

5.6 Comparação do Modelo com Resultado Experimental......................126

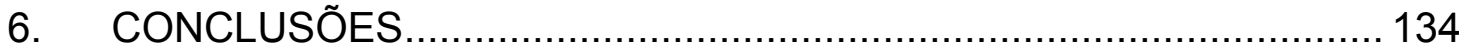

7. REFERÊNCIAS .................................................................... 136

Apêndice A - Captura de uma Célula de CA ............................................. 144

Apêndice B - Equações Gerais de Conservação ....................................... 147

Apêndice C - Deduções das Equações de Conservação ............................. 148

Apêndice D - Discretização das Equações de Conservação ........................ 164

Apêndice E - Cálculo da Espessura Efetiva de Difusão com Convecção .... 179 



\section{INTRODUÇÃO}

A qualidade do produto de fundição tem influência nas etapas subseqüentes como a conformação mecânica ou o tratamento térmico e no uso do produto final, pois os defeitos provenientes da solidificação podem ser irreversíveis ou podem aumentar o custo do produto na tentativa de eliminar estes defeitos. Peças fundidas podem depender de um controle preciso da macroestrutura bruta de solidificação, como por exemplo, na produção de palhetas de turbina, que visa produzir fundidos com a macroestrutura predominantemente colunar, para assim, evitar a fluência por deformação em contornos de grão.

Peças com heterogeneidades de composição (macrossegregação) são constantemente rejeitadas após a fabricação, pois apresentam uma nãouniformidade indesejada de propriedades físicas, comprometendo o seu desempenho. Em grandes lingotes, é possível observar diferenças de composição cujas causas estão atribuídas a fenômenos como: a convecção natural induzida por gradientes térmicos e de concentração de soluto, o fluxo de líquido na zona pastosa por distorção térmica da casca sólida, e a decantação de grãos equiaxiais.

Diversos modelos matemáticos foram apresentados na literatura desde a década de 1960 com tentativas de prever as propriedades finais do produto de solidificação e seus defeitos. Os modelos determinísticos são modelos matemáticos que utilizam um conjunto de equações diferenciais determinísticas, ou seja, sem variáveis estocásticas, que apresentam uma única solução para cada conjunto de condições iniciais e de contorno utilizadas. Estes modelos determinísticos podem utilizar a técnica da média volumétrica ("volume-averaging") para tratar variáveis médias e a mistura de diferentes fases que aparecem no processo de solidificação. Esta abordagem é vantajosa no ponto de vista computacional, mas apresenta desvantagens relativas à previsão da macroestrutura de grãos, pois a formação dos grãos é tratada com parâmetros médios. 
Outra abordagem conhecida é a utilizada pelos modelos chamados de estocásticos, que apresentam variáveis aleatórias em alguma de suas partes. Entre os modelos estocásticos, destacam-se os baseados em adaptações da técnica do autômato celular para a solidificação. Neste tipo de modelo, as etapas de nucleação e crescimento são modeladas para cada grão e não de forma média, como nos modelos determinísticos. Como um de seus principais resultados, os modelos estocásticos apresentam uma imagem completa da macroestrutura de grãos.

Extensões para considerar decantação de grãos para ambas as abordagens (determinística ou estocástica) já foram propostas. Para a técnica do autômato celular, trabalhos como os de Guillemot et al. (2006) prevêem a macroestrutura de grãos, mas carecem de equacionamentos completos para a movimentação do sólido nas equações de conservação. Para os modelos determinísticos, trabalhos como o de Wang e Beckermann (1996), Combeau et al (2009) e Wu e Ludwig (2009) consideram a movimentação de grãos, mas não possuem um cálculo da macroestrutura de grãos eficiente como o da técnica do autômato celular.

O presente modelo utiliza as duas abordagens (determinística e estocástica) em diferentes escalas para prever, sob efeito da decantação de grãos, a macroestrutura de grãos e os perfis de temperatura, soluto e fração de sólido. Para aferir o modelo foram realizados: simulações para casos de solidificação isotérmica, unidirecional ascendente e unidirecional descendente comparando a modelos precursores; a análise da variação de parâmetros da distribuição de superresfriamentos com o efeito da decantação; comparações de uma simulação a um resultado experimental de solidificação com decantação. 


\section{OBJETIVO}

O objetivo do presente trabalho é a implementação e a análise de um modelo matemático multifásico, multiescala e híbrido que combina o equacionamento dos modelos determinísticos e as técnicas estocásticas para simular a solidificação. Este modelo deve prever, entre outros, a macroestrutura de grãos e a macrossegregação formadas durante a solidificação de ligas binárias considerando o efeito da decantação de grãos e o escoamento de líquido decorrente desta decantação. 


\section{REVISÃO DE LITERATURA}

\subsection{Solidificação de Ligas Binárias - Considerações Gerais}

As ligas utilizadas neste trabalho e em diversos outros aqui citados são ligas binárias, que apresentam apenas dois componentes. A utilização destas ligas possibilita uma separação de efeitos, simplificando os estudos dos fenômenos que ocorrem na solidificação

A transformação da fase líquida para a fase sólida para estas ligas ocorre em diferentes etapas separadas basicamente em nucleação e crescimento dos grãos nucleados. A etapa de nucleação pode ser homogênea ou heterogênea (KURZ; FISHER, 1998), sendo que, na primeira, os núcleos sólidos surgem isoladamente no interior do metal líquido, enquanto na segunda estes se formam sobre algum substrato sólido. Estes substratos podem ser partículas naturalmente presentes no metal (impurezas) ou adicionadas propositalmente para induzir o processo de nucleação (inoculação), ou ainda a própria parede do molde. Nos dois tipos de nucleação existe um tamanho crítico acima do qual a nova estrutura de sólido formada a partir do líquido é estável e tende a crescer. Este tamanho, que é chamado de raio crítico $\left(r^{*}\right)$ no caso de um núcleo esférico, é dado por (KURZ; FISHER, 1998):

$$
r^{*}=\frac{-2 \gamma_{s l}}{\Delta G_{s l}}
$$

onde $\gamma_{s l}$ é a tensão interfacial entre a fase sólida e a fase líquida, e $\Delta G_{s l}$ é a variação de energia livre de Gibbs por volume na transformação de sólido para líquido.

Após o seu surgimento, o núcleo começa a crescer resultando na solidificação do metal líquido ao seu redor. Durante este crescimento, na grande 
maioria dos casos de interesse para ligas binárias, o sólido formado apresenta um teor de soluto menor do que o líquido de origem. Desta forma, soluto é transportado da interface sólida para o líquido remanescente (BECKERMANN, 2002).

\subsection{Crescimento Dendrítico}

O núcleo de sólido, que tem formato inicialmente esférico, assume uma morfologia ramificada durante o crescimento, chamada de morfologia dendrítica (KURZ; FISHER, 1998). Microestruturas dendríticas são predominantemente encontradas em ligas metálicas fundidas. O termo dendrita vem do grego 'dendron', que significa árvore, pois possui ramos principais, denominados braços primários, dos quais surgem ramificações, conhecidas como braços secundários, que também podem se ramificar (TRIVEDI; KURZ, 1994).

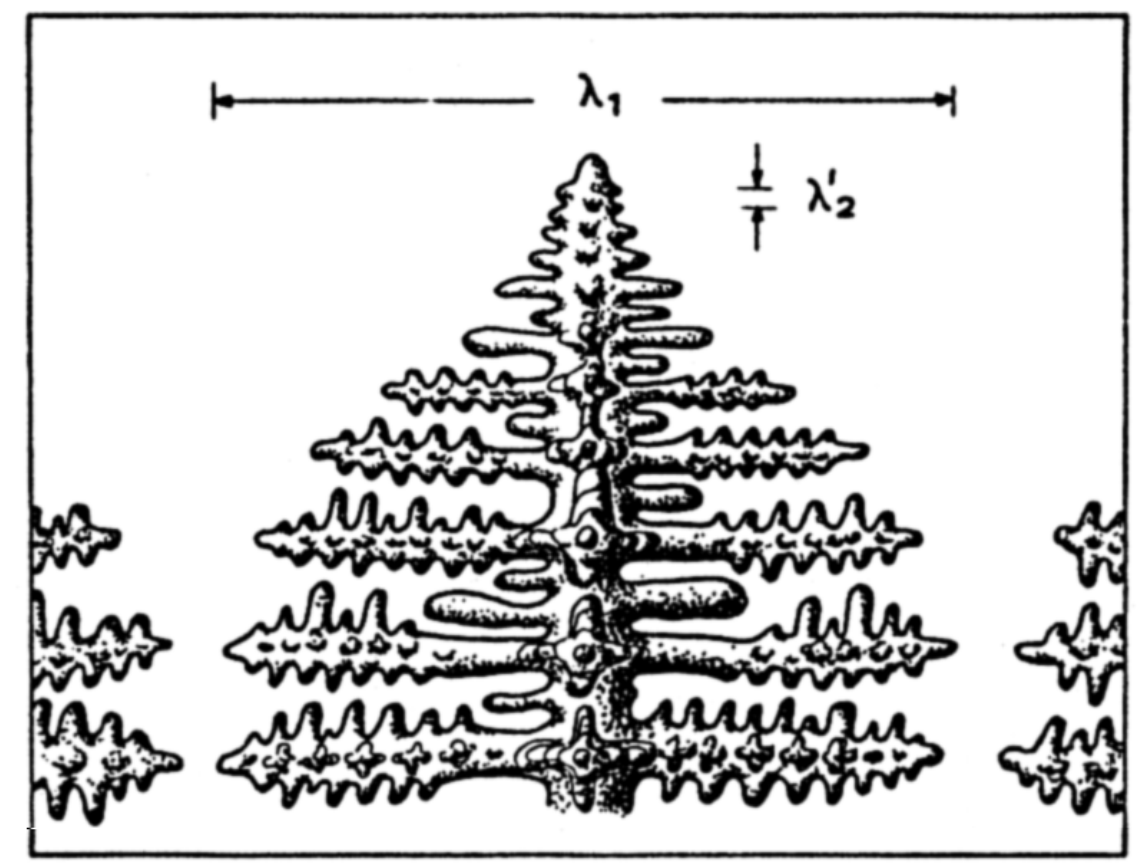

Figura 1 - Imagem de braços primários (com espaçamento $\lambda_{1}$ ) e secundários (espaçamento $\lambda_{2}^{\prime}$ ) em uma dendrita. (KURZ; FISHER, 1998)

O equacionamento do crescimento destes braços dendríticos envolve diferentes modelos matemáticos baseados em soluções de equações diferenciais de 
conservação (TRIVEDI; KURZ, 1994). Para o caso do crescimento dendrítico equiaxial de um metal puro, Ivantsov (KURZ; FISHER, 1998) propôs um modelo para o cálculo da velocidade de crescimento dendrítico analisando o transporte de calor apenas por condução (dendrita térmica). A solução considerando apenas a difusão de soluto, utilizada neste trabalho, é análoga à solução da dendrita térmica exibida abaixo:

$$
\begin{gathered}
\Omega_{T}=I v\left(P e_{T}\right) \\
\Omega_{T}=S t e=\frac{C_{P l}\left(T_{f}-T_{\infty}\right)}{L_{f}} \\
P e_{T}=\frac{v_{t i p} r}{\alpha_{l}}
\end{gathered}
$$

onde $\Omega_{T}$ é o super-resfriamento adimensional térmico; Ste é o número de Stefan; $C_{P l}$ é o calor específico da fase líquida; $T_{f}$ é a temperatura de fusão; $T_{\infty}$ é a temperatura no líquido suficientemente longe da interface sólido-líquido; $P e_{T}$ é o número de Peclet térmico; $\alpha_{L}$ é a difusividade de calor no líquido; $v_{p}$ é a velocidade de crescimento da ponta da dendrita; $r$ é o raio de curvatura da ponta da dendrita, $L_{f}$ o calor latente de fusão, e Iv é a função de Ivantsov, dada por:

$$
I v(z)=z \exp (z) E_{1}(z)
$$

onde $E_{1}$ é a função exponencial integral dada por:

$$
E_{1}(z)=\int_{z}^{\infty} \frac{e^{-z^{\prime}}}{z^{\prime}} d z^{\prime}
$$

Analogamente, é possível obter um conjunto de equações diferenciais semelhantes para o caso do crescimento equiaxial em ligas, considerando-se o transporte de soluto por difusão no líquido. Lipton et al. (1984) estenderam a solução de Ivantsov para o caso de ligas, considerando o transporte de soluto e o efeito de curvatura da interface sólido-líquido no campo de concentrações de soluto. 
O modelo LGK (LIPTON et al., 1984) foi proposto como solução para superresfriamentos relativamente pequenos de até $1^{\circ} \mathrm{C}$, pois considera a hipótese $\mathrm{Pe}<<$ 1. Em seguida, foi estendido por Lipton, Kurz e Trivedi, e por Boettinger, Coriel e Trivedi (TRIVEDI; KURZ, 1994) para super-resfriamentos maiores (modelo LKT e $\mathrm{BCT}$, respectivamente). Estes modelos apresentaram aderência satisfatória em comparação a resultados experimentais. Entretanto, para maiores superresfriamentos, ocorre a convecção induzida por gradientes de temperatura, impedindo uma avaliação mais precisa dos modelos, que assumem transporte de soluto e calor apenas por difusão.

Cantor e Vogel (1977) consideraram o efeito da convecção natural e forçada no crescimento dendrítico. Foi utilizado o conceito de espessura de estagnação ao redor da ponta dendrítica, dentro da qual, apenas a difusão ocorre. Para obter soluções mais precisas, Ananth e Gill (1991) obtiveram soluções analíticas do crescimento dendrítico para casos especiais de escoamento como o de escoamento sem efeitos inerciais ("creeping flow"), o de escoamento viscoso de Oseen, e o de escoamento potencial, sem os efeitos viscosos. Sekerka (1995) obteve um modelo de crescimento dendrítico simplificado analogamente a de Cantor e Vogel (1977), desprezando o efeito da cinética e do raio de curvatura no super-resfriamento da ponta dendrítica, e utilizando uma espessura de estagnação calculada pela convecção natural. Além disso, considerou no crescimento também o efeito da orientação da ponta dendrítica em relação ao movimento relativo do fluido.

Gandin et al. (2003) também aplicaram a técnica da espessura de estagnação para modelar o crescimento dendrítico com convecção. Neste caso, a velocidade do fluido não era previamente conhecida, sendo estimada com base em relações entre grupos adimensionais típicos dos fenômenos que regem a convecção natural e forçada. O modelo proposto por Gandin et al. (2003) apresentou resultados próximos à solução analítica de Ananth e Gill (1991) para velocidades de crescimento da ponta dendrítica até $0,01 \mathrm{~m} / \mathrm{s}$. Li e Beckermann (2002) criaram um modelo que considera a convecção térmica simultaneamente com a de soluto, mas somente válido para o crescimento equiaxial. 
Appolaire et al. (1998) obteve resultados experimentais para o crescimento dendrítico com decantação em uma solução inorgânica de $\mathrm{NH}_{4} \mathrm{Cl}-\mathrm{H}_{2} \mathrm{O}$, mostrando que a solução apresentada por Ananth e Gill (1991) pode ser utilizada para casos mais gerais que uma dendrita isolada, como o caso de um grão equiaxial em movimento. Badillo et al. (2007) mediram experimentalmente na solução orgânica de Succinonitrila-Acetona super-resfriada a velocidade de crescimento de dendritas equiaxiais em queda livre. Os autores concluíram que, devido ao acúmulo de soluto na região da cauda ("wake"), os braços dendríticos desta região cresciam em velocidades menores do que as previstas pelo modelo difusional. Por outro lado, os braços da região frontal ("upstream") cresciam com velocidades aproximadamente duas vezes maiores do que o caso sem a movimentação do sólido. Os autores explicam que isto ocorre porque estes braços estão em contato com o líquido abaixo sempre super-resfriado e com concentrações de soluto à frente menores, mais próximas da concentração inicial.

\subsection{Macroestrutura Bruta de Solidificação}

$\mathrm{Na}$ estrutura bruta de solidificação (Figura 2), são definidas três zonas distintas de grãos: a zona coquilhada formada por grãos pequenos e homogêneos nucleados sobre ou próximos à superfície do molde; a zona colunar, constituída por grãos alongados aproximadamente na direção de extração de calor e a zona equiaxial, que possui grãos arredondados, geralmente localizados na região central dos lingotes (FLOOD; HUNT, 1998). Southin (1967) afirma que há ainda uma quarta zona na estrutura bruta de solidificação composta por grãos em formato de gotas. Estes grãos adquirem este formato ao decantarem livremente pela ação da força gravitacional, ocorrendo crescimento diferente de cada um dos braços abandonando o formato isomórfico inicial. 


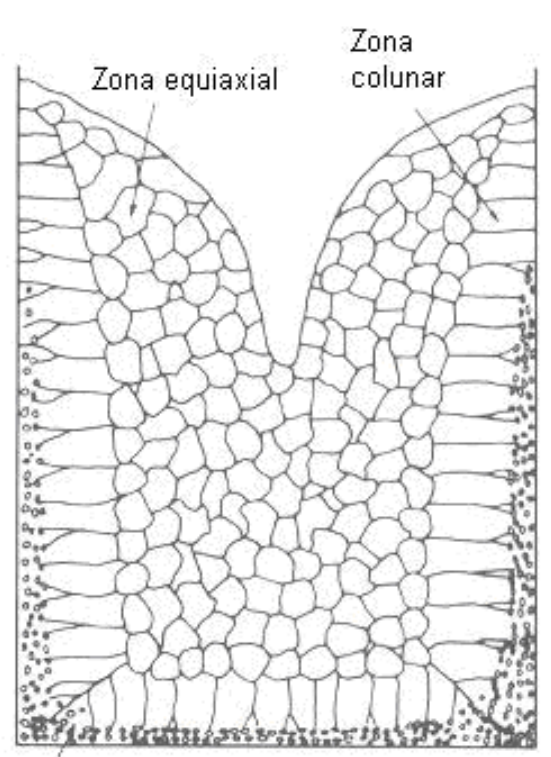

Zona coquilhada

(a)

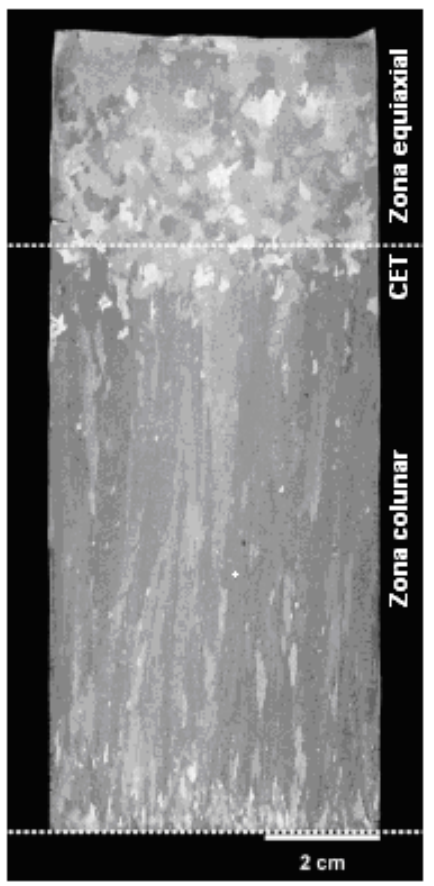

(b)

Figura 2 - Macroestruturas brutas de solidificação (a) esquemática de fundição por gravidade (OHNO, 1987); (b) experimento de solidificação unidirecional ascendente com a liga Al-3\%Si (ARANGO, 2009)

\subsubsection{Zona Coquilhada}

A zona coquilhada está na região da interface metal-molde e é caracterizada por apresentar diversos grãos pequenos de forma globulítica ou equiaxial (PRATES; BILONI, 1972). A geração de múltiplos grãos está associada à alta taxa de resfriamento local que produz um super-resfriamento elevado resultando em uma produção intensa de núcleos (WEIRAUCH et al., 2000). Os parâmetros de fundição que exercem influência nas características desta zona são: o coeficiente de transmissão de calor metal-molde e a temperatura de vazamento (CHALMERS, 1964). 


\subsubsection{Zona Colunar}

A zona colunar é caracterizada por grãos alongados em uma direção preferencial, neste caso, aproximadamente a direção do fluxo de extração de calor pelo molde. A geometria dos grãos colunares é alongada, e estes crescem livremente enquanto há superaquecimento no metal à sua frente e enquanto não forem bloqueados por outros grãos crescendo à sua frente. Há competição no crescimento dos grãos colunares, sobrevivendo aqueles que têm crescimento preferencial mais próxima da direção de extração de calor.

\subsubsection{Zona Equiaxial}

A zona colunar avança sobre o líquido até que o seu crescimento seja possivelmente suprimido pelo surgimento de novos grãos no metal líquido, à sua frente. Estes novos grãos dão origem à zona equiaxial, que tem este nome porque os grãos que a constituem têm em média extensão homogênea nas três direções. Tradicionalmente, na indústria, são utilizados inoculantes para induzir o surgimento desta zona e reduzir o seu tamanho de grão médio. A discussão sobre o mecanismo para seu surgimento durante a solidificação possui vasta literatura acadêmica, sendo destacados a seguir apenas os quatro mais citados atualmente:

\section{a) Teoria do Super-resfriamento Constitucional}

Durante crescimento dos grãos colunares, a frente de crescimento destes grãos apresenta uma temperatura geralmente abaixo da temperatura liquidus da composição média da liga e, portanto, está super-resfriada. Desta forma, em um gradiente de temperatura positivo, o líquido logo à frente desta frente de crescimento também pode estar super-resfriado em relação à sua temperatura liquidus. Este super-resfriamento, quando existe, é chamado de super-resfriamento constitucional. (WINEGARD; CHALMERS, 1954). Esta teoria considera que, se este líquido à frente dos grãos colunares está super-resfriado, então seria possível ocorrer a nucleação e o crescimento de novos grãos. Estes novos grãos poderiam impedir o crescimento dos grãos colunares e criarem a zona equiaxial. 


\section{b) Teoria do "Big-bang"}

Esta teoria foi desenvolvida por Chalmers (1964), e afirma que os grãos da zona equiaxial surgem a partir de grãos nucleados no líquido adjacente à parede do molde (onde a extração de calor é intensa), que são carregados pela convecção do líquido para o interior do molde. Alguns destes grãos poderiam sobreviver no metal líquido caso encontrassem uma zona de super-resfriamento constitucional.

\section{c) Refusão por Oscilações Térmicas}

De maneira análoga à teoria do "big-bang", a teoria proposta por Jackson et al. (1966) sugere que o movimento convectivo é determinante no surgimento da zona equiaxial. Porém, alternativamente aos grãos nucleados na zona coquilhada, os grãos equiaxiais viriam de fragmentos de dendritas presentes no interior da zona colunar em crescimento. Estes fragmentos surgiriam por refusão local dos braços dendríticos devido a flutuações de temperatura ou composição, ou por fratura mecânica provocada por movimentação intensa do líquido. Os fragmentos, caso transportados para região de super-resfriamento constitucional à frente dos grãos colunares, poderiam crescer e se transformarem em grãos equiaxiais, eventualmente bloqueando o crescimento dos grãos colunares.

\section{d) Geração de cristais por radiação no topo}

Para moldes sem isolamento térmico no topo, Southin (1967) verificou que grãos poderiam nuclear na interface entre o metal líquido e o ar (superfície livre) e decantar livremente até a zona colunar. Este resfriamento do topo aconteceria através de transporte de calor por radiação e continuaria gerando grãos até a formação de uma casa sólida coesa no topo. Destes grãos, os que crescem enquanto decantam, apresentam formatos de gota devido às condições cinéticas diferentes de cada braço dendrítico (Badillo et al., 2007) conforme explicado na seção 3.2. Os grãos que decantaram acabariam formando uma zona equiaxial. 


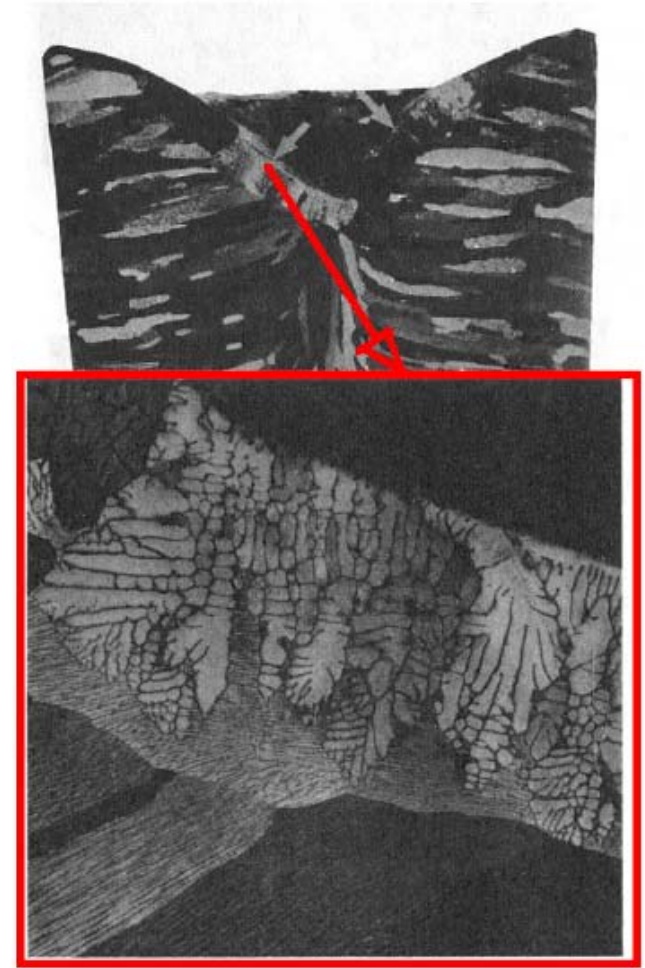

Figura 3 - Macroestrutura da liga $\mathrm{Al}-0,1 \% \mathrm{Cu}$ com as zonas colunares e de grãos equiaxiais sedimentados com formatos de gotas, originados na interface superior do metal líquido.

(SOUTHIN, 1967)

\subsubsection{Transição Colunar-Equiaxial}

Na macroestrutura de grãos final, a região em que ocorre uma transição no formato dos grãos de colunar para equiaxial é definida como a transição colunarequiaxial ("CET - columnar-to-equiaxed transition"). A determinação desta posição é função de diversos fenômenos que ocorrem durante a solidificação.

Alguns autores identificaram quais parâmetros de solidificação influenciam predominantemente na posição da CET. Estes parâmetros são: composição da liga; superaquecimento do metal líquido; propriedades do inoculante, se utilizado; e parâmetros fluido-dinâmicos do metal líquido.

Para verificar a variação da posição da CET com a composição da liga, Tarshis et al. (1971) realizaram experimentos com diferentes composições de ligas à base de níquel e alumínio. Neste trabalho, foi proposto que a posição da CET é 
função de um parâmetro $P$, denominado parâmetro de super-resfriamento constitucional, definido pela equação:

$$
P=\frac{-m_{l}(1-k) C_{0}}{k}
$$

onde $m_{l}$ é a inclinação da linha liquidus, $k$ é o coeficiente de partição, e $C_{0}$ é a composição média da liga.

Para o caso das ligas de alumínio, foi verificado que para valores inferiores a 10 , as macroestruturas eram predominantemente colunares, enquanto para valores abaixo, ocorria a CET mais próxima da base quanto menor o valor de $P$.

Jung et al. (2007) realizaram experimentos de solidificação unidirecional em forno tipo Bridgman com a liga Al-7\%Si em terra, no qual a posição da CET é conhecida, e, em condições de microgravidade, no qual não obtiveram região equiaxial. Os autores verificaram que para a formação da CET nas condições testadas, a ocorrência da convecção natural é determinante.

Griffiths e McCartney (1993) obtiveram macroestruturas para as ligas binárias Al-Si e Al-Cu por solidificação descendente (solidificação inicia-se no topo do molde e termina na sua base), e identificaram heterogeneidade de tamanho de grão verticalmente pelo lingote. Rerko et al. (2002) realizaram experimentos com a liga binária Al-Cu para identificar a influência da decantação de grãos na macroestrutura em solidificação ascendente (solidificação inicia-se na base e termina no topo do molde) comparada com a solidificação descendente. Nos dois casos, foi observada uma variação de tamanho de grão médio local ao longo do lingote, com grãos menores localizados mais próximos à base do molde. Porém, na solidificação ascendente da liga $\mathrm{Al}-10 \% \mathrm{Cu}$, identificou-se um tamanho de grão até três vezes menor do que o obtido por solidificação descendente. Este efeito justificado pelos autores como causado pelo transporte de grãos ou por decantação, ou por arraste do líquido em movimento de convecção natural. 


\subsection{Mecanismo de Ocorrência da Transição Colunar-Equiaxial}

A CET ocorre quando o crescimento dos grãos colunares é bloqueado por grãos equiaxiais crescendo à sua frente. $O$ bloqueio da zona colunar pela zona equiaxial possui três mecanismos distintos: (a) interação mecânica (HUNT, 1984), (b) interação entre campos de concentração (MARTORANO et al., 2003) e interação térmica (MCFADDEN; BROWNE, 2004). O bloqueio mecânico, como já explícito pelo nome, ocorre através do bloqueio físico dos grãos.

Hunt (1984) criou um dos primeiros modelos matemáticos para previsão da CET. Este modelo utiliza as seguintes hipóteses: estado quase-estacionário e unidirecional nas equações de conservação para um referencial que se move com a velocidade das isotermas, nucleação instantânea, grãos colunares crescem na mesma velocidade da isoterma liquidus, crescimento equiaxial ocorre simultaneamente ao crescimento colunar. O modelo prevê qual será a estrutura predominante dos grãos, para um determinado gradiente de temperatura e para uma dada velocidade da isoterma liquidus. Conforme um critério de bloqueio proposto no trabalho de Hunt (1984), haverá crescimento completamente colunar para frações de grãos equiaxiais menores que 0,0066 , crescimento misto para frações entre 0,0066 e 0,49, e crescimento completamente equiaxial para frações maiores que 0,49 , que é denominada fração de bloqueio mecânico. A partir desta fração, apenas os grãos equiaxiais crescem até atingirem a fração unitária. Segundo o modelo, haverá predominância total de grãos equiaxiais quando for obedecido o critério expresso na Eq. [8]:

$$
G<0,617 n^{1 / 3}\left[1-\left(\Delta T_{N}\right)^{3} /\left(\Delta T_{C}\right)^{3}\right] \Delta T_{C}
$$

onde $n$ é a densidade de número de substratos para nucleação heterogênea de grãos equiaxiais; $\Delta T_{N}$ é o super-resfriamento para a nucleação sobre um substrato; $\Delta T_{C}$ é o super-resfriamento na posição da frente colunar, definido por: 


$$
\Delta T_{C}=\left(\frac{v_{i s o} C_{0}}{A_{N}}\right)^{1 / 2}
$$

onde $v_{\text {iso }}$ é a velocidade de avanço dos grãos colunares (velocidade da isoterma liquidus); e $A_{N}$ é uma constante determinada experimentalmente para cada liga. Haverá crescimento completamente colunar quando:

$$
G>0,617(100 n)^{1 / 3}\left[1-\left(\Delta T_{N}\right)^{3} /\left(\Delta T_{C}\right)^{3}\right] \Delta T_{C}
$$

Biscuola e Martorano (2008) estenderam este modelo para casos com distribuições normal e log-normal de super-resfriamentos para nucleação (item 3.7), e mostraram significativas diferenças do mapa de Hunt para diferentes superresfriamentos.

Hunt (1984) afirma que o critério para o bloqueio mecânico é de 0,49 para a fração de grãos equiaxiais, e este valor foi utilizado sem ser questionado na literatura. Martorano e Biscuola (2007) obtiveram macroestruturas calculadas com a técnica do autômato celular de Rappaz e Gandin (1993). Uma análise destas macroestruturas mostrou que o bloqueio mecânico ocorria em valores próximos de 0,2 .

Martorano et al. (2003) propuseram o mecanismo de bloqueio por enriquecimento de soluto à frente da zona colunar causado pela solidificação equiaxial. Utilizando o modelo difusional de Wang e Beckermann (1993), Martorano et al. (2002) utilizaram a concentração média de soluto no líquido extradendrítico para calcular a velocidade de crescimento da frente colunar. Verificaram que, em determinadas condições, os grãos equiaxiais rejeitavam uma quantidade de soluto suficiente para parar o crescimento dos grãos colunares.

McFadden e Browne (2006) realizaram simulações utilizando a técnica de acompanhamento de contorno dos grãos desenvolvido em Browne e Hunt (2004) para calcular as interações das duas zonas no campo de concentração de soluto e térmico. Verificaram que os campos de soluto de cada grão só interagem a partir de 
distâncias da ordem da espessura efetiva de difusão, enquanto o campo de temperatura é modificado quase que instantaneamente na presença de mais grãos (Figura 4).

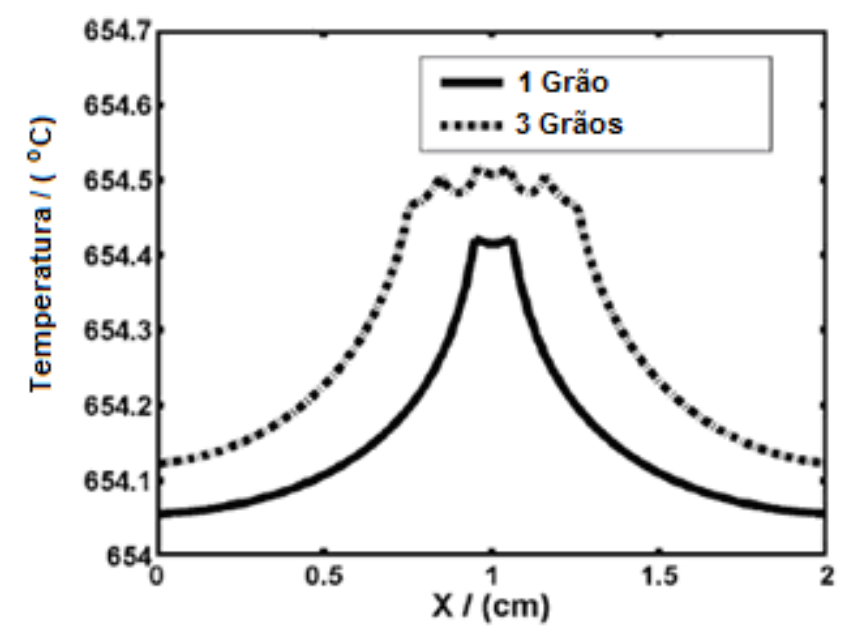

Figura 4 - Resultados de McFadden e Browne (2006) para o campo de temperatura no sólido e no líquido para os casos de um grão isolado e três grãos.

\subsection{Decantação de Envelopes Dendríticos}

Durante a queda, um corpo sólido imerso em um fluido viscoso sofre a ação de uma força de arraste $\vec{F}_{D}$ devido à interação com o fluido. $O$ coeficiente de arraste $C_{D}$ é definido pela equação abaixo:

$$
C_{D}=\frac{\left|\vec{F}_{D}\right|}{\left(\frac{1}{2} \rho_{s}\left|\vec{v}_{f}\right|\right) A_{\text {proj }}}
$$

onde $\rho_{s}$ é a densidade do sólido, $\vec{v}_{f}$ é a velocidade do fluido ao longe, e $A_{\text {proj }}$ é a área projetada do sólido na direção do fluxo de fluido.

No chamado regime de Stokes ("creeping flow"), onde $R e \ll 1$, e para corpos esféricos, a expressão para o coeficiente de arraste é obtido analiticamente como: 


$$
C_{D}=\frac{24}{\operatorname{Re}}
$$

onde Re é o número de Reynolds definido por:

$$
\operatorname{Re}=\frac{\rho_{f}\left|\vec{v}_{f}\right| d_{s}}{\mu_{f}}
$$

onde $\rho_{f}$ é a densidade do fluido; $d_{s}$ o diâmetro da esfera sólida; $\mu_{f}$ a viscosidade dinâmica do fluido.

Haider e Levenspiel (1989) estudaram experimentalmente a decantação de corpos não-esféricos. Eles utilizaram uma regressão não-linear para estimar um fator de correção empírico $C_{s h}$, que corresponde à razão entre a força de arraste de uma esfera equivalente em volume dividida pela força de arraste sobre o corpo nãoesférico:

$$
C_{s h}=0,843 \log \left(\frac{\psi}{0,065}\right)
$$

onde $\psi$ é o fator de forma, calculado pela razão entre a área superficial da esfera equivalente e a área superficial do corpo sólido. O coeficiente de arraste para os corpos não-esféricos foi calculado para regimes de Reynolds menores que $2,6.10^{5}$, e é dado por:

$$
C_{D}=\frac{24}{C_{\text {sh }}(\psi) \operatorname{Re}}\left[1+C_{\text {sh }}(\psi) \cdot 8,1716 \exp (-4,0655 \psi) \operatorname{Re}^{-0,0964+0,5564 \psi}\right]+\frac{73,69 \cdot \operatorname{Re} \cdot \exp (-5,0748 \psi)}{\operatorname{Re}+5,378 \cdot \exp (6,2122 \psi)}
$$

Neale e Epstein (1973) obtiveram uma solução analítica utilizando a extensão de Brinkman para a lei de Darcy, com a hipótese de fluido incompressível newtoniano e em regime de Stokes, para solucionar o escoamento dentro e ao redor de uma esfera porosa, obtendo uma nova expressão para o coeficiente de arraste. $O$ coeficiente se torna função de um raio adimensional $\beta$, definido como: 


$$
\beta=\frac{d_{s p h}}{\sqrt{k_{p}}}
$$

onde $d_{s p h}$ é o diâmetro da esfera porosa; e $k_{p}$ a permeabilidade desta, considerada constante em seu interior (meio isotrópico). A razão $(\Omega)$ entre o coeficiente de arraste para uma esfera porosa e uma esfera rígida de mesmo raio é dada pela equação:

$$
\Omega=\frac{2 \beta^{2}(1-\tan \beta / \beta)}{2 \beta^{2}-3(1-\tan \beta / \beta)}
$$

Como a equação de Haider e Levenspiel (1989) (Eq. [15]) é válida apenas para as geometrias mais simples de sólidos regulares (cubos, tetraedros e octaedros), o coeficiente $C_{s h}$ deve ser modificado para considerar geometrias mais complexas. Para a geometria dos grãos equiaxiais, Zakhem et al. (1992) propôs um modelo geométrico de cilindro com ponta hemisférica para representar o braço de uma dendrita. Para o cálculo do fator de forma, foi necessário definir o conceito de envelope dendrítico (Figura 5), composto por sólido e líquido interdendrítico.

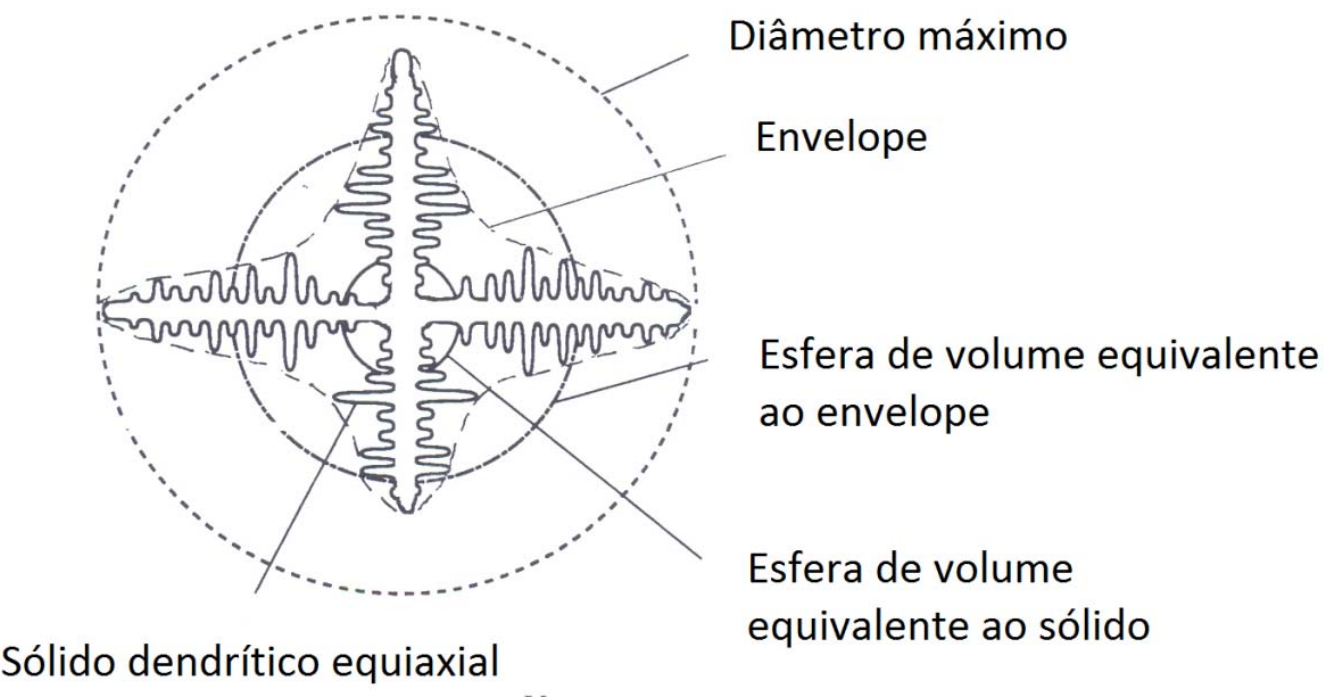

Figura 5 - Esquema de um envelope a partir de um sólido dendrítico equiaxial e as esferas equivalentes em volume do envelope e do sólido.(Ahuja, 1992)

O envelope proposto por Zahkem et al. (1992) tem a forma de um esferóide, que é calculado em função dos cilindros que definem os braços primários e 
secundários. Desta forma, dados experimentais foram plotados em função do fator de forma deste modelo de envelope e foi obtida uma nova expressão para $C_{\text {sh }}$ dada por:

$$
C_{s h}=1,2376 \cdot \log \left(\frac{\psi_{e}}{0,1556}\right)
$$

onde é utilizado o fator de forma do envelope $\psi_{e}$, e não o do corpo sólido.

Ahuja (1992) propôs um diferente modelo de envelope, descrito por seis pirâmides de base quadrada sobre as seis faces de um cubo. De Groh et al. (1993) examinou diferentes tipos de envelopes (Figura 6) e obteve resultados mais próximos dos experimentais com um modelo de envelope dendrítico que se assemelha ao envelope proposto por Ahuja (1992). Entretanto, os vértices das pirâmides posicionam-se no centro das arestas do cubo em vez de nos próprios vértices do cubo e as pirâmides externas cujos picos são os vértices do cubo são descartados.

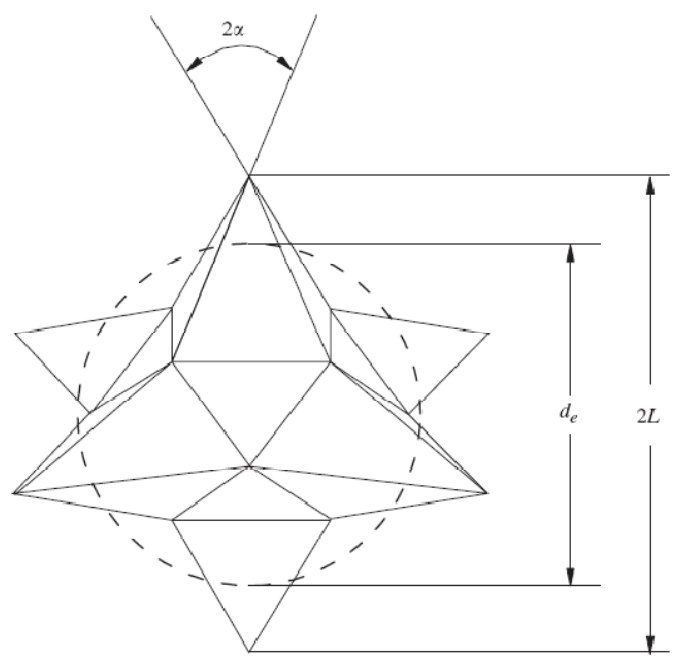

Figura 6 - Estrela do trabalho de de Groh III (1993) com seus parâmetros de medida: $L$, a distância entre a ponta de um braço e o centro do envelope, diâmetro equivalente $d_{e}$ e ângulo da ponta $\alpha$.

(BADILLO et al., 2007)

Ahuja (1992) considerou também o efeito da porosidade de um envelope individual, proveniente do espaçamento entre braços secundários de dendrita. Ele assumiu que o efeito da forma e o efeito da porosidade podem ser considerados 
separadamente. A porosidade tem dois efeitos no coeficiente de arraste: diminui a densidade do envelope e diminui a diferença de pressão entre a região anterior e posterior da partícula. O primeiro efeito deve ser considerado no balanço de forças e o segundo deve ser considerado por um fator de ajuste para partículas esféricas porosas no coeficiente de arraste.

Wang et al (1995) estenderam o modelo de Ahuja (1992) para o caso de múltiplas dendritas decantando. Este modelo foi implementado com o conceito de permeabilidade equivalente, calculado através da permeabilidade interna de cada grão e da permeabilidade de um sistema de vários grãos completamente sólidos.

Para o cálculo do fluxo médio de cada fase líquida (interdendrítica e extradendrítica), foi introduzido um coeficiente de partição de escoamento $\kappa_{v}$, definido como:

$$
\kappa_{v}=\frac{\varepsilon_{d}\left(\left\langle\vec{v}_{d}\right\rangle^{d}-\left\langle\vec{v}_{s}\right\rangle^{s}\right)}{\varepsilon_{f}\left(\left\langle\vec{v}_{f}\right\rangle^{f}-\left\langle\vec{v}_{s}\right\rangle^{s}\right)}
$$

onde $\varepsilon_{d}$ é a fração de líquido interdendrítico, $\left\langle\vec{v}_{d}\right\rangle^{d}$ e $\left\langle\vec{v}_{s}\right\rangle^{s}$ são as velocidades médias das fases líquida interdendrítica e sólida , $\varepsilon_{f}$ e $\left\langle\vec{v}_{f}\right\rangle^{f}$ são a fração de líquido total e a velocidade média do líquido total definidos por:

$$
\begin{gathered}
\varepsilon_{f}=\varepsilon_{l}+\varepsilon_{d} \\
\rho_{f} \varepsilon_{f}\left\langle\vec{v}_{f}\right\rangle^{f}=\rho_{d} \varepsilon_{d}\left\langle\vec{v}_{d}\right\rangle^{d}+\rho_{l} \varepsilon_{l}\left\langle\vec{v}_{l}\right\rangle^{l}
\end{gathered}
$$

Pela solução do modelo, é obtida uma expressão para $\kappa_{v}$ em função dos raios adimensionais dada por:

$$
\kappa_{v}=\left(1-\varepsilon_{l}\right)\left(\beta / \beta_{d}\right)^{2}
$$


onde $\beta_{d}$ e $\beta$ são raios adimensionais, sendo o primeiro relativo ao fluxo interdendrítico, e o segundo para todo o conjunto, expresso por:

$$
\beta=\frac{\beta_{d}}{\left[\left(1-\varepsilon_{l}\right)^{n}+\left(\beta_{d} / \beta_{l}\right)^{2 n}\right]^{1 / 2 n}}
$$

onde $n$ é uma constante ajustada para que o modelo se aproxime do modelo implementado por Neale e Epstein (1979) para casos limites de uma esfera porosa; e $\beta_{l}$ o raio adimensional relativo ao fluxo extradendrítico ao redor do conjunto de envelopes.

\subsection{Macrossegregação}

É definida como macrossegregação toda a diferença espacial de composição em uma escala de comprimento da ordem de centímetros a metros. Dependendo da magnitude desta diferença, é considerada como um defeito de fundição por si só, ou como causa de defeitos como "freckles" (BECKERMANN, 2002). A macrossegregação pode ser positiva (valores maiores que a concentração média do lingote) ou negativa.

A movimentação do metal líquido e metal sólido na presença de partição de soluto é a causa principal da macrossegregação. Portanto, a macrossegregação será determinada por fatores que provocam a movimentação do líquido na zona pastosa que são (OLSSON et al., 1986):

1. Diferença de densidade induzida por gradientes de temperatura e composição;

2. Decantação e arraste dos envelopes dendríticos equiaxiais livres e permeáveis;

3. Distorção da fase sólida nas regiões pastosas por gradientes de temperatura acentuados próximos a superfície de extração de calor. 
O movimento convectivo induzido por variações de densidade no metal líquido é conhecido como convecção natural ("buoyancy convection"). A diferença de densidade na fase líquida é provocada ou pela contração/expansão com a diminuição/aumento da temperatura ou pela diferença de concentração de soluto que pode causar tanto expansão quanto contração dependendo das propriedades químicas do soluto (BECKERMANN 2002). Durante o crescimento de grãos sólidos, é notado que parte da fase líquida se localiza entre os braços dendríticos, que é mais enriquecida em soluto, rejeitado pela fase sólida, do que o líquido que está ao redor do contorno dos grãos. Logo, regiões onde há grãos sólidos têm a fase líquida (dentro e ao redor dos envelopes dendríticos) enriquecida em soluto comparado a regiões onde não há grãos.

O movimento convectivo do metal líquido durante a solidificação apresenta padrões diferentes em cada etapa da formação da estrutura bruta de solidificação (HELLAWELL et al., 1997), gerando também padrões na macrossegregação final do lingote. Os tipos de padrões de macrossegregação mais citados na literatura são (HULTGREN, 1967): a segregação em V (também conhecida como "ghosts" ou "freckles") e a segregação em A (também conhecida como $V$ invertido, ou "Schattenstreifen"). Na fundição por gravidade, a segregação em $V$ ocorre na região central enquanto a segregação em $A$ ocorre lateralmente conforme ilustra a Figura 7. A segregação em V é creditada na literatura (BECKERMANN, 2002) aos grãos equiaxiais que decantam na região central, mas não exclusivamente, enquanto a segregação em A é causada pela convecção natural na região (BECKERMANN, 2002). 


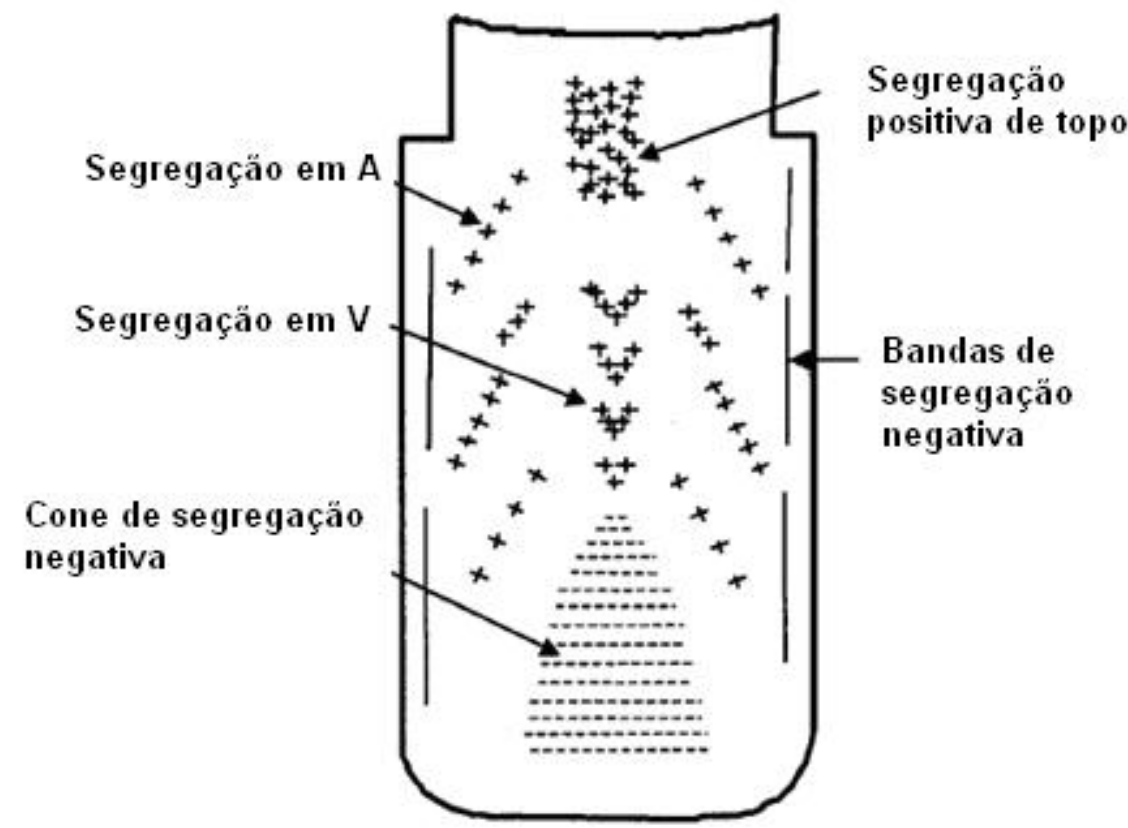

Figura 7 - Padrões de macrossegregação encontrados em lingotes. O sinal indica se a segregação é positiva ou negativa. (BECKERMANN, 2002).

Olsson et al (1986) realizaram um estudo para separar a influência de cada mecanismo na macrossegregação total através de modelos matemáticos simplificados. Pelas equações do modelo foi mostrado que a decantação isoladamente causa segregação negativa na base e dentro da região de sedimentação e pouca segregação positiva no topo desta. O mecanismo se dá tanto pelo líquido interdendrítico enriquecido em soluto deixado pelos grãos em queda livre, tanto pela substituição de líquido extradendrítico abaixo por sólido pobre em soluto dos grãos sedimentados, diminuindo a concentração média na zona de empacotamento. Neste trabalho, foi apontado que a decantação de grãos foi o mecanismo predominante para explicar a segregação na linha de centro, conhecida como núcleo de segregação negativa (Figura 7). 


\subsection{Modelos de Nucleação}

Duas abordagens são conhecidas para o tratamento da nucleação de grãos em ligas metálicas: modelos de nucleação instantânea, onde todos os núcleos surgem imediatamente ao se atingir um determinado super-resfriamento; e modelos de nucleação contínua, onde a cada acréscimo de super-resfriamento, são nucleados novos grãos.

Um dos primeiros usos da abordagem de nucleação contínua foi realizado no trabalho de Oldfield (1966), que obteve expressões empíricas para a taxa de formação de núcleos dada por:

$$
N=A_{N} \Delta T^{2}
$$

onde $N$ é o número total de núcleos formados no metal líquido, $A_{N}$ é uma constante empírica entre 0,91 e 7,12, e $\Delta T$ é o super-resfriamento dado pela equação:

$$
\Delta T=T_{l i q}-T
$$

onde $T_{\text {liq }}$ é a temperatura liquidus para a liga considerada e $T$ é a temperatura da mistura, considerada uniforme dentro do domínio.

Thévoz et al. (1989) propuseram que, para uma população de substratos, há uma distribuição normal (Figura 8) de super-resfriamentos críticos dada pela equação:

$$
\frac{d n}{d(\Delta T)}=\left(\frac{n_{\max }}{\sqrt{2 \pi} \Delta T_{\sigma}}\right) \exp \left[-\frac{1}{2}\left(\frac{\Delta T-\overline{\Delta T_{N}}}{\Delta T_{\sigma}}\right)^{2}\right]
$$

onde $n$ é densidade de núcleos, $\Delta T$ é a super-resfriamento, $n_{\max }$ é a densidade máxima de núcleos ou a densidade de partículas de substratos sobre as quais a 
nucleação pode ocorrer, $\overline{\Delta T_{N}}$ é o super-resfriamento médio da distribuição e $\Delta T_{\sigma}$ é o desvio-padrão.

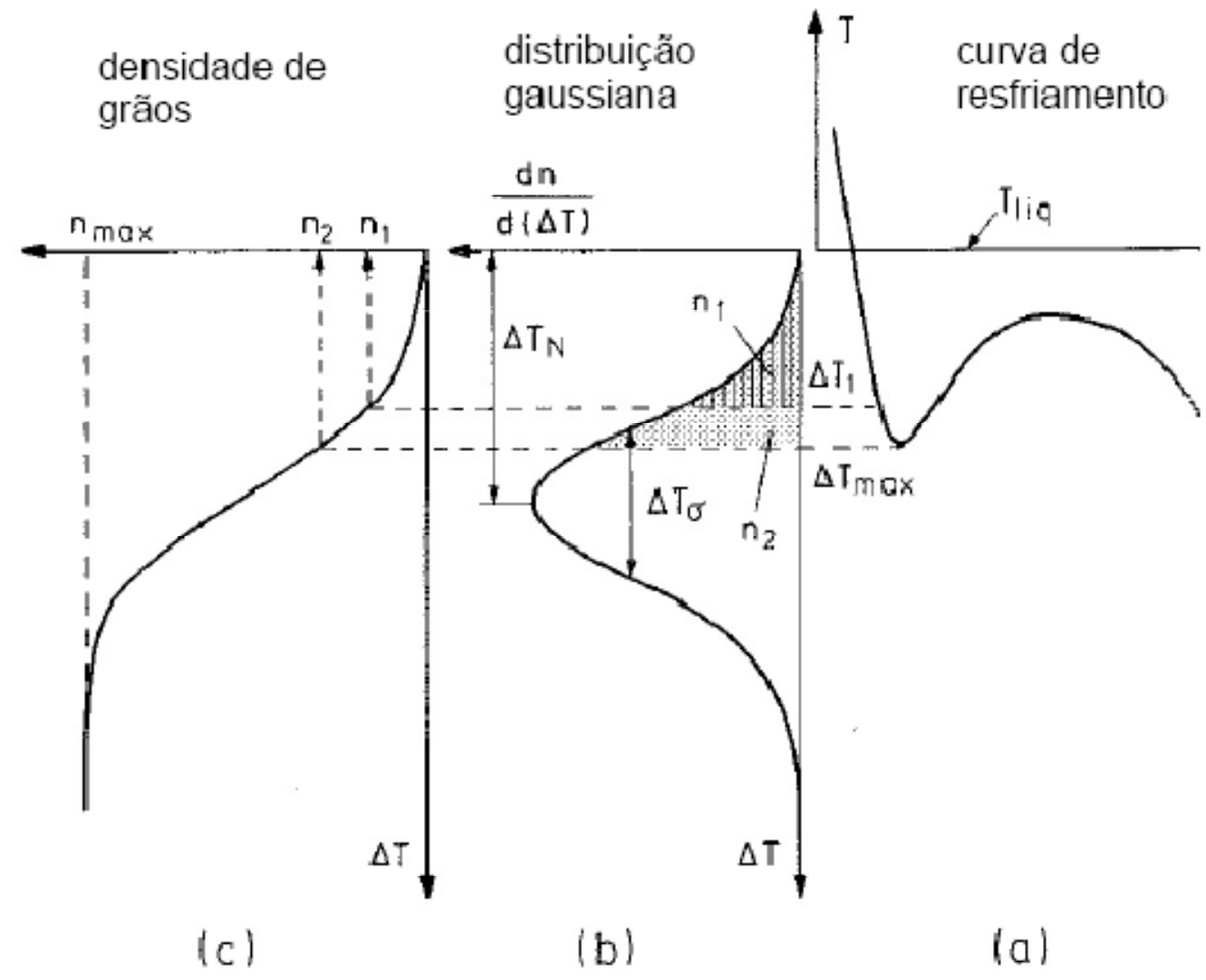

Figura 8 - Curvas para os modelos de nucleação contínua da densidade de núcleos $n$ para um super-resfriamento $\Delta T$. (a) curva de resfriamento (b) distribuição normal da equação [26]

(THEVOZ et al, 1989) (c) população de núcleos pela integral da curva (b).

$\mathrm{Na}$ literatura, outras distribuições foram utilizadas também, como a distribuição exponencial e log-normal (GREER et al., 2000; QUESTED; GREER., 2004).

\subsection{Modelos Determinísticos}

Os modelos determinísticos são definidos por conjuntos de equações diferenciais determinísticas, ou seja, que não possuem em seus cálculos variáveis aleatórias. Em problemas multifásicos como a solidificação, foram desenvolvidos modelos determinísticos multi-escala utilizando a técnica de média nas equações de conservação (NI; BECKERMANN, 1991). 
As deduções das equações de conservação de grandezas médias são obtidas integrando as equações diferenciais de conservação locais sobre um volume representativo $V_{0}$. Este volume representativo deve ser maior do que a escala em que as variações médias no espaço podem ser bruscas e menores do que a escala do domínio total (WHITAKER, 1969). Para uma grandeza por unidade de volume $\Psi$, a média desta num volume $V_{0}$ é definida como:

$$
\langle\Psi\rangle=\frac{1}{V_{0}} \int_{V_{0}} \Psi d V
$$

Quando a grandeza $\Psi$ é medida sobre uma fase $k$, é integrado apenas sobre o volume da fase $k$ :

$$
\left\langle\Psi_{k}\right\rangle=\frac{1}{V_{0}} \int_{V_{k}} \Psi_{k} d V
$$

onde $\Psi_{k}$ é o valor de $\Psi$ na fase $k$ e $V_{k}$ é o volume da fase $k$.

A média da grandeza $\Psi_{k}$ no volume da própria fase k é chamada de média intrínseca $\left(\left\langle\Psi_{k}\right\rangle^{k}\right)$, e é dada por:

$$
\left\langle\Psi_{k}\right\rangle^{k}=\frac{1}{V_{0}} \int_{V_{k}} \Psi_{k} d V
$$

e logo, possui uma relação com a média $\left\langle\Psi_{k}\right\rangle$ :

$$
\left\langle\Psi_{k}\right\rangle=\frac{V_{k}}{V_{0}}\left\langle\Psi_{k}\right\rangle^{k}=\varepsilon_{k}\left\langle\Psi_{k}\right\rangle^{k}
$$

onde $\varepsilon_{k}$ é a fração volumétrica de fase $k$. 
A equação para a média do gradiente $\langle\vec{\nabla} \Psi\rangle$ para a fase $k$ é dada como:

$$
\left\langle\vec{\nabla} \Psi_{k}\right\rangle=\vec{\nabla}\left\langle\Psi_{k}\right\rangle+\frac{1}{V_{0}} \int_{A_{k}} \Psi_{k} \vec{n}_{k} d A_{k}
$$

onde $\vec{n}_{k}$ é o versor normal a interface $A_{k}$ da fase $k$. E a derivada no tempo é expressa por:

$$
\left\langle\frac{\partial \Psi_{k}}{\partial t}\right\rangle=\frac{\partial\left\langle\Psi_{k}\right\rangle}{\partial t}-\frac{1}{V_{0}} \int_{A_{k}} \Psi_{k} \vec{w}_{k} \cdot \vec{n}_{k} d A_{k}
$$

Com estas relações é obtida uma equação geral de transporte para $\left\langle\Psi_{k}\right\rangle$ dada por:

$$
\frac{\partial\left(\varepsilon_{k}\left\langle\Psi_{k}\right\rangle^{k}\right)}{\partial t}+\vec{\nabla} \cdot\left(\varepsilon_{k}\left\langle\Psi_{k}\right\rangle^{k}\left\langle\vec{v}_{k}\right\rangle^{k}\right)=-\vec{\nabla} \cdot\left(\left\langle\Phi_{k}\right\rangle+\left\langle\Phi_{k}\right\rangle^{t}\right)+\sum_{j, j \neq k} \Theta_{k j}
$$

onde $\left\langle\vec{v}_{k}\right\rangle$ é a velocidade média da fase $k ;\left\langle\Phi_{k}\right\rangle$ é o fluxo macroscópico médio da grandeza $\Psi ;\left\langle\Phi_{k}\right\rangle^{t}$ é o fluxo dispersivo que são modelados utilizando o conceito de transporte efetivo:

Ni e Beckermann (1991) aplicaram a técnica com duas fases distintas, a de metal líquido e a de metal sólido, para obter o conjunto de equações de conservação de massa, energia, momento e espécies químicas para três dimensões. O VER do modelo foi definido como suficientemente maior que o espaçamento entre braços secundários, e menor que a escala do molde, englobando um conjunto de grãos (Figura 9). Wang e Beckermann (1993) estenderam o modelo para o caso de três fases: uma fase sólida e duas fases líquidas, sendo uma o líquido interdendrítico que se localiza entre os braços dendríticos dentro do grão, e o líquido extradendrítico exterior ao grão. 


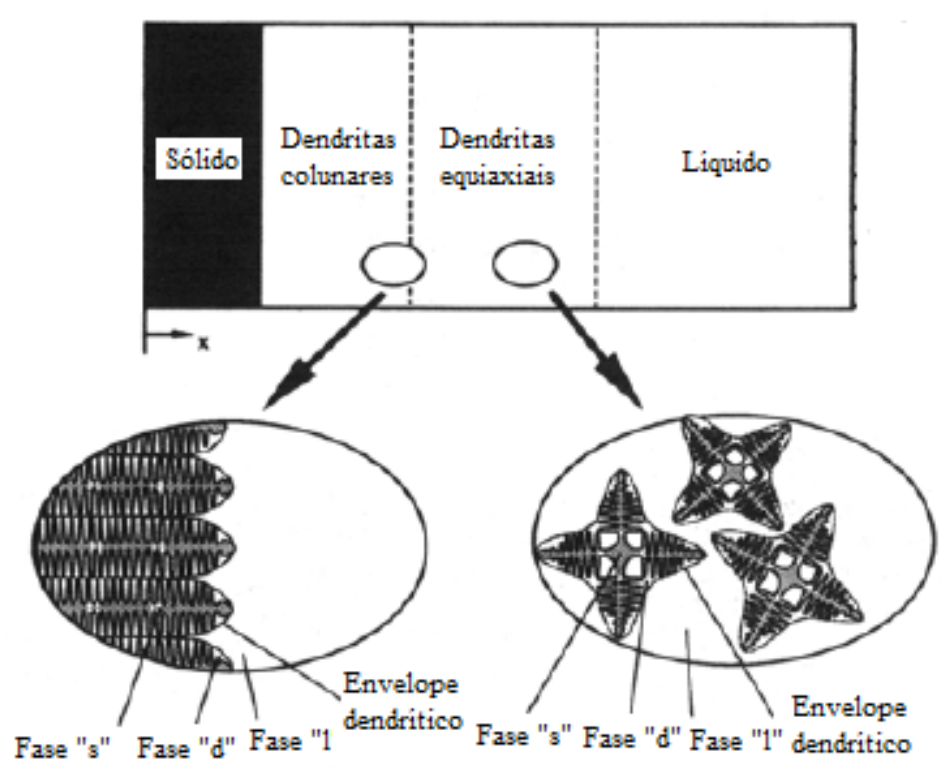

Figura 9 - Desenho esquemático de volumes elementares representativos (VER) na zona colunar e na zona equiaxial, distinguindo cada fase constituinte: sólido (s), líquido interdendrítico (d) e líquido extradendrítico (I). (Wang e Beckermann, 1994)

No trabalho de Wang e Beckermann (1994), o modelo tri-fásico foi utilizado com adaptações para considerar o crescimento colunar e prever a CET. Os grãos colunares foram representados como cilindros que cortam um volume na direção paralela à extração de calor, com crescimento radial e o avanço da frente acompanhado até chegar ao próximo ponto na malha de diferenças finitas. A formação da CET por bloqueio mecânico da frente colunar por grãos equiaxiais ocorre segundo critério proposto por Hunt (1984) de fração de grãos equiaxiais iguis a 0,49 .

Nestes modelos, o fluxo difusivo entre o líquido interdendrítico e o líquido extradendrítico é calculado através de uma solução analítica (corrigida por Martorano et al (2002)) para a difusão ao redor de uma esfera de concentração constante, para grãos equiaxiais, e ao redor de um cilindro, para grãos colunares. Nesta solução, é obtida uma expressão para a espessura efetiva de difusão no líquido extradendrítico em função da concentração de grãos e da velocidade de crescimento da interface.

Wang e Beckermann (1996) propuseram um modelo multi-fásico e multiescala com convecção em três dimensões utilizando equacionamentos feitos por 
Wang et al (1995) para cálculo de partição de escoamento das fases líquidas e para o cálculo do arraste da fase sólida. Os resultados do modelo comparado com trabalhos experimentais com $\mathrm{NHCl}_{2}-\mathrm{H}_{2} \mathrm{O}$ mostram o núcleo de segregação negativa (Figura 7) e a redução de tamanho de grão perto da base causada pela sedimentação de grãos.

Combeau et al (2009) examinaram a influência do movimento de grãos equiaxiais e de sua morfologia (globulítica ou dendrítica) utilizando o modelo de Wang e Beckermann (1996). Seus testes mostraram que para grãos dendríticos apenas diminui o fluxo interdendrítico, atenuando 0 efeito deste na macrossegregação, mas permanecendo como o mecanismo principal. Para grãos globulíticos, não houve macrossegregação significativa.

Wu e Ludwig (2009) propuseram um modelo próximo ao de Wang e Beckermann (1996) com diferenças ao não considerar o líquido interdendrítico com concentração homogênea e distinguindo o formato dos grãos entre globulíticos e dendríticos. Os autores obtiveram, nos casos de grãos globulíticos, durante os estágios finais da solidificação, macrossegregação mais intensa do que nos casos onde os grãos eram dendríticos.

\subsection{Técnica do Autômato Celular}

Os modelos estocásticos são geralmente baseados na técnica de MonteCarlo (MC) e do autômato celular (CA) e se mostraram capazes de simular a formação da completa macroestrutura de grãos durante a solidificação (ZHU et al., 2007). Spittle e Brown (1989) foram os precursores na criação de um modelo estocástico baseado no método de MC.

Rappaz e Gandin (1993) propuseram um modelo estocástico baseado na técnica de autômato celular em escala mesoscópica. O modelo utilizava um submodelo macroscópico e um microscópico. No macroscópico, o domínio de cálculo era subdividido em elementos finitos para resolução numérica da equação diferencial de conservação de energia. No submodelo microscópico, baseado na 
técnica de autômato celular, simulava-se a nucleação e o crescimento de grãos dentro de um elemento finito. Nesta técnica, o domínio de um elemento finito é dividido em uma malha de células quadradas, onde cada célula tinha um estado físico determinado de líquido ou sólido (Figura 19). As células líquidas poderiam conter um substrato com dado super-resfriamento crítico para nucleação de um novo grão.

(a)

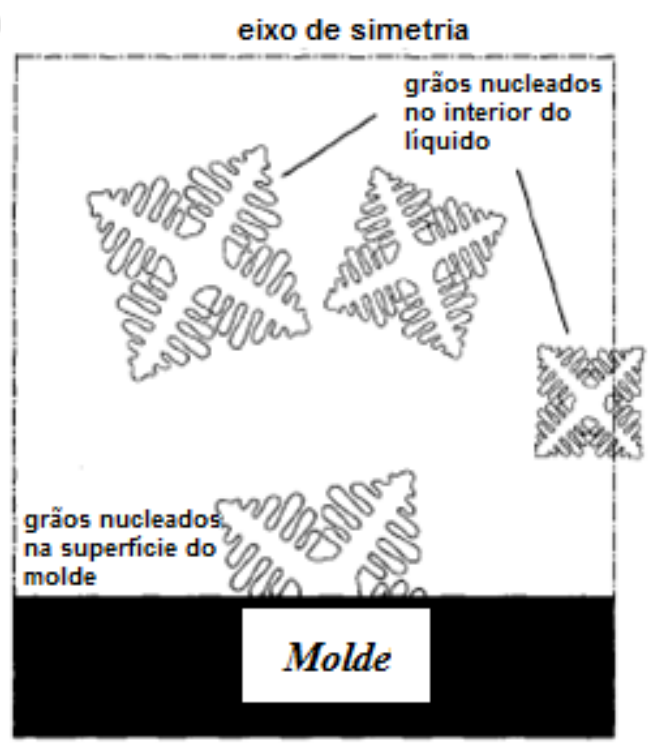

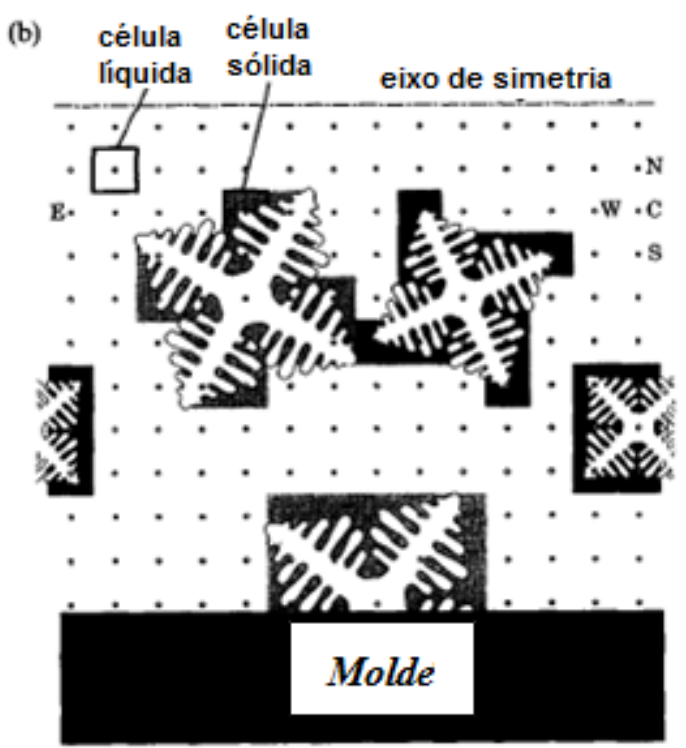

Figura 10- Representação dos envelopes dendríticos com a técnica do autômato celular.

(RAPPAZ; GANDIN,1993)

Uma quantidade de substratos para a nucleação heterogênea é distribuída aleatoriamente através do domínio, e cada um com um super-resfriamento crítico para nucleação previamente determinado. Os autores utilizaram a proposta de Thévoz et al. (1989), na qual a densidade de distribuição de super-resfriamentos críticos obedece a uma curva Gaussiana (distribuição normal). Esta distribuição normal é determinada por três parâmetros: super-resfriamento médio, desvio-padrão e densidade máxima de núcleos. Tanto em modelos estocásticos quanto em determinísticos, não há uma preocupação em simular fisicamente os fenômenos responsáveis pela formação da zona equiaxiais apresentados na seção 3.3 (HELLAWELL et al., 1997) 
No caso dos modelos bidimensionais, nas células sólidas há um quadrado de crescimento que representa um grão ou uma parte de um grão, cujas diagonais crescem com uma velocidade determinada pelos modelos de crescimento dendrítico.

Gandin e Rappaz (1994) propuseram um modelo de autômato celular com retângulos de crescimento para evitar alguns problemas de distorção na forma dos grãos, provocados pelo desalinhamento das diagonais dos quadrados de crescimento. Posteriormente, mais uma modificação foi proposta por Rappaz e Gandin (1997) envolvendo novamente quadrados de crescimento, porém estes eram agora descentrados em relação às células e não distorciam a forma do grão.

Considerando o efeito da convecção no crescimento dendrítico, a técnica do autômato celular foi capaz de mostrar a deflexão de grãos colunares resultante do movimento do fluido (TAKATANI, 2000). A técnica do CA também foi adaptada para simular fenômenos microscópicos, que ocorrem em uma menor escala de tamanho. Os modelos originários desta adaptação foram denominados como técnica do CA modificado. Com esta técnica foi possível estudar mais detalhadamente alguns fenômenos do crescimento dendrítico, como o efeito da anisotropia cristalográfica no parâmetro de estabilidade do crescimento dendrítico (BELTRAN-SANCHEZ; STEFANESCU, 2004) e a formação de braços dendríticos primários e secundários.

Guillemot et al. (2006) adaptaram a técnica do CA para considerar a movimentação dos grãos e convecção da fase líquida. Entretanto, foram utilizadas hipóteses simplificadoras, como velocidade nula para a fase sólida nas equações de conservação macroscópicas, considerando o efeito de movimento do sólido apenas no termo de arraste na equação de momento. O modelo também desconsidera o fluxo difusivo entre o envelope e o líquido ao redor deste. Os resultados mostraram diferenças entre o modelo de CA sem movimentação e com movimentação. $O$ algoritmo com movimentação apresentou refino de grão na base, e a formação de canais de segregação, apontados como responsáveis pela formação de "freckles".

Biscuola e Martorano (2007) desenvolveram um modelo híbrido chamado CADE, utilizando informações micro-estruturais retiradas do modelo de CA para um modelo macroscópico semelhante ao trabalho de Martorano et al. (2003). Variáveis 
como fração de sólido interna a um grão e área interfacial do envelope são calculadas pela técnica do CA e acopladas ao modelo determinístico macroscópico. O modelo apresentou resultados próximos ao modelo determinístico, porém, acompanhando os detalhes da macroestrutura de grãos que a técnica do CA providencia. Mosbah et al. (2010) consideraram a movimentação de grãos utilizada em Guilletmot et al. (2006) e considerando o fluxo difusivo entre as fases líquidas, porém, obtendo uma expressão simplificada para as áreas interfaciais entre as fases, diferentemente de Biscuola e Martorano (2007) que obtinham esta informação através da imagem do CA. 


\section{METODOLOGIA}

\subsection{Aspectos Gerais do Modelo Matemático}

Um modelo matemático foi implementado para simular principalmente a formação da macroestrutura de grãos em um domínio bidimensional e a macrossegregação durante a solidificação unidirecional sob efeito da decantação de grãos. O presente modelo foi implementado em três partes: (a) algoritmo baseado na técnica do autômato celular para simular a nucleação, crescimento e translação dos

grãos; (b) submodelo microscópico que se baseia nos princípios de conservação aplicado no interior de cada grão e (c) submodelo macroscópico que se baseia nos princípios de conservação aplicados no interior de todo o domínio. O algoritmo do autômato celular e o submodelo microscópico consideram fenômenos que são importantes na escala de tamanho microscópico, enquanto o submodelo macroscópico, fenômenos importantes na escala macroscópica. Cada submodelo possui um domínio e um próprio conjunto de equações diferenciais de conservação específicos. 


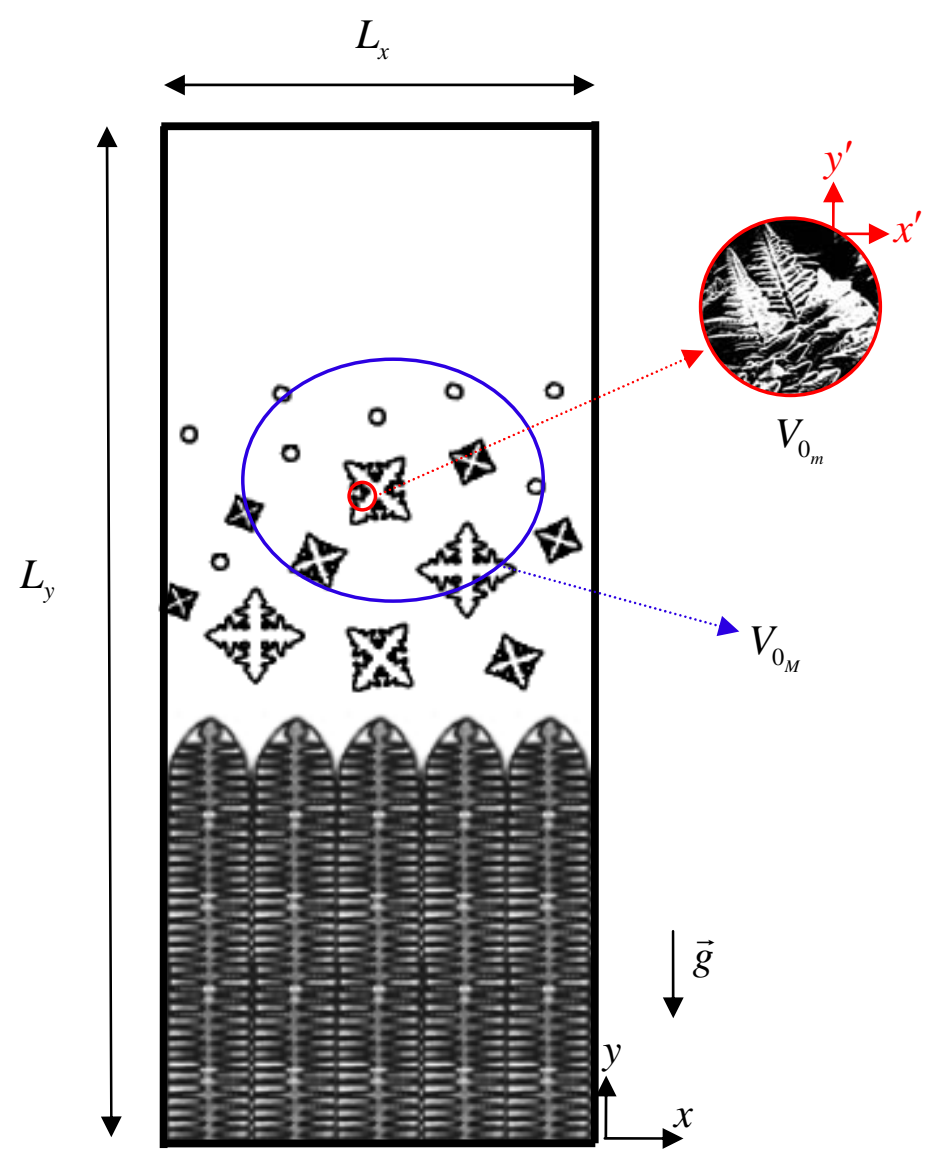

Figura 11 - Domínio onde será utilizado cada modelo. O contorno do molde $\left(L_{x}\right.$ e $\left.L_{y}\right)$ delimita o

domínio do modelo macroscópico, enquanto cada conjunto de grãos (destacados com cores diferentes) que se tocam define um domínio onde será solucionado o conjunto de equações do modelo microscópico. As linhas cinzas tracejadas representam o contorno dos volumes finitos que discretizam o domínio macroscópico, enquanto a malha quadriculada representa a discretização do domínio microscópico em células do autômato celular.

O domínio do submodelo microscópico é definido como a região interna dos grãos, enquanto o do submodelo macroscópico consiste de toda a região contendo o metal (equivalente à cavidade de um molde de fundição) como seu domínio. A Figura 11 ilustra estes dois domínios. O submodelo microscópico, utilizando a técnica do autômato celular, simula fenômenos como a nucleação, o crescimento e a translação de grãos, enquanto seu conjunto de equações diferenciais fornece a fração de sólido e a concentração de soluto internamente aos grãos. No submodelo macroscópico, por outro lado, calculam-se os campos de temperatura e de concentração de soluto no líquido extradendrítico.

Cada um dos submodelos (microscópico e macroscópico) possui um conjunto de equações diferenciais específico, baseadas nos princípios de conservação de massa, energia e espécies químicas. Além disso, devido às escalas de tamanho dos 
fênomenos que são tratados em cada um dos submodelos serem diferentes, definiram-se dois volumes elementares representativos (VER) de tamanhos diferentes para difinir as variáveis médias: um volume microscópico $\left(V_{0 m}\right)$ e um macroscópico $\left(V_{0_{M}}\right)$. As variáveis médias dos submodelos micro e macroscópicos são definidas, respectivamente, através das médias volumétricas ("volume averaging"), também chamadas de superfíciais, apresentadas abaixo:

$$
\begin{gathered}
\left\langle\psi_{k}\right\rangle=\frac{1}{V_{0_{m}}} \int_{V_{k_{m}}} \psi_{k} d V \\
\left\langle\psi_{k}\right\rangle_{M}=\frac{1}{V_{0_{M}}} \int_{V_{k_{M}}} \psi_{k} d V
\end{gathered}
$$

sendo, $\left\langle\psi_{k}\right\rangle$ a operação da média em uma grandeza $\psi$ qualquer sobre o VER microscópico $V_{0_{m}}$ e $\left\langle\psi_{k}\right\rangle_{M}$ sobre o VER macroscópico $V_{0_{M}} ; V_{k_{m}}$ e $V_{k_{M}}$ são os volumes da fase $k$ nos VERs micro e macroscópico respectivamente; Logo, as médias intrínsecas ("intrinsic volume average") sobre uma fase $k$ serão indicadas por:

$$
\begin{aligned}
& \left\langle\psi_{k}\right\rangle_{m}^{k}=\frac{1}{V_{k_{m}}} \int_{V_{k_{m}}} \psi_{k} d V_{k} \\
& \left\langle\psi_{k}\right\rangle_{M}^{k}=\frac{1}{V_{k_{M}}} \int_{V_{k_{M}}} \psi_{k} d V_{k}
\end{aligned}
$$

onde $\left\langle\psi_{k}\right\rangle_{m}^{k}$ é a média intrínseca da grandeza $\psi$ no VER microscópico e $\left\langle\psi_{k}\right\rangle_{M}^{k}$ no VER macroscópico;

para o submodelo microscópico e o submodelo macroscópico respectivamente.

No desenvolvimento das equações de conservação para cada submodelo, hipóteses comuns e específicas foram definidas. As hipóteses comuns aos modelos micro e macroscópicos estão listadas a seguir: 
1. A liga metálica modelada é considerada pertencer a um sistema binário eutético.

2. As densidades de todas as fases são consideradas iguais e constantes: $\rho=\rho_{s}=\rho_{e}=\rho_{d}=\rho_{l}$, exceto no cálculo da velocidade de decantação.

3. Os calores específicos de todas as fases são iguais e constantes: $C_{P}=C_{P s}=C_{P e}=C_{P d}=C_{P l}$

4. Considera-se que os grãos apresentam apenas o movimento de decantação, ou seja, apresentam movimento apenas na direção paralela à aceleração gravitacional.

5. A convecção natural do líquido, seja induzida por gradientes de temperatura ou concentrações é desprezada, porém aquela induzida pela decantação de grãos é considerada.

6. As velocidades médias de todas pseudofases líquidas e sólidas nos dois submodelos apresentam direção paralela à da aceleração gravitacional.

7. O eutético apresenta velocidade de movimentação igual à da fase primária no interior do grão, portanto: $\vec{v}_{e}=\vec{v}_{s}$ (no interior de cada grão).

8. Os coeficientes efetivos de difusão de calor e soluto no líquido serão considerados iguais aos coeficientes de difusão das respectivas fases.

9. Não há difusão de soluto nas fases sólidas e eutético.

10. A fase líquida extradendrítica não tem área de contato com as fases sólidas.

11. Existe equilíbrio termodinâmico local na interface sólido-líquido interdendrítico, portanto as composições do líquido e sólido adjacentes à interface estão relacionadas através das equações: $T=T_{f}+m_{l} C_{d}$ e $k=C_{s} / C_{d}$

12. Existe equilíbrio térmico no interior dos volumes representativos (VER) adotados para os dois submodelos (micro e macroscópico), portanto as temperaturas médias de todas as fases são iguais em um mesmo ponto do domínio. 


\subsection{Técnica do Autômato Celular}

No submodelo microscópico utiliza-se a técnica do autômato celular (CA) para simular a nucleação, o crescimento e a decantação dos grãos. Na técnica do CA , o domínio é dividido em uma malha de células quadradas de lado $\Delta x_{C A}$ que podem apresentar três estados: ativa, inativa ou líquida (Figura 12). Cada célula ativa contém uma mistura entre sólido e líquido interdendrítico, e possui um polígono de crescimento definido como um quadrilátero de diagonais ortogonais conforme foi apresentado em Guillemot et al. (2006).

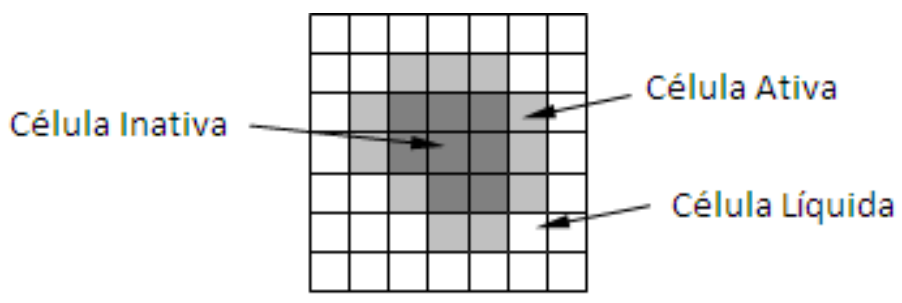

Figura 12 - Representação de um envelope dendrítico na malha de células do modelo de autômato celular com a definição do estado de suas células (ativo ou inativo) e das células líquidas ao redor.

$\mathrm{Na}$ célula ativa, armazena-se a posição do centro de crescimento do polígono (intersecção das diagonais) (Figura 13) relativo ao centro da célula e a distância de cada vértice em relação à intersecção das diagonais. Cada distância de um vértice ao centro será chamada de diagonal para simplificação dos conceitos

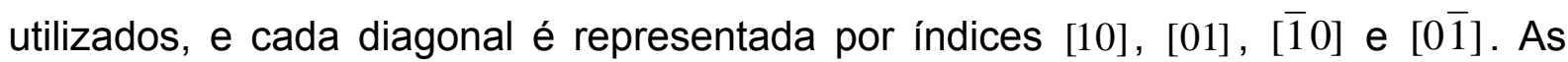
células ativas têm os seus polígonos em crescimento e determinam o contorno de um envelope dendrítico. Estas células ativas tornam-se novamente inativas quando todas as células vizinhas mais próximas (quatro no caso de uma malha quadrada) estiverem ativas ou tiverem sido ativadas em algum momento. Neste caso, o polígono de crescimento da célula inativa não mais muda de tamanho e não tem mais nenhuma função em delinar o envelope de grão. 


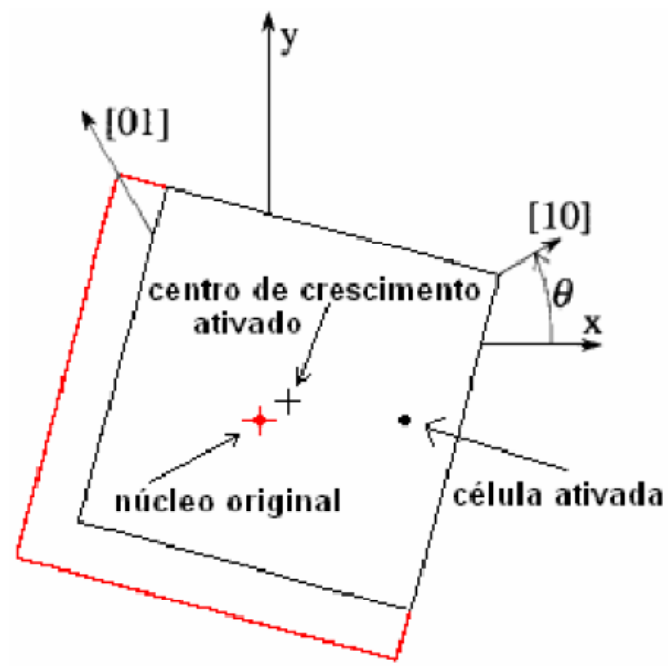

Figura 13 - Exemplo de um quadrado de crescimento descentrado em uma célula de CA.

Uma célula líquida pode conter apenas líquido, ou pode conter também um substrato para nucleação heterogênea de um novo grão. Cada célula líquida que contém uma partícula de substrato para nucleação torna-se uma célula ativa originando um novo grão através do processo de nucleação.

\subsubsection{Nucleação}

Assume-se que a nucleação de um novo grão ocorre heterogeneamente sobre uma partícula de substrato, cada um apresentando um super-resfriamento crítico distinto. Considera-se que a distribuição de super-resfriamentos críticos associados a estes substratos obedece a uma distribuição gaussiana (normal). Duas distribuições gaussianas de super-resfriamento são definidas: uma para os substratos distribuídos na parede interna do molde e outra para os substratos distribuídos no interior do líquido. A equação que define a distribuição de superresfriamentos para nucleação entre os substratos é dada abaixo (RAPPAZ; GANDIN, 1993):

$$
\frac{d n}{d(\Delta T)}=\left(\frac{n_{\max }}{\sqrt{2 \pi} \Delta T_{\sigma}}\right) \exp \left[-\frac{1}{2}\left(\frac{\Delta T-\overline{\Delta T_{N}}}{\Delta T_{\sigma}}\right)^{2}\right]
$$


onde $n$ é densidade de núcleos, $\Delta T$ é o super-resfriamento, $n_{\max }$ é a densidade máxima de número de núcleos, ou seja, a densidade de partículas de substratos sobre as quais a nucleação pode ocorrer, $\overline{\Delta T_{N}}$ é o super-resfriamento médio da distribuição e $\Delta T_{\sigma}$ é o desvio-padrão. Para simular a nucleação neste modelo , são necessários, portanto, seis parâmetros: três para os núcleos da superfície do molde e três para os núcleos no interior do metal líquido.

As densidades de número de substratos no interior do líquido e na superfície do molde representam o número de substratos por unidade de volume e por unidade de superfície, respectivamente. O submodelo microscópico desenvolvido no presente trabalho é bidimensional, o que implica que o volume interior do líquido é representado por uma determinada área e a superfície do molde, por um dado comprimento. Portanto, é necessário converter as densidades indicadas na distribuição para serem utilizadas no presente modelo. Esta conversão estereológica é indicada abaixo (RAPPAZ; GANDIN, 1993).

$$
\begin{gathered}
n_{S}^{*}=\frac{\pi}{4}\left(n_{L}\right)^{2} \\
n_{V}^{*}=\sqrt{\frac{\pi}{6}}\left(n_{A}\right)^{3 / 2}
\end{gathered}
$$

onde $n_{L}$ é a quantidade de substratos por unidade de comprimento da borda do domínio; $n_{S}^{*}$ é a quantidade de substratos por unidade de superfície do molde; $n_{A}$ é a quantidade de substratos por unidade de área do domínio e $n_{V}^{*}$ é a quantidade de substratos por unidade de volume.

Através destas duas grandezas, é calculada a quantidade de substratos na superfície e no interior do molde, e este valor é utilizado como a densidade máxima $n_{\max }$ na Eq. [38]. O cálculo para a quantidade de substratos que possui um dado super-resfriamento crítico para nucleação é realizado pela integral numérica da Eq. [38]. 
No início da simulação, todos os substratos são distribuídos aleatoriamente no domínio. Se durante o resfriamento a célula em que o substrato está contido atingir um super-resfriamento maior ou igual ao indicado para o substrato e esta célula ainda for líquida, este substrato se torna um núcleo e a célula é ativada. No processo de ativação define-se um polígono de crescimento com diagonais nulas e com orientação selecionada aleatoriamente entre 48 classes no intervalo $\left[-45^{\circ},+45^{\circ}\right]$ (RAPPAZ; GANDIN, 1993).

\subsubsection{Crescimento de Grãos}

Durante cada passo de tempo do método numérico, utilizado para solucionar as equações de conservação dos modelos microscópico e macroscópico, cada uma das quatro diagonais do polígono de crescimento de uma célula ativa crescerá com a mesma velocidade conforme a equação abaixo:

$$
\left|\vec{w}_{g}^{\prime}\right|=\frac{D_{l}(k-1)\left(\langle T\rangle_{M}-T_{f}\right)}{\pi^{2} \Gamma}\left[0,4567\left(\frac{\Omega_{C}}{1-\Omega_{C}}\right)^{1,195}\right]^{2}
$$

onde $\vec{w}_{g}^{\prime}$ é a velocidade de crescimento da ponta da dendrita (relativa ao referencial do grão); $\langle T\rangle_{M}$ é a temperatura do centro da célula de CA interpolada do submodelo macroscópico; $T_{f}$ é a temperatura de fusão do metal líquido puro; $D_{l}$ é a difusividade de soluto no líquido; $k$ é coeficiente de partição de soluto; $\Gamma$ é o coeficiente de Gibbs-Thompson; e $\Omega$ é um super-resfriamento adimensional de soluto dado por:

$$
\Omega_{C}=\frac{\left(\langle T\rangle_{M}-T_{l i q}\right)}{\left(\langle T\rangle_{M}-T_{f}\right)(1-k)}
$$

onde $m_{l}$ é a inclinação da curva liquidus do diagrama de fases e $T_{l i q}$ é a temperatura liquidus para a concentração $C_{0}$. 
Embora na literatura seja descrito que cada braço dendrítico tem a sua cinética de crescimento em função do movimento de convecção e da concentração de soluto ao redor de sua ponta, estes efeitos foram descartados com justificativa baseada nos experimentos de Badillo et al (2007). Estes experimentos mostraram que a média da velocidade de crescimento das seis pontas de um envelope dendrítico é aproximadamente a velocidade calculada pelo modelo difusional (item 3.2), dada pela Eq. [2].

Durante o crescimento, o polígono de crescimento inicial atingirá o centro de suas células vizinhas. Quando isto ocorrer, se a célula atingida estiver no estado líquido, ela deve ser ativada, e um novo polígono de crescimento deve ser criado na mesma, pertencendo ao mesmo grão. Diferentemente do processo de nucleação, a orientação deste novo polígono deve ser igual a do polígono que o ativou. Se as quatro células ao redor da original estiverem ativadas, a célula original passa a ser uma célula inativa, ou seja, seu polígono de crescimento não cresce mais nos próximos instantes. Um exemplo da captura de uma célula é esquematizado na Figura 14. Nesta figura $\Delta \vec{C}_{\mu}$ é o vetor deslocamento entre o centro da célula e a posição do centro do polígono de crescimento; $\Delta \vec{r}_{\mu}^{v}$ a distância entre os centros das células $\mu$ e $v ; \vec{L}_{\mu[10]}, \vec{L}_{\mu[01]}, \vec{L}_{\mu[\overline{1} 0]}$ e $\vec{L}_{\mu[0 \overline{1}]}$ as quatro diagonais que compõem o polígono de crescimento no instante " $\mathrm{t}$ " e representam de maneira simplificada um corte bidimensional de um envelope dendrítico tri-dimensional (composto de seis braços), 


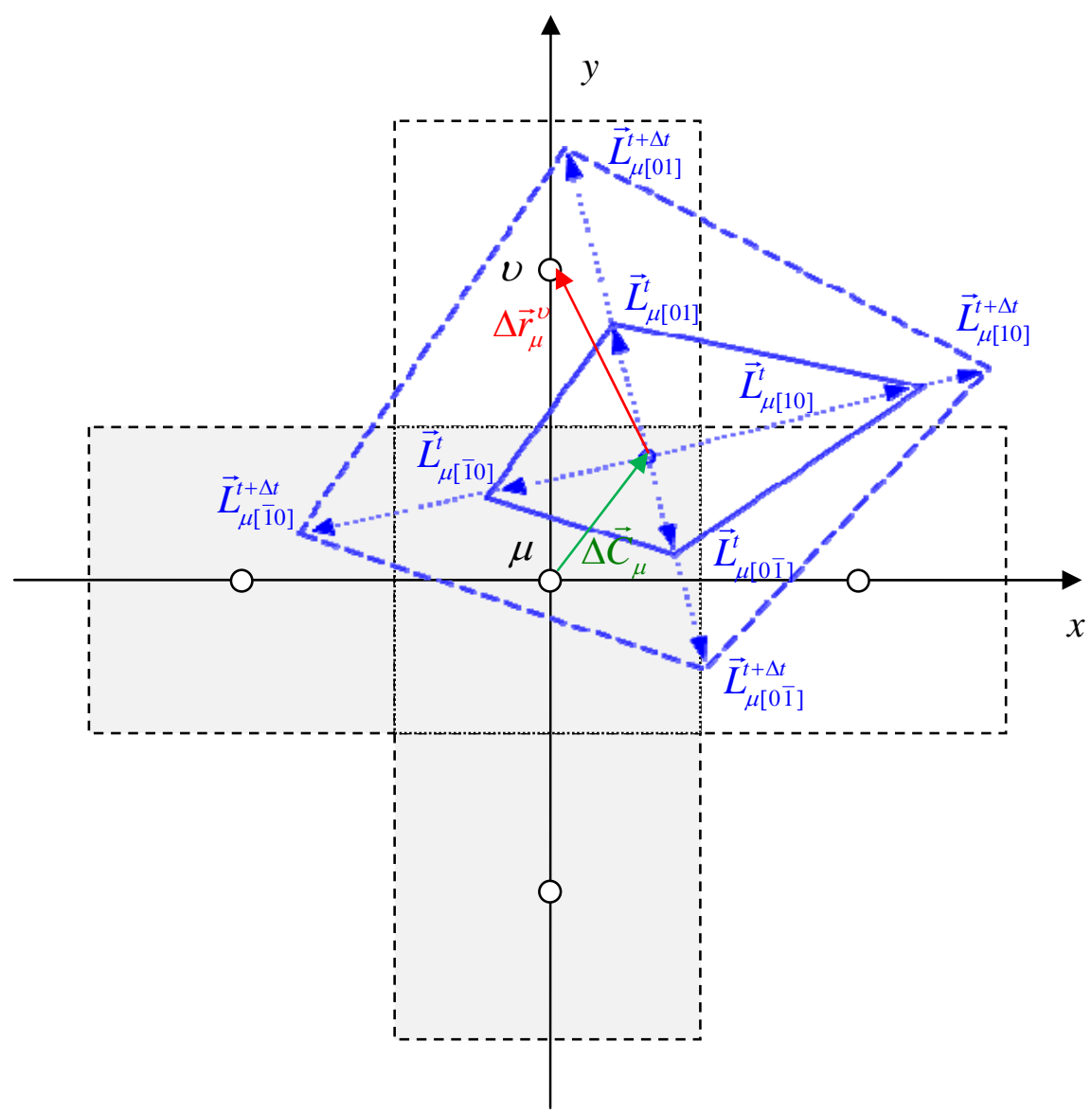

Figura 14 - Exemplo da captura de uma célula líquida $v$ (célula branca superior) pelo polígono de crescimento de sua célula vizinha $\mu$ (célula cinza ao centro). $O$ polígono descentrado da célula ativa $\mu$ é definido no instante $t$ pelas quatro diagonais $\vec{L}_{\mu}^{t}$, e no instante $t+\Delta t$ (após crescimento) pelas diagonais $\vec{L}_{\mu}^{t+\Delta t}$, e pela descentralização $\Delta \vec{C}_{\mu}$. No instante de captura $(t+\Delta t)$, o vetor $\Delta \vec{r}_{\mu}^{v}$ está contido no triângulo formado pelas diagonais $\vec{L}_{\mu[01]}^{t+\Delta t}$ e $\vec{L}_{\mu[\overline{10}]}^{t+\Delta t}$.

Para verificar a captura de um centro de uma célula vizinha, é necessário examinar se o ponto pertence ao interior de algum dos quatros triângulos formados pelas diagonais do polígono de crescimento. Na Figura 14, cada triângulo é formado por um par de vetores e por uma linha conectando os seus vértices. Se o vetor $\Delta \vec{r}_{\mu}^{v}$, correspondente à distância entre o centro do polígono de crescimento da célula $\mu \mathrm{e}$ o centro da célula a ser capturada $v$, obedecer simultaneamente às duas equações abaixo (dedução no Apêndice $A$ ), a célula u será capturada:

$$
0 \leq \frac{\Delta \vec{r}_{\mu}^{v} \cdot \vec{L}_{\mu[01]}^{t+\Delta t}}{\left|\vec{L}_{\mu[01]}^{t+\Delta t}\right|^{2}} \leq 1
$$




$$
0 \leq \frac{\Delta \vec{r}_{\mu}^{v} \cdot \vec{L}_{\mu[\overline{1} 0]}^{t+\Delta t}}{\left|\vec{L}_{\mu[\overline{1} 0]}^{t+\Delta t}\right|^{2}} \leq 1-\frac{\Delta \vec{r}_{\mu}^{v} \cdot \vec{L}_{\mu[01]}^{t+\Delta t}}{\left|\vec{L}_{\mu[01]}^{t+\Delta t}\right|^{2}}
$$

onde as distâncias $\vec{L}_{\mu[\overline{1} 1]}^{t+\Delta t}$ e $\vec{L}_{\mu[01]}^{t+\Delta t}$ estão definidas na Figura 14, que mostra o critério de captura para o triângulo formado por $\vec{L}_{\mu[\overline{10}]}^{t+\Delta t}$ e $\vec{L}_{\mu[01]}^{t+\Delta t}$.

Quando a célula capturada é ativada, um novo polígono de crescimento é associado à mesma. O novo polígono de crescimento deve manter o contorno do polígono que o ativou. Entretanto, não é necessário que o novo polígono tenha as mesmas dimensões do envelope que o contém para cobrir o seu contorno. Portanto, foi proposto um truncamento para o cálculo das suas dimensões, dado por Takatani (2000) para o caso tridimensional. No presente trabalho, este algoritmo foi adaptado para um domínio bidimensional. A seguir, será descrito o algoritmo para a captura de uma nova célula pelas diagonais $\vec{L}_{\mu[10]}$ e $\vec{L}_{\mu[01]}$ (Figura 15), que pode ser analogamente utilizado para captura de outros pares de diagonais:

i) Obtém-se a posição do ponto I (indicado na Figura 15), cuja distância ao centro da célula recém-ativada $v$ é ortogonal ao vetor $\vec{L}_{\mu[01]}-\vec{L}_{\mu[10]}$.

ii) Calculam-se as distâncias $\overline{I L}_{\mu[10]}$ e $\overline{I L}_{\mu[01]}$ (Apêndice A).

iii) O módulo do vetor $\vec{L}_{v[01]}-\vec{L}_{v[10]}$ é calculado pelo truncamento:

$$
\left|\vec{L}_{v[01]}-\vec{L}_{v[10]}\right|=\min \left(\overline{I L}_{\mu[01]}, \sqrt{2} \Delta x_{C A}\right)+\min \left(\overline{I L}_{\mu[10]}, \sqrt{2} \Delta x_{C A}\right)
$$

iv) Adota-se como condição que a razão entre os tamanhos das diagonais do novo polígono de crescimento deve ser igual à do polígono que o ativou. Portanto, as novas diagonais são calculadas por:

$$
\vec{L}_{v[10]}=\frac{\left|\vec{L}_{v[01]}-\vec{L}_{v[10]}\right|}{\left|\vec{L}_{\mu[01]}-\vec{L}_{\mu[10]}\right|} \vec{L}_{\mu[10]}
$$


v) Outra condição adotada é a de que o novo polígono de crescimento deve ter parte do contorno em comum ao polígono que o ativou; logo, o novo centro de crescimento deve pertencer à diagonal mais próxima ao centro da célula recém-ativada. A descentralização da célula recémativada é calculada por:

$$
\Delta \vec{C}_{v}=\vec{L}_{\mu[10]}-\Delta \vec{r}_{\mu}^{v}-\vec{L}_{v[10]}
$$

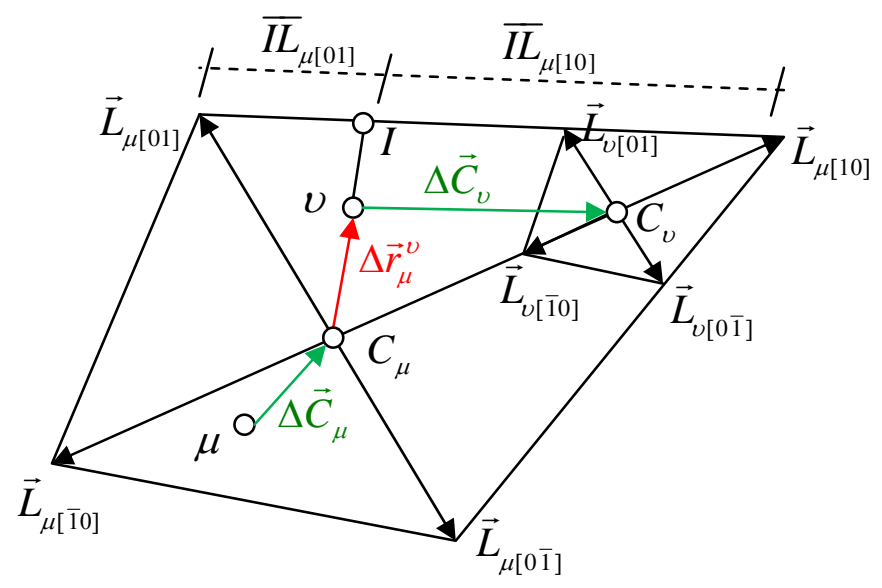

Figura 15 - Definição dos vetores para o cálculo do novo polígono de crescimento.

\subsubsection{Translação de Grãos}

A decantação de grãos foi simulada através de um algoritmo de translação que consiste de três partes com as seguintes tarefas específicas: (a) cálculo da velocidade de decantação do grão; (b) incremento ao deslocamento do grão; (c) verificação do critério para migração completa do grão entre células adjacentes e migração propriamente dita à célula vizinha.

\section{a) Cálculo da Velocidade de Decantação do Grão}

Um procedimento foi desenvolvido para calcular a velocidade de um grão ou de um aglomerado de grãos. Antes de calcular a velocidade de um aglomerado, é feita a verificação de interfaces comuns entre grãos. Esta tem como função assegurar que, após a translação, um envelope não ocupe a posição que outro já ocupa, ou garantir que estes não saiam do domínio, considerando o contorno como 
as paredes de um molde. Ao notificar que células pertencentes a envelopes diferentes são vizinhas (superior, inferior, à direita ou à esquerda, não considerando as células nas diagonais), estes dois envelopes formam um aglomerado (denominado também como "cluster"), que é um conjunto de envelopes.

Se uma célula de um aglomerado ou envelope isolado apresentar uma interface comum com a parede do molde, este aglomerado será fixado. Qualquer outro aglomerado será fixado ao apresentar uma interface comum com outros aglomerados fixados.

Se o grão não está fixado, sua velocidade de decantação será assumida igual à velocidade terminal de decantação que tem apenas componente vertical. É considerado que grãos equiaxiais são aproximadamente octaedros regulares com densidade calculada por:

$$
\rho_{C}=\varepsilon_{s, C} \rho_{s}+\left(1-\varepsilon_{s, C}\right) \rho_{l}
$$

onde $\rho_{C}$ é a densidade média do "cluster", $\rho_{s}$ e $\rho_{l}$ são as densidades da fase sólida e líquida respectivamente e $\varepsilon_{s, C}$ é a fração de sólido média do cluster calculada por:

$$
\varepsilon_{s, C}=\frac{1}{N_{C}} \sum_{N_{C}} \varepsilon_{s}
$$

onde $N_{C}$ é o número de células do CA que compõem o "cluster", e $\varepsilon_{s}$ a fração de sólido interna de uma destas células.

Como o modelo microscópico, onde os grãos são representados através da malha de células, é bidimensional, é necessário estabelecer algumas relações com a forma tridimensional real dos grãos. Para isto, uma hipótese semelhante à do modelo de Guillemot et al (2006) é assumida: o grão representado na malha bidimensional de células do CA possui uma área igual à do quadrado que constitui o centro do octaedro, como ilustrado na Figura 16. 

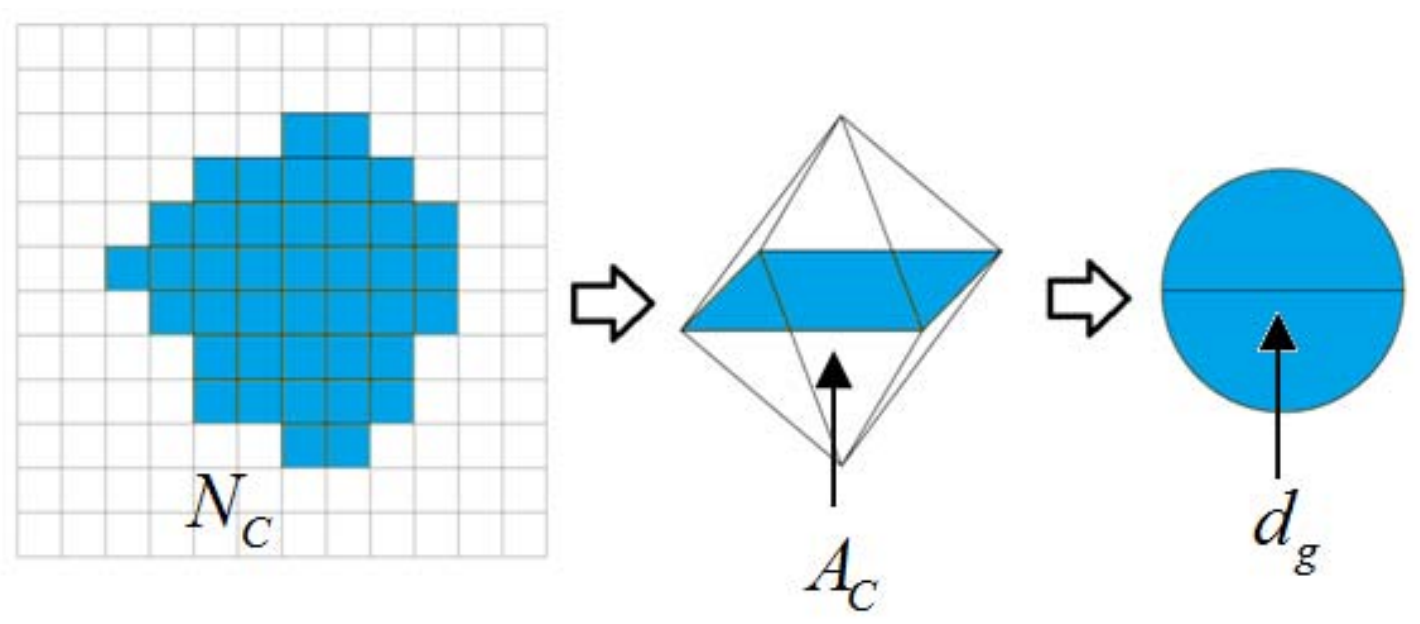

Figura 16 - Esquema do cálculo do volume da esfera equivalente, obtendo-se a área com o número de células ativas para calcular o octaedro correspondente ao grão. $N_{C}$ é o número de células que pertencem ao grão, $A_{C}$ é a área do quadrado interno ao octaedro e $d_{g}$ o diâmetro da esfera equivalente.

Deste modo, o diâmetro $d_{g}$ da esfera equivalente ao octaedro é calculado por:

$$
d_{g}=\frac{\left(2 A_{C}\right)^{1 / 2}}{\pi^{1 / 3}}
$$

sendo $A_{C}$ a área que o "cluster" ocupa na malha de células do CA, dada por:

$$
A_{C}=\sum_{N_{C}} \Delta x_{C A}^{2}
$$

onde $N_{C}$ é o número de células que compõem o "cluster" e $\Delta x_{C A}$ é o lado de uma célula do CA.

A área total $A_{s p h}$ (da esfera equivalente) e o volume do octaedro $V_{g}$ são dados, respectivamente, por:

$$
\begin{gathered}
A_{s p h}=\pi d_{g}^{2} \\
V_{g}=\frac{\pi d_{g}^{3}}{6}
\end{gathered}
$$


Após a definição da forma do grão em decantação, a sua velocidade de decantação é assumida igual à velocidade terminal (despreza-se o transiente inicial, que normalmente representa um deslocamento desprezível), que é calculada através do modelo de Haider e Levenspiel (1989), onde o efeito da forma do corpo é considerado no coeficiente de arraste. Para obter a velocidade terminal, é preciso calcular valores para os seguintes adimensionais: $\psi_{g}$ (fator de forma do envelope), $\nu_{*}$ (velocidade de decantação adimensional), $d_{*}$ (diâmetro adimensional). As equações são apresentadas a seguir, respectivamente

$$
\begin{gathered}
\psi_{g}=\frac{A_{s p h}}{A_{s h}} \\
v_{*}=\left|\vec{v}_{s}\right|\left[\frac{\rho_{l}^{2}}{|\vec{g}| \mu_{l}\left(\rho_{C}-\rho_{l}\right)}\right]^{1 / 3} \\
d_{*}=d_{g}\left[\frac{|\vec{g}| \rho_{l}\left(\rho_{C}-\rho_{l}\right)}{\mu_{l}^{2}}\right]^{1 / 3}
\end{gathered}
$$

onde $\vec{v}_{s}$ é a velocidade terminal; $\vec{g}$ é o vetor gravidade; $A_{s p h}$ é a área superficial de uma esfera de mesmo volume que o octaedro; $A_{s h}$ é a área superficial do octaedro, $\mu_{l}$ a viscosidade do fluido em que o octaedro está imerso, $d_{g}$ o diâmetro da esfera equivalente de mesmo volume que o octaedro. Através de uma regressão não-linear, foi obtida uma expressão que correlaciona $v_{*}$ em função de $d_{*}$.

$$
u_{*}=\left[\left(\frac{18}{d_{*}^{2}}\right)^{K_{2}}+\left(\frac{2 K_{1}}{4 d_{*}^{0,5}}\right)^{K_{2}}\right]^{-1 / K_{1}}
$$

\begin{tabular}{|c|c|c|c|}
\hline Forma & $\psi$ & $K_{1}$ & $K_{2}$ \\
\hline Esfera & 1,000 & 0,7554 & 0,8243 \\
\hline Octaedro & 0,846 & 1,1272 & 0,9677 \\
\hline
\end{tabular}

onde $K_{1}$ e $K_{2}$ são parâmetros calculados em função do fator de forma (Tabela 1). 
Apesar de existir na literatura modelos que considerem também o arraste provocado pelo fluxo de líquido entre os braços dendríticos internos (AHUJA, 1992), a diferença em relação à velocidade de decantação calculada por estes modelos mostrou-se pequena para as permeabilidades internas do envelope de grão.

Os aglomerados ou envelopes isolados que não estão fixos (livres) recebem um incremento ao seu deslocamento após cada passo de tempo. Este deslocamento é a distância que o envelope está do centro de uma célula (diferente das descentralizações dos polígonos de crescimento que o compõem) (Figura 17). $O$ incremento ao deslocamento, $\Delta \vec{d}_{i}$, é calculado após cada passo de tempo por:

$$
\Delta \vec{d}_{i}=\vec{v}_{s_{i}} \delta t
$$

onde $\delta$ té o passo de tempo e $\vec{v}_{s_{i}}$ é a velocidade do "cluster". Este passo de tempo deve obedecer ao seguinte critério para manter a estabilidade do modelo:

$$
\delta t=\min \left(\frac{\alpha_{\text {mov }} \Delta x_{C A}}{\left|\vec{v}_{s, \max }\right|}, \Delta t_{\max }\right)
$$

onde $\alpha_{\text {mov }}$ é um coeficiente de segurança igual a 0,1 (GUILLEMOT et al., 2006), $\vec{v}_{s, \max }$ é a maior velocidade de algum grão encontrado no domínio, $\Delta t_{\max }$ é o passo de tempo máximo dado como parâmetro de entrada para solução numérica das equações de conservação do modelo. $O$ passo de tempo $\Delta t$ para solução numérica de todas as equações de conservação tem que ser igual à $\delta t$ calculado a cada instante. Este critério é utilizado para garantir que o envelope não percorra distâncias maiores que uma célula, e é o critério que mais restringe a definição do passo de tempo do modelo numérico. 


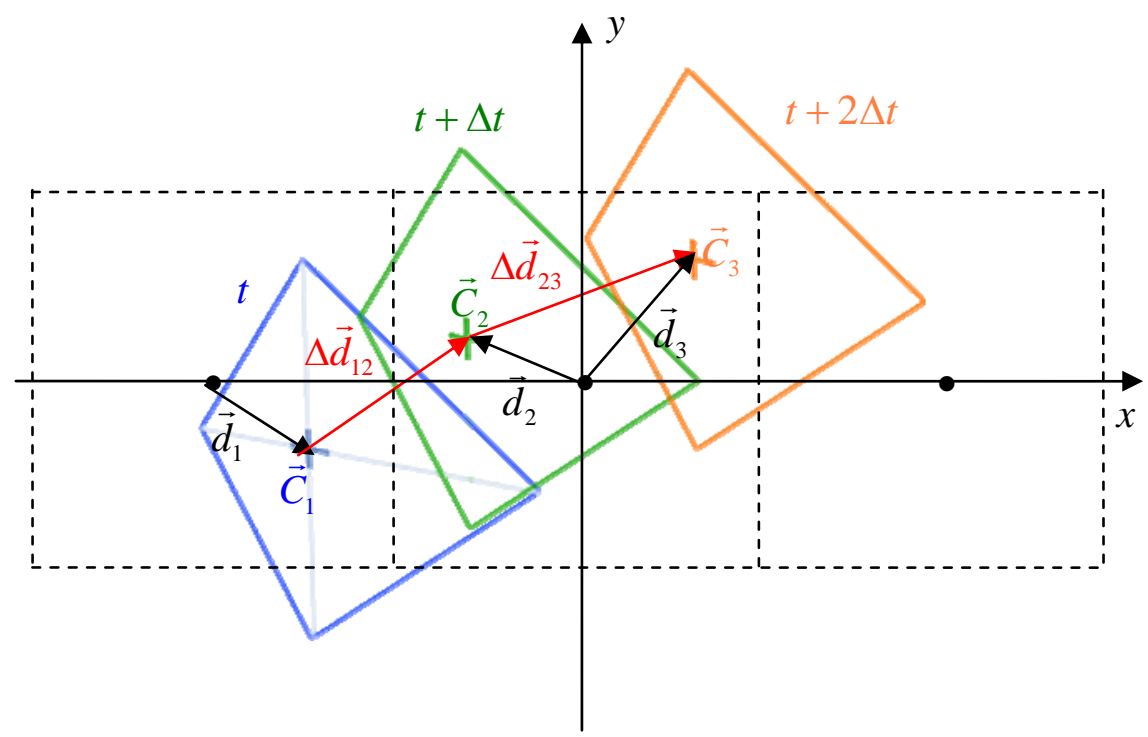

Figura 17 - Representação da migração de um envelope durante três instantes diferentes; onde

$\vec{C}_{1}, \vec{C}_{2}$ e $\vec{C}_{3}$ são os centros do envelope nos instantes $t$ (azul), $t+\Delta t$ (verde) e $t+2 \Delta t$ (laranja) respectivamente; $\vec{d}$ indica o deslocamento do centro do envelope em relação ao centro da célula de CA que este estiver contido e $\Delta \vec{d}$ a variação de deslocamento dado pela Eq. [58].

\section{b) Verificação do Critério de Translação}

O incremento $\Delta \vec{d}$ é adicionado ao vetor deslocamento relativo $\vec{d}$ de cada centro de envelope. No momento em que o vetor posição $\vec{d}$ ultrapassar os limites da célula à qual o centro do envelope pertence, as informações contidas em todas as outras células do envelope devem migrar para as células vizinhas correspondentes. A condição de migração é dada, de maneira generalizada, por:

$$
\left|\vec{d} \cdot \vec{n}_{x}\right|>\frac{\Delta x_{C A}}{2} \text { ou }\left|\vec{d} \cdot \vec{n}_{y}\right|>\frac{\Delta y_{C A}}{2}
$$

onde $\vec{n}_{x}$ e $\vec{n}_{y}$, são os versores das direções horizontal e vertical, respectivamente; $\vec{d}$ é o vetor deslocamento representado na Figura 17; e $\Delta x_{C A}$ e $\Delta y_{C A}$ são as dimensões de uma célula da malha do autômato celular nas direções horizontal e vertical. Se a condição de migração for atendida, as informações relativas a um dado grão, associadas a alguma célula, são atribuídas à célula vizinha e o vetor deslocamento atualizado, subtraindo-se o deslocamento ocorrido (Figura 17). 


\subsection{Submodelo Microscópico}

Na construção do submodelo microscópico, serão desenvolvidas equações a partir dos princípios de: conservação de energia da mistura das fases; conservação de espécies químicas na fase líquida interdendrítica e na fase sólida e conservação de massa em cada fase. O domínio do submodelo microscópico é o interior dos grãos, cuja localização, forma e tamanho são obtidas pelo algoritmo do autômato celular. Desta forma, o submodelo microscópico é aplicado no interior de cada grão existente. Além das hipóteses comuns aos dois submodelos, descritas no item 4.1, para a dedução do sistema de equações do submodelo microscópico, são consideradas as seguintes hipóteses específicas:

1. O domínio deste modelo corresponde a um grão ou cluster de grãos, ou seja, conjunto de grãos que estão unidos e apresentam a mesma velocidade.

2. Há apenas três pseudofases: sólido primário (s), eutético (e) e líquido interdendrítico (d).

3. Os grãos não sofrem rotação ou deformação, ou seja, movimentam-se apenas por translação por decantação (hipótese geral 6), implicando em: $\left\langle\vec{v}_{s}\right\rangle^{s}=\vec{v}_{s}=\left(0, v_{s}, 0\right)$.

4. Como apresentado na hipótese geral 6, o escoamento médio no interior do grão é unidirecional e tem a direção da aceleração gravitacional, logo: $\left\langle\vec{v}_{d}\right\rangle^{d}=\left(0,\left\langle v_{d}\right\rangle^{d}, 0\right)$.

5. Como apresentado na hipótese geral 7 , a velocidade do eutético é igual à da fase sólida no interior do grão.

6. O sistema de referência é fixo no próprio grão ou "cluster" de grãos, portanto, as velocidades do líquido interdendrítico e sólido podem ser escritas no novo referencial como: $\vec{v}_{s}^{\prime}=\vec{v}_{e}^{\prime}=0$ e $\left\langle\vec{v}_{d}^{\prime}\right\rangle^{d}=\left\langle\vec{v}_{d}\right\rangle^{d}-\vec{v}_{s}=\left(0,\left\langle v_{d}\right\rangle^{d}-v_{s}, 0\right)$.

7. Utilizando a hipótese geral, as temperaturas médias das fases no volume de controle são iguais (equilíbrio térmico) e será denominada: $T=\left\langle T_{s}\right\rangle^{s}=\left\langle T_{e}\right\rangle^{e}=\left\langle T_{d}\right\rangle^{d}$ 
8. O líquido interdendrítico apresenta composição $\left\langle C_{d}\right\rangle^{d}$ uniforme (mistura homogênea) no volume representativo microscópico.

9. A concentração média da pseudofase eutético $\left\langle C_{e}\right\rangle^{e}$ é constante e igual a $C_{e}$ obtida pelo diagrama de equilíbrio.

10. Utilizando a hipótese geral 12 de equilíbrio termodinâmico na interface sólidolíquido, a concentração da fase sólida na interface é correlacionada com a concentração média na fase líquida interdendrítica por: $C_{s}=k\left\langle C_{d}\right\rangle^{d}$, onde $k$ é o coeficiente de partição de soluto.

11. Utilizando novamente a hipótese geral 11, a concentração de soluto na pseudofase líquida interdendrítica é correlacionada com a temperatura local pela equação do diagrama de fase: $T=T_{f}+m_{l}\left\langle C_{d}\right\rangle^{d}$, onde $m_{l}$ é a inclinação da curva liquidus considerada constante e $T_{f}$ é a temperatura de fusão do metal puro.

\subsubsection{Conservação de Massa}

Como as equações de conservação tem referencial no próprio grão ou "cluster" de grãos unidos (hipótese específica 6), a equação de conservação de massa de cada fase é dada por:

$$
\begin{gathered}
\frac{\partial \varepsilon_{s}}{\partial t}=\frac{\Gamma_{s}}{\rho} \\
\frac{\partial \varepsilon_{e}}{\partial t}=\frac{\Gamma_{e}}{\rho} \\
\frac{\partial \varepsilon_{d}}{\partial t}=-\frac{\Gamma_{s}}{\rho}-\frac{\Gamma_{e}}{\rho}
\end{gathered}
$$

onde $\rho$ é a densidade, $\varepsilon_{d}$ é a fração de líquido interdendrítico, $\varepsilon_{s}$ e $\varepsilon_{s}$ são as frações de fase e $\Gamma_{s}$ e $\Gamma_{s}$ são as taxas de transformação de fases para a fase sólida primária e eutética respectivamente. 
Na dedução (Apêndice $C$ ), a equação de conservação da mistura das fases com a hipóteses consideradas é expressa por:

$$
\frac{\partial}{\partial y}\left(\varepsilon_{d}\left\langle v_{d}^{\prime}\right\rangle^{d}\right)=0
$$

onde $\left\langle v_{d}^{\prime}\right\rangle^{d}$ é a velocidade média relativa do líquido interdendrítico, e o produto $\varepsilon_{d}\left\langle v_{d}^{\prime}\right\rangle^{d}$ é dado como constante ao longo do eixo vertical dentro de um grão. Para cálculo deste produto, é utilizado um acoplamento com o submodelo macroscópico que fornece a velocidade relativa média da fase líquida interdendrítica (descrito no próximo item). Substituindo o produto pela equação fornecida pelo submodelo macroscópico:

$$
\varepsilon_{d}\left\langle v_{d}^{\prime}\right\rangle^{d}=-\frac{\kappa_{v}\left\langle v_{s}\right\rangle_{M}^{s}}{\varepsilon_{g_{M}}}
$$

onde $\kappa_{v}$ é o coeficiente de partição de escoamento, $\left\langle v_{s}\right\rangle_{M}^{s}$ é a velocidade média das fases sólidas no VER macroscópico e $\varepsilon_{g_{M}}$ é a fração de grão no VER macroscópico.

\subsubsection{Cálculo do Coeficiente de Partição de Escoamento}

O cálculo de $\kappa_{v}$ é apresentado no trabalho de Wang et al. (1995) pela equação:

$$
\kappa_{v}=\left(1-\varepsilon_{l_{M}}\right)\left(\frac{\beta}{\beta_{d}}\right)^{2}
$$

onde $\varepsilon_{l_{M}}$ é a fração de líquido extradendrítico no submodelo macroscópico, $\beta$ e $\beta_{d}$ são raios adimensionais calculados por: 


$$
\begin{gathered}
\beta_{d}=\frac{3 \sqrt{5}}{\psi_{g}\left(1-\frac{\varepsilon_{s_{M}}}{\varepsilon_{g_{M}}}\right)^{3 / 2}}\left(\frac{2 V_{0_{M}}}{\lambda_{2}^{\prime} A_{l d}}\right) \\
\beta=\frac{\beta_{d}}{\left[\varepsilon_{g_{M}}^{n}-\left(\beta_{d} / \beta_{l}\right)^{2 n}\right]^{1 / 2 n}}
\end{gathered}
$$

onde $\psi_{g}$ é a esfericidade do grão, dada pela razão entre a área da esfera de volume equivalente e a área do grão (neste modelo, grãos dendríticos são aproximados por octaedros regulares); $\varepsilon_{s_{M}}$ é a fração de sólido no volume macroscópico; $\varepsilon_{g_{M}}$ é a fração de grãos no volume macroscópico $V_{0_{M}} ; \lambda_{2}^{\prime}$ é o espaçamento secundário médio dos grãos equiaxiais (considerado constante e igual a $10^{-5} \mathrm{~m}$ no modelo); $A_{1 d}$ é a interface total entre grãos e líquido extradendrítico dentro de $V_{0_{M}} ; n$ é calculado por:

$$
n=0,176 \log _{10} \beta_{d}+0,275
$$

$\beta_{l}$ é um raio adimensional calculado por:

$$
\beta_{l}=\left\{\frac{9}{2} \varepsilon_{g_{M}} \frac{2+\frac{4}{3} \varepsilon_{g_{M}}^{5}}{2-3 \varepsilon_{g_{M}}+3 \varepsilon_{g_{M}}^{5}-2 \varepsilon_{g_{M}}^{6}} \frac{1}{C_{s h}\left(\psi_{g}\right)} \frac{2 \beta_{d}^{2}\left[1-\tanh \left(\beta_{d}\right) / \beta_{d}\right]}{2 \beta_{d}^{2}+3\left[1-\tanh \left(\beta_{d}\right) / \beta_{d}\right]}\right\}^{1 / 2}
$$

onde $C_{s h}\left(\psi_{g}\right)$ é o ajuste do coeficiente de arraste considerando a forma dos envelopes, e tem a seguinte equação:

$$
C_{s h}\left(\psi_{g}\right)= \begin{cases}\psi_{g}^{2} & 0,3<\varepsilon_{g_{M}}<1 \\ 1,26 \log _{10}\left(\frac{\psi_{g}}{0,163}\right) & 0<\varepsilon_{g_{M}}<0,3\end{cases}
$$




\subsubsection{Conservação de Energia}

A equação de energia, sob estas hipóteses e outras considerações (Apêndice C), tem o seguinte formato:

$$
\rho C_{P}\left[\frac{\partial T}{\partial t}+\varepsilon_{d}\left\langle v_{d}^{\prime}\right\rangle^{d} \frac{\partial\langle T\rangle_{M}}{\partial y}\right]=L_{f}\left(\Gamma_{s}+\Gamma_{e}\right)+\frac{\partial}{\partial y}\left(\bar{K} \frac{\partial\langle T\rangle_{M}}{\partial y}\right)
$$

onde $\langle T\rangle_{M}$ é a temperatura do VER macroscópico que o ponto está definido, $T$ é a temperatura dentro do grão, $\Gamma_{s}$ e $\Gamma_{e}$ são as taxas de transformação de fase de sólido primário e eutético respectivamente, $L_{f}$ é o calor latente de fusão, e $\bar{K}$ a condutividade térmica média das fases.

Esta equação contém acoplamentos com o modelo macroscópico, em quase todos os seus termos $\left(\varepsilon_{d}\left\langle v_{d}^{\prime}\right\rangle^{d}\right.$ também é função do modelo macroscópico, como visto no item 4.3.1), exceto o termo da derivada no tempo, são função do modelo macroscópico, e o termo de taxa de transformação de fase, que é um termo fonte em função do tempo. Portanto, esta equação é caracterizada como uma EDO (Equação Diferencial Ordinária), pois tem apenas derivada em relação a uma variável ("t"), e todos os outros podem ser considerados termos fontes em função do tempo.

\subsubsection{Conservação das Espécies Químicas}

Para a fase líquida interdendrítica, a equação de conservação de soluto tem o seguinte formato:

$$
\frac{\partial\left(\varepsilon_{d}\left\langle C_{d}\right\rangle^{d}\right)}{\partial t}+\varepsilon_{d}\left\langle v_{d}^{\prime}\right\rangle^{d} \frac{\partial\left\langle C_{d}\right\rangle^{d}}{\partial y}=\vec{\nabla} \cdot\left(\varepsilon_{d} D_{d} \vec{\nabla}\left\langle C_{d}\right\rangle^{d}\right)-\frac{k\left\langle C_{d}\right\rangle^{d}}{\rho} \Gamma_{s}-\frac{C_{e}}{\rho} \Gamma_{e}
$$


onde $\varepsilon_{d}$ é a fração de líquido interdendrítico dentro do REV microscópico; $D_{d}^{*}$ o coeficiente efetivo de difusão na fase líquida interdendrítica; $k$ o coeficiente de partição; $C_{e}$ a concentração da fase eutética dada pelo diagrama de equilíbrio.

Como a equação também será solucionada sobre o contorno dos grãos, é necessário utilizar uma condição de contorno para o cálculo da concentração na interface e subseqüentemente o fluxo difusivo:

$$
\frac{\partial\left\langle C_{d}\right\rangle^{d}}{\partial \vec{n}_{l d}} \cdot \vec{n}_{l d}=-\frac{D_{l}}{\delta_{l d}}\left(C_{d}^{*}-\left\langle C_{l}\right\rangle_{M}^{l}\right)
$$

onde $\vec{n}_{l d}$ é a direção da interface entre o líquido interdendrítido e o líquido extradendrítico, $C_{d}^{*}$ é a concentração calculada na interface, $\left\langle C_{l}\right\rangle_{M}^{l}$ é a concentração do líquido extradendrítico fornecido pelo submodelo macroscópico, e $\delta_{l d}$ é a espessura efetiva de difusão (Apêndice E), calculada por:

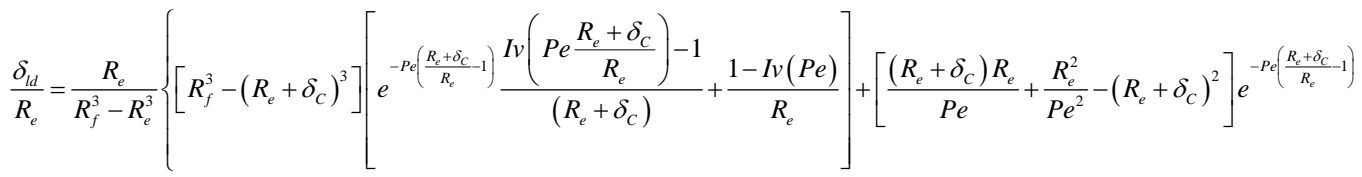

$$
\begin{aligned}
& \left.-\left[\frac{R_{e}^{2}}{P e}+\frac{R_{e}^{2}}{P e^{2}}-\frac{\left(R_{e}+\delta_{C}\right)^{3}}{R_{e}}\right]+P e \frac{\left(R_{e}+\delta_{C}\right)^{3}}{R_{e}}\left[\frac{I V\left(P e \frac{R_{e}+\delta_{C}}{R_{e}}\right) e^{-P e\left(\frac{R_{e}+\delta_{C}}{R_{e}}-1\right)}}{P e \frac{\left(R_{e}+\delta_{C}\right)}{R_{e}}}-\frac{I V(P e)}{P e}\right]\right\}
\end{aligned}
$$

onde $R_{f}$ é o raio de referência calculado por:

$$
R_{f}=\left(\frac{3}{4 \pi n_{g}}\right)^{1 / 3}
$$

onde $n_{g}$ é a concentração de grãos calculado no volume representativo macroscópico; $R_{e}$ é o raio médio de envelopes dentro do VER macroscópico calculado por: 


$$
R_{e}=R_{f}\left(1-\varepsilon_{l_{M}}\right)^{1 / 3}
$$

onde $\varepsilon_{l_{M}}$ é a fração de líquido extradendrítico no VER macroscópico; Pe é o número de Peclet calculado com a velocidade de crescimento pela Eq. [41] e raio $R_{e}$ :

$$
P e=\frac{R_{e}\left|\vec{w}_{g}^{\prime}\right|}{D_{l}}
$$

e $\delta_{C}$ é a espessura de estagnação (Apêndice E), baseado na equação de transferência de massa sob convecção forçada em multipartículas obtida no trabalho de Rowe e Claxton (1967), calculada por:

$$
\delta_{C}=\frac{R_{e}}{\frac{R_{f}}{R_{f}-R_{e}}+\frac{\operatorname{Re}^{1 / 2} S c^{1 / 3}}{3-3\left(R_{e} / R_{f}\right)^{3}}-1}
$$

onde Re é o número de Reynolds:

$$
\operatorname{Re}=\frac{2 \rho_{l} v_{s} R_{e}}{\mu_{l}}
$$

onde $\rho_{l}$ é a densidade da fase líquida, $v_{s}$ é a velocidade do grão, $\mu_{l}$ é a viscosidade do líquido; e Sc é número Schmidt:

$$
S c=\frac{\mu_{l}}{\rho_{l} D_{l}}
$$

A equação de conservação das espécies químicas para a fase sólido primário deve ser solucionada devido à hipótese de difusão nula no sólido. A concentração média do sólido primário será calculada pela equação:

$$
\frac{\partial\left(\varepsilon_{s}\left\langle C_{s}\right\rangle^{s}\right)}{\partial t}=\frac{k\left\langle C_{d}\right\rangle^{d}}{\rho} \Gamma_{s}
$$


onde $\left\langle C_{s}\right\rangle^{s}$ é a concentração media de soluto na fase sólida, e $\varepsilon_{s}$ a fração de fase de sólido primário. 


\subsubsection{Sistema de Equações para o Submodelo Microscópico}

Tabela 2 - Equações Diferenciais solucionadas no submodelo microscópico e suas respectivas condições iniciais e de contorno.

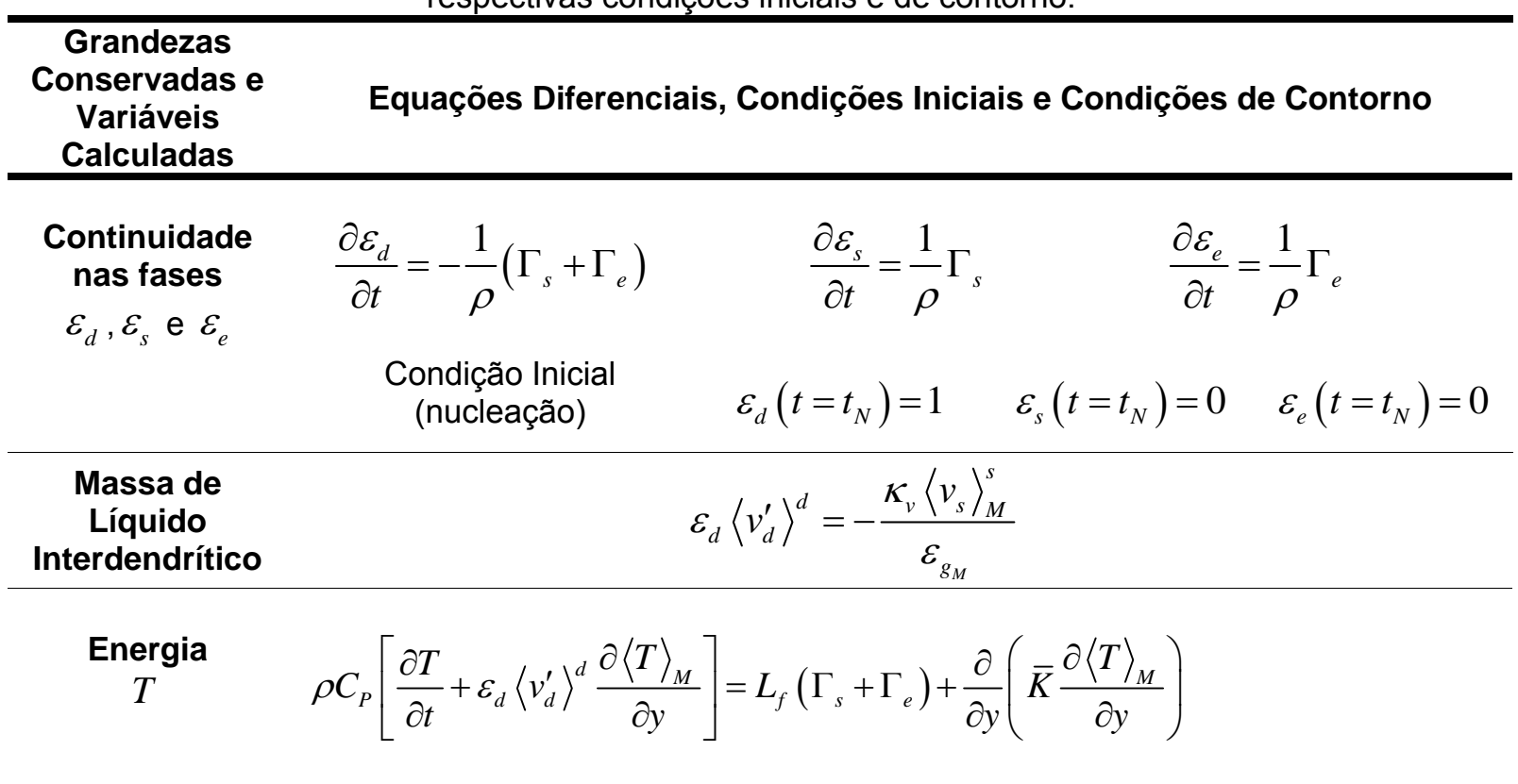

Espécies

Químicas na

fase Líquida Interdendrítica

$$
\frac{\partial\left(\varepsilon_{d}\left\langle C_{d}\right\rangle^{d}\right)}{\partial t}+\varepsilon_{d}\left\langle v_{d}^{\prime}\right\rangle^{d} \frac{\partial\left\langle C_{d}\right\rangle^{d}}{\partial y}=\vec{\nabla} \cdot\left(\varepsilon_{d} D_{d} \vec{\nabla}\left\langle C_{d}\right\rangle^{d}\right)-\frac{k\left\langle C_{d}\right\rangle^{d}}{\rho} \Gamma_{s}-\frac{C_{e}}{\rho} \Gamma_{e}
$$

$\left\langle C_{d}\right\rangle^{d}$

$$
\text { Condição Inicial (nucleação) }\left\langle C_{d}\right\rangle^{d}\left(t=t_{N}\right)=\left\langle C_{l}\right\rangle_{M}^{l}
$$

$$
\begin{gathered}
\text { Condição de Contorno } \\
\text { (interface } \left.A_{l d}\right)
\end{gathered} \quad \frac{\partial\left\langle C_{d}\right\rangle^{d}}{\partial \vec{n}_{l d}} \cdot \vec{n}_{l d}=-\frac{D_{l}}{\delta_{l d}}\left(C_{d}^{*}-\left\langle C_{l}\right\rangle_{M}^{l}\right)
$$

\section{Espécies}

Químicas na fase de Sólido

Primário

$\left\langle C_{s}\right\rangle^{s}$

$$
\frac{\partial\left(\varepsilon_{s}\left\langle C_{s}\right\rangle^{s}\right)}{\partial t}=\frac{k\left\langle C_{d}\right\rangle^{d}}{\rho} \Gamma_{s}
$$

$$
\text { Condição Inicial (nucleação) }\left\langle C_{s}\right\rangle^{s}\left(t=t_{N}\right)=k\left\langle C_{l}\right\rangle_{M}^{l}
$$

Equilíbrio

Termodinâmico

$$
\Gamma_{s} \text { e } \Gamma_{e}
$$

$$
T=T_{f}+m_{l}\left\langle C_{d}\right\rangle^{d}
$$




\subsection{Submodelo Macroscópico}

O submodelo macroscópico tem como domínio o molde (Figura 11) e as equações diferenciais de conservação desenvolvidas neste modelo baseiam-se nos seguintes princípios de conservação: conservação de energia de mistura das fases, conservação de massa na fase líquida extradendrítica e conservação de soluto na fase líquida extradendrítica. As hipóteses utilizadas por este submodelo são:

1. O domínio deste modelo corresponde ao molde de solidificação, sendo o seu volume representativo (VER) da ordem de escala entre um conjunto de grãos e o tamanho do molde.

2. Há as seguintes pseudofases: sólido primário (s), eutético (e), líquido interdendrítico (d) e líquido extradendrítico (I).

3. Utilizando a hipótese geral 7 , a fase eutética tem velocidade média igual a fase primária: $\left\langle\vec{v}_{e}\right\rangle_{M}^{e}=\left\langle\vec{v}_{s}\right\rangle_{M}^{s}$.

4. Com a hipótese geral 12, as temperaturas médias das fases no volume representativo são iguais (equilíbrio térmico entre as fases): $\langle T\rangle_{M}=\left\langle T_{s}\right\rangle_{M}^{s}=\left\langle T_{e}\right\rangle_{M}^{e}=\left\langle T_{d}\right\rangle_{M}^{d}=\left\langle T_{l}\right\rangle_{M}^{l}$.

5. Pela hipótese geral 10 , não há área de contato entre a fase de líquido extradendrítico e as fases sólidas, logo: $A_{l s}=A_{l e}=0$.

\subsubsection{Conservação de Energia}

A equação de conservação de energia da mistura para o modelo macroscópico desenvolvida no Apêndice C a partir das hipóteses acima está apresentada a seguir:

$$
\rho C_{P} \frac{\partial\langle T\rangle_{M}}{\partial t}=L_{f}\left(\Gamma_{s_{M}}+\Gamma_{e_{M}}\right)+\frac{\partial}{\partial y}\left(\bar{K} \frac{\partial\langle T\rangle_{M}}{\partial y}\right)
$$


onde $\langle T\rangle_{M}$ é a temperatura media da mistura das fases; $\Gamma_{s_{M}}$ e $\Gamma_{e_{M}}$ são as taxas de transformação da fases de sólido primário e eutético respectivamente; e $\bar{K}$ é a condutividade térmica média das fases. Nota-se que a equação não tem termo convectivo, que é eliminado devido à hipótese de densidades e calor sensível das fases iguais e constantes.

As taxas de solidificação $\Gamma_{s_{M}}$ e $\Gamma_{e_{M}}$ são obtidas a partir da média macroscópica destas variáveis calculadas pelo submodelo microscópico, expressa pelas equações:

$$
\begin{aligned}
& \Gamma_{s_{M}}=\frac{1}{V_{0_{M}}} \int_{V_{0_{M}}} \Gamma_{s} d V \\
& \Gamma_{e_{M}}=\frac{1}{V_{0_{M}}} \int_{V_{0_{M}}} \Gamma_{e} d V
\end{aligned}
$$

\subsubsection{Conservação de Massa}

No submodelo macroscópico, é solucionada a conservação de massa para a fase líquida extradendrítica (Apêndice C para dedução e Apêndice D para a discretização detalhada), expressa por:

$$
\frac{\partial}{\partial y}\left(\varepsilon_{l_{M}}\left\langle v_{l}\right\rangle_{M}^{l}\right)=\frac{1}{V_{0_{M}}} \int_{A_{l d}}\left[\frac{\kappa_{v}\left\langle\vec{v}_{s}\right\rangle_{M}^{s}}{\left(1-\varepsilon_{l_{M}}\right)}-\vec{v}_{s}\right] \cdot \vec{n}_{l} d A
$$

onde $\left\langle v_{l}\right\rangle_{M}^{l}$ é a velocidade média da fase líquida extradendrítica na direção vertical, $\varepsilon_{l_{M}}$ é a fração de fase líquida extradendrítica, $\left\langle\vec{v}_{s}\right\rangle_{M}^{s}$ é a velocidade média intrínseca da fase sólida total, $\vec{v}_{s}$ é a velocidade do grão que a interface pertence, $\vec{n}_{l}$ é o versor da interface $A_{l d}$ orientado para dentro do grão, e $\kappa_{v}$ é o coeficiente de partição de escoamento (Eq. [66]). 
Nota-se que, ao discretizar esta equação pelo método dos volumes finitos, temos como incógnita o valor do produto $\varepsilon_{l_{M}}\left\langle v_{l}\right\rangle_{M}^{l}$ nas interfaces do VF. Observando a integral de superfície, é possível notar que ela será nula na interface de grãos completamente contidos no VER macroscópico, enquanto, o mesmo não se aplica para grãos que atravessam o contorno deste. Logo, $\varepsilon_{l_{M}}\left\langle v_{l}\right\rangle_{M}^{l}$ só poderá ser diferente de zero quando houver grãos atravessando as interfaces do VER macroscópico (neste modelo, assumido de mesmas dimensões do VF utilizado na discretização do submodelo macroscópico).

As frações de fases são calculadas da seguinte forma. Para a fase líquida extradendrítica, calcula-se o espaço não ocupado por grãos (fornecido pelo $C A$ ). As frações das fases sólidas são calculadas pelas equações:

$$
\begin{aligned}
& \varepsilon_{S_{M}}=\frac{1}{V_{0_{M}}} \int_{V_{0_{M}}} \varepsilon_{s} d V \\
& \varepsilon_{e_{M}}=\frac{1}{V_{0_{M}}} \int_{V_{0_{M}}} \varepsilon_{e} d V
\end{aligned}
$$

para a fase de sólido primário e para a fase eutética respectivamente.

\subsubsection{Conservação de Soluto}

A conservação das espécies químicas para a fase líquida extradendrítica é expressa por:

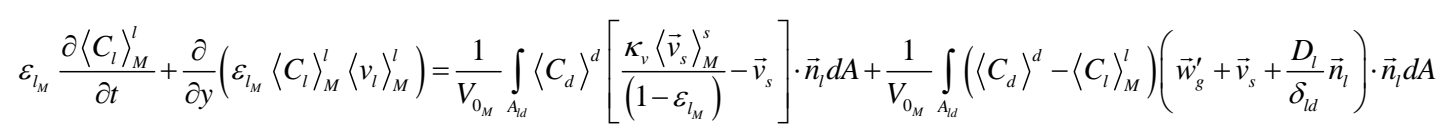

onde $\left\langle C_{l}\right\rangle_{M}^{l}$ é a concentração de soluto na fase líquida extradendrítica, $\left\langle C_{d}\right\rangle^{d}$ é a concentração de soluto na fase líquida interdendrítica calculada na interface dos 
grãos (integral de superfície sobre os grãos), $\vec{w}_{g}^{\prime}$ é a velocidade de crescimento da interface dos grãos, $\vec{v}_{s}$ é a velocidade de translação da interface dos grãos, $D_{l}$ é o coeficiente de difusão da fase líquida extradendrítica, $\delta_{l d}$ é a espessura efetiva de difusão para o líquido extradendrítico na interface dos grãos (calculada no modelo microscópico em cada ponto da interface, Eq. [75]).

Esta equação contém integrais sobre a superfície $A_{l d}$, que serão calculadas na discretização sobre o contorno dos grãos fornecidos pelo autômato celular (detalhes no Apêndice D). O termo convectivo é solucionado através do cálculo de $\left\langle v_{l}\right\rangle_{M}^{l}$ fornecido pela equação de conservação de massa (Eq. [86]). Resumidamente, esta equação é acoplada com o modelo microscópico para cálculo de soluto transferido para a fase líquida extrandendrítica através da: difusão para fora do envelope; movimento de interface do grão por translação ou crescimento; líquido que atravessa os grãos e líquido que é movimentado ao redor dos grãos.

Para o cálculo da concentração média em cada ponto do domínio macroscópico, as concentrações das outras fases (sólido e líquido interdendrítico) solucionadas pelo submodelo microscópico, são calculadas através da média macroscópica pelas equações:

$$
\begin{aligned}
& \varepsilon_{s_{M}}\left\langle C_{s}\right\rangle_{M}^{s}=\frac{1}{V_{s_{M}}} \int_{V_{s_{M}}} C_{s} d V \\
& \varepsilon_{d_{M}}\left\langle C_{d}\right\rangle_{M}^{s}=\frac{1}{V_{d_{M}}} \int_{V_{d_{M}}} C_{d} d V
\end{aligned}
$$

sendo, a concentração média $\langle C\rangle_{M}$, calculada por:

$$
\langle C\rangle_{M}=\varepsilon_{l_{M}}\left\langle C_{l}\right\rangle_{M}^{l}+\varepsilon_{d_{M}}\left\langle C_{d}\right\rangle_{M}^{d}+\varepsilon_{s_{M}}\left\langle C_{s}\right\rangle_{M}^{s}+\varepsilon_{e_{M}} C_{e}
$$




\subsubsection{Sistema de Equações para o Submodelo Macroscópico}

Tabela 3 - Equações Diferenciais solucionadas no submodelo macroscópico com suas respectivas condições iniciais e de contorno.

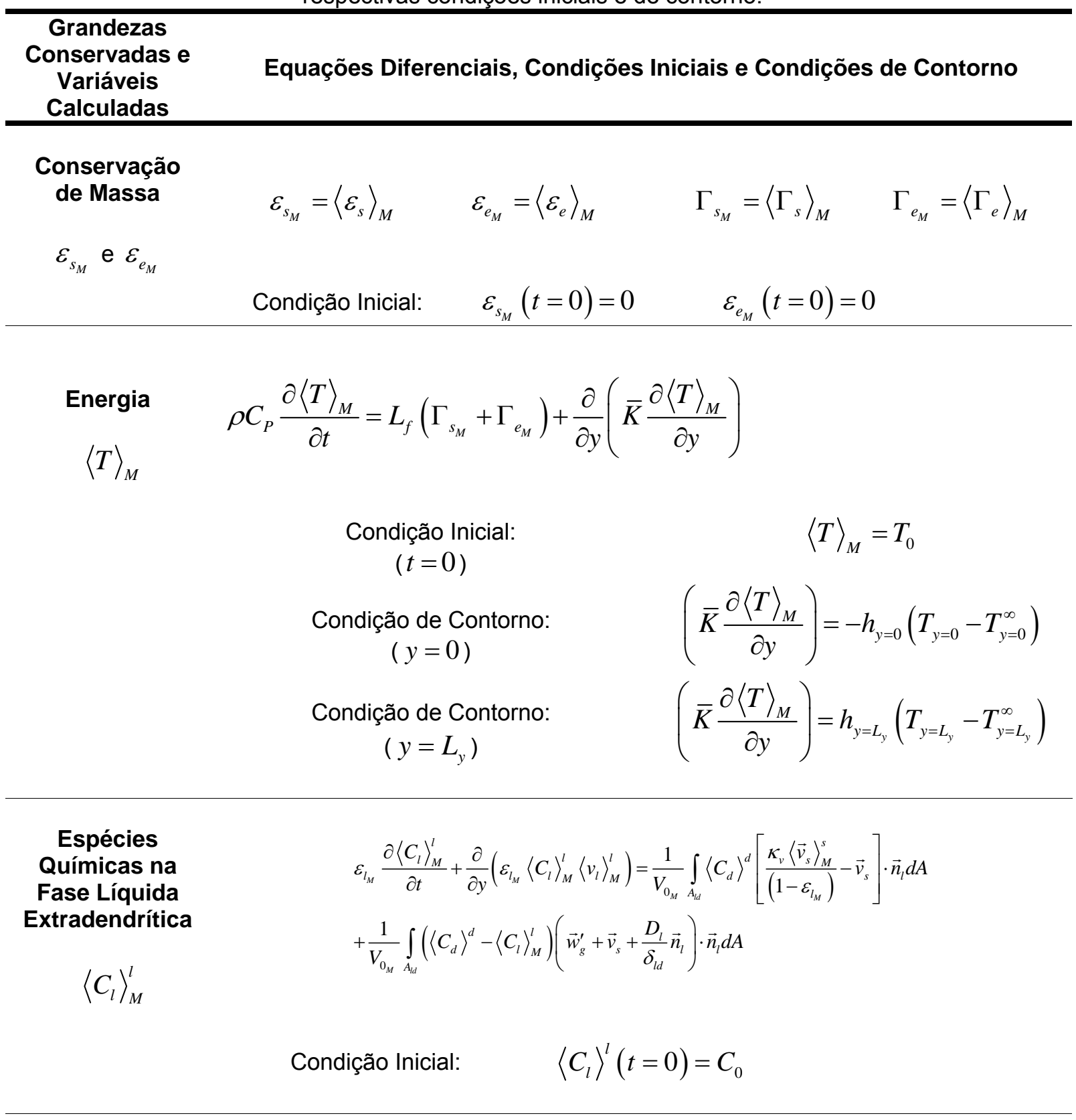

Continuidade da Fase Líquida Extradendrítica

$$
\frac{\partial}{\partial y}\left(\varepsilon_{l_{M}}\left\langle v_{l}\right\rangle_{M}^{l}\right)=\frac{1}{V_{0_{M}}} \int_{A_{l d}} \frac{\kappa_{v}\left\langle\vec{v}_{s}\right\rangle_{M}^{s}}{\left(1-\varepsilon_{l_{M}}\right)} \cdot \vec{n}_{l} d A
$$

$\left\langle v_{l}\right\rangle_{M}^{l}$

$$
\begin{aligned}
& \text { Condição de Contorno: } \quad\left\langle v_{l}\right\rangle_{M}^{l}=0 \\
& (y=0)
\end{aligned}
$$




\subsection{Método Numérico}

O conjunto de equações diferenciais de cada submodelo foi solucionado através da discretização destas equações pelo método dos volumes finitos em sua formulação explícita (Apêndice D). Nesta formulação, os termos difusionais foram aproximados por diferenças centrais e os termos convectivos pela técnica de "upwind". Os passos de tempo para ambos os submodelos foram iguais e calculados através do critério de estabilidade para a translação na técnica do CA (Eq. [59]) ou para o crescimento, que forneceu passos de tempo suficientemente pequenos para a estabilidade da solução numérica. $O$ algoritmo utilizado foi implementado na linguagem ANSI C e compilado pelo compilador Borland C++ versão 4 em um Intel Core i7. A visualização da imagem dos grãos foi obtida pelo software MATLAB versão 6.1 e TECPLOT 360, e os perfis pelo sofware Origin versão 7. 


\section{RESULTADOS E DISCUSSÃO}

O modelo apresentado tem como objetivo prever, sob efeito da decantação de grãos, a macroestrutura bruta de solidificação e perfis de temperatura, fração de sólido e concentração de soluto nas fases. Para aferir o modelo, primeiro, foram simulados testes de crescimento de grão em movimentação com campos de temperatura conhecidos. Este teste tem como fim verificar se o algoritmo de translação não distorce o formato dos grãos enquanto crescem e se movimentam. Em seguida, para observar o comportamento do modelo, foram simulados casos ideais de decantação para: uma esfera sólida, uma esfera porosa com troca de massa; um conjunto de esferas porosas com troca de massa; e um grão dendrítico, que nucleia e cresce em líquido super-resfriado. Foram, então, comparados com modelos precursores, casos de solidificação isotérmica sem movimentação e com movimentação. Para aferir o cálculo da macroestrutura bruta de grãos para casos de solidificação unidirecional, foi feita uma análise do efeito de refino da malha numérica. Por fim, o modelo simulou casos de solidificação unidirecional para: cálculo da CET sob efeito da decantação de grãos, em condições iguais às do trabalho de Wang e Beckermann (1994), para solidificação unidirecional ascendente e descendente; previsão de macroestruturas variando parâmetros da distriuição normal de super-resfriamentos para nucleação comparando-as com resultados obtidos por Martorano e Biscuola (2009); e em condições próximas às de um resultado experimental de Rerko et al. (2003).

\subsection{Aferição do Cálculo do Crescimento de Grão}

O modelo desenvolvido é capaz de simular o crescimento e a translação simultânea de um envelope dendrítico imerso em um líquido com temperatura conhecida e variável. Três simulações (Tabela 4) foram realizadas onde um envelope quadrado de tamanho nulo e com uma velocidade de translação constante foi posicionado no domínio bidimensional de cálculo. Com o decorrer do tempo, o grão transladou com uma velocidade horizontal constante $\vec{v}_{s}$ e cresceu simultaneamente em um líquido com campo de temperatura definido para cada 
teste. Apesar do grão estar se movimentando, desprezou-se uma possível movimentação do líquido. Desta forma, esta simulação permitiu verificar se a técnica utilizada para deslocar o grão na malha de células manteria o formato correto do envelope, sem provocar distorções. Estes formatos foram comparados com os formatos obtidos por Gandin e Rappaz (1994) para o caso de um grão fixo nas mesmas condições de crescimento.

Nas simulações, considerou-se que o líquido inicial consistia de uma solução orgânica de SCN-1,3\%Acetona, que sofre solidificação de forma análoga às ligas metálicas. A velocidade de crescimento foi calculada em função do superresfriamento local, $\Delta \mathrm{T}$, utilizando a Eq. [93]. Neste teste, a cinética de crescimento do grão é calculada pela equação abaixo:

$$
\left|\vec{w}_{g}^{\prime}\right|=a_{2} \Delta T^{2}+a_{3} \Delta T^{3}
$$

onde $a_{2}=8,26 \times 10^{-6}\left(\mathrm{~ms}^{-1} \mathrm{~K}^{-2}\right)$ e $a_{3}=8,18 \times 10^{-5}\left(\mathrm{~ms}^{-1} \mathrm{~K}^{-3}\right)$ são constantes. $\mathrm{O}$ campo de temperatura no domínio bidimensional é dado pela equação:

$$
T(y, t)=T_{l i q}+G_{y}\left(y-\frac{L_{y}}{2}\right)+\dot{T} . t
$$

onde $G_{y}$ é o gradiente de temperatura no eixo y, e $\dot{T}$ é a taxa de resfriamento.

Tabela 4 - Dados de entrada para as simulações A, B e C

\begin{tabular}{ccccc}
\hline Simulação & $\theta$ & $\dot{T}(\mathrm{~K} / \mathrm{s})$ & $\mathrm{G}(\mathrm{K} / \mathrm{m})$ & $\left|\vec{V}_{s}\right|(\mathrm{m} / \mathrm{s})$ \\
\hline A & $15^{\circ}$ & $-0,01$ & 0 & $1,3 \times 10^{-4}$ \\
B & $-15^{\circ}$ & $-0,025$ & 250 & $3 \times 10^{-4}$ \\
C & $-15^{\circ}$ & $-0,05$ & 500 & $6 \times 10^{-4}$ \\
\hline
\end{tabular}

Os resultados das simulações dos Testes A, B e C estão apresentados respectivamente na Figura 18, Figura 19, e Figura 20. Na simulação A, o gradiente de temperatura é nulo, portanto, o envelope deve manter o formato quadrado, como é observado na Figura 18. Nos testes B e C, foram obtidos formatos idênticos aos resultados de Rappaz e Gandin (1993) sem a translação. Os resultados mostram 
que o método de translação utilizado na técnica do CA mantém o formato do envelope calculado pelo modelo precursor de Rappaz e Gandin (1993).

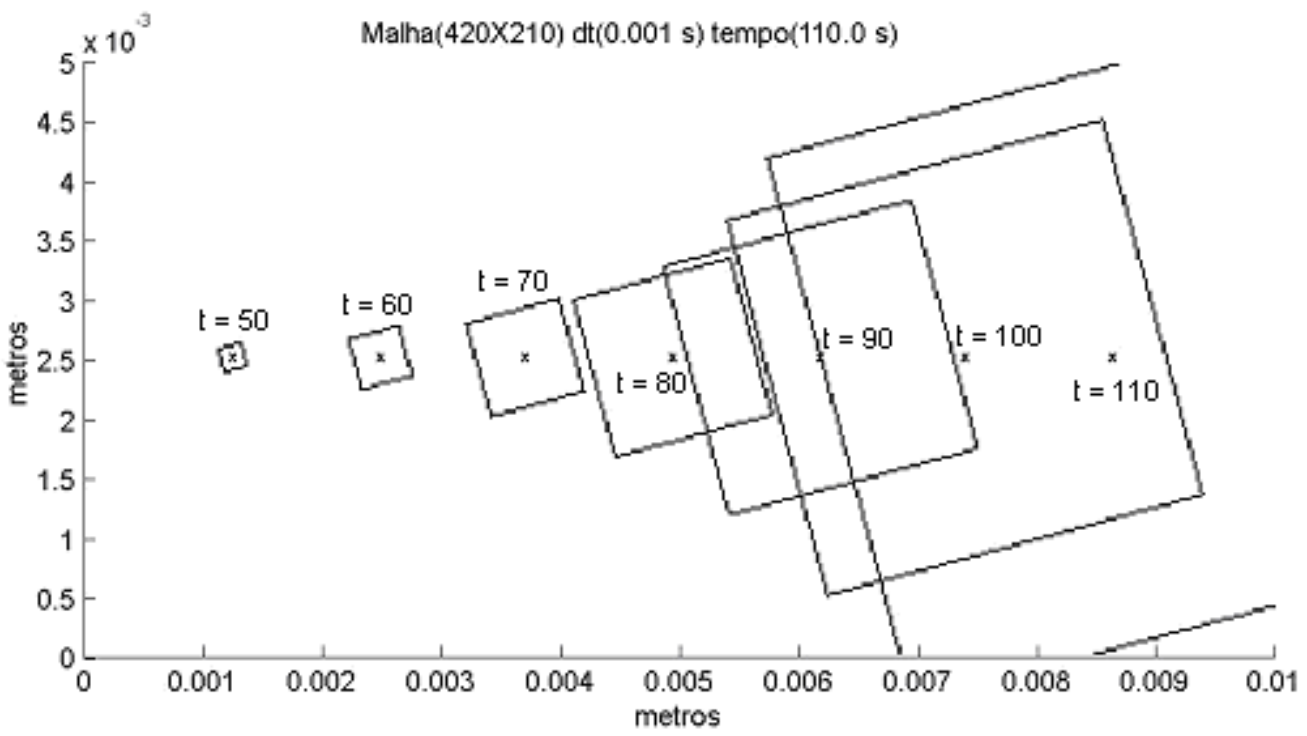

a)

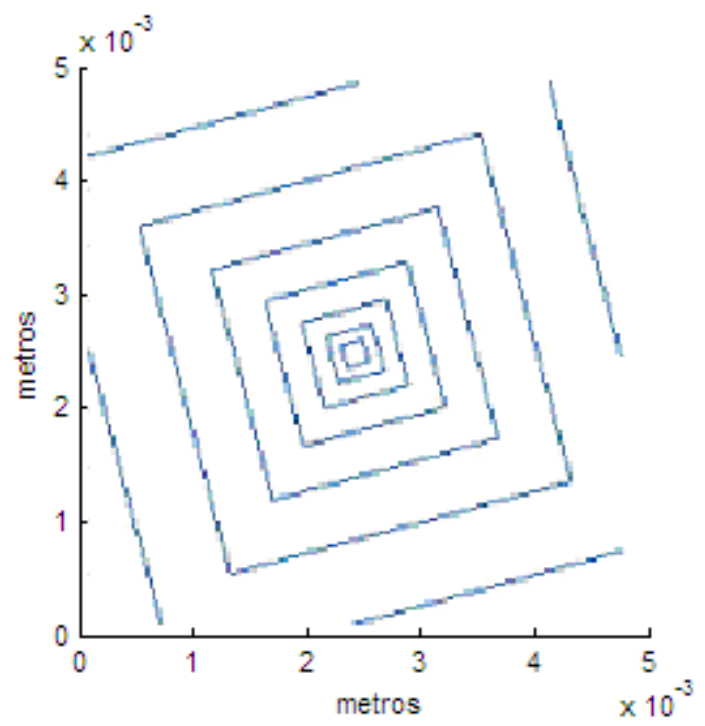

b)

Figura 18 - Simulação de um único grão sob a condição A: (a) formato de posição do envelope para vários instantes de tempo dados em segundos; (b) formatos apresentados por Gandin e Rappaz (1994) para os mesmos instantes, sem considerar a translação. 


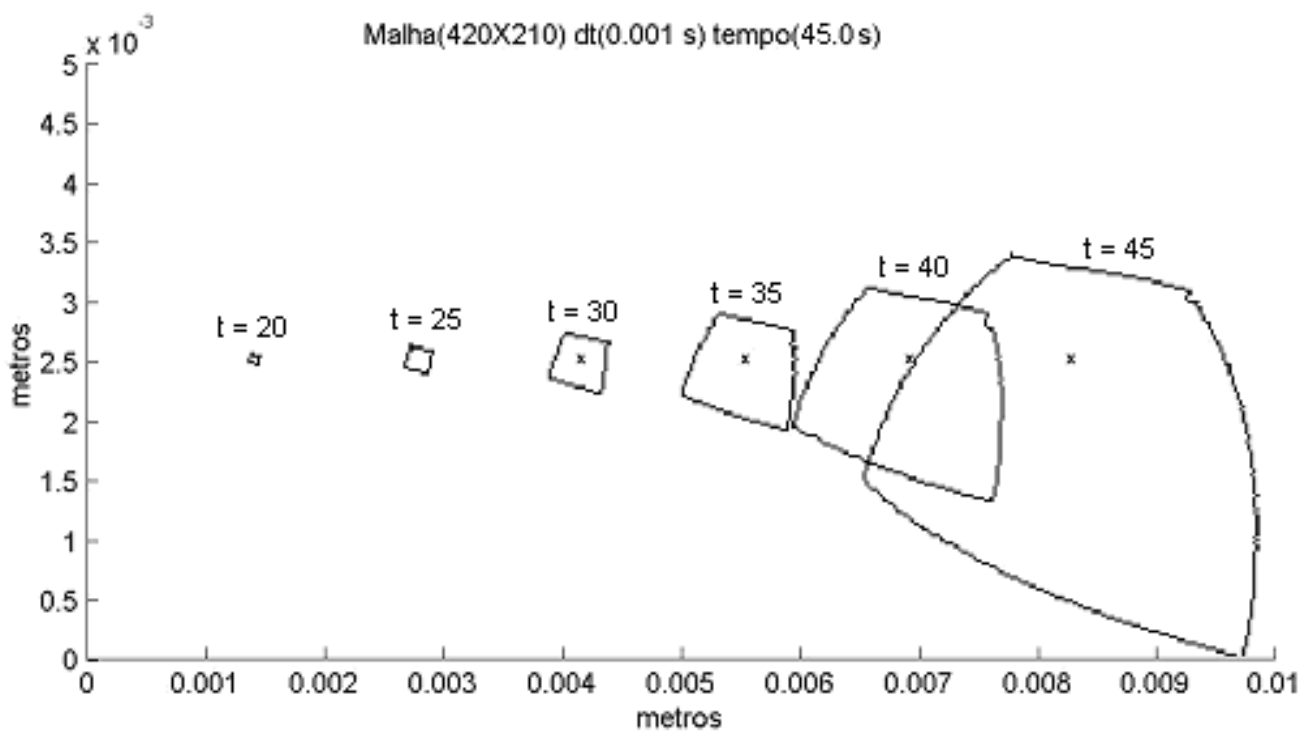

a)

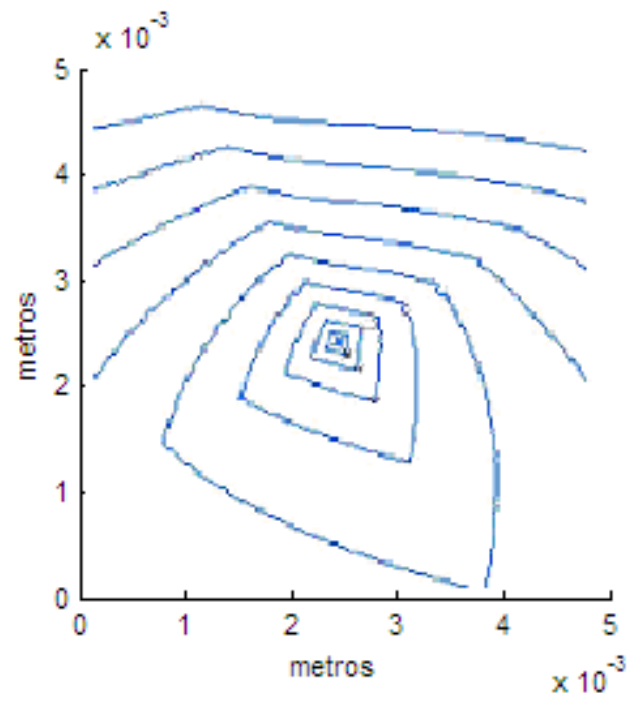

b)

Figura 19 - Simulação de um único grão sob a condição B: (a) formato de posição do envelope para vários instantes de tempo dados em segundos; (b) formatos apresentados por Gandin e Rappaz (1994) para os mesmos instantes, sem considerar a translação 


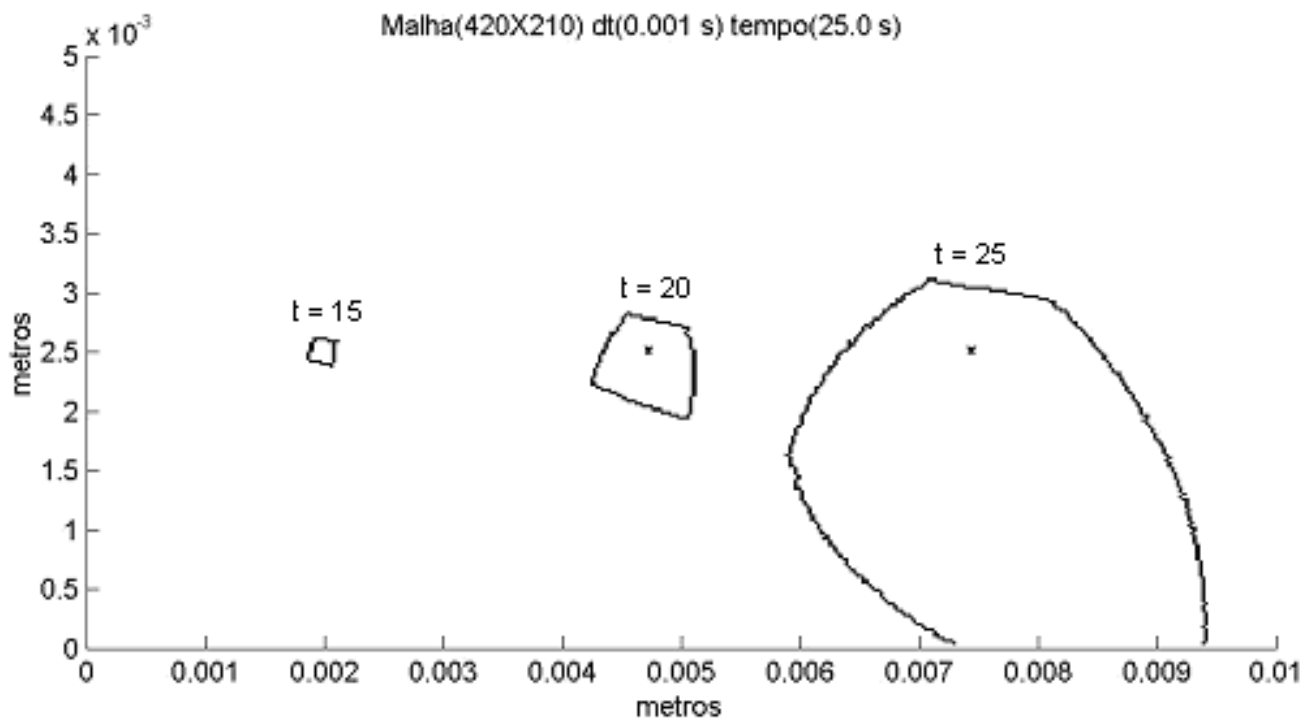

a)

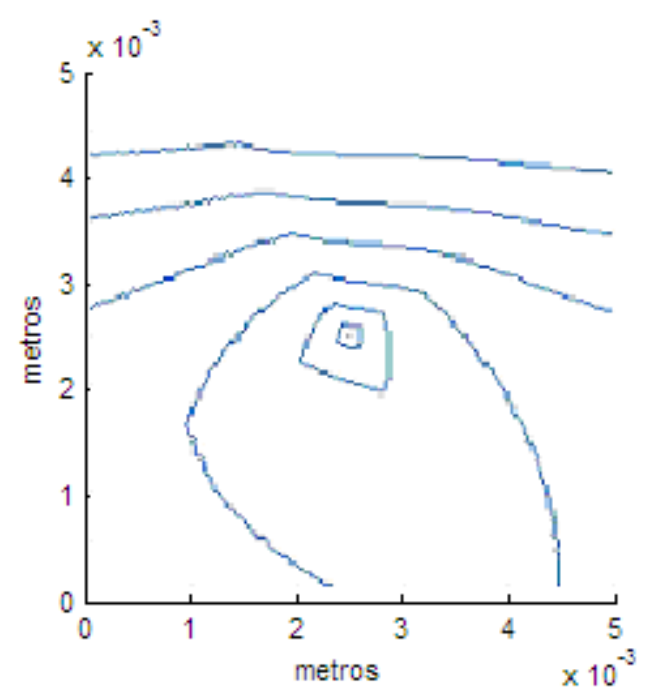

b)

Figura 20 - Simulação de um único grão sob a condição C: (a) formato de posição do envelope para vários instantes de tempo dados em segundos; (b) formatos apresentados por Gandin e Rappaz (1994) para os mesmos instantes, sem considerar a translação

\subsection{Decantação de Grãos}

Neste item foi examinado isoladamente o efeito que a decantação de grãos causa nas equações de conservação. Foram feitos testes simples com sistemas para um grão isolado e para múltiplos grãos, com parâmetros para a liga $\mathrm{Al}-7 \% \mathrm{Si}$ (Tabela 5). Nos sistemas de grão isolado, o modelo foi testado para a queda livre de um grão esférico, com e sem troca de massa com o fluido, e de queda livre de um 
grão dendrítico em líquido super-resfriado; enquanto no sistema de múltiplos grãos, o modelo foi testado para o caso de queda livre de um conjunto de esferas porosas com troca de massa.

Tabela 5 - Parâmetros da liga Al- $7 \% \mathrm{Si}$.

\begin{tabular}{cccc}
\hline$C_{0}(\%)$ & 7,0 & $\rho_{s}\left(\mathrm{~kg} \cdot \mathrm{m}^{-3}\right)$ & 2535,0 \\
$T_{\text {liq }}(\mathrm{K})$ & 891,0 & $\rho_{l}\left(\mathrm{~kg} \cdot \mathrm{m}^{-3}\right)$ & 2370,0 \\
$T_{f}$ & 936,5 & $T_{e}(\mathrm{~K})$ & 850,0 \\
$L_{f}\left(\mathrm{~J} \cdot \mathrm{kg}^{-1}\right)$ & $387.400,0$ & $C_{P}\left(\mathrm{~J} \cdot \mathrm{K}^{-1} \mathrm{~kg}^{-1}\right)$ & 1126,0 \\
$m_{l}(\mathrm{~K} / \%)$ & $-6,5$ & $k(-)$ & 0,13 \\
$D_{l}\left(\mathrm{~m}^{2} \mathrm{~s}^{-1}\right)$ & $6,45.10^{-9}$ & $\Gamma\left(\mathrm{m}^{-1} \mathrm{~K}\right)$ & $1,96 \cdot 10^{-7}$ \\
$K_{s}\left(\mathrm{Wm}^{-1} \mathrm{~K}^{-1}\right)$ & $233,0-$ & $K_{l}\left(\mathrm{Wm}^{-1} \mathrm{~K}^{-1}\right)$ & $36,5+0,028 \mathrm{xT}$ \\
$\mu_{l}(\mathrm{~Pa} \cdot \mathrm{s})$ & $0,110 . T$ & $\lambda_{2}(\mathrm{~m})$ & $10^{-5}$ \\
\hline Tabela 6-Parâmetros de entrada para simulação de decantação de grãos \\
\hline$L_{x}(\mathrm{~m})$ & 0,001 & $L_{y}(\mathrm{~m})$ & 0,028 \\
$\Delta x_{C A}(\mathrm{~m})$ & 0,007 & $\Delta y_{V F}(\mathrm{~m})$ & 0,007 \\
$\Delta t(\mathrm{~m})$ & $7,0 \times 10^{-5}$ & $\Delta T_{0}(\mathrm{~m})$ & $10^{-5}$ \\
\hline
\end{tabular}

\subsubsection{Decantação de um Grão Esférico}

Neste teste, foi simulada a decantação de um grão esférico e completamente sólido imerso em um líquido onde existia um gradiente de concentração inicial paralelo à direção de decantação. O perfil de concentração inicial era linear, contendo $7 \%$ Si no topo e 10\%Si na base, além de um grão esférico de diâmetro $0,35 \mathrm{~cm}$ posicionado no topo, à $2,45 \mathrm{~cm}$ da base. Durante a simulação, o grão simplesmente decanta, causando um movimento do líquido no sentido ascendente. Este problema foi dimensionado para se examinar a capacidade do modelo em prever a mistura do líquido que ocorre devido à corrente de convecção para o topo, causada pela queda do grão.

A Figura 21 mostra a macroestrutura calculada pelo modelo em três instantes de tempo diferentes. A Figura 22 apresenta os perfis de velocidade ascendente média do líquido externo ao envelope (líquido extradendrítico) em quatro 
instantes de tempo correspondentes a macroestrutura da Figura 21. Nota-se que na coordenada "y" onde está o grão em decantação com velocidade na direção descendente, existe uma velocidade média do líquido na direção ascendente. No entanto, em posições distantes deste grão, a velocidade do líquido é nula. Este comportamento está consistente com a equação da continuidade da mistura para o caso de uma esférica completamente sólida $\left(\varepsilon_{d}=0\right)$, expressa abaixo:

$$
\varepsilon_{s_{M}}\left\langle v_{s}\right\rangle_{M}^{s}+\varepsilon_{l_{M}}\left\langle v_{l}\right\rangle_{M}^{l}=0
$$

Esta equação mostra que quando a velocidade local média do sólido $\left(\left\langle v_{s}\right\rangle_{M}^{s}\right)$ é diferente de zero, a velocidade do líquido extradendrítico $\left(\left\langle v_{l}\right\rangle_{M}^{l}\right)$ também é diferente de zero e tem sinal oposto. Quando $\left\langle v_{s}\right\rangle_{M}^{s}=0$, ou seja, em locais onde não há grão, tem-se $\left\langle v_{l}\right\rangle_{M}^{l}=0$, exatamente como mostrado na Figura 22.

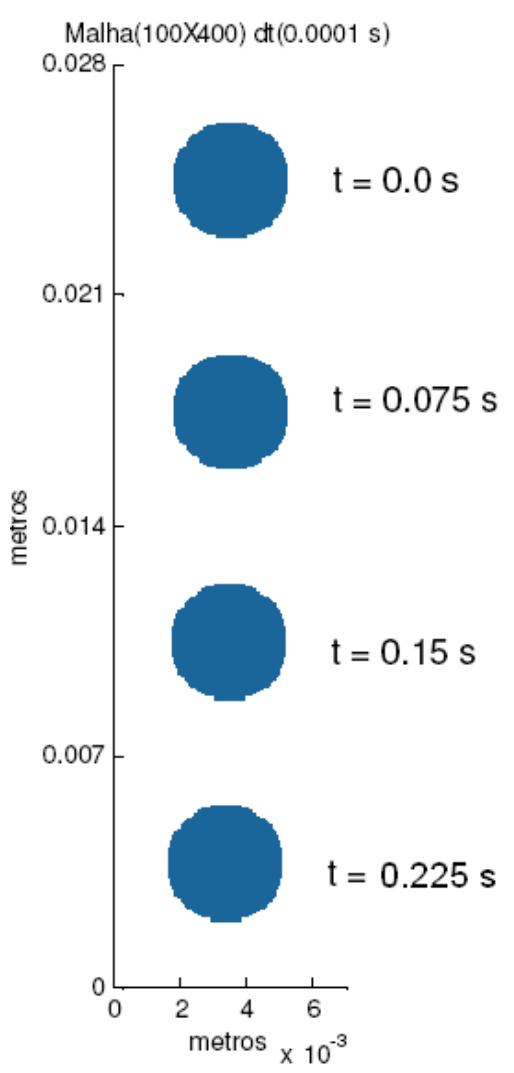

Figura 21 - Esfera sólida decantando e com sua posição ilutrada nos instantes 0,0s, 0,075s, $0,15 \mathrm{~s}, 0,225 \mathrm{~s}$ 
Os perfis de teor de Si para os mesmos instantes de tempo discutidos nas figuras anteriores, estão apresentados na Figura 23. Nota-se que, à medida que o grão esférico decanta, o perfil de concentração inicial $(t=0 \mathrm{~s})$ é alterado: as concentrações superiores vão se tornando cada vez maiores, resultando em um pequeno efeito de deslocamento do perfil de concentração inicial de soluto no líquido. Este efeito ocorre porque o líquido mais enriquecido em soluto, localizado nas regiões mais inferiores, é transportado para cima conforme a esfera decanta, ocupando o espaço deixado por esta esfera e, portanto, aumentando a concentração nas regiões superiores. Este resultado mostra que o equacionamento proposto para simular o transporte massa no líquido parece estar reproduzindo, pelo menos qualitativamente, o comportamento físico esperado.

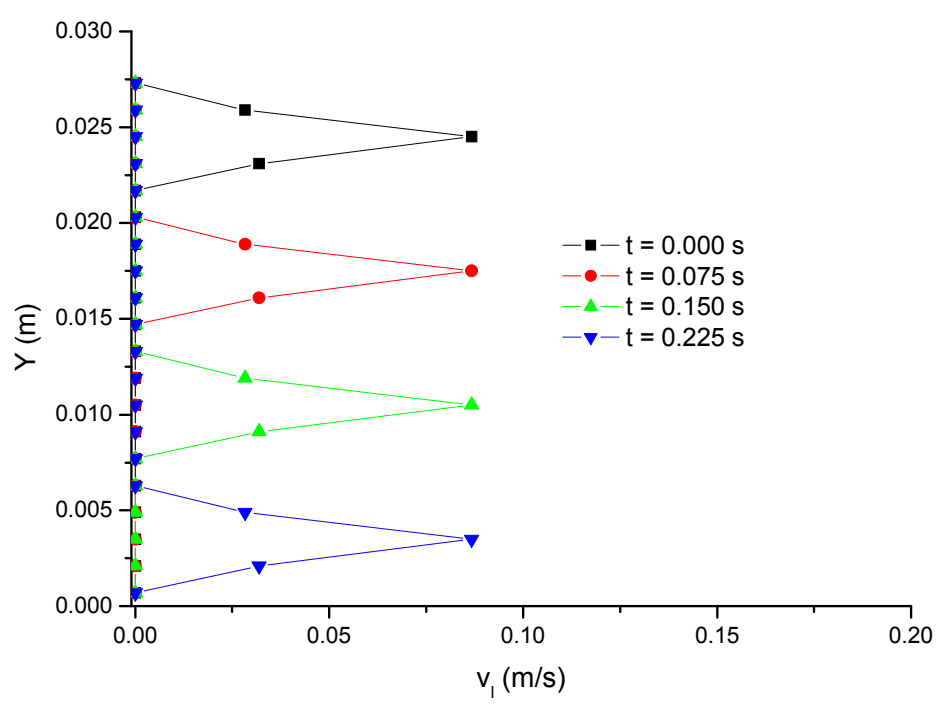

Figura 22 - Perfis de velocidade média do líquido extradendrítico em função da altura em quatro instantes de tempo diferentes. 


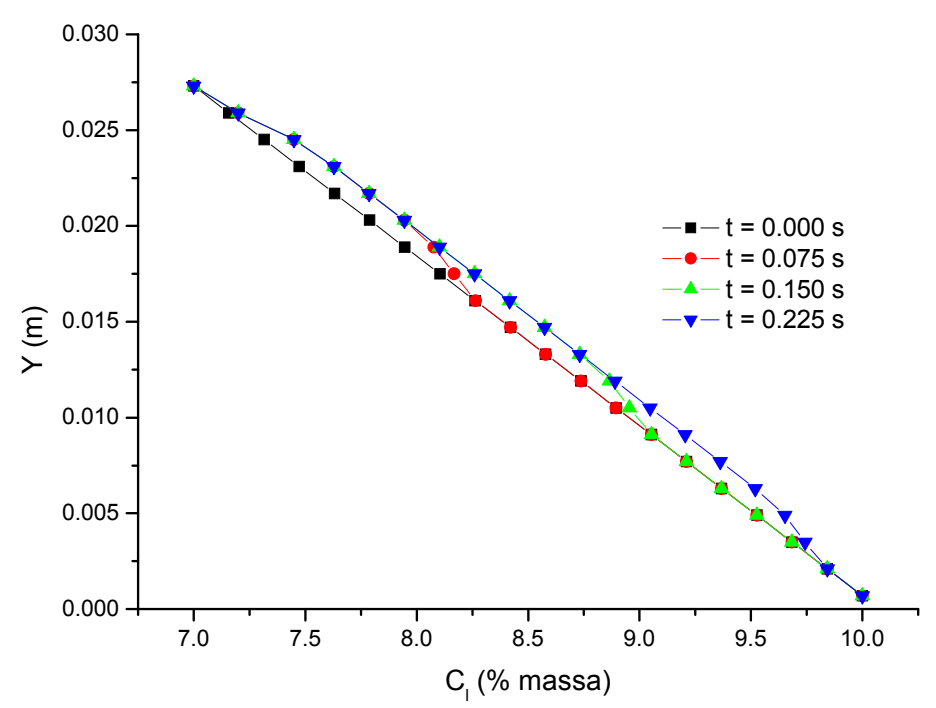

Figura 23 - Perfis de concentração de Si no líquido extradendrítico em função da altura em dois instantes de tempo diferentes.

\subsubsection{Decantação de um Grão Esférico Poroso}

Neste teste, foi simulada a decantação de um grão esférico poroso (com fração de sólido interna constante $\left.\varepsilon_{s i}=0,1\right)$ em um líquido de composição inicial uniforme, contendo $7 \% \mathrm{Si}$, com troca de massa entre o grão e o líquido extradendrítico (com concentração de soluto no líquido interdendrítico $\left\langle C_{d}\right\rangle^{d}$ constante igual a 10\%). Este grão, sendo poroso, aproxima-se melhor ao caso de um grão dendrítico. Novamente, um grão esférico de diâmetro $0,35 \mathrm{~cm}$ foi posicionado a $2,45 \mathrm{~cm}$ da base e a evolução da macroestrutura, do perfil de velocidade média e de concentração de soluto média do líquido extradendrítico foi calculada pelo modelo. A macroestrutura da esfera em decantação em quatro instantes de tempo diferentes está apresentada na Figura 24, mostrando um resultado semelhante ao caso anterior, da esfera completamente sólida. Porém, a esfera porosa atinge os mesmos pontos da esfera completamente sólida em instantes de tempo aproximadamente quatro vezes maior. 


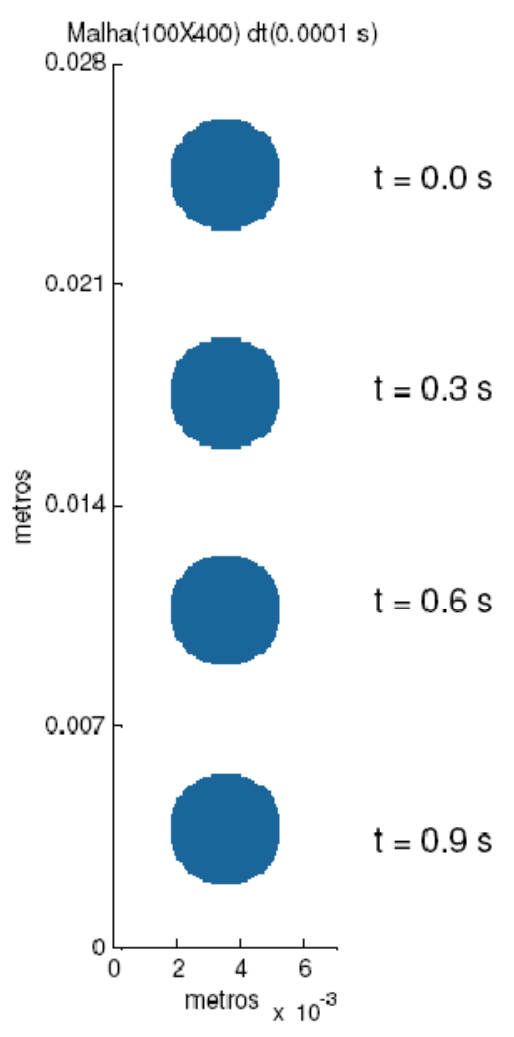

Figura 24 - Macroestrutura da esfera porosa decantando em diferentes instantes de tempo.

Observou-se também, que para um tamanho de poro médio de aproximadamente $10 \mu \mathrm{m}$ (consistente com o espaçamento entre braços secundários de uma dendrita), praticamente não existe escoamento de líquido através da esfera. Então, ela se comporta como uma esfera completamente sólida, mas com uma densidade menor, portanto decantando com menor velocidade, o que explica os maiores tempos de decantação.

Os perfis de velocidade média do líquido extradendrítico estão apresentados na Figura 25 para quatro instantes de tempo correspondentes à macroestrutura apresentada na Figura 24. 


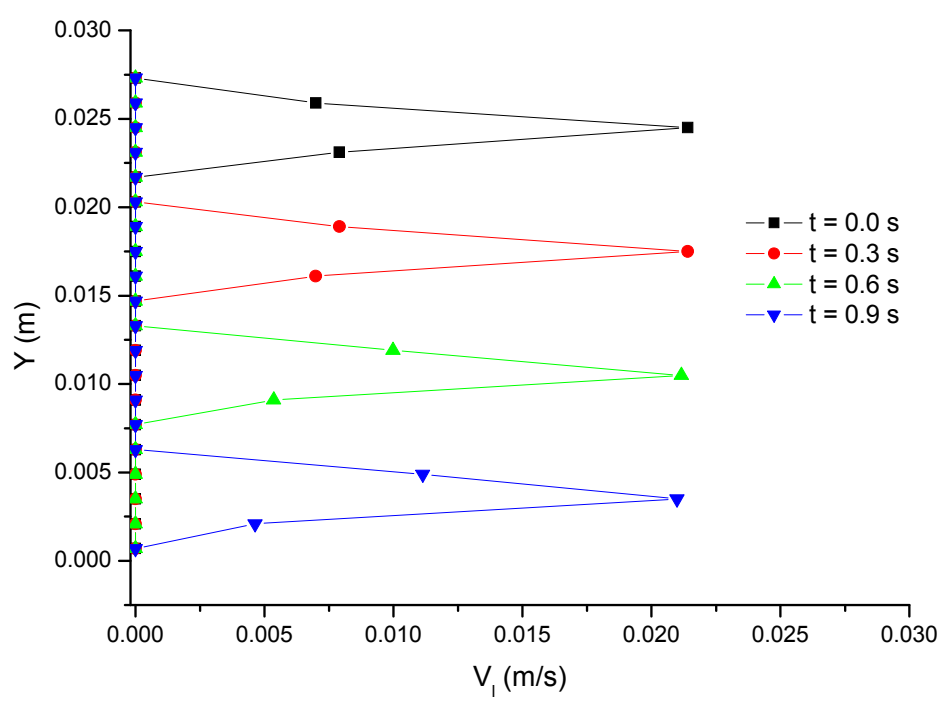

Figura 25 - Perfis de velocidade média do líquido extradendrítico em função da altura em quatro instantes de tempo diferentes para o caso de decantação da esfera porosa.

Os perfis de velocidade apresentam as mesmas características daqueles apresentados na Figura 22 para a esfera completamente sólida. Entretanto, existe uma diferença importante: as velocidades atingem valores cerca de 5 vezes menor. Esta menor velocidade de ascensão do líquido extradendrítico está consistente com a menor velocidade de decantação da esfera. Finalmente, os perfis de concentração de Si no líquido extradendrítico estão apresentados na Figura 26. Inicialmente, este líquido tem composição homogênea, em um teor de $7 \%$ Si. Conforme o grão decanta, ele rejeita uma certa quantidade de soluto para o líquido interdendrítico e começa a enriquecer este líquido. Observa-se na figura que, para $t=0,3 \mathrm{~s}$, o líquido ao redor da esfera foi enriquecido com Si. Este enriquecimento passa a aumentar em posições cada vez mais inferiores quanto mais o grão decanta, pois o soluto rejeitado pelo grão passa a ser transportado para o topo devido ao movimento convectivo do líquido induzido pela decantação do sólido. 


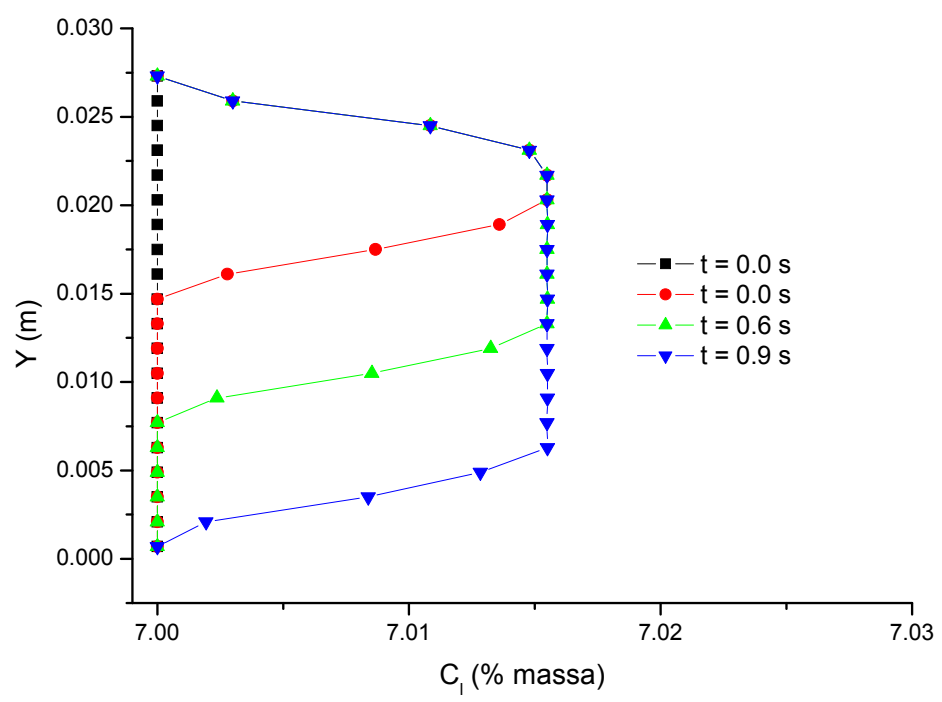

Figura 26 - Perfis de concentração de Si no líquido extradendrítico em função da altura em quatro instantes de tempo diferentes no caso de decantação da esfera porosa.

\subsubsection{Decantação de um Grão Dendrítico}

Resultados da simulação de decantação de um grão dendrítico estão mostrados neste item. Um grão dendrítico com formato de losango de lado muito pequeno $(70 \mu \mathrm{m})$ da liga $\mathrm{Al}-7 \% \mathrm{Si}$ foi posicionado no topo do domínio, que está preenchido com líquido a uma temperatura uniforme de $881 \mathrm{~K}$, representando um super-resfriamento de $10 \mathrm{~K}$ abaixo da linha liquidus. Durante a queda do grão no líquido super-resfriado, este grão também apresenta crescimento, libera calor latente e troca soluto com o líquido ao redor. A Figura 27 mostra as macroestruturas calculadas pelo modelo em três instantes de tempo diferentes. 


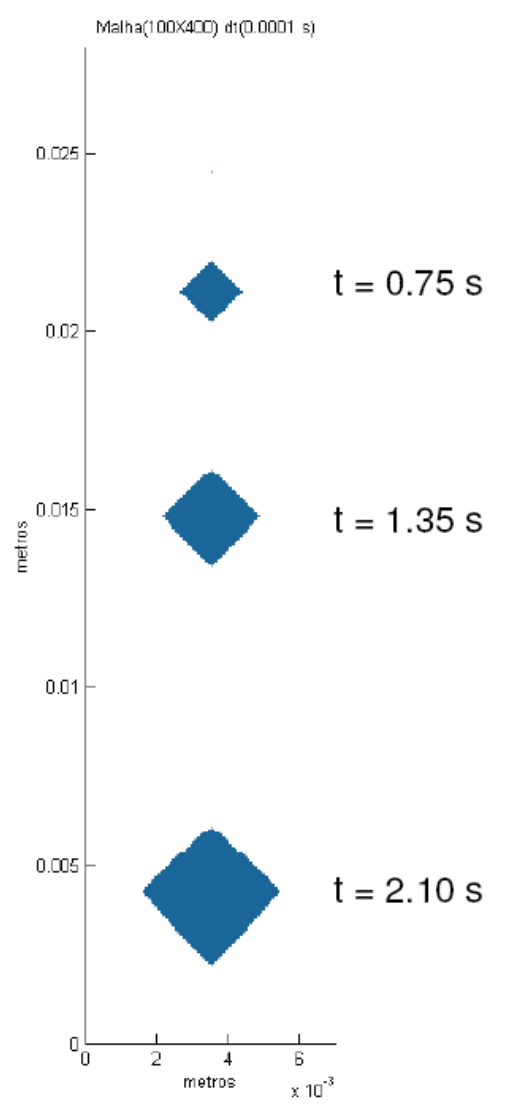

Figura 27 - Macroestrutura de um grão dendrítico decantando em um liquido super-resfriado em $5 \mathrm{~K}$ em relação a temperatura liquidus em diferentes instantes.

Este resultado do modelo mostra um envelope dendrítico em queda durante um intervalo de aproximadamente 2 segundos. Observa-se claramente o crescimento do envelope que apresentava um formato inicial de losango, que se tornou assimétrico durante a queda, devido ao crescimento um pouco mais acentuado da região inferior. Este efeito pode ser entendido com o auxílio dos perfis de temperatura apresentados na Figura 28 para diversos instantes de tempo. Inicialmente, o líquido apresenta temperatura uniforme, mas à medida que o grão decanta, a temperatura aumenta com o aumento da aumentando a quantidade de sólido. Esta solidificação do grão resulta na liberação de calor latente que eleva a temperatura local do líquido. 


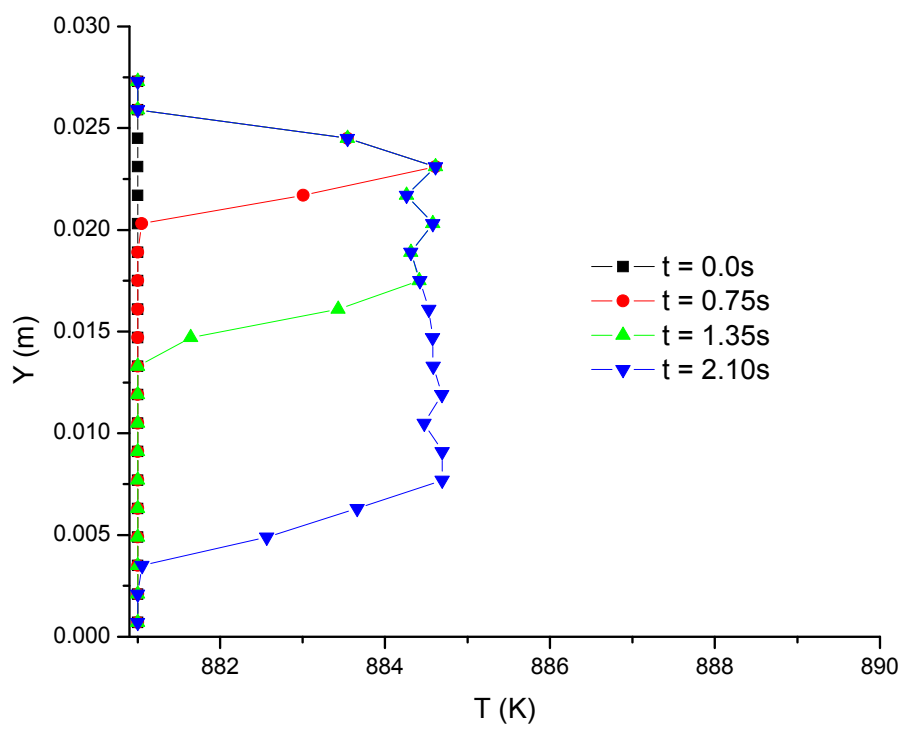

Figura 28 - Perfis de temperatura em função da altura em quatro instantes de tempo diferentes para o caso de decantação do grão dendrítico.

O perfil de velocidade inicial local média do líquido extradendrítico está apresentado na Figura 29 para os instantes correspondentes aos apresentados na Figura 27. Os perfis são muito semelhantes aos apresentados na Figura 22 e Figura 25 para os grãos de tamanhos constantes, esféricos, completamente sólidos ou porosos: nota-se que a velocidade do líquido é diferente de zero na posição instantânea onde o grão está. Distanciando-se desta posição, a velocidade é nula. Entretanto, no presente problema, existe uma importante diferença em relação aos problemas anteriores: o grão cresce ao decantar. Logo, o pico de velocidade do líquido é maior nas regiões inferiores, onde a grão é maior. 


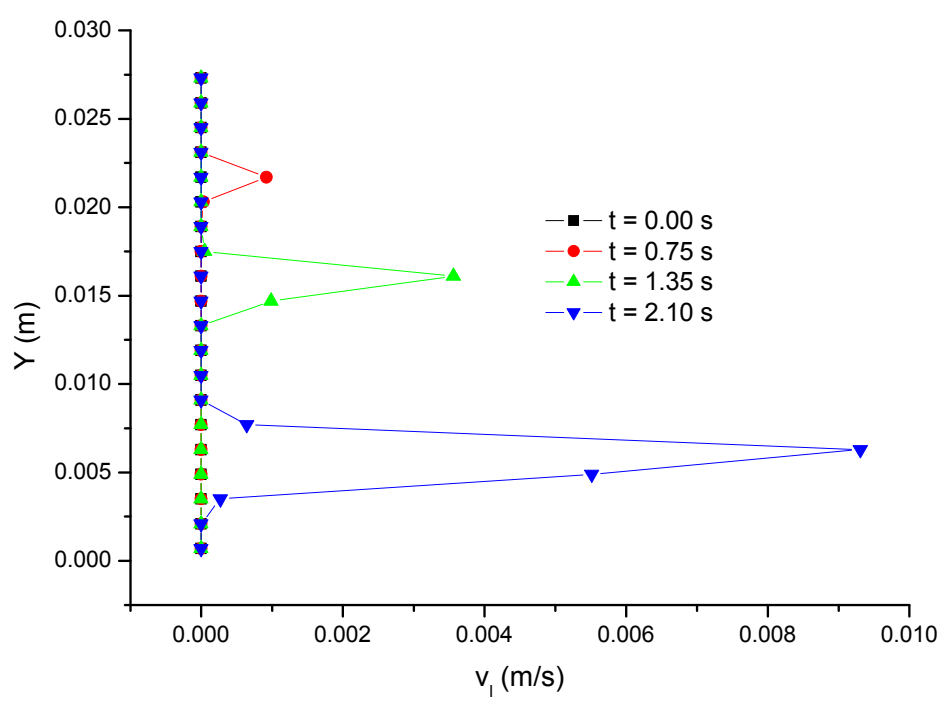

Figura 29 - Perfis de velocidade média do líquido extradendrítico em função da altura em dois instantes de tempo diferentes para o caso de decantação do grão dendrítico.

Os perfis de concentração no líquido extradendrítico para diversos instantes de tempo estão apresentados na Figura 30. Eles são semelhantes aos da Figura 26 para o caso de um grão esférico de tamanho constante, ou seja, o teor de Si aumenta nas regiões inferiores, conforme o grão decanta, com o fluxo difusivo de soluto para o líquido extradendrítico ao redor do envelope.

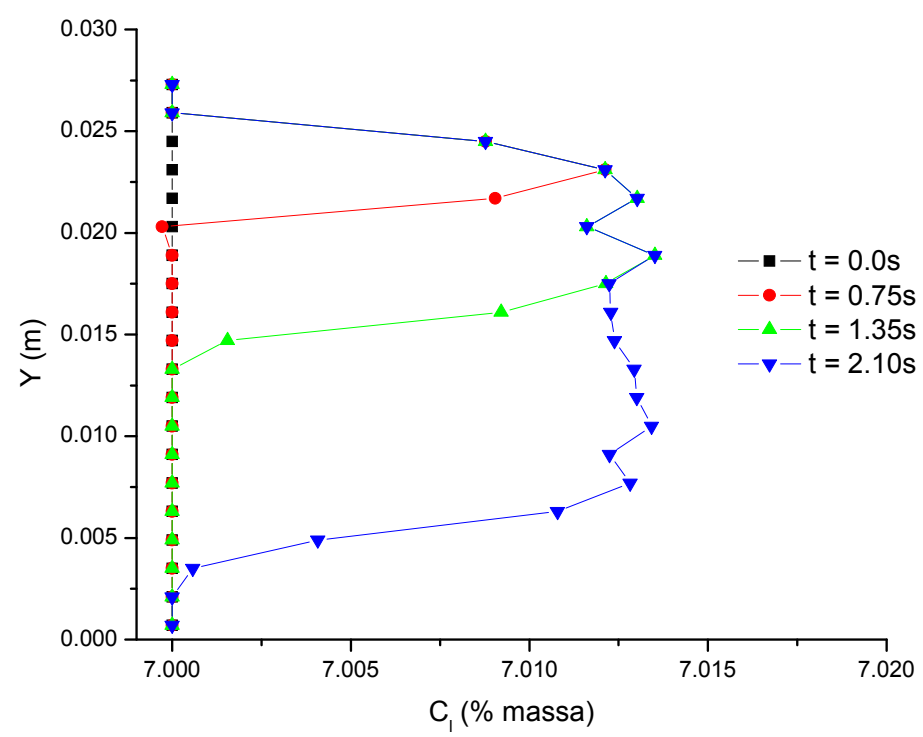

Figura 30 - Perfis de concentração média do líquido extradendrítico em função da altura em quatro instantes de tempo diferentes para o caso de decantação do grão dendrítico. 
Os perfis de temperatura (Figura 28), de velocidade do líquido extradendrítico (Figura 29) e de concentração do líquido extradendrítico (Figura 30) foram obtidos a partir da solução das equações do modelo macroscópico. Como mencionado na metodologia, o submodelo macroscópico está acoplado ao submodelo microscópico, onde algumas equações de conservação são solucionadas dentro do grão (item 4.3). A solução destas equações resulta em um campo de fração de sólido e de velocidade da fase líquida interdendrítica dentro do grão, que está mostrado na Figura 31 para o instante $t=2,1 \mathrm{~s}$. 


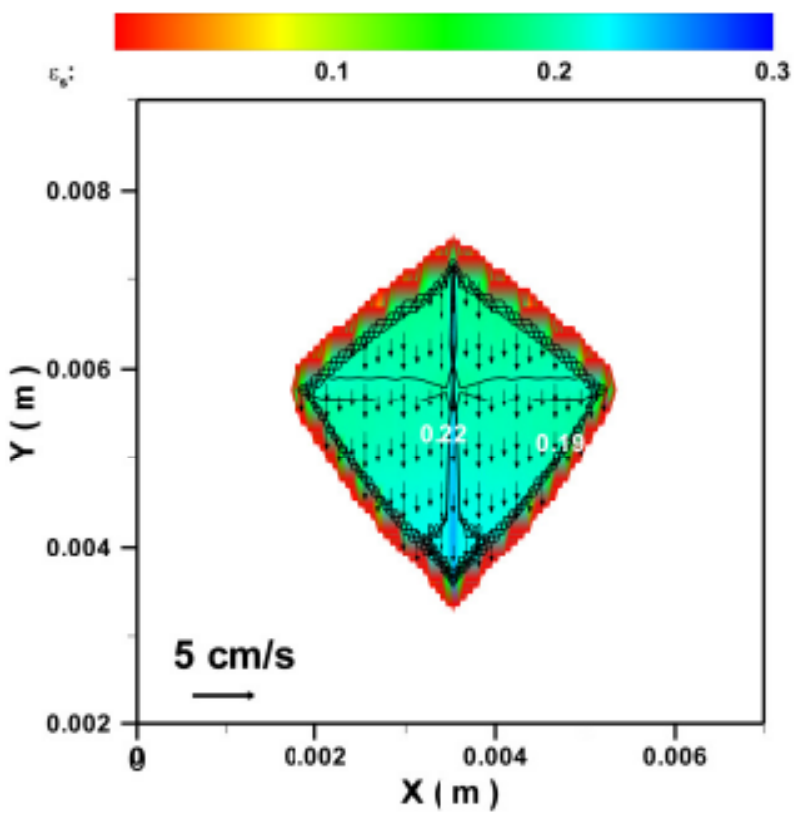

(a)

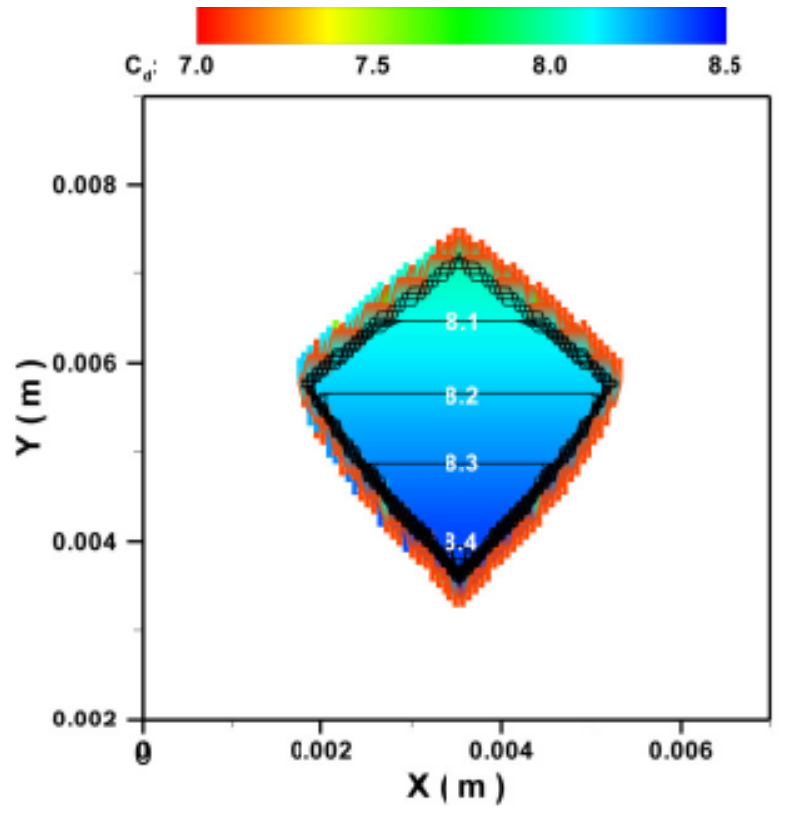

(b)

Figura 31 - Campos internos ao grão dendrítico em decantação apresentado na Figura 27 para o instante de tempo 2,1s: (a) campo de fração de sólido $\varepsilon_{\mathrm{s}}$ e velocidade do líquido interdendrítico $\left\langle v_{d}\right\rangle^{d}$; (b) campo de concentração do líquido interdendrítico $\left\langle C_{d}\right\rangle^{d}$.

Observa-se na Figura 31(a) que a fração de sólido interna ao grão $\varepsilon_{s}$ varia de 0,19 na borda até 0,22 no centro, ou seja, nota-se que esta fração é praticamente uniforme com um gradiente desprezível dentro do grão de tamanho reduzido $(\approx$ $4 \mathrm{~mm})$. O campo de velocidades calculado no líquido interdendrítico $\left\langle v_{d}\right\rangle^{d}$ também 
está mostrado, apresentando-se praticamente uniforme, com um móludo de aproximadamente $1,5 \mathrm{~cm} / \mathrm{s}$. Esta velocidade é aproximadamente a velocidade instantânea de decantação do grão, ou seja, o grão dendrítico poroso praticamente arrasta todo o seu líquido interno para baixo, pois este grão é muito pouco permeável. A Figura 31(b) apresenta a concentração de soluto no líquido interdendrítico $\left\langle C_{d}\right\rangle^{d}$. Observa-se um gradiente de $\left\langle C_{d}\right\rangle^{d}$ na direção ascendente, causando uma variação de teor de Si de 8,4\% até aproximadamente $8 \%$. Este gradiente existe, pois o líquido interno foi assumido estar em equilíbrio com a temperatura. Desta forma, como a temperatura aumenta do topo para a base, a concentração deste líquido aumenta no sentido contrário.

Nota-se que este líquido interdendrítico apresenta uma quantidade de soluto maior do que a do líquido de composição inicial $(7 \% \mathrm{Si})$ e maior do que a do líquido externo $(\approx 7,015 \% \mathrm{Si})$, mostrado na Figura 30. Esta maior concentração ocorre devido à rejeição de soluto da solidificação primeiro para o líquido interdendrítico entre os braços dendríticos, e depois se difundindo para líquido externo ao evelope.

\subsubsection{Decantação de um Conjunto de Esferas Porosas}

Nos itens anteriores, foram apresentados alguns resultados obtidos pelo modelo para simular a queda de grãos isolados. No presente item, aumentou-se o grau de complexidade do problema através de simulações de um conjunto de grãos em decantação. Neste teste, simulou-se a decantação de um conjunto de grãos esféricos porosos de tamanho constante, com mesmo raio e velocidade de decantação. Considerou-se que estes grãos trocavam massa (soluto) com o líquido externo aos grãos à medida que decantavam.

Foram posicionadas 25 esferas no topo do domínio completamente líquido, análogo aos itens anteriores. A malha numérica e o passo de tempo utilizado foram idênticos aos testes anteriores. A macroestrutura no instante inicial e a calculada pelo modelo em $t=0,84 \mathrm{~s}$ estão mostradas na Figura 32. A velocidade das esferas foi mantida constante e, portanto, o espaçamento entre elas também até atingirem a base. 


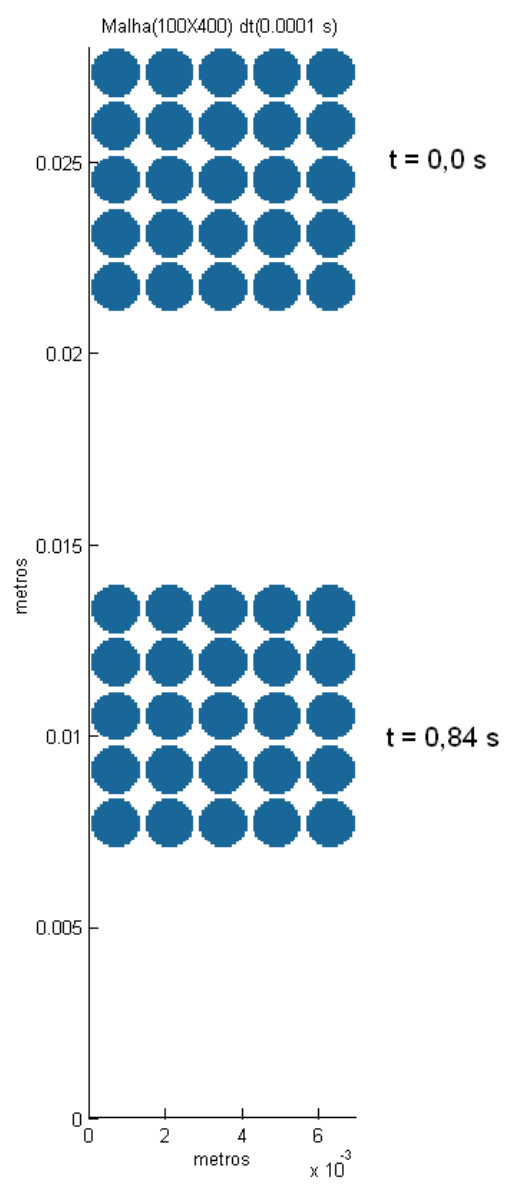

Figura 32 - Conjunto de esferas com fração de sólido interna igual a 0.1 decantando em dois instantes de tempo.

Os perfis de velocidade do líquido extradendrítico na direção vertical ascendente estão mostrados na Figura 33. Nota-se um aumento de velocidade no local onde o conjunto de grãos está passando, como observado no teste para a esfera porosa isolada (Figura 25). No entanto, no presente caso, a magnitude desta velocidade é aproximadamente 6 vezes maior que a da esfera isolada. Este comportamento está fisicamente correto, pois agora existe um conjunto de grão que ocupa um maior volume, deslocando uma maior quantidade de líquido à medida que decanta. 


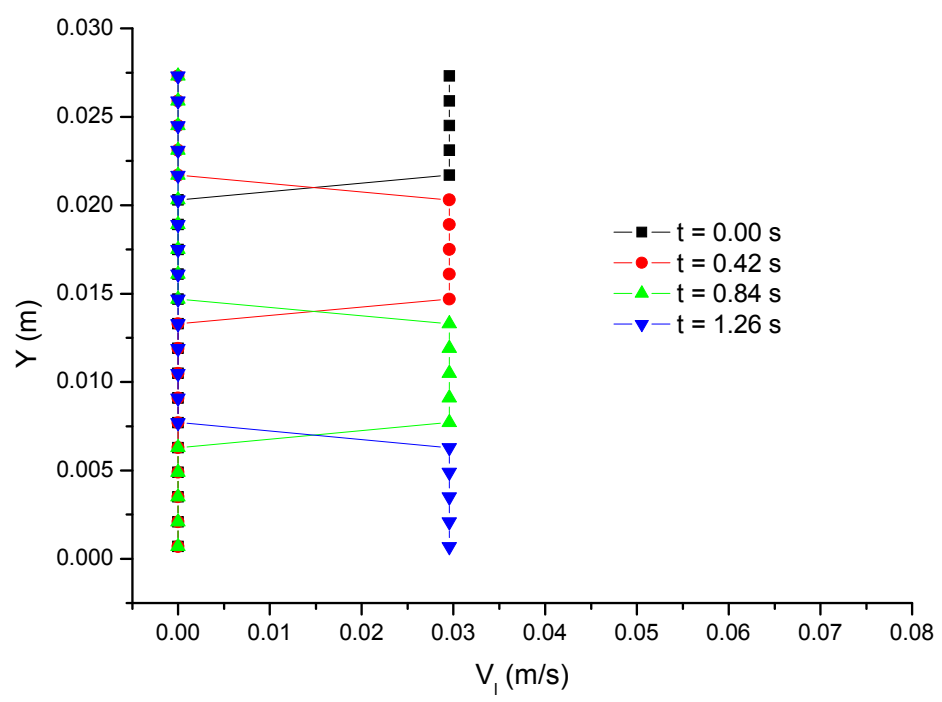

Figura 33 - Perfis de velocidade média do líquido extradendrítico em função da altura em quatro instantes de tempo diferentes para o caso da decantação de um conjunto de esferas porosas.

Os perfis de concentração de soluto no líquido extradendrítico estão apresentados na Figura 34. Estes perfis mostram um comportamento análogo ao da simulação da decantação de uma esfera isolada (Figura 26), ou seja, observa-se que o líquido da região inferior torna-se cada vez mais enriquecido em soluto conforme o conjunto atinge posições mais inferiores. No entanto, as concentrações atingidas no presente teste foram maiores que no teste da esfera isolada, o que era esperado, visto que agora existem 25 esferas (maior área específica de grãos) fornecendo soluto ao líquido externo. 


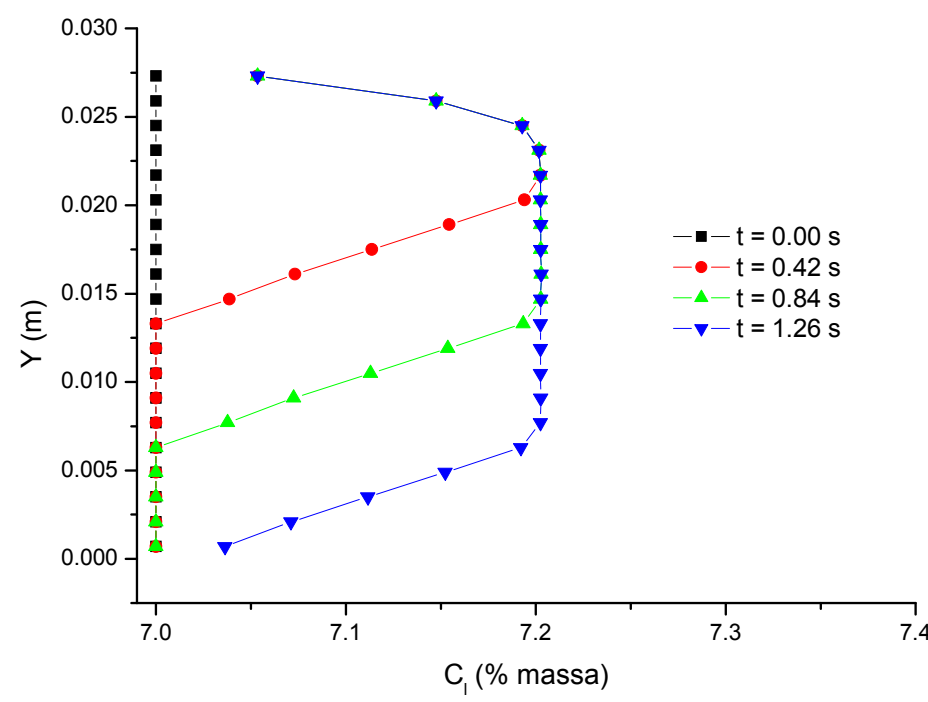

Figura 34 - Perfis de concentração de Si no líquido extradendrítico em função da altura em quatro instantes de tempo diferentes no problema da decantação de um conjunto de esferas porosas.

\subsection{Simulação da Solidificação Isotérmica}

A chamada "solidificação isotérmica" é um tipo idealizado de solidificação onde os gradientes internos de temperatura no interior do sistema são nulos. Este tipo de condição de solidificação já foi simulado por diversos autores (GREER et al, 2000; MAXWELL; HELAWELL, 1975; WANG; BECKERMANN, 1993; LAMEIRAS; MARTORANO; 2007) tanto para o cálculo do tamanho de grão final em uma estrutura bruta de solidificação como simplesmente para avaliar o comportamento de um novo modelo proposto. A análise de um novo modelo torna-se mais simples nesta condição simplificada de ausência de gradientes de temperatura. A situação prática que mais se aproxima destas condições é a solidificação que ocorre durante a análise térmica utilizada na industria do Al para determinação do nível de inoculação do banho metálico.

Neste item, o modelo do presente trabalho foi utilizada para simular a solidificação num sistema de domínio quadrado com solidificação isotérmica (temperatura do domínio é uniforme) para os casos com e sem a movimentação dos grãos. Diferentemente da simulação do item 5.1 , os seguintes efeitos foram considerados no presente item: (a) a temperatura do sistema foi calculada (e não 
imposta) a partir da equação da conservação de energia do modelo, submetida a um fluxo de calor fornecido como condição de contorno; (b) considerou-se o efeito da movimentação relativa do líquido através dos envelopes dendríticos quando estes têm movimento; (c) considerou-se a troca de soluto com o líquido extradendrítico, no qual os grãos estavam imersos; (d) considerou-se o movimento do líquido inter e extradendrítico induzido pela decantação dos grãos.

Dois tipos de simulação foram conduzidos: um para os grãos imóveis, pois para este caso existem resultados de outros modelos disponíveis na literatura, e outro para grãos em movimento de decantação. O segundo caso será utilizado para analisar o efeito da decantação no modelo tradicional de solidificação isotérmica.

\subsubsection{Solidificação Isotérmica com Grãos Fixos}

Neste caso isotérmico, após se desprezarem os gradientes de temperatura, a equação de energia no submodelo macroscópico reduziu-se a:

$$
\frac{\partial\langle T\rangle_{M}}{\partial t}=\dot{T}+\frac{L_{f}}{\rho C_{P}}\left(\Gamma_{s_{M}}+\Gamma_{e_{M}}\right)
$$

onde $\dot{T}$ é a taxa de resfriamento para o sistema imediatamente antes do início da solidificação. A equação da velocidade de crescimento dendrítico também foi modificada para considerar o efeito do enriquecimento em soluto da fase líquida extradendrítica. Neste caso a equação [42] foi substituída por:

$$
\Omega_{C}=\frac{\left(\langle T\rangle_{M}-T_{f}-m_{l}\left\langle C_{l}\right\rangle^{l}\right)}{\left(\langle T\rangle_{M}-T_{f}\right)(1-k)}
$$

Os resultados do modelo serão comparados com os de modelos como o de Wang e Beckermann (1993), determinístico, e de Rappaz e Gandin (1993), estocástico. O modelo de Wang e Beckermann (1993) foi ajustado com a correção de Avrami para considerar a redução de área específica de grãos com o encontro destes durante o crescimento. As condições deste sistema foram definidas em 
Biscuola e Martorano (2007) para examinar o comportamento das equações de conservação para este modelo.

Tabela 7 - Parâmetros da liga Al-5\%Si

\begin{tabular}{cccc}
\hline$C_{0}(\%)$ & 5,0 & $\rho\left(\mathrm{kg} \cdot \mathrm{m}^{-3}\right)$ & 2500,0 \\
$T_{f}$ & 933,0 & $T_{l i q}(\mathrm{~K})$ & 894,5 \\
$L_{f}\left(\mathrm{~J} \mathrm{~kg}^{-1}\right)$ & $372,0.10^{3}$ & $C_{P}\left(\mathrm{~J} . \mathrm{K}^{-1} \mathrm{~kg}^{-1}\right)$ & 921,5 \\
$m_{l}(\mathrm{~K} / \%)$ & $-7,7$ & $k(-)$ & 0,117 \\
$D_{l}\left(\mathrm{~m}^{2} \mathrm{~s}^{-1}\right)$ & $3,0.10^{-9}$ & $\Gamma(\mathrm{m} \cdot \mathrm{K})$ & $9,0.10^{-8}$ \\
\hline
\end{tabular}

Tabela 8 - Parâmetros de entrada para a simulação do caso isotérmico com grãos fixos

\begin{tabular}{cccc}
\hline$L_{x}=L_{y}(\mathrm{~m})$ & 0,001 & $T_{0}(\mathrm{~K})$ & 894,5 \\
Malha de VFs & $1 \times 1$ & Número de células & $200 \times 200$ \\
Taxa de Resfriamento $\dot{T}\left({\left.\mathrm{~K} . \mathrm{s}^{-1}\right)}\right.$ & $-45,0$ & $n_{V}^{*}\left(\mathrm{~m}^{-3}\right)$ & $2,4.10^{8}$ \\
\hline
\end{tabular}

A Figura 35 mostra a evolução da macroestrutura de grãos em diferentes instantes. No instante $t=0,5$ s (Figura 35a), alguns envelopes permanecem isolados no crescimento, enquanto outros cresceram até a interface dos grãos vizinhos. $O$ tamanho de grão permanece aproximadamente o mesmo para todos os grãos, com exceção daqueles que tiveram formato alterado pela supressão de seu crescimento por outros grãos. No instante $t=1,5 \mathrm{~s}$, praticamente, não há mais grãos isolados, diminuindo significativamente a área específica $S_{l d}$ de contato entre os grãos e o líquido externo (extradendrítico), conforme mostra o gráfico na Figura 37. Nos instante $\mathrm{t}=4,0$ s, o domínio já está completamente preenchido por grãos.

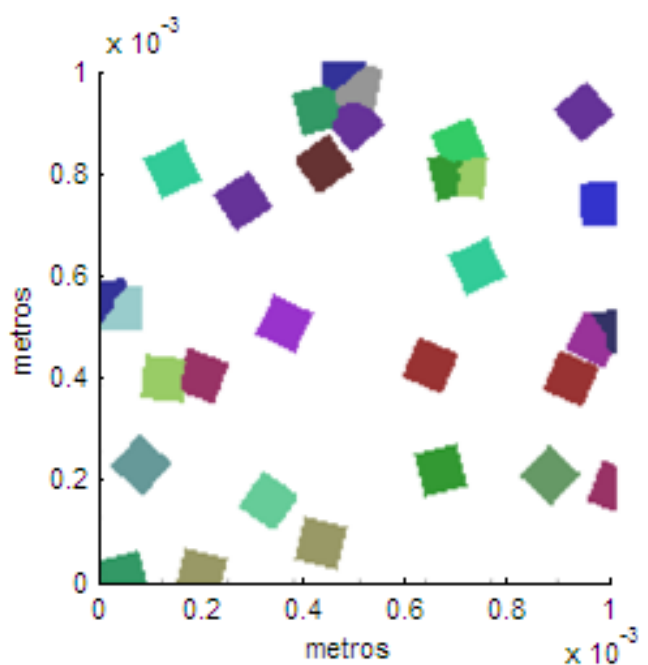

(a)

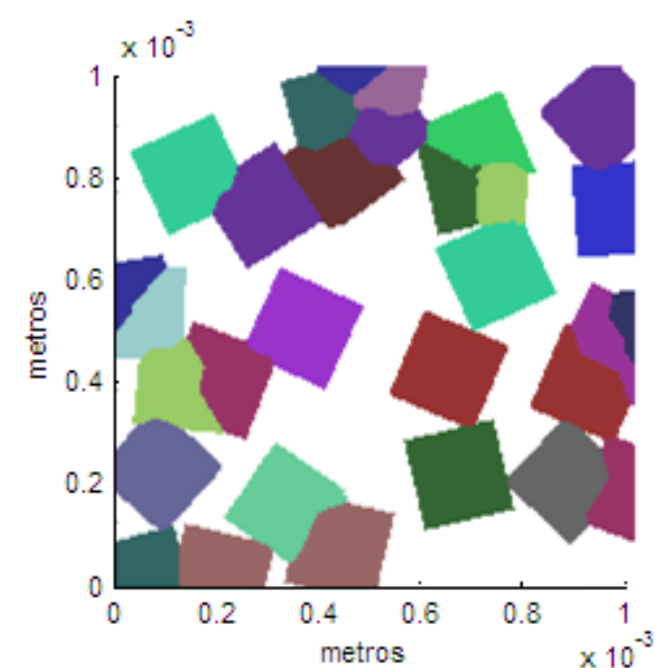

(b) 


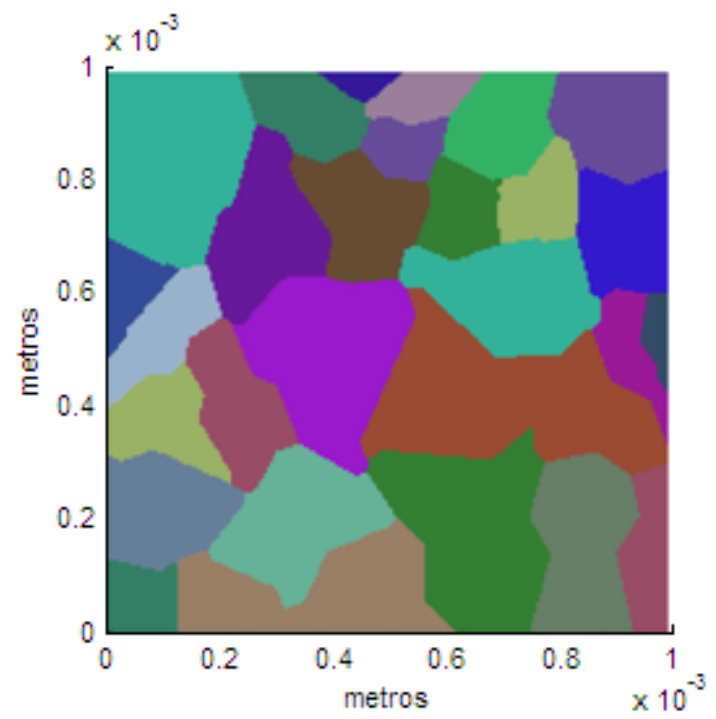

(c)

Figura 35 - Macroestrutura de grãos nos instantes $(a) t=0,5 \mathrm{~s}(\mathrm{~b}) \mathrm{t}=1,5 \mathrm{~s}$ e (c) $t=4,0 \mathrm{~s}$

$\mathrm{Na}$ evolução da temperatura do volume macroscópico (Figura 36), é observado que os três modelos apresentam pontos de recalescência distintos. $O$ modelo atual e o determinístico de Wang e Beckermann (1993) apresentam comportamento semelhante. O modelo estocástico de Rappaz e Gandin (1993) teve um mínimo local de temperatura menor na recalescência, o que está relacionado com as diferenças na fração de sólido formada inicialmente dentro dos grãos (Figura 38) e, portanto, na quantidade liberada de calor latente no início da solidificação, quando se forma a recalescência.

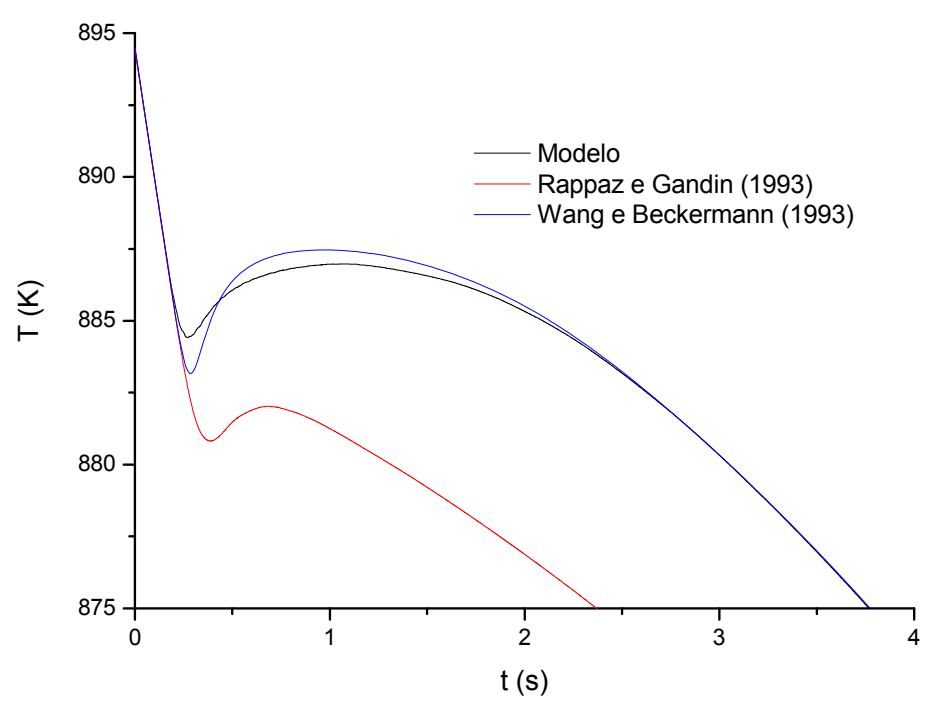

Figura 36 - Evolução da temperatura macroscópica nos modelos examinados. 
A Figura 38 mostra a evolução da fração de sólido nos três modelos. As curvas do modelo atual e do modelo de Wang e Beckermann (1993) são muito próximas, enquanto a fração de sólido para o modelo de Rappaz e Gandin (1993) é sempre menor. A fração volumétrica de grãos, ilustrada na Figura 40 , teve maiores valores inicialmente para o modelo de Rappaz e Gandin (1993), pois este atingiu um maior super-resfriamento neste estágio. Isto mostra que, mesmo com maior quantidade de grãos, a quantidade de sólido formada foi menor, o que implica que a taxa de transformação de fase interna dos grãos é menor neste modelo.

No modelo de Rappaz e Gandin (1993), não há um método de cálculo para a concentração de soluto no líquido extradendrítico e para a área específica de grãos $\left(S_{l d}\right)$, sendo comparados somente o presente modelo e o determinístico de Wang e Beckermann (1993). Na evolução de $\left\langle C_{l}\right\rangle_{M}^{l}$ (Figura 39), as variações iniciais são pequenas, tornando-se significativas apenas quando a fração de grãos se aproxima de $1 \mathrm{em} \mathrm{t}=2,0$ s (Figura 40).

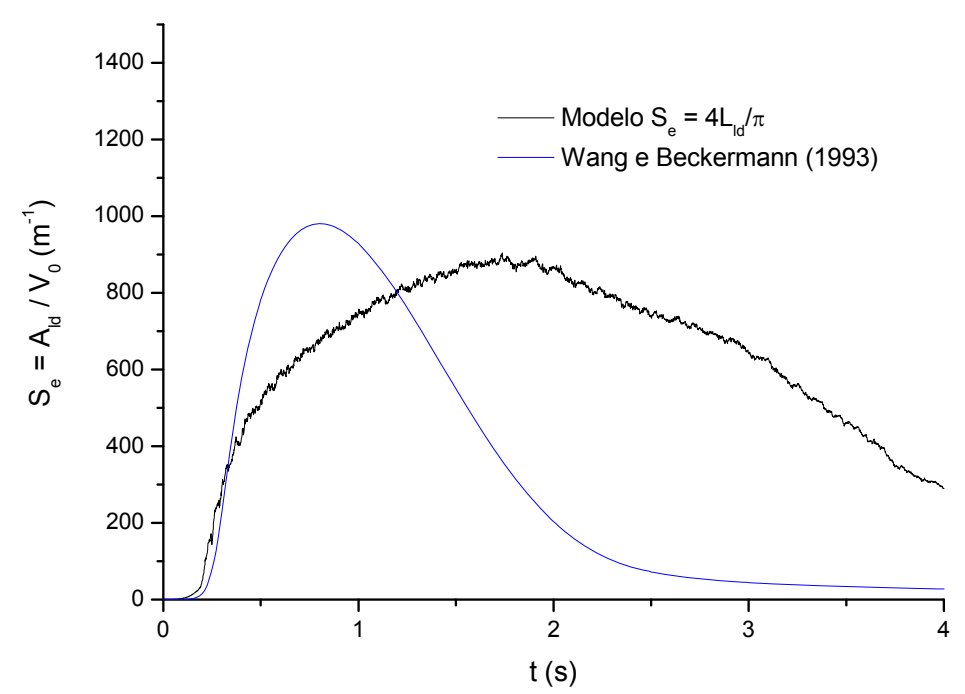

Figura 37 - Evolução da área específica de grãos no modelo atual e no modelo de Wang e Beckermann (1993) com a correção de Avrami. No modelo de Rappaz e Gandin (1993) não há cálculo para $S_{l d}$. 


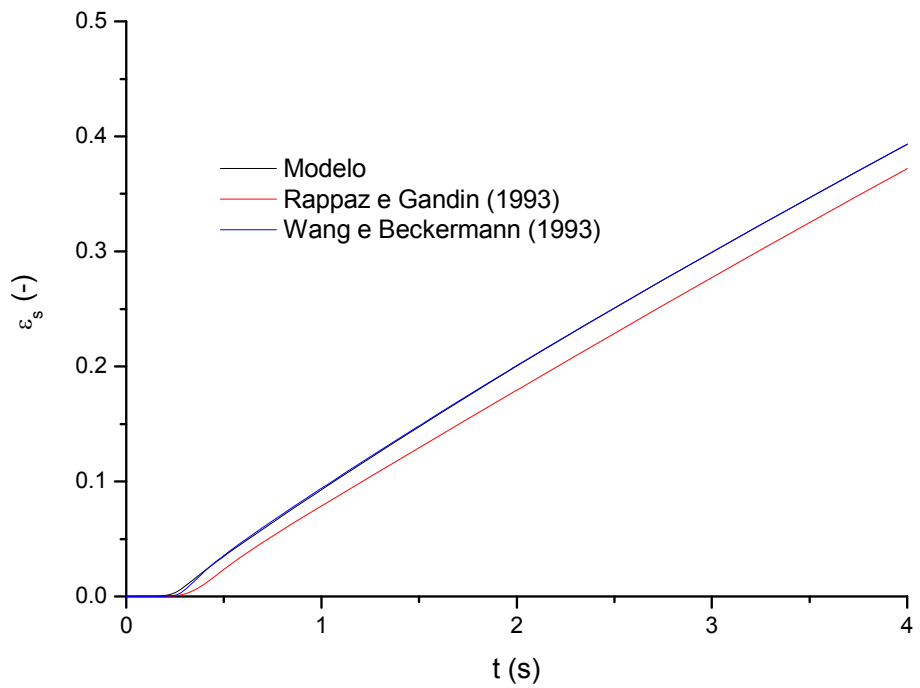

Figura 38 - Evolução fração de fase sólida nos modelos examinados.

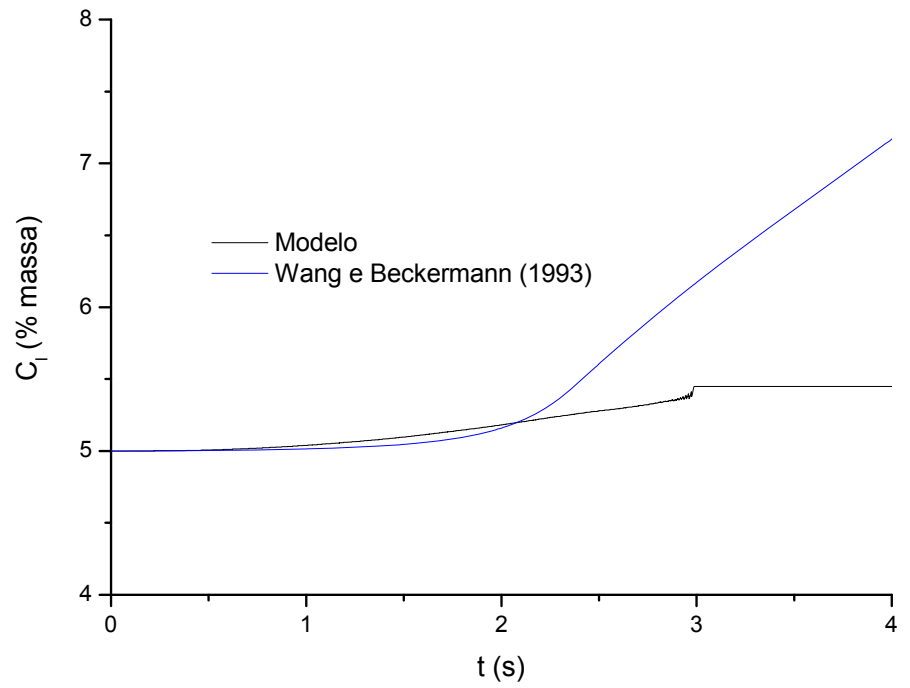

Figura 39 - Evolução da concentração de soluto no líquido extradendrítico para modelos examinados 


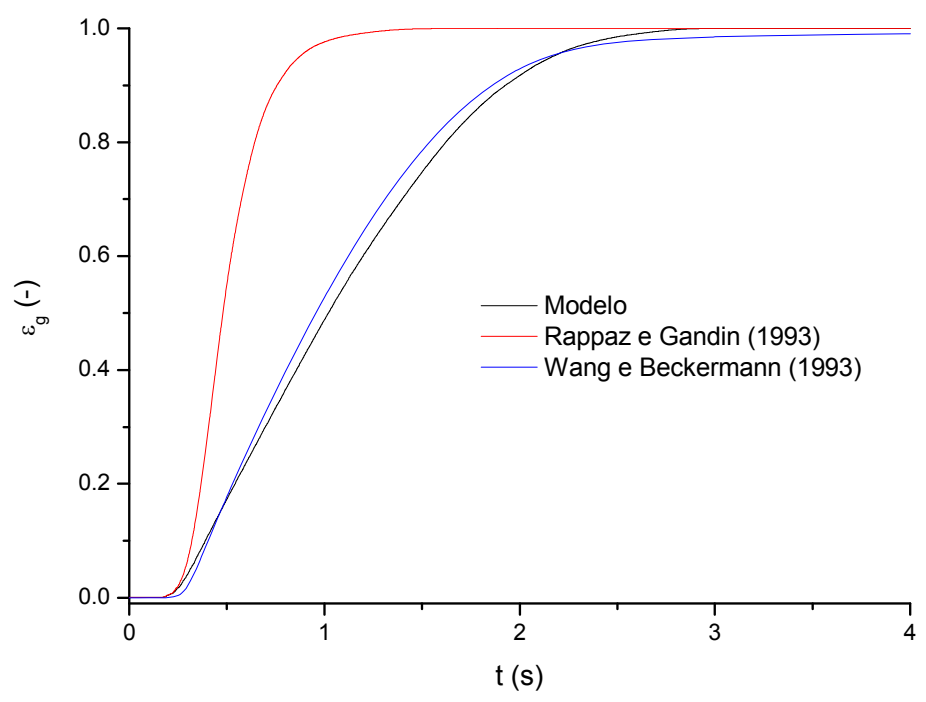

Figura 40 - Evolução da fração de grão $\left(\varepsilon_{g}=1-\varepsilon_{l}\right)$ nos diferentes modelos.

\subsubsection{Solidificação Isotérmica com Grãos em Decantação}

Neste item o efeito da decantação de grãos na solidificação isotérmica foi analisada. Para esta análise, as condições de solidificação foram idênticas às do caso anterior, porém a densidade de número de grãos no sistema foi aumentada para acentuar o efeito da decantação. Desta forma, neste item, além da simulação com o efeito de decantação, foi simulada novamente a solidificação isotérmica sem decantação para possibilitar a comparação entre os resultados.

Para a simulação da solidificação isotérmica com grãos em decantação, inicialmente se considerou que não há gradientes de temperatura e de soluto no líquido extradendrítico e, posterioremente, as equações propostas para o submodelo macroscópico foram reescritas para um referencial móvel com a velocidade média de decantação dos grãos (acompanhando o conjunto de grãos). Na ausência dos gradientes, apenas os termos envolvendo derivadas no tempo são modificados utilizando-se o operador abaixo:

$$
\frac{\partial}{\partial t}=\frac{\partial}{\partial t^{\prime}}-v_{s} \frac{\partial}{\partial y^{\prime}}
$$


Após a alteração de sistema de referência, a equação de conservação de soluto na fase líquida extradendrítica foi reescrita na seguinte forma:

$$
\begin{aligned}
& \varepsilon_{l_{M}} \frac{\partial\left\langle C_{l}\right\rangle_{M}^{l}}{\partial t}+\frac{\partial}{\partial y}\left(\varepsilon_{l_{M}}\left\langle C_{l}\right\rangle_{M}^{l}\left\langle v_{l}^{\prime}\right\rangle_{M}^{l}\right)=\frac{1}{V_{0_{M}}} \int_{A_{d d}}\left\langle C_{d}\right\rangle^{d}\left(\frac{\kappa_{v}\left\langle\vec{v}_{s}\right\rangle_{M}^{s}}{\left(1-\varepsilon_{l_{M}}\right)}\right) \cdot \vec{n}_{l} d A \\
& +\frac{1}{V_{0_{M}}} \int_{A_{d d}}\left(\left\langle C_{d}\right\rangle^{d}-\left\langle C_{l}\right\rangle_{M}^{l}\right)\left(\vec{w}_{g}^{\prime}+\frac{D_{l}}{\delta_{l d}} \vec{n}_{l}\right) \cdot \vec{n}_{l} d A
\end{aligned}
$$

e a equação de conservação da fase líquida extradendrítica como:

$$
\frac{\partial}{\partial y}\left(\varepsilon_{l_{M}}\left\langle v_{l}^{\prime}\right\rangle_{M}^{l}\right)=\frac{1}{V_{0_{M}}} \int_{A_{d d}} \frac{\kappa_{v}\left\langle\vec{v}_{s}\right\rangle_{M}^{s}}{\left(1-\varepsilon_{l_{M}}\right)} \cdot \vec{n}_{l} d A
$$

onde $\left\langle v_{l}^{\prime}\right\rangle_{M}^{l}$ é a velocidade da fase líquida extradendrítica em relação ao novo referencial (conjunto de grãos com a mesma velocidade). A velocidade do conjunto de grãos é calculada através da média entre a velocidade de cada grão no modelo e esta velocidade média é considerada a velocidade do sistema de referência.

Os parâmetros utilizados são semelhantes ao caso de solidificação isotérmica com referencial fixo sem decantação, apenas com a densidade do número de grãos

\begin{tabular}{|c|c|c|c|}
\hline$\rho_{s}\left(\mathrm{~kg} \cdot \mathrm{m}^{-3}\right)$ & 2535,0 & $\rho_{l}\left(\mathrm{~kg} \cdot \mathrm{m}^{-3}\right)$ & 2370,0 \\
\hline$T_{f}$ & 933,0 & $T_{\text {liq }}(\mathrm{K})$ & 894,5 \\
\hline$L_{f}\left(\mathrm{~J} \mathrm{~kg}^{-1}\right)$ & $372,0.10^{3}$ & $C_{P}\left(\mathrm{~J} \mathrm{~K}^{-1} \mathrm{~kg}^{-1}\right)$ & 921,5 \\
\hline$m_{l}(\mathrm{~K} / \%)$ & $-7,7$ & $k(-)$ & 0,117 \\
\hline$D_{l}\left(\mathrm{~m}^{2} \mathrm{~s}^{-1}\right)$ & $3,0.10^{-9}$ & $\Gamma(\mathrm{m} . \mathrm{K})$ & $9,0.10^{-8}$ \\
\hline$L_{x}=L_{y}(\mathrm{~m})$ & 0,001 & $T_{0}(\mathrm{~K})$ & 894,5 \\
\hline Malha de VFs & $1 \times 1$ & Número de células & $200 \times 200$ \\
\hline Taxa de Resfriamento $\dot{T}\left(\mathrm{~K}^{-\mathrm{s}^{-1}}\right)$ & $-45,0$ & $n_{V}^{*}\left(m^{-3}\right)$ & $7,6.10^{9}$ \\
\hline
\end{tabular}
diferente igual a $7,6.10^{9} \mathrm{~m}^{-3}$ (equivalente a 300 grãos distribuídos no domínio):

Tabela 9 - Parâmetros da liga Al-5\%Si. 
A macroestrutura calculada pelo modelo apresenta grãos mais refinados devido a maior densidade de grãos utilizada (Figura 41).

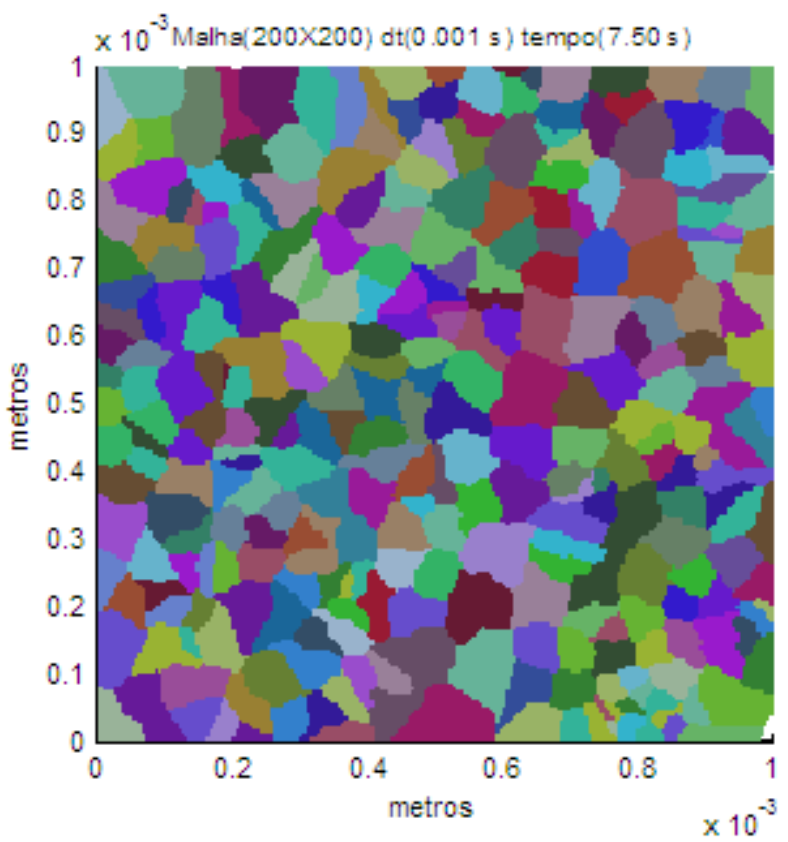

Figura 41 - Macrosestrutura final da simulação do modelo para o caso isotérmico com referencial móvel.

A curva de temperatura (Figura 42), comparando com o modelo com referencial fixo e o modelo determinístico, não apresenta diferença significativa, indicando que a taxa de solidificação foi aproximadamente igual para os três modelos (Figura 43).

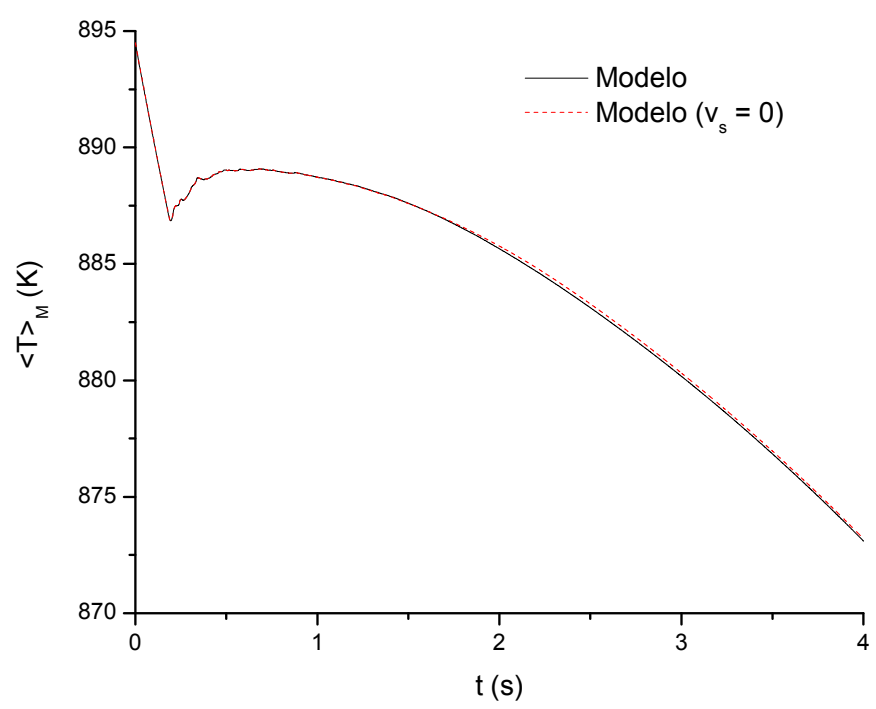

Figura 42 - Comparação da evolução da temperatura do submodelo macroscópico entre o modelo com movimentação, o modelo sem movimentação e o modelo determinístico de envelope com correção de Avrami. 


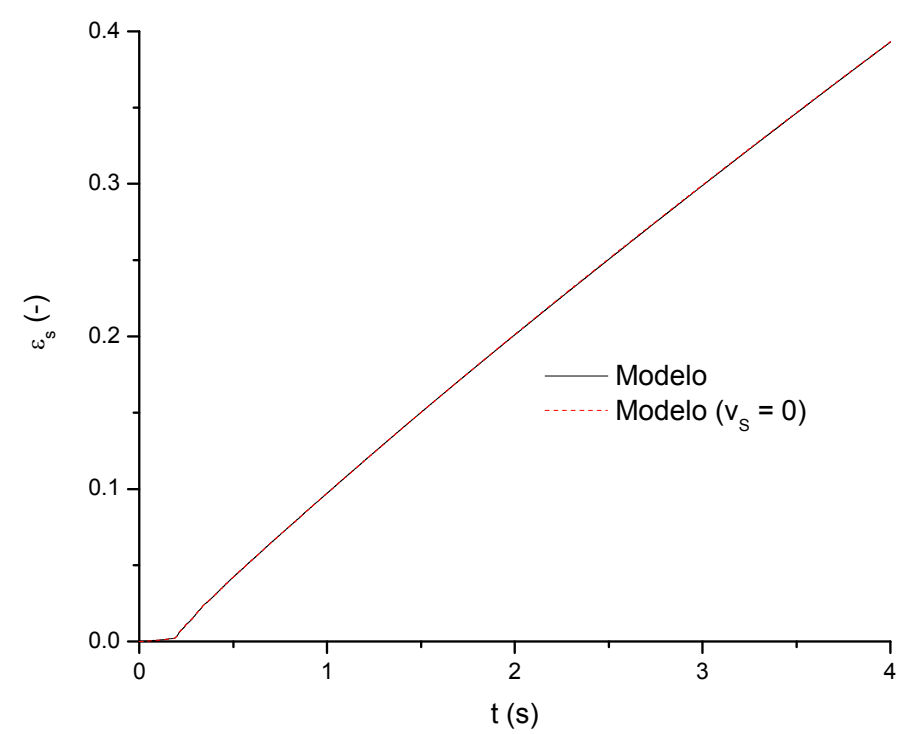

Figura 43 - Comparação da evolução da fração de sólido dos três modelos analisados

A evolução da concentração de soluto no líquido extradendrítico $\left\langle C_{l}\right\rangle_{M}^{l}$ (Figura 44) mostra que a decantação resulta em maiores concentrações de soluto no líquido extradendrítico. Este aumento é resultado de um maior fluxo de soluto que os envelopes de grão rejeitam para o líquido, porque a velocidade relativa do líquido diminui a espessura efetiva de difusão ao redor dos envelopes.

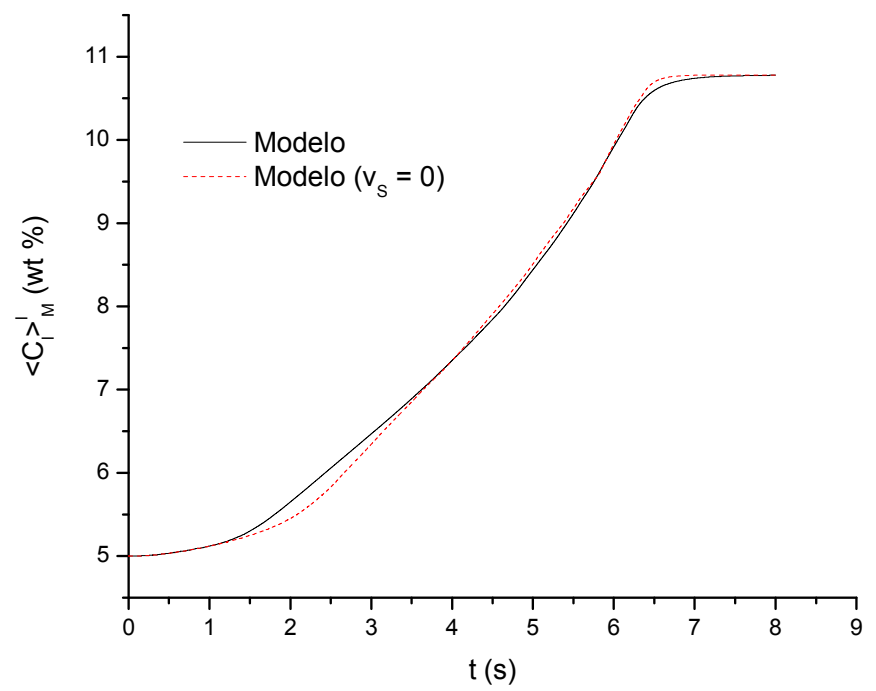

Figura 44 - Comparação da evolução da concentração de soluto na fase líquida extradendrítica para os diferentes modelos. 
No gráfico que apresenta a evolução da interface específica $S_{l d}$ de interface dos grãos com o líquido extradendrítico, é mostrado que no caso do presente modelo esta interface é inicialmente maior, mas ocorre uma brusca diminuição devido ao encontro de grãos que nuclearam muito próximos uns aos outros. Em seguida, esta quantidade de interface volta a aumentar atingindo um máximo, a partir do qual ela começa a decrescer até o valor nulo, quando todos os grãos já se esbarraram.

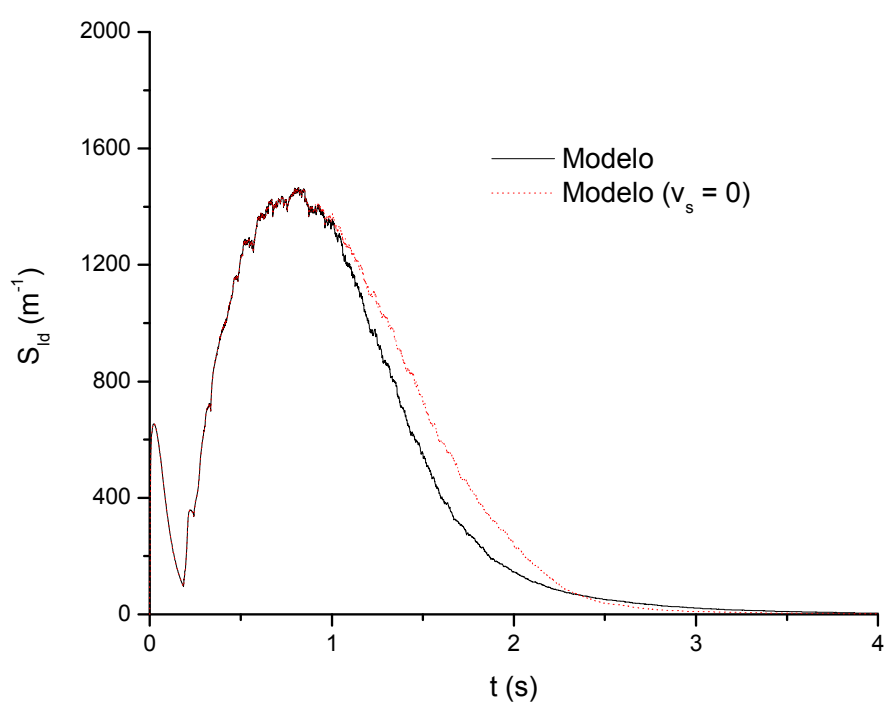

Figura 45 - Comparação da evolução da área específica de grãos $S_{l d}$ dos três modelos analisados.

A concentração de soluto na fase líquida extradendrítica diminui o crescimento progressivamente, sendo a fração de grãos $\varepsilon_{g_{M}}$ menor no modelo com o efeito da decantação (Figura 46). 


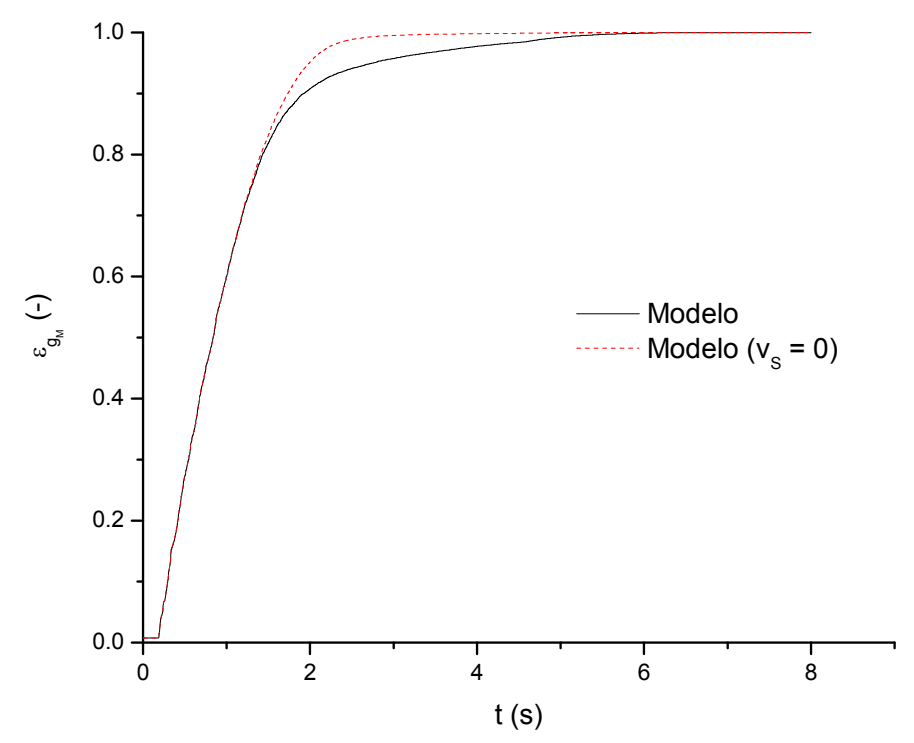

Figura 46 - Comparação da evolução da fração de grão $\varepsilon_{g_{M}}$

O modelo com decantação calcula a velocidade da fase líquida interdendrítica enquanto o conjunto de grãos se movimenta (Figura 47). Quanto maior a diferença entre esta velocidade e a velocidade de decantação dos grãos (velocidade relativa do líquido), mais intenso é o escoamento de líquido através dos grãos. Os resultados mostram que o aumento da fração de grãos em funçao do tempo causado pelo crescimento resulta em um aumento da velocidade relativa do líquido interdendrítico. Esta simulação mostra que esta velocidade relativa não é significativa nos estágios iniciais da solidificação (fração de grãos menor), o que significa que o grão move-se como se fosse um único conjunto de sólido e líquido. No entanto, velocidades relativas significativas através dos grãos aparecem conforme os grãos crescem. 


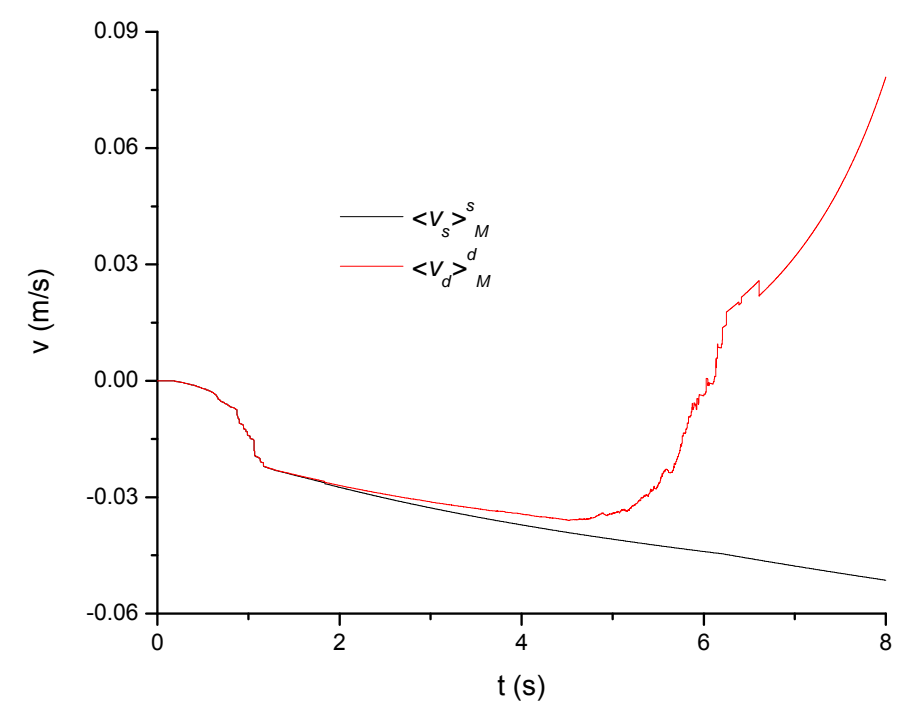

Figura 47 - Evolução da velocidade do referencial $\left\langle v_{s}\right\rangle_{M}^{s}$ e velocidade da fase líquida interdendrítica $\left\langle v_{d}\right\rangle_{M}^{d}$ para o modelo com referencial móvel.

\subsection{Solidificação Unidirecional}

Neste item, serão apresentados um teste de refino de malha numérica, e os resultados de duas simulações da solidificação unidirecional: uma para a solidificação vertical ascendente e outra parta a solidificação vertical descendente, originada no topo do domínio. Nestes testes, utilizaram-se os mesmo dados de entrada e parâmetros empregados por Wang e Beckermann (1994) para simular a solidificação da liga Al-3\%Cu através de um modelo determinístico, apresentados na Tabela 11 e na Tabela 12.

No interior do domínio de cálculo, que foi retangular com dimensões $5 \mathrm{~cm} \mathrm{x}$ $10 \mathrm{~cm}$, inicialmente existia líquido de temperatura uniforme igual a $20 \mathrm{~K}$ acima da temperatura liquidus da liga. A troca de calor ocorreu apenas ou pela base (solidificação ascendente), ou pelo topo (solidificação descendente), ou seja, a parede lateral foi assumida adiabática para se ter características de solidificação unidirecional. O coeficiente de transferência de calor entre o metal e a base ou entre o metal e o topo foi assumido igual a $65 \mathrm{Wm}^{-2} \mathrm{~K}^{-1}$. Uma densidade de número de grãos igual a $10^{5} \mathrm{~m}^{-3}$ foi assumida no interior do líquido, enquanto uma densidade de $3,8 \times 10^{6} \mathrm{~m}^{-2}$ foi assumida na superfície onde o calor foi extraído. Considerou-se por 
conveniência que os grãos nucleavam exatamente na temperatura liquidus, ou seja, o super-resfriamento para a nucleação foi igual a $0 \mathrm{~K}$.

Tabela 11 - Parâmetros da liga Al-3\%Cu

\begin{tabular}{cccc}
\hline$C_{0}(\%)$ & 3,0 & $\rho_{s}\left(\mathrm{~kg} \cdot \mathrm{m}^{-3}\right)$ & 2633,2 \\
$T_{l i q}(\mathrm{~K})$ & 922,89 & $\rho_{l}\left(\mathrm{~kg} \cdot \mathrm{m}^{-3}\right)$ & 2370,0 \\
$T_{f}$ & 933,0 & $T_{e}(\mathrm{~K})$ & 821,0 \\
$L_{f}\left(\mathrm{~J} \cdot \mathrm{kg}^{-1}\right)$ & $382,0.10^{3}$ & $C_{P}\left(\mathrm{~J} \cdot \mathrm{K}^{-1} \mathrm{~kg}^{-1}\right)$ & 1291,2 \\
$m_{l}(\mathrm{~K} / \%)$ & $-3,37$ & $k(-)$ & 0,17 \\
$D_{l}\left(\mathrm{~m}^{2} \mathrm{~s}^{-1}\right)$ & $5,0.10^{-9}$ & $\Gamma(\mathrm{m} \cdot \mathrm{K})$ & $9,8.10^{-8}$ \\
$K_{s}\left(\mathrm{Wm}^{-1} \mathrm{~K}^{-1}\right)$ & 153,0 & $K_{l}\left(\mathrm{Wm}^{-1} \mathrm{~K}^{-1}\right)$ & 77,0 \\
$\mu_{l}$ (Pa.s $)$ & 0,001 & $\lambda_{2}(\mathrm{~m})$ & $10^{-5}$ \\
\hline
\end{tabular}

Tabela 12 - Parâmetros de entrada para a simulação do caso de solidificação unidirecional

\begin{tabular}{cccc}
$L_{x}(\mathrm{~m})$ & 0,05 & $L_{y}(\mathrm{~m})$ & 0,1 \\
Número de VFs & $1 \times 20$ & Número de células & $110 \times 220$ \\
$h_{\infty}\left(\mathrm{Wm}^{-2} \mathrm{~K}^{-1}\right)$ & 65,0 & $T_{0}(\mathrm{~K})$ & 942,89 \\
$n_{A}^{*}\left(\mathrm{~m}^{-2}\right)$ & $3,8.10^{6}$ & $n_{V}^{*}\left(\mathrm{~m}^{-3}\right)$ & $10^{5}$ \\
\hline
\end{tabular}

\subsubsection{Análise da Malha Numérica}

Para o teste de refino da malha, foi utilizado um valor maior de concentração de núcleos $\left(n_{V}^{*}=10^{7}\right)$ para possibilitar uma análise mais rigorosa do efeito do tamanho da malha na imagem da macroestrutura de grãos.

Foram realizados testes para três malhas distintas, cujas dimensões da célula de CA são: $\Delta x_{C A}=10^{-3} \mathrm{~m}, \Delta x_{C A}=5,0 \times 10^{-4} \mathrm{~m}$ e $\Delta x_{C A}=10^{-4} \mathrm{~m}$. As macroestruturas resultantes não apresentaram diferença significativa quanto à posição da CET (identificada qualitativamente na Figura 48), apenas com diferença quanto à resolução da imagem dos grãos. A zona de grãos alongados acima da zona de grãos equiaixiais aparece no modelo em alguns casos devido à pequena quantidade de grãos equiaxiais nesta região. Esta ausência foi causada pela decantação e sedimentação dos grãos 


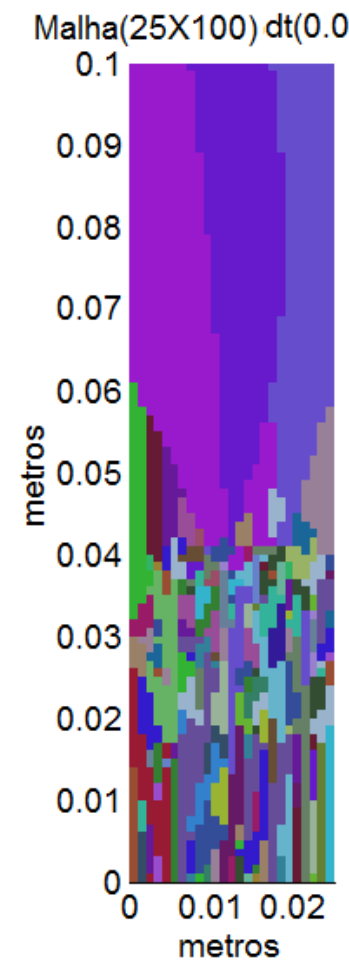

(a)

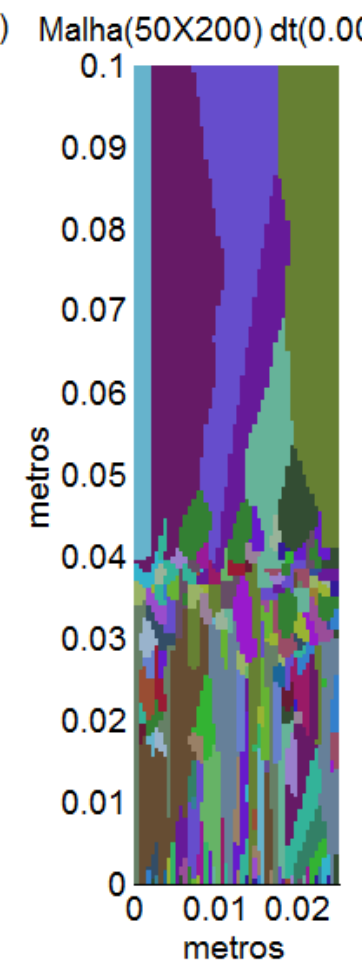

(b)

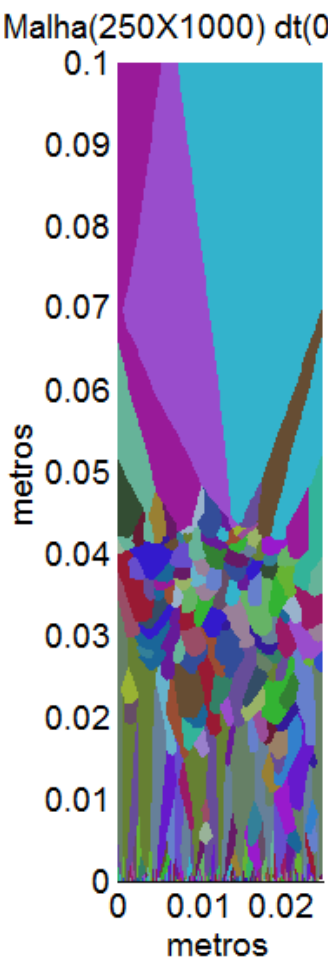

(c)

Figura 48 - Macroestruturas finais para o caso de solidificação unidirecional ascendente com diferentes malhas: (a) $\Delta x_{C A}=10^{-3} \mathrm{~m}$ (b) $\Delta x_{C A}=5 \times 10^{-4} \mathrm{~m}$ (c) $\Delta x_{C A}=10^{-4} \mathrm{~m}$

Nestes casos, para as diferentes malhas de células do CA, não há diferenças significativas na macroestrutura, e portanto nos fenômenos de crescimento e movimentação.

\subsubsection{Solidificação Unidirecional Ascendente}

A solidificação unidirecional ascendente da liga $\mathrm{Al}-3 \% \mathrm{Cu}$ foi simulada utilizando-se o modelo desenvolvido no presente trabalho. A macroestrutura de grãos fornecida pelo modelo está apresentada na Figura 49a, onde se observam apenas grãos colunares que cresceram a partir da base e atingiram o topo, passando pelo bem conhecido período de competição entre grãos. Não há transição colunar-equiaxial. Outra simulação foi conduzida eliminando-se a decantação dos grãos e a convecção do líquido, resultando na macroestrutura apresentada na Figura 49b. 


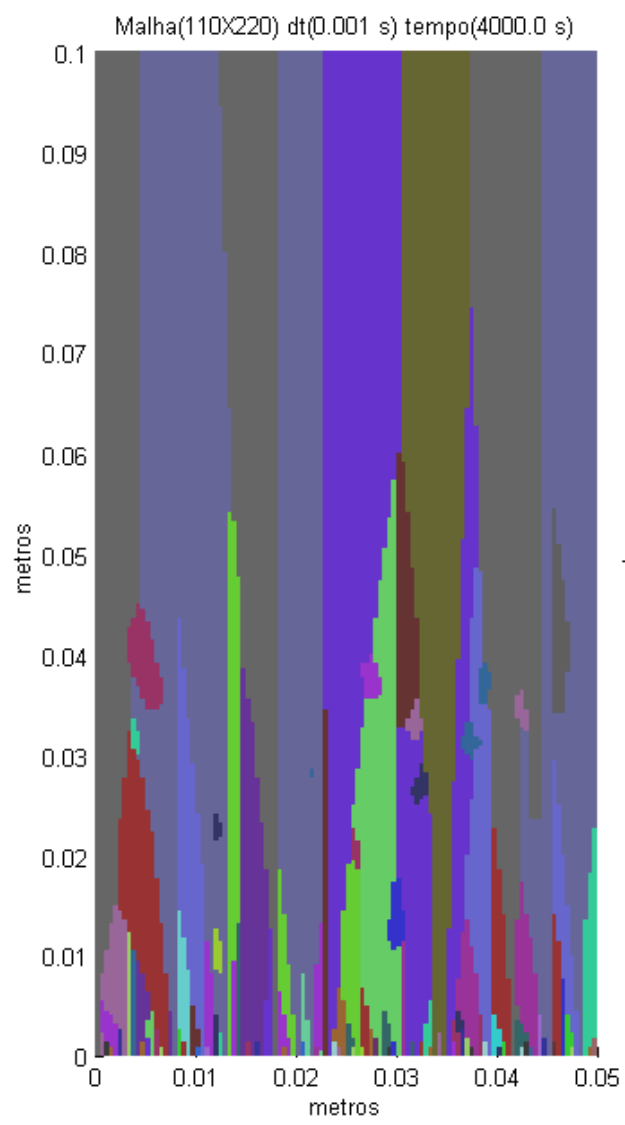

(a)

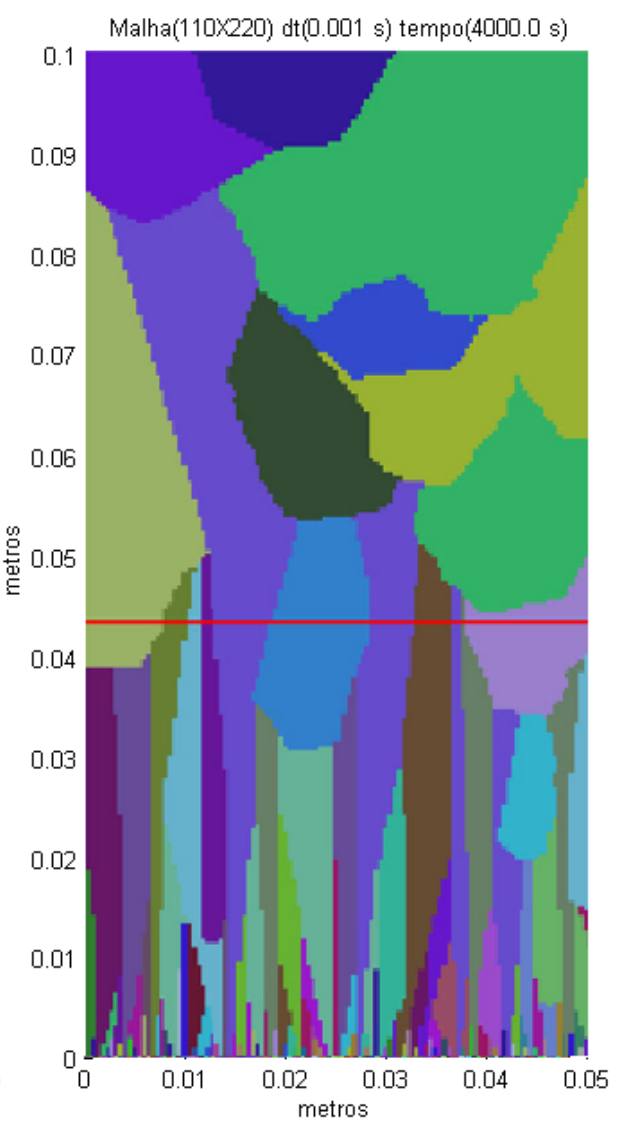

(b)

Figura 49 - Macroestrutura de grãos calculada para a solidificação unidirecional da liga Al-3\%Cu:

(a) considerando o efeito de decantação de grãos; (b) efeito de decantação dos grãos não foi considerado. A linha vermelha horizontal é a posição da transição colunar-equiaxial prevista pelo modelo de Wang e Beckermann (1994) para o caso sem decantação

Nota-se uma diferença significativa quando a convecção dos grãos não é considerada. Neste caso, os grãos colunares foram bloqueados pelos grãos equiaxiais e a transição colunar-equiaxial ocorreu. Como mencionado, quando a decantação de grãos é considerada, não existe a transição, pois os grãos equiaxiais decantam e atingem a frente de crescimento colunar mais rapidamente, quando ainda têm um tamanho relativamente pequeno. Este tamanho não é suficiente para causar o bloqueio da frente e resultar na transição colunar-equiaxial. A linha horizontal vermelha traçada na Figura 49b mostra a posição da transição colunarequiaxial calculada por Wang e Beckermann (1994) através de um modelo completamente determinístico, onde não foi considerada a decantação dos grãos. Nota-se também que o modelo implementado no presente trabalho, sem considerar a decantação de grãos, forneceu um resultado muito semelhante para a posição da CET. 
Na Figura 50, está apresentada uma macroestrutura calculada pelo modelo implementado (considerando a decantação) no instante $t=450,0 \mathrm{~s}$, ou seja, durante a solidificação. Nota-se que, neste instante, a macroestrutura de grãos é composta apenas de grãos colunares, com alguns pequenos grãos equiaxiais no líquido à frente dos grãos colunares.

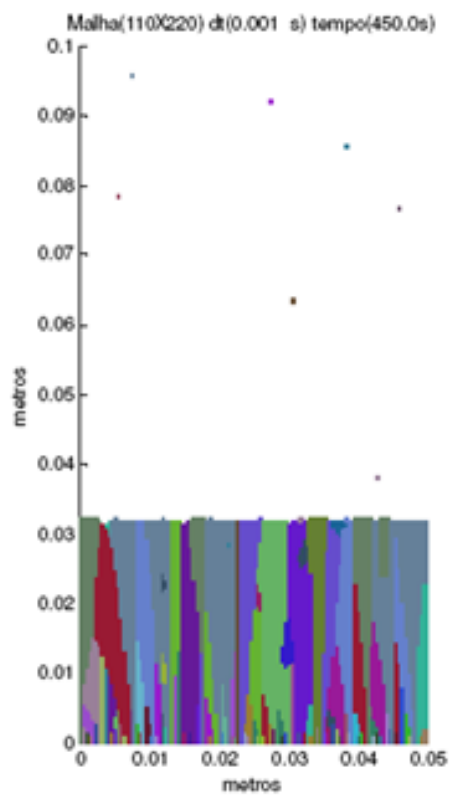

(a)

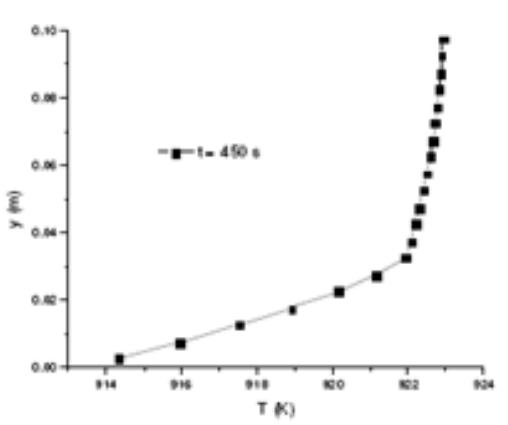

(b)

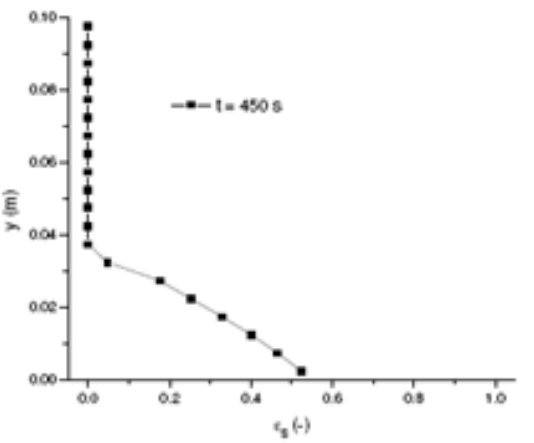

(c)

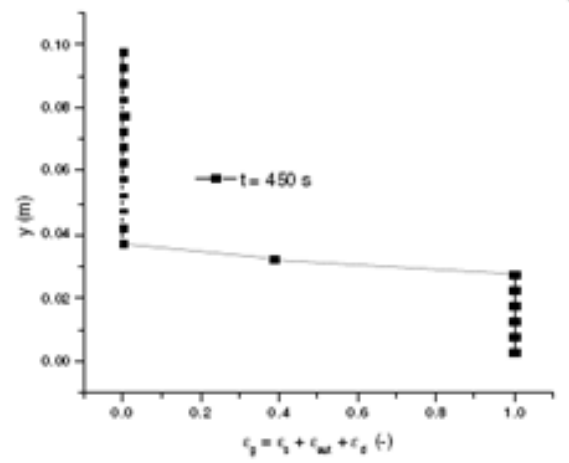

(d)

Figura 50 - (a) Macroestrutura de grãos calculada para a solidificação unidirecional ascendente da liga Al- $3 \%$ Cu no instante $t=450,0$ s considerando o efeito de decantação de grãos. À direita, os perfis de (b) temperatura, (c) fração de sólido e (d) fração de grãos correspondente à macroestrutura à esquerda.

Nos itens (b), (c) e (d) na Figura 50, são apresentados os perfis de temperatura, fração de sólido e fração de grãos correspondentes à macroestrutura da Figura 50a. Uma mudança brusca de temperatura e fração de sólido ocorre exatamente na posição donde está a frente de crescimento colunar, como esperado.

\subsubsection{Solidificação Unidirecional Descendente}

A solidificação unidirecional descendente nas mesmas condições de extração de calor utilizadas na solidificação ascendente foi simulada empregando-se o 
modelo implementado. A macroestrutura final calculada pelo modelo está apresentada na Figura 51. Ao comparar esta macroestrutura com aquelas apresentada na Figura 49, pode-se verificar o efeito mais acentuado da decantação dos grãos no presente caso. Observa-se a formação de grãos colunares que cresceram a partir do topo, onde a solidificação se iniciou devido à extração de calor pelo domínio superior, porém, existe uma camada de grãos formada na região inferior, causada pela deposição de grãos equiaxiais que decantaram e posteriormente cresceram, encontrando a frente descendente de grãos colunares.

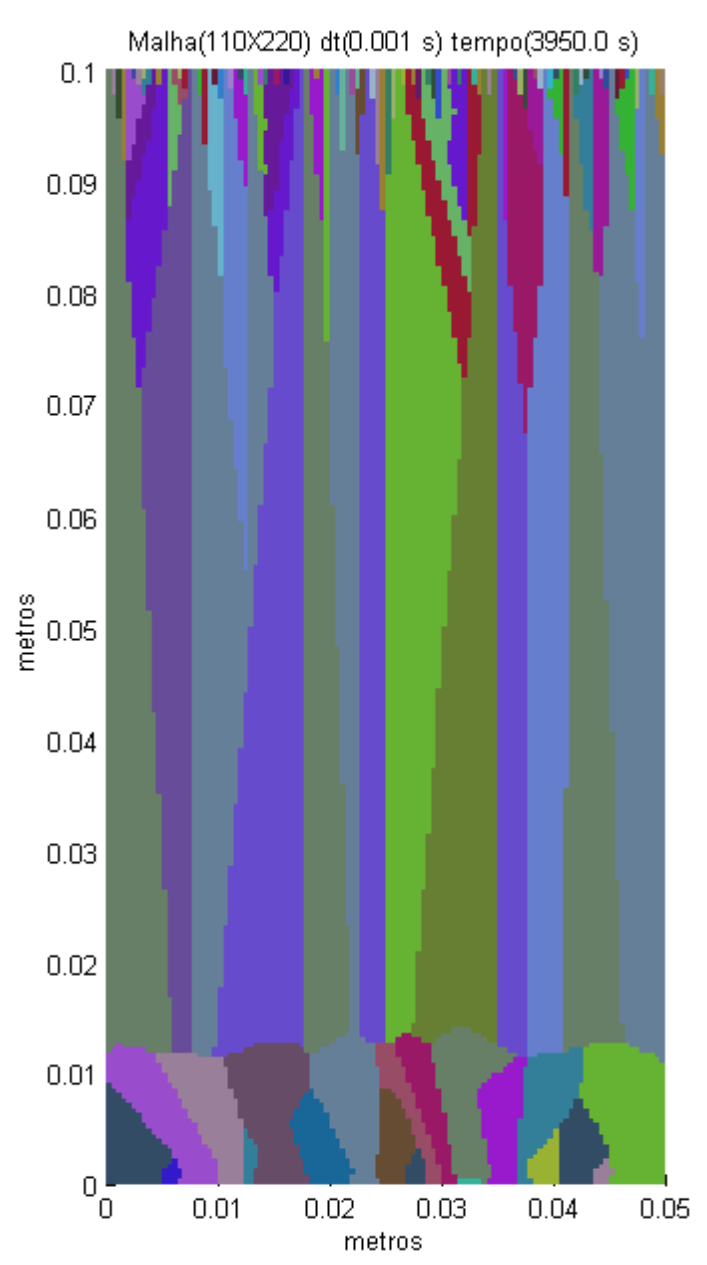

Figura 51 - Macroestrutura final de grãos calculada para a solidificação unidirecional descendente da liga $\mathrm{Al}-3 \% \mathrm{Cu}$.

Na Figura 52a, está mostrada uma macroestrutura calculada para o instante $t=450,0 \mathrm{~s}$, durante $\mathrm{o}$ processo de solidificação unidirecional descendente. Observam-se os grãos colunares crescendo e diversos pequenos grãos equiaxiais decantando para o contorno inferior. Estes grãos formarão a camada de grãos do contorno inferior mostrada na Figura 51. Os perfis de temperatura, de fração de 
sólido e de fração de grãos correspondentes estão mostrados na Figura 52 (b), (c) e (d) respectivamente. Estes perfis são muitos semelhantes aos apresentados na Figura 50 para a solidificação ascendente, porém, invertido no eixo das ordenadas. No entanto, nota-se no perfil de fração de grãos, a presença de uma pequena fração de grãos a uma distância de aproximadamente $2 \mathrm{~cm}$ da base. Esta fração é correspondente aos grãos que estão decantando no líquido.

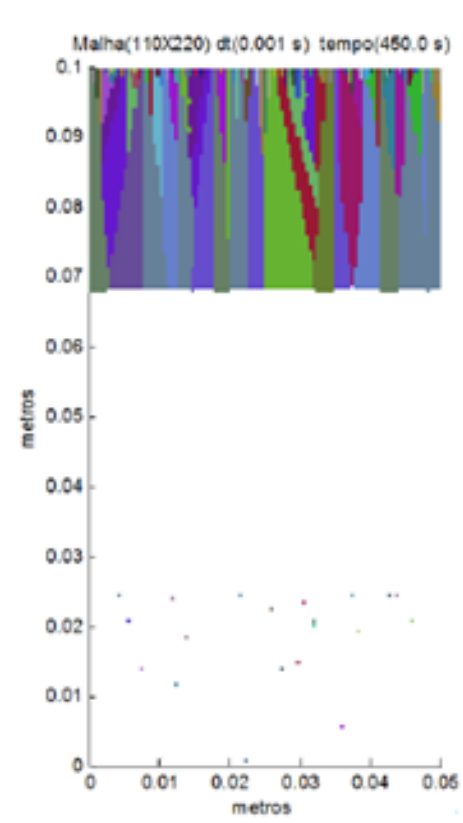

(a)

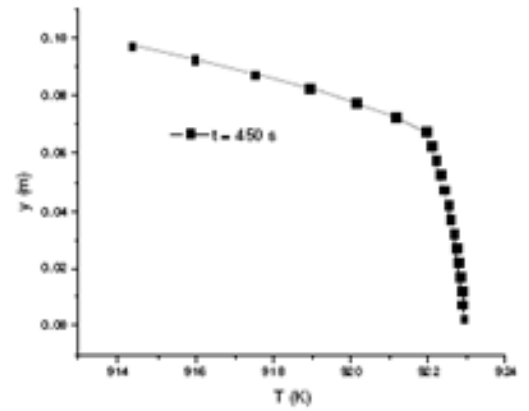

(b)

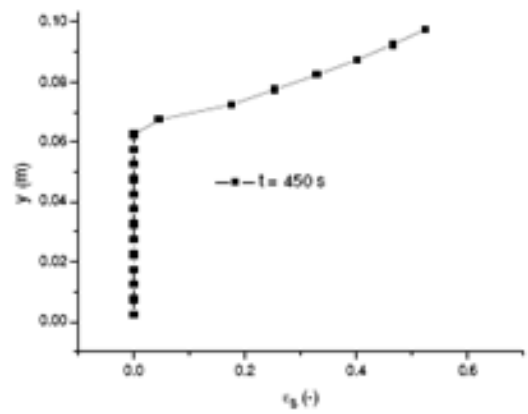

(c)

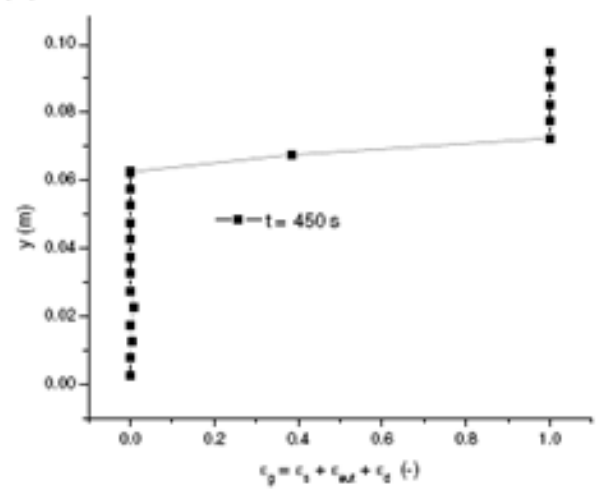

(d)

Figura 52 - (a) Macroestrutura de grãos calculada para a solidificação unidirecional descendente da liga Al-3\%Cu no instante $t=450,0$ s considerando o efeito de decantação de grãos. À direita, os perfis de (b) temperatura, (c) fração de sólido e (d) fração de grãos correspondente à macroestrutura à esquerda

No caso da solidificação descendente, há uma disputa entre a velocidade de crescimento colunar e a velocidade de decantação dos grãos equiaxiais para haver a formação de CET. Com os parâmetros utilizados, os grãos equiaxiais se depositaram na base do molde antes que a zona colunar os "capturasse", formando assim duas zonas colunares distintas: Uma originada da parede em que ocorre a extração de calor, e a outra dos grãos equiaxiais depositados na parede inferior e que posteriormente cresceram no formato colunar. 


\subsection{Efeito da Distribuição de Super-resfriamentos}

O presente modelo possibilita a utilização de uma distribuição normal de super-resfriamentos para modelar a nucleação de grãos. Para avaliar o efeito dos diferentes parâmetros da distribuição de super-resfriamento em conjunto com a decantação, foi realizada uma comparação com as simulações descritas por Martorano e Biscuola (2009) (Tabela 13 e Tabela 14), que não consideraram o efeito de decantação dos grãos. Os parâmetros para a distribuição normal de superresfriamento neste trabalho foram: super-resfriamento médio $\overline{\Delta T_{N}}=2,0 \mathrm{Ke}$ $\overline{\Delta T_{N}}=5,0 \mathrm{~K}$, com desvio-padrão $\Delta T_{\sigma}$ variando entre $0 \mathrm{~K}$ e 3,0K.

Tabela 13 - Parâmetros da liga Al-7\%Si utilizados

\begin{tabular}{cccc}
\hline$C_{0}(\%)$ & 7,0 & $\rho_{s}\left(\mathrm{~kg} \cdot \mathrm{m}^{-3}\right)$ & 2452,0 \\
$T_{\text {liq }}(\mathrm{K})$ & 891,0 & $\rho_{l}\left(\mathrm{~kg} \cdot \mathrm{m}^{-3}\right)$ & 2370,0 \\
$T_{f}$ & 933,0 & $T_{e}(\mathrm{~K})$ & 850,0 \\
$L_{f}\left(\mathrm{~J} \cdot \mathrm{kg}^{-1}\right)$ & $387,4.10^{3}$ & $C_{P}\left(\mathrm{~J} \cdot \mathrm{K}^{-1} \mathrm{~kg}^{-1}\right)$ & 1126,0 \\
$m_{l}(\mathrm{~K} / \%)$ & $-6,5$ & $k(-)$ & 0,13 \\
$D_{l}\left(\mathrm{~m}^{2} \mathrm{~s}^{-1}\right)$ & $6,45.10^{-9}$ & $\Gamma(\mathrm{m} \cdot \mathrm{K})$ & $1,96 \cdot 10^{-7}$ \\
$K_{s}\left(\mathrm{Wm}^{-1} \mathrm{~K}^{-1}\right)$ & 137,5 & $K_{l}\left(\mathrm{Wm}^{-1} \mathrm{~K}^{-1}\right)$ & 60,5 \\
$\mu_{l}(\mathrm{~Pa} \cdot \mathrm{s})$ & 0,001 & $\lambda_{2}(\mathrm{~m})$ & $10^{-5}$ \\
\hline
\end{tabular}

Tabela 14 - Parâmetros de entrada para a simulação do caso de solidificação unidirecional

$\begin{array}{cccc}L_{x}(\mathrm{~m}) & 0,05 & L_{y}(\mathrm{~m}) & 0,15 \\ \text { Número de VFs } & 1 \times 30 & \text { Número de células } & 100 \times 300 \\ h_{\infty}\left(\mathrm{Wm}^{-2} \mathrm{~K}^{-1}\right) & 250,0 & T_{0}(\mathrm{~K}) & 991,0 \\ n_{A}^{*}\left(\mathrm{~m}^{-2}\right) & 3,0.10^{6} & n_{V}^{*}\left(\mathrm{~m}^{-3}\right) & 5,0.10^{6}\end{array}$

Foi utilizada a equação abaixo para o cálculo da velocidade do crescimento dendrítico também utilizada por Martorano e Biscuola (2009), em substituição a equação Eq. [41]:

$$
\left|\vec{w}_{g}^{\prime}\right|=A_{C_{0}} \Delta T^{m}
$$

com $A_{C_{0}}=3 \times 10^{-6} \mathrm{~m} \mathrm{~s}^{-1} \mathrm{~K}^{-2,7}$ e $m=2,7$ para a liga Al-7\%Si. 
Para a distribuição normal com $\overline{\Delta T_{N}}=2,0 \mathrm{~K}$, as macroestruturas calculadas pelo modelo (Figura 53) apresentaram posição da CET constante com a variação da largura da distribuição $\left(\Delta T_{\sigma}\right)$, enquanto que, no modelo sem decantação (MARTORANO; BISCUOLA, 2009), houve variação da posição da CET. Isto implica que, para este caso, o a decantação diminui o efeito do desvio-padrão de superresfriamento.

A decantação foi apontada em outra simulação neste trabalho (item 5.4.2) como responsável por diminuir a zona equiaxial em casos de solidificação unidirecional ascendente, o que é também verificado em todas as macroestruturas apresentadas. A região de grãos alongados acima da zona de grãos equiaxiais pode ser um problema do modelo (pois não constam resultados experimentais com macroestruturas semelhantes), que aparece, pois a região superior resta sem substratos para a nucleação no final da solidificação, enquanto que, experimentalmente sempre existem substratos para a nucleação heterogênea. $\mathrm{Na}$ literatura, ainda não foi examinado o efeito da decantação na CET concomitantemente com o efeito da distribuição de super-resfriamentos. 

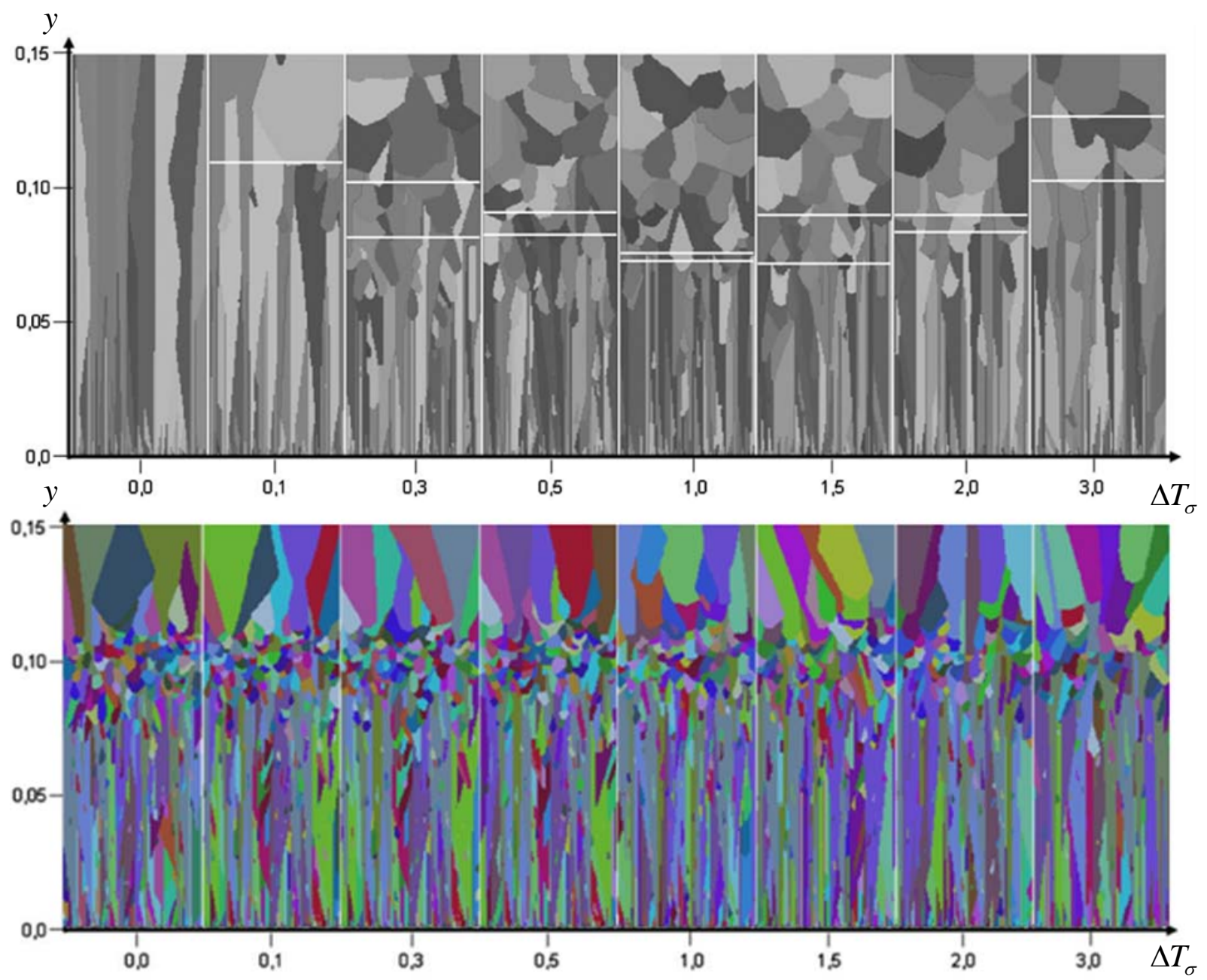

Figura 53 - Comparação entre as macroestruturas fornecidas no trabalho de Martorano e Biscuola (2009) (sequência acima) e as calculadas pelo presente modelo (seqüência abaixo) para $\overline{\Delta T_{N}}=2 \mathrm{~K}$, com o desvio-padrão $\Delta T_{\sigma}$ variando entre $0,0 \mathrm{~K}$ e 3,0 K.

Para a distribuição normal com $\overline{\Delta T_{N}}=5,0 \mathrm{~K}$, no trabalho de Martorano e Biscuola (2009), há CET logo para o caso de $\Delta T_{\sigma}$ próximo de 0,1 , enquanto que, para o presente modelo, só há uma zona equiaxial distinta a partir de desviopadrões com valor próximos de 1,0 K (Figura 54). Para o valor de desvio-padrão igual a 3,0 K, a posição da CET calculada pelo modelo com decantação está abaixo da posição calculada pelo modelo de CA sem decantação, mostrando que para algumas condições, a decantação contribui para uma zona equiaxial maior quando comparada ao modelo difusional (sem convecção). 

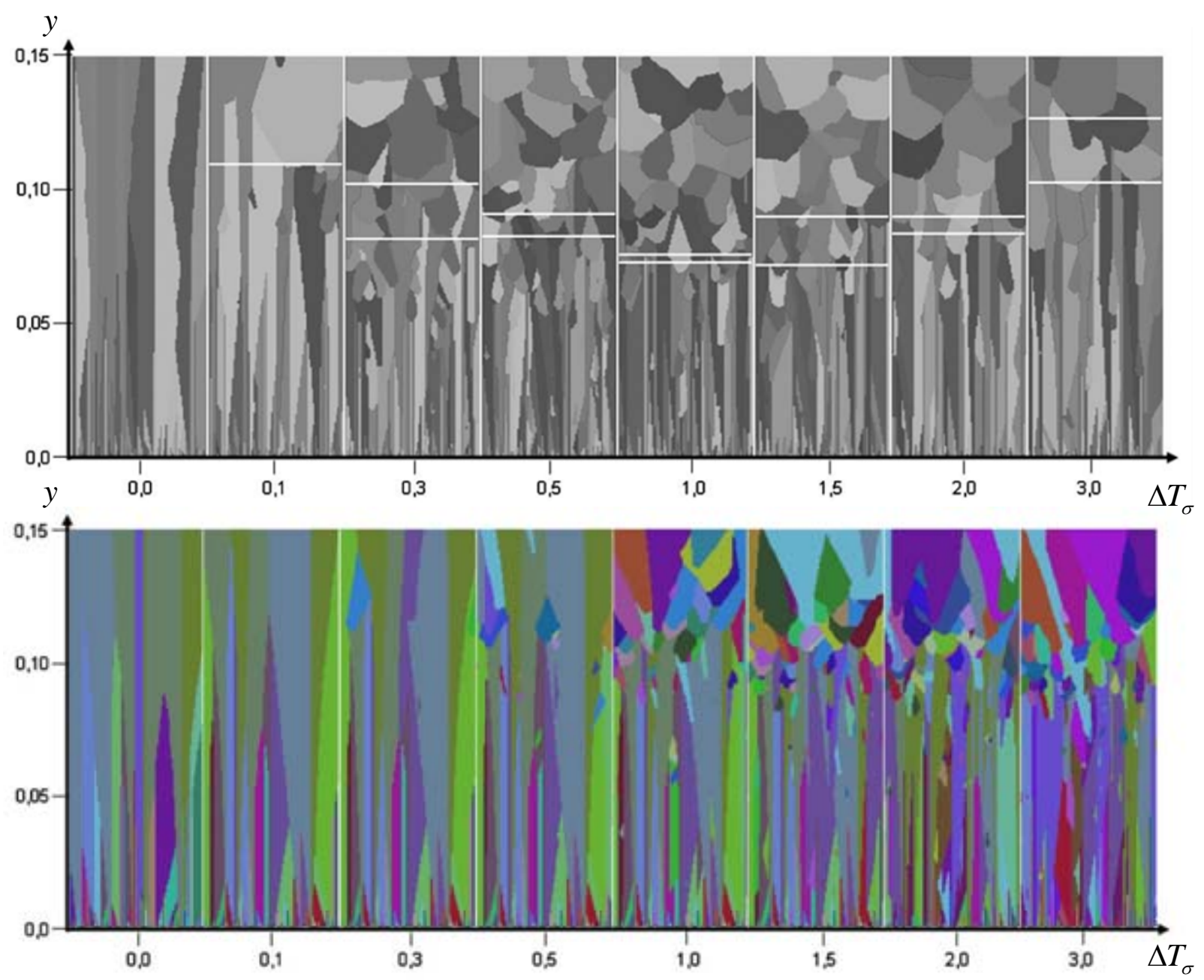

Figura 54 - Comparação entre as macroestruturas fornecidas no trabalho de Martorano e Biscuola (2009) (sequência acima) e as calculadas pelo modelo para $\overline{\Delta T_{N}}=5 \mathrm{~K}$, com o desvio-padrão $\Delta T_{\sigma}$ variando entre $0,0 \mathrm{~K}$ e $3,0 \mathrm{~K}$.

\subsection{Comparação do Modelo com Resultado Experimental}

Neste trabalho, foi também simulado um caso experimental apresentado por Rerko et al. (2003). O experimento selecionado para a simulação foi realizado com a liga $\mathrm{Al}-10 \% \mathrm{Cu}$ em solidificação unidirecional ascendente. O coeficiente de transporte de calor em uma das extremidades do domínio foi estimado com base na temperatura do molde fornecida no tempo e em quatro temperaturas medidas no interior do metal. A partir de várias ajustes, o coeficiente de transporte de calor entre o metal e a base refrigerada adotado foi:

$$
h_{y=0}^{\infty}(t)=600,0+3,125 \times t
$$


onde $t$ representa o tempo (em segundos) a partir do início do resfriamento.

Outros parâmetros que tiveram que ser estimados foram: a distribuição de super-resfriamentos e a quantidade de partículas de inoculante. Para isto, com o dado de tamanho médio de partículas de inoculante, foi possível estimar $\overline{\Delta T_{N}}$ utilizando uma equação proposta por Greer et al. (2000):

$$
\overline{\Delta T_{N}}=\frac{4 \sigma_{s l}}{\Delta S_{v} \bar{\phi}}
$$

onde $\sigma_{s l}$ é a energia de interface entre a fase sólida e a fase líquida $\left(158,0 . \mathrm{mJ} / \mathrm{m}^{2}\right.$ para ligas de alumínio), $\Delta S_{v}$ é a entropia de fusão por unidade de volume $\left(1,112.10^{6}\right.$ $\mathrm{J} / \mathrm{K} / \mathrm{m}^{-3}$ ), e $\bar{\phi}$ é o diâmetro médio de partículas de inoculante.

Para tamanho médio de partícula igual a $11 \mu \mathrm{m}$ (RERKO et al., 2003), a equação fornece $\overline{\Delta T_{N}}=0,05 \mathrm{~K}$. Como este super-resfriamento é próximo de zero, a distribuição escolhida para os super-resfriamentos é a log-normal (GREER et al., 2000) indicada abaixo:

$$
\frac{d n}{d(\Delta T)}=\frac{n_{\max }}{\sigma_{\phi} \sqrt{2 \pi} \Delta T} \exp \left[-\frac{1}{2}\left(\frac{\ln \left(\Delta T / \overline{\Delta T_{N}}\right)}{\sigma_{\phi}}\right)^{2}\right]
$$

onde $\sigma_{\phi}$ é um parâmetro adimensional da distribuição log-normal que é correlacionada com o desvio-padrão através da equação:

$$
\Delta T_{\sigma}=\overline{\Delta T_{N}} \sqrt{e^{\sigma_{\phi}^{2}}\left(e^{\sigma_{\phi}^{2}}-1\right)}
$$

No trabalho de Rerko et al. (2003), foi fornecido o total de massa de inoculante no banho metálico. A distribuição de tamanho das partículas também pode ser assumida igual a uma log-normal, fornecida abaixo (GREER et al., 2000): 


$$
\frac{d n}{d \phi}=\frac{n_{\max }}{\sigma_{\phi} \phi \sqrt{2 \pi}} \exp \left[-\frac{1}{2}\left(\frac{\ln (\phi / \bar{\phi})}{\sigma_{\phi}}\right)^{2}\right]
$$

onde, $\phi$ é o tamanho de partícula e $\bar{\phi}$ o valor médio de tamanho. A partir desta distribuição, é possível calcular o volume total de inoculante adicionado através da equação:

$$
V_{T_{i B_{2}}}=\int_{0}^{\infty}\left(\frac{d n}{d V}\right) V d V=\int_{0}^{\infty}\left(\frac{d n}{d \phi}\right)\left(\frac{\pi \phi^{3}}{6}\right) d \phi=\frac{\pi n_{\max }}{6 \sigma_{\phi} \sqrt{2 \pi}} \int_{0}^{\infty} \phi^{2} \exp \left[-\frac{1}{2}\left(\frac{\ln (\phi / \bar{\phi})}{\sigma_{\phi}}\right)^{2}\right] d \phi
$$

onde a integral definida pode ser calculada analiticamente por:

$$
\int_{0}^{\infty} \phi^{2} \exp \left[-\frac{1}{2}\left(\frac{\ln (\phi / \bar{\phi})}{\sigma_{\phi}}\right)^{2}\right] d \phi=\sqrt{2 \pi} \sigma_{\phi} \bar{\phi}^{3} \exp \left(\frac{9 \sigma_{\phi}^{2}}{2}\right)
$$

A partir desta equação, da massa de partículas adicionadas e da densidade das partículas, é possível obter a densidade do número de partículas de inoculante dentro do banho metálica pela expressão:

$$
n_{\max }=\frac{6 M_{T i B_{2}}}{V \rho_{T i B_{2}} \pi \bar{\phi}^{3}} \exp \left(-\frac{9 \sigma_{\phi}^{2}}{2}\right)
$$

onde $M_{T i_{2}}$ é a massa total de inoculante no banho metálico, $\rho_{T i_{2}}$ é a densidade do inoculante e $V$ é o volume total do metal líquido. Como não pode haver um $n_{\max }$ que resulte em tamanhos de grãos menores do que os encontrados na macroestrutura, foi estimado um valor de $\sigma_{\phi}$ igual a 0,45 que fornece o valor para $n_{\max }$ de $1,38.10^{10}$, que é próxima e maior que a máxima densidade de número de grãos encontrada na macroestrutura.

Nesta liga, a diferença entre a densidade da fase sólida e da fase líquida, para temperaturas próximas a da temperatura liquidus, é pequena 
(aproximadamente $7 \mathrm{~kg} \cdot \mathrm{m}^{-3}$ ). Porém, na macroestrutura obtida no experimento, são encontrados grãos maiores na região superior do lingote (Figura 56), que é apontado pelos autores como um efeito inexplicável apenas com as análises dos resultados experimentais, pois a decantação é considerada desprezível para esta composição. Portanto, a simulação utilizando o presente modelo deve verificar a validade desta hipótese. Os dados utilizados na simulação estão detalhados nas tabelas abaixo (Tabela 14 e Tabela 15):

Tabela 15 - Parâmetros da liga $\mathrm{Al}-10 \% \mathrm{Cu}$

\begin{tabular}{cccc}
\hline$C_{0}(\%)$ & 10,0 & $\rho_{s}\left(\mathrm{~kg} \cdot \mathrm{m}^{-3}\right)$ & 2582,0 \\
$T_{\text {liq }}(\mathrm{K})$ & 908,0 & $\rho_{l}\left(\mathrm{~kg} \cdot \mathrm{m}^{-3}\right)$ & 2589,0 \\
$T_{f}$ & 941,7 & $T_{e}(\mathrm{~K})$ & 821,0 \\
$L_{f}\left(\mathrm{~J} \cdot \mathrm{kg}^{-1}\right)$ & $382,0.10^{3}$ & $C_{P}\left(\mathrm{~J} \cdot \mathrm{K}^{-1} \mathrm{~kg}^{-1}\right)$ & 1291,2 \\
$m_{l}(\mathrm{~K} / \%)$ & $-3,37$ & $k(-)$ & 0,17 \\
$D_{l}\left(\mathrm{~m}^{2} \mathrm{~s}^{-1}\right)$ & $5,0.10^{-9}$ & $\Gamma\left(\mathrm{m}^{-1} \mathrm{~K}\right)$ & $9,8.10^{-8}$ \\
$K_{s}\left(\mathrm{Wm}^{-1} \mathrm{~K}^{-1}\right)$ & 153,0 & $K_{l}\left(\mathrm{Wm}^{-1} \mathrm{~K}^{-1}\right)$ & 77,0 \\
$\mu_{l}(\mathrm{~Pa} . \mathrm{s})$ & 0,001 & $\lambda_{2}(\mathrm{~m})$ & $10^{-5}$ \\
\hline
\end{tabular}

Tabela 16 - Parâmetros de entrada para a simulação do caso de solidificação unidirecional

\begin{tabular}{cccc}
\hline$L_{x}(\mathrm{~m})$ & 0,0184 & $L_{y}(\mathrm{~m})$ & 0,1 \\
Número de VFs & $1 \times 25$ & Número de células & $115 \times 625$ \\
$n_{V}^{*}\left(\mathrm{~m}^{-3}\right)$ & $1,38.10^{10}$ & $T_{0}(\mathrm{~K})$ & 958,0 \\
$\overline{\Delta T_{N}}(\mathrm{~K})$ & 0,05 & $\sigma_{\phi}$ & 0,45 \\
\hline
\end{tabular}

A curva de resfriamento calculada pelo modelo está próxima às curvas experimentais (Figura 55). Este resultado só pôde ser obtido pela modificação do valor do coeficiente de transporte de calor $h_{y=0}^{\infty}$, que é maior do que o fornecido pelo trabalho de Rerko et al. (2003). 


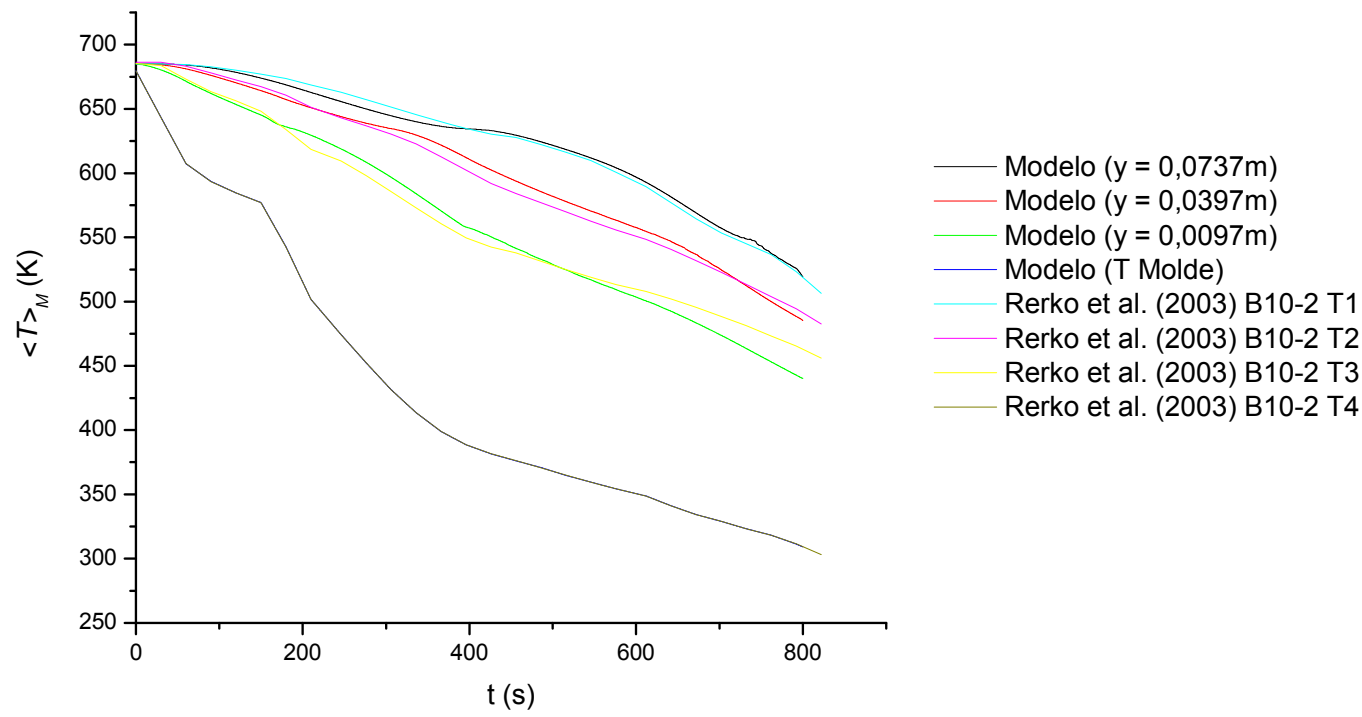

Figura 55 - Curvas de temperatura do modelo interpolada nas posições dos termopares do experimento de Rerko et al. (2003), e as curvas fornecidas no próprio experimento.

A macroestrutura calculada apresentou grãos maiores na região superior do lingote, mas acima de linha em que a macroestrutura real começa a apresentar diferença no tamanho de grão (Figura 56). Como foi utilizada uma distribuição de super-resfriamentos nas simulações, o aumento dos grãos no topo poderia ser explicado pelos grãos que crescem sobre os substratos, impedindo a nucleação destes no modelo. Porém, o modelo fornece a informação de que todos os substratos foram ativados durante a simulação. 

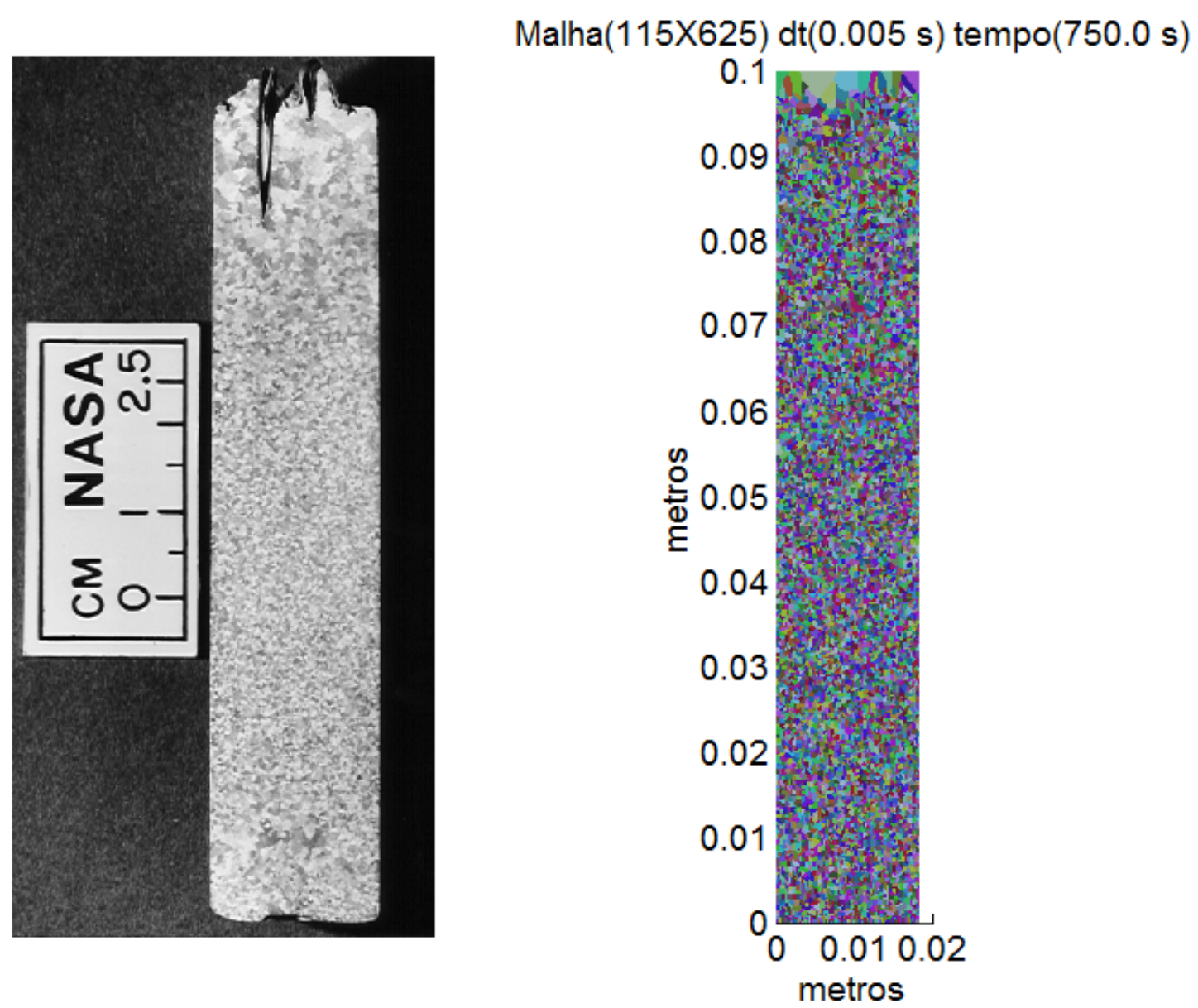

Figura 56 - Macroestrutura obtida no trabalho experimental de Rerko et al. (2003) à esquerda e macroestrutura calculada pelo modelo à direita.

Para quantificar o efeito da decantação de grãos, foi construída uma curva de distribuição de distância percorrida pelos grãos, que está relacionada com a massa transportada no sistema causada pela decantação (Figura 57). O gráfico indica que grãos decantaram a uma distância do topo até a linha em que o tamanho de grão se modifica. 


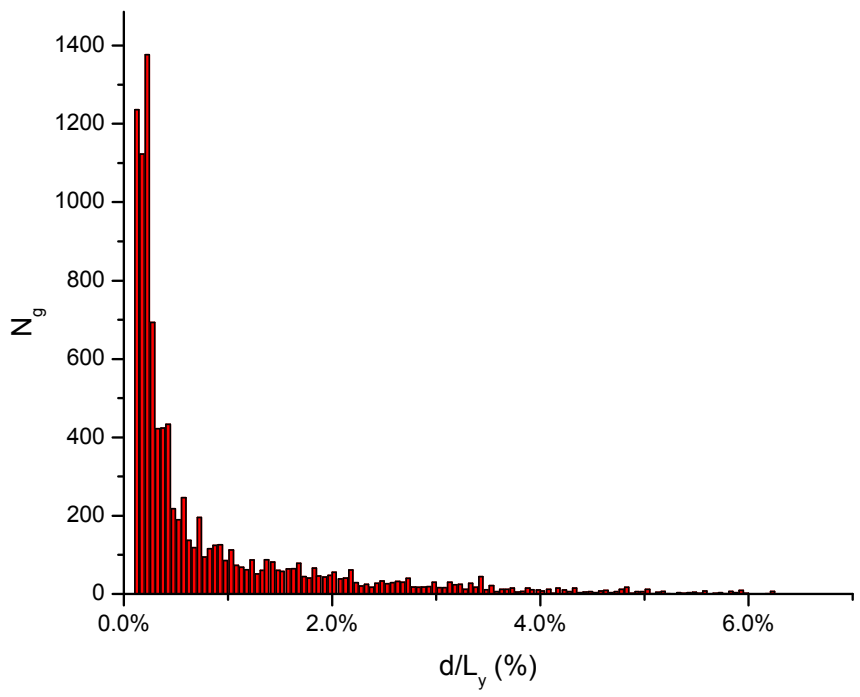

Figura 57 - População de grãos (N) para determinadas distâncias percorridas por decantação (d)

O tamanho médio local de grão na macroestrutura calculada pode ser estimado através da concentração local de núcleos por unidade de volume (Eq. [40]). O perfil de tamanho médio de grão em função da distância ao longo do lingote a partir de sua base está ilustrado na Figura 58.

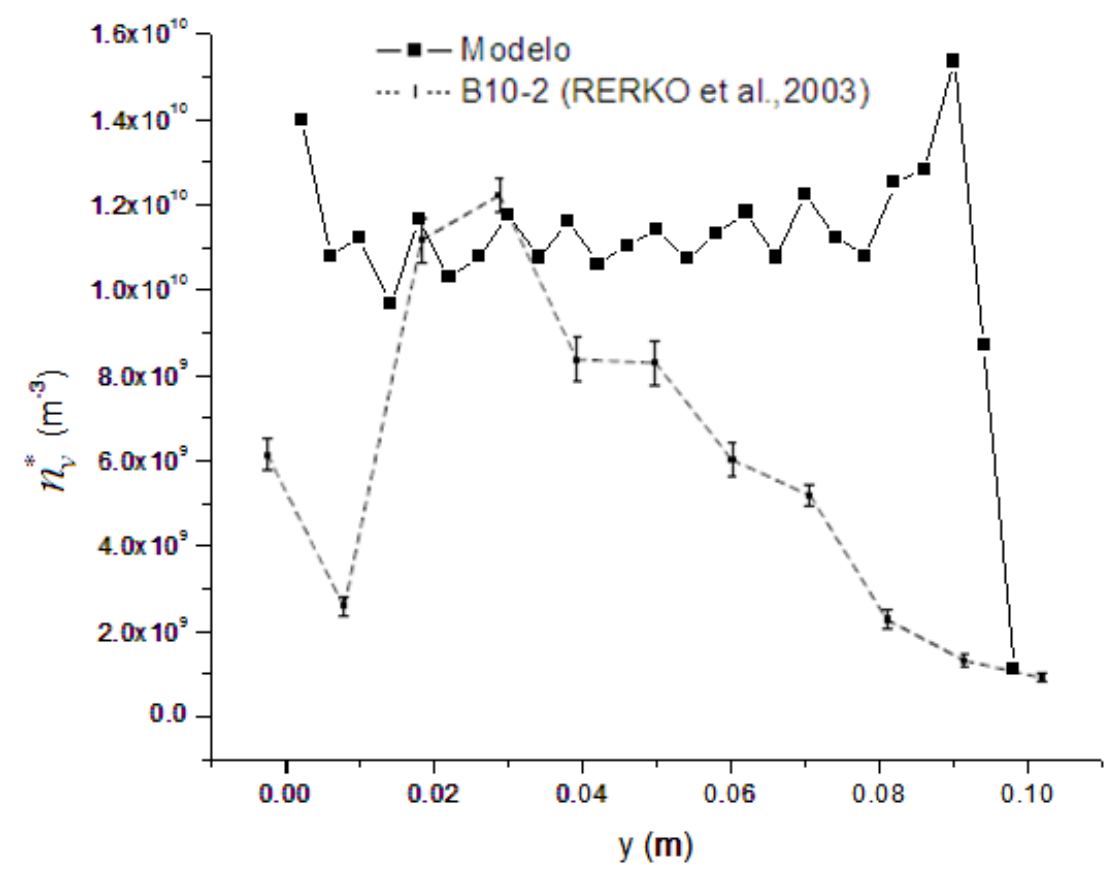

Figura 58 - Densidade de número de grãos por volume $n_{V}^{*}$ calculada pelo modelo ao longo do lingote a partir de sua base e no experimento de Rerko et al. (2003) 
Rerko et al. (2003) forneceu o perfil medido de tamanho médio local de grão (Figura 58). Uma comparação entre estes dois perfis mostra que o presente modelo apresenta variação brusca de tamanho de grão somente próximo ao topo do lingote, enquanto que no experimento de Rerko et al. (2003), o aumento de tamanho de grão ocorre um pouco na base e a partir da metade do lingote.

A concentração média de soluto no eixo vertical também foi calculada pelo modelo, sendo ilustrada na Figura 59 junto com a análise experimental B10-2 de Rerko et al. (2003). A curva de segregação calculada pelo modelo tem o comportamento inverso em relação ao medido experimentalmente e em menor ordem de grandeza que este. Isto mostra que a decantação isoladamente não parece explicar o padrão de segregação observado experimentalmente.

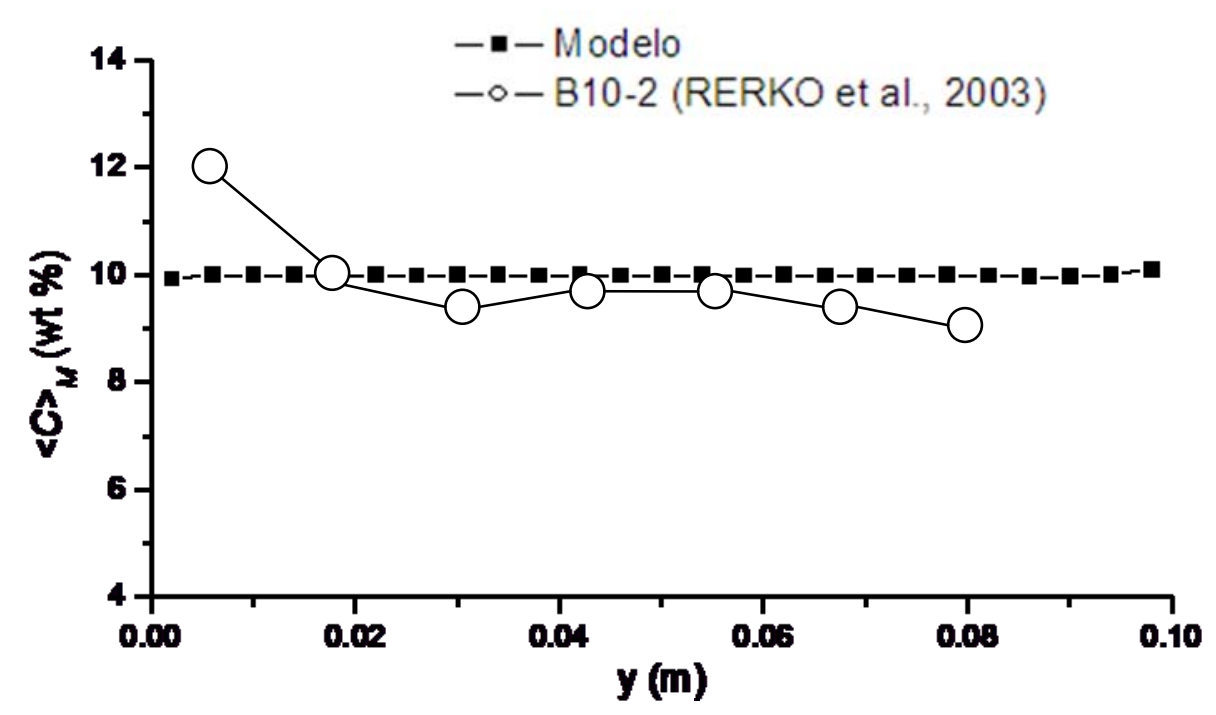

Figura 59 - Concentração média de soluto $\langle C\rangle_{M}$ no eixo vertical calculado pelo modelo e obtido experimentalmente por Rerko et al. (2003) 


\section{CONCLUSÕES}

Os resultados obtidos no presente trabalho possibilitaram a formulação das seguintes conclusões:

1. O modelo matemático implementado fornece automaticamente através de seu equacionamento: a macroestrutura de grãos, o perfil de temperatura, a fração volumétrica de fases e a concentração média de soluto nas fases.

2. O algoritmo utilizado para realizar a translação dos grãos mantém o formato destes grãos, sem distorcê-los.

3. A utilização do presente modelo para simular a solidificação isotérmica mostra que, sem o efeito da decantação, os seus resultados aproximam-se mais dos resultados do modelo determinístico (WANG; BECKERMANN, 1993) que dos resultados do modelo do autômato celular proposto por Rappaz e Gandin (RAPPAZ; GANDIN, 1993).

4. As macroestruturas obtidas pelo modelo no caso da solidificação unidirecional nas condições simuladas por Wang e Beckermann (1994) diferem significativamente dos resultados obtidos por estes autores.

5. Na simulação da solidificação unidirecional ascendente, o presente modelo mostra em determinadas condições que os grãos equiaxiais que decantam não atingem tamanho suficiente para bloquear o crescimento colunar e causar a transição colunar-equiaxial, resultando em uma macroestrutura composta apenas de grãos colunares. Entretanto, quando a decantaçao não é simulada, a macroestrutura calculada apresenta a transição colunar-equiaxial em uma posição próxima à apresentada pelo modelo determínstico de Wang e Beckermann (1994).

6. Na simulação da solidificação unidirecional descendente utilizando o presente modelo, observam-se grãos equiaxiais que sedimentam na base do molde sem bloquear a zona colunar. Este depósito de grãos gera uma nova zona colunar na região inferior que se encontra com os grãos colunares que crescem a partir do contorno superior.

7. O modelo matemático mostrou que a decantação de grãos altera o efeito da largura da distribuição de super-resfriamentos de nucleação na posição da 
transição colunar-equiaxial. Em determinadas condições de solidificação, o efeito da largura da distribuição foi completamente eliminado quando se considera a decantação de grãos.

8. O modelo implementado foi utilizado para simular um experimento de solidificação direcional ascendente apresentado na literatura e seus resultados mostraram uma boa concordância entre as curvas de resfriamento medidas e calculadas, porém uma concordância ruim entre os resultados medidos e calculados para a tendência nas variações de tamanho de grão local e macrossegregação ao longo do lingote. 


\section{REFERÊNCIAS}

AHUJA. S. Solid Interfacial Drag in Equiaxed Solidification. M.S. Thesis, University of lowa, lowa City, IA, 1992.

ANANTH, R.; GILL, W. Self-Consistent Theory of Dendritic Growth with Convection. Journal of Crystal Growth, v. 108, p.173-189, 1991.

APPOLAIRE, B.; ALBERT, V.; COMBEAU H.; LESOULT G. Free Growth of Equiaxed Crystals Settling in Undercooled $\mathrm{NH} 4 \mathrm{Cl}-\mathrm{H} 2 \mathrm{O}$. Acta Materialia, v. 46, n. 16, p. 5851-5862, 1998.

BADILLO, A.; CEYNAR, D; BECKERMANN, C. Growth of Equiaxed Dendritic Crystals Settling in an Undercooled Melt. Journal of Crystal Growth, v. 309, p. 197-224, 2007.

BECKERMANN, C. Modelling of Macrosegregation: Applications and Future Needs. International Materials Reviews, v. 47, n. 5, p. 243-261, 2002.

BELTRAN-SANCHEZ, L.; STEFANESCU, D. M. A Quantitative Dendrite Growth Model and Analysis of Stability Concepts. Metallurgical and Materials Transactions A, v. 35A, p. 2471-2485, 2004.

BISCUOLA, V.B.; MARTORANO, M.A. A hybrid stochastic-deterministic model for the multiphase solidification of alloys. 5th Decennial International Conference on Solidification Processing - Solidification Processing 2007 - SP07. University of Sheffield, Sheffield, p. 139-143, 2007.

BISCUOLA, V.B.; MARTORANO, M.A. Mechanical Blocking Mechanism for the Columnar to Equiaxed Transition, Metallurgical and Materials Transactions A, v. 39, p. 2885-2895, 2008. 
BROWNE, D.J.; HUNT, J.D. A Fixed Grid Front Tracking Model of the Growth of a Columnar Front and an Equiaxed Grain during Solidification of an Alloy. Numerical Heat Transfer Part B - Fundamentals, v. 45, n. 5, p. 395-419, 2004.

CANTOR, B.; VOGEL, A. Dendritic Solidification and Fluid Flow. Journal of Crystal Growth, v. 41, p.109-123, 1977.

CHALMERS, F. Principles of solidification. New York : John Wiley, 1964.

COMBEAU, H.; ZALOZNIK, M.; HANS, S.; RICKY, P.E. Prediction of Macrosegregation in Steel Ingots: Influence of the Motion and the Morphology of Equiaxed Grains. Metallurgical and Materials Transaction B - Process Metallurgy and Materials Processing Science, v. 40, n. 3, p. 289-304, 2009.

DE GROH III, H.C. ; WEIDMAN, P.D.; ZAKHEM, R.; AHUJA, S.; BECKERMANN, C. Calculations of Dendrite Settling Velocities Using a Porous Envelope. Metallurgical Transactions B, Vol. 24B, p.749-753, 1993.

FLOOD, S. C.; HUNT, J. D. ASM Handbook, ASM, Materials Park, Oh, v. 15, p. 13036, 1998.

GARCIA, Amauri. Solidificação: Fundamentos e Aplicações. Campinas: Unicamp, 1980.

GANDIN, Ch-A; RAPPAZ, M. A Coupled Finite Element-Cellular Automaton Model for the Prediction of Dendritic Grain Structures in Solidification Processes. Acta Metallurgica, v. 42, p. 2233-2246, 1994.

GANDIN, Ch-A.; RAPPAZ, M. A 3D Cellular Automaton Algorithm for the Prediction of Dendritic Grain Growth. Acta Materalia, v. 45, p. 2187-2195, 1997.

GANDIN, Ch-A.; GUILLEMOT, G.; APPOLAIRE, B.; NIANE, N.T. Boundary Layer Correlation for Dendritic Tip Growth with Fluid Flow. Materials Science and Engineering A, v. 342, p.44-50, 2003. 
GUILLEMOT, G.; GANDIN, Ch-A.; COMBEAU, H. Modeling of Macrosegregation and Solidification Grain Structures with a Coupled Cellular Automaton-Finite Element Model. ISIJ Internacional, v. 46, p. 880-895, 2006.

GREER, A.L.; BUNN, A.M.; TRONCHE, A.; EVANS, P.V.; BRISTOW, D.J. Modelling of Inoculation of Metallic Melts: Application to Grain Refinement of Aluminium by Al-Ti-B. Acta Materialia Vol.48, p. 2823-2835, 2000.

GRIFFITHS, W.D.; MCCARTNEY, D.G. Macrostructural development in aluminum-alloys solidified vertically downwards. Materials Science and Engineering A, v. 173, n. 1-2, p. 123-127, 1993.

HAIDER, A.; LEVENSPIEL, O. Drag Coefficient and Terminal Velocity of Spherical and Nonspherical Particles. Powder Technology, v.58, p.63-70, 1989.

HELLAWELL, A.; LIU, S.; LU, S.Z. Dendrite Fragmentation and the Effects of Fluid Flow in Castings. JOM - Journal of the Minerals Metals \& Materials Society. v. 49 n. 3 p.18-20, 1997.

HULTGREN, A. A and V Segregation in Killed Steel Ingots. Scandinavian Journal of Metallurgy, v. 2, p. 217-227, 1973.

HUNT, J.D. Steady-state columnar and equiaxed growth of dendrites and eutectic. Materials Science and Engineering, v. 65, n. 1, p. 75-83, 1984.

JACKSON, K.A.; HUNT, J.D.; UHLMANN, D.R.; SEWARD, T.P. On origin of equiaxed zone in castings. Transactions of the Metallurgical Society of AIME, v. 236, n. 2, p. 149-158, 1966.

KURZ, W.; FISHER, D.J. Fundamentals of solidification. Aedermannsdorf, Trans Tech Publications Ltd., 1998. 
LAMEIRAS JÚNIOR, F. Efeito da Nucleação de Grãos nas Previsões do Modelo Multifásico para a Solidificação Equiaxial. 2006. 99p. Dissertação (Mestrado) Escola

Politécnica. Universidade de São Paulo, São Paulo, 2006.

LAMEIRAS, F. Jr; MARTORANO, M.A. Modelo Matemático para a Solidificação Equiaxial em Ligas Binárias. Publicatio UEPG Ciências Exatas e da Terra, v. $13 \mathrm{n}$. 2, p. 17-29, 2007.

LI, Q.; BECKERMANN, C. Modeling of Free Dendritic Growth of SuccinonitrileAcetone Alloys with Thermosolutal Melt Convection. Journal of Crystal Growth 236, p.482-498, 2002.

LIPTON, J.; GLICKSMAN, M.E.; KURZ, W. Dendritic Growth into Undercooled Alloy Melts. Materials Science and Engineering, v. 65, p. 57-63, 1984.

MARTORANO, M.A.; BECKERMANN, C.; GANDIN, Ch.-A. A Solutal Interaction Mechanism for the Columnar-to-Equiaxed Transition in Alloy Solidification. Metallurgical and Materials Transactions A, vol. 34, p. 1657-1674, 2003.

MARTORANO, M.A.; BISCUOLA, V.B. Predicting the Columnar-to-Equiaxed Transition for a Distribution of Nucleation Undercoolings. Acta Materialia, v. 57, pp. 607-615, 2009.

MAXWELL, I.; HELLAWELL, A. Simple Model for Grain Refinement During Solidification. Acta Materialia, v. 23, n. 2, p.229-237, 1975.

MCFADDEN, S.; BROWNE, D.J. Meso-scale Simulation of Grain Nucleation, Growth and Interaction in Castings. Scripta Materialia, v. 55, n. 10, p. 847-850, 2006.

MOSBAH, S.; BELLET, M.; GANDIN, Ch-A. Experimental and Numerical Modelling of Segregation in Metallic Alloys. Metallurgical Transactions A Physical Metallurgy, v. 41A i.3 p.651-699, 2010 
NADELLA R.; ESKIN D.G.; DU Q.; KATGERMAN L. Macrosegregation in DirectChill Casting of Aluminium Alloys. Progress in Materials Science, v. 53 p.421-480, 2008.

NEALE, G.; EPSTEIN, N. Creeping Flow relative to Permeable Spheres. Chemical Engineering Science, v. 28, n. 10, p. 1865-1874, 1973.

NI, J., BECKERMANN, C., A Volume-Averaged Two-Phase Model for Transport Phenomena during Solidification, Metallurgical Transactions B, v. 22B, p. 349-361, 1991.

OLDFIELD, W. A Quantitative Approach to Casting Solidification: freezing of Cast

Iron. Transactions of the ASM, v. 59, p. 945-961, 1966.

OLSSON, A.; WEST, R.; FREDIKSON, W. Macrosegregation in Ingots. Scadinavian Journal of Metallurgy v.15 p.104-112, 1986.

PATANKAR, S. V. Numerical Heat Transfer and Fluid Flow. New York: Publishing Corp., 1981.

PRATES, M.; BILONI, H. Variables affecting the nature of the chill zone. Metallurgical Transactions, Metals Park, v.3, n.6, p. 1501-10, 1972.

QUESTED, T.E.; GREER, A.L. The Effect of the Size Distribution of Inoculant Particles on As-Cast Grain Size in Aluminium Alloys. Acta Materialia, v. 52, n. 17, p. 3859-3868, 2004.

RANZ, W.E.; MARSHALL, W.R. Evaporation from drops. Chemical Engineering Progress. v. 48. n. 3. p. 141-146, 1952.

RAPPAZ, M.; GANDIN, Ch-A. Probabilistic Modelling of Microstructure Formation in Solidification Processes. Acta Metallurgica, v. 41, p. 345-360, 1993. 
RERKO, R.S.; DE GROH III, H.C.; BECKERMANN, C. Effect of Melt Convection and Solid Transport on Macrosegregation and Grain Structure in Equiaxed Al-Cu Alloys. Materials Science and Engineering A, v. A347, p. 186-197, 2003.

ROWE, P.N.; CLAXTON, K.T.; Heat and Mass Transfer from a Single Sphere to Fluid Flowing Through an Array. Transactions of the Institution of Chemical Engineers and the Chemical Engineer, v. 43, n. 10, p. T321, 1965.

SEKERKA, R.F.; CORIELL, S.R.; MCFADDEN, G.B. Stagnant Film Model of the Effect of Natural Convection on the Dendrite Operating State. Journal of Crystal Growth 154, p. 370-376, 1995.

SOUTHIN, R.T. Nucleation of the Equiaxed Zone in Cast Metals. Transactions of the Metallurgical Society of AIME Vol. 239, p.220-239, 1967.

SPITTLE, J.A.; BROWN, G.R. Computer Simulation of the Effects of Alloy Variables on the Grain Structures of Castings. Acta Metallurgica, v. 37, n. 7, p. 1803-1810, 1989.

TAKATANI, H.; GANDIN, Ch.-A.; RAPPAZ, M. EBSD Characterisation and Modelling of Columnar Dendritic Grains Growing in the Presence of Fluid Flow. Acta Materialia 48, p.675-688, 2000.

TARSHIS, L.A.; WALKER, J.L.; RUTTER, J.W. Experiments on the solidification structure of alloy castings. Metallurgical Transactions, v. 2, n. 1, p. 25892597, 1971.

THÉVOZ, P.; DESBIOLLES, J. L.; RAPPAZ, M. Modeling of Equiaxed Microstructure formation in Casting. Metallurgical Transactions A, Vol. 20A, p.311-322, 1989.

TRIVEDI, R.; KURZ, W. Dendritic Growth. International Materials Review, v. 39, n. 2, p. 49-74, 1994. 
WANG, C.Y; BECKERMANN, C. A Multiphase Solute Diffusion Model for Dendritic Alloy Solidification. Metallurgica Transactions A, v. 24A, p. 2787-2802, 1993.

WANG, C.Y; BECKERMANN, C. Prediction of Columnar to Equiaxed Transition During Diffusion-Controlled Dendritic Alloy Solidification. Metallurgical and Materials Transactions A, v. 25A, p. 1081-1093, 1994.

WANG, C.Y;, AHUJA, S.; BECKERMANN, C.; DE GROH III, H.C. Multiparticle Interfacial Drag in Equiaxed Solidification. Metallurgical and Materials Transactions B, v. 26B, p. 111-119, 1995.

WANG, C.Y.; BECKERMANN, C. Equiaxed Dendritic Solidification with Convection. Metallurgical and Materials Transactions A Vol. 27A, p. 2754, 1996.

WEIRAUCH, DA; MARTONIK, L.; GIRON, A.; ZIEGLER, D.; CHU, M.G. Laboratory Study of Cast Surface Evolution I. Mold-contact Stage. Technical Session on Light Metals 2000 held at the $129^{\text {th }}$ TMS Annual Meeting, p. 649-655, 2000.

WHITAKER, S. Advances in Theory of Fluid Motion in Porous Media. Industrial and Engineering Chemistry, v. 61, n. 12, 1969.

WINEGARD, W.C.; CHALMERS, B. Supercooling and dendritic freezing in alloys. Transactions of the American Society for Metals, v. 46, p. 1214-1224, 1954.

WU, M.; LUDWIG, A. Modelling Equiaxed Solidification with Melt Convection and Grain Sedimentation I: Model Description. Acta Materialia, v. 57, n. 19, p.5621-5631, 2009.

ZHU, M.F.; HONG, C.P.; STEFANESCU, D.M.; CHANG, Y.A. Computational Modeling of Microstructure Evolution in Solidification of Aluminum Alloys. Metallurgical and Materials Transaction B - Process Metallurgy and Materials Processing Science, v. 38, n. 4, p. 517-524, 2007. 
ZAKHEM, R; WEIDMAN, P.D.; DE GROH III, H.C. On the Drag of Model Dendrite Fragment at Low Reynolds Number. Metallurgical Transactions A, v. 23A, p. 21692181, 1992. 


\section{APÊNDICE A - CAPTURA DE UMA CÉLULA DE CA}

Neste apêndice, será apresentada a dedução do critério de captura de uma célula citado nas equações [43] e [44] e para o cálculo do novo polígono de crescimento explicado no final do item 4.2.2.

Sendo $\vec{L}_{1}$ e $\vec{L}_{2}$ linearmente independentes, um ponto qualquer dado pelo vetor $\vec{L}$ em relação a uma origem pode ser representado pela seguinte equação:

$$
\vec{L}=\alpha_{1} \vec{L}_{1}+\alpha_{2}\left(1-\alpha_{1}\right) \vec{L}_{2}
$$

sendo $\alpha_{1}$ e $\alpha_{2}$ números reais.

É demonstrado que se $\alpha_{1}$ e $\alpha_{2}$ pertencem ao intervalo [0,1], o ponto pertence ao triângulo formado pelos vetores $\vec{L}_{1}$ e $\vec{L}_{2}$ posicionados na origem.

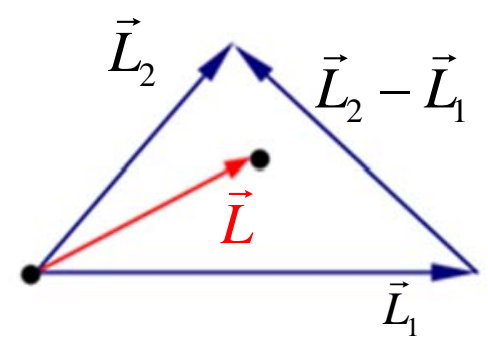

Figura A1 - Representação do triângulo formado pelos vetores $\vec{L}_{1}$ e $\vec{L}_{2}$, e um ponto dado pelo vetor $\vec{L}$

Para o caso particular do polígono de crescimento deste modelo (quadrilátero com diagonais perpendiculares), os vetores $\vec{L}_{1}$ e $\vec{L}_{2}$ são ortogonais, representando cada semidiagonal do quadrilátero, e, portanto:

$$
\vec{L}_{1} \cdot \vec{L}_{2}=0
$$


Com o produto escalar em ambos os lados da Eq. [A1] por $\vec{L}_{1}$, e por $\vec{L}_{2}$, geramos duas equações, das quais é possível calcular $\alpha_{1}$ e $\alpha_{2}$ de um ponto qualquer no espaço bidimensional em relação:

$$
\begin{gathered}
\alpha_{1}=\frac{\vec{L} \cdot \vec{L}_{1}}{\left|\vec{L}_{1}\right|^{2}} \\
\alpha_{2}\left(1-\alpha_{1}\right)=\frac{\vec{L} \cdot \vec{L}_{2}}{\left|\vec{L}_{2}\right|^{2}}
\end{gathered}
$$

Sendo $\vec{L}$ correspondente a distância $\Delta \vec{r}_{\mu}^{v}, \vec{L}_{1}$ e $\vec{L}_{2}$ aos vetores $\vec{L}_{\mu[01]}^{t+\Delta t}$ e $\vec{L}_{\mu[10]}^{t+\Delta t}$ (a ordem dos vetores é no sentido anti-horário), representados na Figura 14, as Eq. [A3] e [A4], mais o critério de $\alpha_{1} \in[0,1]$ e $\alpha_{2} \in[0,1]$ fornecem as equações [43] e [44], repetidas abaixo:

$$
\begin{gathered}
0 \leq \frac{\Delta \vec{r}_{\mu}^{v} \cdot \vec{L}_{\mu[01]}^{t+\Delta t}}{\left|\vec{L}_{\mu[01]}^{t+\Delta t}\right|^{2}} \leq 1 \\
0 \leq \frac{\Delta \vec{r}_{\mu}^{v} \cdot \vec{L}_{\mu[\overline{1} 0]}^{t+\Delta t}}{\left|\vec{L}_{\mu[\overline{0}]}^{t+\Delta t}\right|^{2}} \leq 1-\frac{\Delta \vec{r}_{\mu}^{v} \cdot \vec{L}_{\mu[01]}^{t+\Delta t}}{\left|\vec{L}_{\mu[01]}^{t+\Delta t}\right|^{2}}
\end{gathered}
$$

Para o cálculo das diagonais do novo polígono de crescimento da célula ativada, é necessário obter o ponto I, indicado na Figura 15 (reproduzida abaixo) conforme os passos mencionados no item 4.2.2. Para obter os segmentos $\overline{I L}_{[10]}^{\mu} \mathrm{e}$ $\overline{I L}_{[01]}^{\mu}$ (Figura 15) são utilizadas as equações de [A7] até [A9]. As equações [A5] e [A6] são as condições suficientes para se obter a equação [A7], explicadas abaixo.

Para o calculo da posição do ponto I, é definido um número real $\beta$ que é a fração do segmento $\left(\vec{L}_{[01]}^{\mu}-\vec{L}_{[10]}^{\mu}\right)$, partindo do vetor $\vec{L}_{[01]}^{\mu}$, para chegar no ponto I:

$$
\vec{L}_{[10]}^{\mu}+\beta\left(\vec{L}_{[01]}^{\mu}-\vec{L}_{[10]}^{\mu}\right)=(1-\beta) \vec{L}_{[10]}^{\mu}+\beta \vec{L}_{[01]}^{\mu}
$$




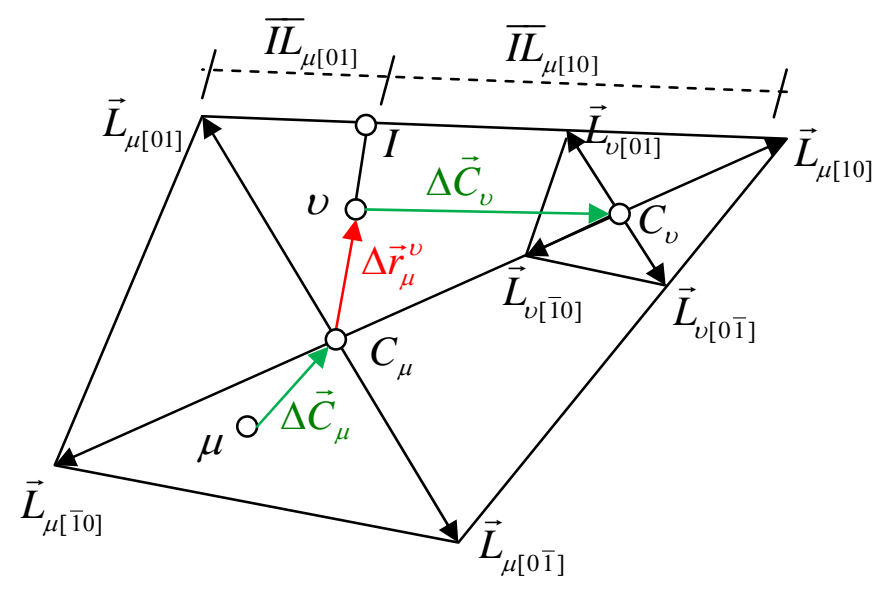

Figura 15 - Definição dos vetores para o cálculo do novo polígono de crescimento.

Como o vetor que liga o ponto I ao ponto $v$ é ortogonal ao o vetor $\left(\vec{L}_{[01]}^{\mu}-\vec{L}_{[10]}^{\mu}\right)$, seu produto escalar deve ser igual a zero:

$$
\left\{\left[(1-\beta) \vec{L}_{[10]}^{\mu}+\beta \vec{L}_{[01]}^{\mu}\right]-\Delta \vec{r}_{\mu}^{\nu}\right\} \cdot\left(\vec{L}_{[10]}^{\mu}-\vec{L}_{[01]}^{\mu}\right)=0
$$

Assim, obtemos uma expressão para $\beta$, dada por:

$$
\beta=\frac{\Delta \vec{r}_{\mu}^{\nu} \cdot\left(\vec{L}_{[10]}^{\mu}-\vec{L}_{[01]}^{\mu}\right)+\left|\vec{L}_{[10]}^{\mu}\right|^{2}}{\left|\vec{L}_{[10]}^{\mu}\right|^{2}+\left|\vec{L}_{[01]}^{\mu}\right|^{2}}
$$

E finalmente, as expressão para o módulo de cada segmento $\overline{I L}_{[10]}^{\mu}$ e $\overline{I L}_{[01]}^{\mu}$ :

$$
\begin{gathered}
\overline{I L}_{[10]}^{\mu}=\beta\left|\vec{L}_{[10]}^{\mu}-\vec{L}_{[01]}^{\mu}\right|^{2} \\
\overline{I L}_{[01]}^{\mu}=(1-\beta)\left|\vec{L}_{[10]}^{\mu}-\vec{L}_{[01]}^{\mu}\right|^{2}
\end{gathered}
$$




\section{APÊNDICE B - EQUAÇÕES GERAIS DE CONSERVAÇÃO}

Este apêndice é designado à consulta das equações gerais de conservação de grandezas médias, mostradas em Wang e Beckermann (1996), que serão utilizadas para a dedução das equações deste modelo. A equação geral de transporte para grandezas é expressa abaixo (Eq.[33]):

$$
\frac{\partial\left(\rho_{k} \varepsilon_{k}\left\langle\Psi_{k}\right\rangle^{k}\right)}{\partial t}+\vec{\nabla} \cdot\left(\rho_{k} \varepsilon_{k}\left\langle\Psi_{k}\right\rangle^{k}\left\langle\vec{v}_{k}\right\rangle\right)^{k}=-\vec{\nabla} \cdot\left(\left\langle\Phi_{k}\right\rangle+\left\langle\Phi_{k}\right\rangle^{t}\right)+\sum_{j, j \neq k} \Theta_{k j}
$$

Conservação da Energia ( $\Psi=\rho h$, entalpia por volume)

$$
\frac{\partial}{\partial t}\left(\rho_{k} \varepsilon_{k} h_{k}\right)+\vec{\nabla} \cdot\left(\rho_{k} \varepsilon_{k} h_{k}\left\langle\vec{v}_{k}\right\rangle^{k}\right)=\vec{\nabla} \cdot\left(\varepsilon_{k} K_{k}^{*} \vec{\nabla}\left\langle T_{k}\right\rangle^{k}\right)+\sum_{j, j \neq k} Q_{k j}^{\Gamma}+\sum_{j, j \neq k} Q_{k j}^{D}
$$

Conservação das Espécies Químicas ( $\Psi=\rho C$, concentração de soluto)

$$
\frac{\partial}{\partial t}\left(\rho_{k} \varepsilon_{k}\left\langle C_{k}\right\rangle^{k}\right)+\vec{\nabla} \cdot\left(\rho_{k} \varepsilon_{k}\left\langle C_{k}\right\rangle^{k}\left\langle\vec{v}_{k}\right\rangle^{k}\right)=\vec{\nabla} \cdot\left(\varepsilon_{k} D_{k}^{*} \vec{\nabla}\left\langle C_{k}\right\rangle^{k}\right)+\sum_{j, j \neq k} J_{k j}^{\Gamma}+\sum_{j, j \neq k} J_{k j}^{D}
$$

Conservação de Massa (Continuidade) ( $\Psi=\rho$, massa por volume)

$$
\frac{\partial\left(\rho_{k} \varepsilon_{k}\right)}{\partial t}+\vec{\nabla} \cdot\left(\rho_{k} \varepsilon_{k}\left\langle\vec{v}_{k}\right\rangle^{k}\right)=\Gamma_{k}=\sum_{j, j \neq k} \Gamma_{k j}
$$

Acoplamento entre as fases:

$$
\Gamma_{k j}=-\Gamma_{j k} \quad[\mathrm{~B} 5] \quad Q_{k j}^{\Gamma}+Q_{k j}^{D}=-Q_{j k}^{\Gamma}-Q_{j k}^{D} \quad[\mathrm{~B} 6] \quad J_{k j}^{\Gamma}+J_{k j}^{D}=-J_{j k}^{\Gamma}-J_{j k}^{D}
$$

Definições dos termos interfaciais:

$$
\begin{aligned}
& \Gamma_{k j}=\frac{1}{V_{0}} \int_{A_{j k}} \rho_{k}\left(\vec{w}_{k}-\vec{v}_{k}\right) \cdot \vec{n}_{k} d A \\
& J_{k j}^{\Gamma}=\frac{1}{V_{0}} \int_{A_{k j}} \rho_{k} C_{k}\left(\vec{w}_{k}-\vec{v}_{k}\right) \cdot \vec{n}_{k} d A \\
& Q_{k j}^{\Gamma}=\frac{1}{V_{0}} \int_{A_{k j}} \rho_{k} h_{k}\left(\vec{w}_{k}-\vec{v}_{k}\right) \cdot \vec{n}_{k} d A \\
& \varepsilon_{k}=\frac{1}{V_{0}} \int_{V_{0}} \gamma_{k}(\vec{r}, t) d V \\
& J_{k j}^{D}=-\frac{1}{V_{0}} \int_{A_{k j}} \vec{j}_{k j} \cdot \vec{n}_{k} d A \\
& Q_{k j}^{D}=-\frac{1}{V_{0}} \int_{A_{k j}} \vec{q}_{k j} \cdot \vec{n}_{k} d A \\
& \left\langle v_{k}\right\rangle^{k}=\frac{1}{V_{k}} \int_{V_{k}} \vec{v}_{k} d V=\frac{1}{\varepsilon_{k} V_{0}} \int_{V_{k}} \vec{v}_{k} d V
\end{aligned}
$$




\section{APÊNDICE C - DEDUÇÕES DAS EQUAÇÕES DE CONSERVAÇÃO}

Neste apêndice, são apresentadas as deduções das equações de conservação para cada submodelo (microscópico e macroscópico), a partir das equações gerais (Apêndice B), utilizando as hipóteses consideradas nos itens 4.1, 4.3 e 4.4. Como cada submodelo tem suas grandezas médias calculadas sobre seu próprio volume representativo (sendo $V_{0_{m}}$ e $V_{0_{M}}$ os volumes representativos (VER) do submodelo micro e macroscópico respectivamente), as grandezas médias serão definidas:

$$
\begin{gathered}
\left\langle\psi_{k}\right\rangle=\frac{1}{V_{0_{m}}} \int_{V_{k_{m}}} \psi_{k} d V \\
\left\langle\psi_{k}\right\rangle_{M}=\frac{1}{V_{0_{M}}} \int_{V_{k_{M}}} \psi_{k} d V
\end{gathered}
$$

onde $V_{k_{m}}$ e $V_{k_{M}}$ são os volumes das fases dentro do VER micro e macroscópico respectivamente.

Logo, as médias intrínsecas do submodelo microscópico serão indicadas por:

$$
\left\langle\psi_{k}\right\rangle^{k}=\frac{1}{V_{k_{m}}} \int_{V_{k_{m}}} \psi_{k} d V_{k}
$$

e para o submodelo macroscópico:

$$
\left\langle\psi_{k}\right\rangle_{M}^{k}=\frac{1}{V_{k_{M}}} \int_{V_{k_{M}}} \psi_{k} d V_{k}
$$

Ambos os modelos contam com hipóteses comuns entre dois e hipóteses específicas. As hipóteses gerais estão descritas abaixo (reescritas a partir do item 4.1), e as específicas nos itens 4.3 e 4.4 para os submodelos micro e macroscópico: 
1. A liga metálica modelada é considerada pertencer a um sistema binário eutético.

2. As densidades de todas as fases são consideradas iguais e constantes:

3. Os calores específicos de todas as fases são iguais e constantes: $C_{P}=C_{P s}=C_{P e}=C_{P d}=C_{P l}$

4. Considera-se que os grãos apresentam apenas o movimento de decantação, ou seja, apresentam movimento apenas na direção paralela à aceleração gravitacional.

5. A convecção natural do líquido, seja induzida por gradientes de temperatura ou concentrações é desprezada, porém aquela induzida pela decantação de grãos é considerada.

6 As velocidades médias de todas pseudofases líquidas e sólidas nos dois submodelos apresentam direção paralela à da aceleração gravitacional.

7. O eutético apresenta velocidade de movimentação igual à da fase primária no interior do grão, portanto: $\vec{v}_{e}=\vec{v}_{s}$ (no interior de cada grão).

8. Os coeficientes efetivos de difusão de calor e soluto no líquido serão considerados iguais aos coeficientes de difusão das respectivas fases.

9. Não há difusão de soluto nas fases sólidas e eutético.

10. A fase líquida extradendrítica não tem área de contato com as fases sólidas.

11. Existe equilíbrio termodinâmico local na interface sólido-líquido interdendrítico, portanto as composições do líquido e sólido adjacentes à interface estão relacionadas através das equações: $T=T_{f}+m_{l} C_{d}$ e $k=C_{s} / C_{d}$

12. Existe equilíbrio térmico no interior dos volumes representativos (VER) adotados para os dois submodelos (micro e macroscópico), portanto as temperaturas médias de todas as fases são iguais em um mesmo ponto do domínio.

\section{Submodelo Microscópico}

O submodelo microscópico tem como domínios cada grão definido pelo autômato celular (CA). Seu volume representativo deve ter uma escala de tamanho que corresponde à distância de um número significativo de braços secundários de 
uma dendrita, mas menor do que o tamanho de um grão. As equações da média são definidas sobre este volume representativo $V_{0_{m}}$ pela Eq. [C3].

As hipóteses específicas para o submodelo microscópico estão escritas no item 4.3.

\subsection{Conservação de Massa no Modelo Microscópico}

A equação geral pra a conservação de massa é reescrita a partir da equação [B4] do Apêndice $B$, com as velocidades relativas:

$$
\frac{\partial\left(\rho_{k} \varepsilon_{k}\right)}{\partial t}+\vec{\nabla} \cdot\left(\rho_{k} \varepsilon_{k}\left\langle\vec{v}_{k}^{\prime}\right\rangle^{k}\right)=\sum_{j, j \neq k} \Gamma_{k j}=\sum_{j, j \neq k} \frac{1}{V_{0_{m}}} \int_{A_{k j}} \rho_{k}\left(\vec{w}_{k}^{\prime}-\vec{v}_{k}^{\prime}\right) \cdot \vec{n}_{k j} d A=\Gamma_{k}
$$

Aplicando as hipóteses gerais 2 (densidades iguais e constantes) e 7 (fase eutéetica tem mesma velocidade da fase primária), e modificando o sistema de refencial para o grão (hipótese 6 do submodelo microscópico), somando as equações de conservação de massa de todas as fases, é obtida a equação:

$$
\vec{\nabla} \cdot\left(\varepsilon_{d}\left\langle\vec{v}_{d}^{\prime}\right\rangle^{d}\right)=0
$$

e com a hipótese de movimento unidirecional (hipótese 4 do submodelo microscópico) :

$$
\frac{\partial}{\partial y}\left(\varepsilon_{d}\left\langle v_{d}^{\prime}\right\rangle^{d}\right)=0
$$

Portanto, o produto $\varepsilon_{d}\left\langle v_{d}^{\prime}\right\rangle^{d}$ é constante na direção vertical dentro de um grão. Com o acoplamento micro-macro proposto, este produto será admitido constante dentro dos grãos contidos no mesmo volume representativo macroscópico. Logo, será calculado pela seguinte equação, deduzida no item 2.1: 


$$
\varepsilon_{d}\left\langle v_{d}^{\prime}\right\rangle^{d}=\frac{\varepsilon_{d_{M}}\left\langle v_{d}^{\prime}\right\rangle_{M}^{d}}{\varepsilon_{g_{M}}}
$$

cujo produto $\varepsilon_{d_{M}}\left\langle v_{d}^{\prime}\right\rangle_{M}^{d}$ é obtido pelas equações de partição de escoamento no trabalho de Wang et al. (1995), representado na equação abaixo:

$$
\varepsilon_{d}\left\langle v_{d}^{\prime}\right\rangle^{d}=-\frac{\kappa_{v}\left\langle v_{s}\right\rangle_{M}^{s}}{\varepsilon_{g_{M}}}
$$

onde $\kappa_{v}$ é o coeficiente de partição de escoamento, e $\varepsilon_{g_{M}}=1-\varepsilon_{l_{M}}$. Pela conservação de massa da fase líquida interdendrítica:

$$
\rho \frac{\partial \varepsilon_{d}}{\partial t}+\rho \vec{\nabla} \cdot\left(\varepsilon_{d}\left\langle\vec{v}_{d}^{\prime}\right\rangle^{d}\right)=\Gamma_{d s}+\Gamma_{d e}
$$

e utilizando a Eq. [C6] e os acoplamento entre as fases [B5] (Apêndice B), obtemos o formato final para a conservação de massa na fase líquida interdendrítica:

$$
\frac{\partial \varepsilon_{d}}{\partial t}=-\frac{1}{\rho}\left(\Gamma_{s}+\Gamma_{e}\right)
$$

Analogamente, utilizando as hipóteses da equação anterior (continuidade na fase líquida interdendrítica) na equação da continuidade das fases sólidas, temos respectivamente a equação para a fase sólida primária e para a fase eutética:

$$
\begin{aligned}
& \frac{\partial \varepsilon_{s}}{\partial t}=\frac{1}{\rho} \Gamma_{s} \\
& \frac{\partial \varepsilon_{e}}{\partial t}=\frac{1}{\rho} \Gamma_{e}
\end{aligned}
$$




\subsection{Conservação de Energia no Modelo Microscópico}

Somando-se as equações gerais de conservação de energia de cada fase (Apêndice B, equação [B2]), obtemos uma expressão para a conservação de energia na mistura:

$$
\begin{aligned}
& \frac{\partial}{\partial t}\left(\rho_{s} \varepsilon_{s}\left\langle h_{s}\right\rangle^{s}+\rho_{e} \varepsilon_{e}\left\langle h_{e}\right\rangle^{e}+\rho_{d} \varepsilon_{d}\left\langle h_{d}\right\rangle^{d}\right)= \\
& -\vec{\nabla} \cdot\left(\rho_{s} \varepsilon_{s}\left\langle h_{s}\right\rangle^{s}\left\langle\vec{v}_{s}\right\rangle^{s}+\rho_{e} \varepsilon_{e}\left\langle h_{e}\right\rangle^{e}\left\langle\vec{v}_{e}\right\rangle^{e}+\rho_{d} \varepsilon_{d}\left\langle h_{d}\right\rangle^{d}\left\langle\vec{v}_{d}\right\rangle^{d}\right) \\
& +\vec{\nabla} \cdot\left(\varepsilon_{s} K_{s}^{*} \vec{\nabla}\left\langle T_{s}\right\rangle^{s}\right)+\vec{\nabla} \cdot\left(\varepsilon_{e} K_{e}^{*} \vec{\nabla}\left\langle T_{e}\right\rangle^{e}\right)+\vec{\nabla} \cdot\left(\varepsilon_{d} K_{d}^{*} \vec{\nabla}\left\langle T_{d}\right\rangle^{d}\right)
\end{aligned}
$$

com as entalpias de cada fase definidas por:

$$
h_{s}=C_{P s} T_{s}, h_{e}=C_{P e} T_{e}, h_{d}=C_{P d} T_{d}+L_{f}
$$

Aplicando a hipótese geral 12 (temperaturas médias das fases iguais):

$$
h_{s}=h_{\text {eut }}=C_{P} T, h_{d}=C_{P} T+L_{f}
$$

com a substituição na equação de conservação de energia de mistura e aplicando as hipóteses gerais 2, 3, 7 e 8, e o sistema de referencia no grão (hipótese 6 do submodelo microscópico):

$$
\rho C_{P} \frac{\partial T}{\partial t}+\rho L_{f} \frac{\partial \varepsilon_{d}}{\partial t}=-\rho C_{P} \vec{\nabla} \cdot\left(\varepsilon_{d}\left\langle\vec{v}_{d}^{\prime}\right\rangle^{d} T\right)-\rho L_{f} \vec{\nabla} \cdot\left(\varepsilon_{d}\left\langle\vec{v}_{d}^{\prime}\right\rangle^{d}\right)+\vec{\nabla} \cdot(\bar{K} \vec{\nabla} T)
$$

onde $\bar{K}=\left(\varepsilon_{s}+\varepsilon_{e}\right) K_{s}+\varepsilon_{d} K_{d}$ é definida como a condutividade térmica média efetiva. Aplicando a equação da continuidade para a fase interdendrítica [C11] e a Eq. [C6]:

$$
\rho C_{P} \frac{\partial T}{\partial t}=-\rho C_{P}\left(\varepsilon_{d}\left\langle\vec{v}_{d}^{\prime}\right\rangle^{d}\right) \cdot \vec{\nabla} T+L_{f}\left(\Gamma_{s}+\Gamma_{e}\right)+\vec{\nabla} \cdot(\bar{K} \vec{\nabla} T)
$$


Com as hipótese 4, 5 e 6 do submodelo microscópico (movimento unidirecional), obtemos o formato final da equação de conservação de energia para o modelo microscópico:

$$
\rho C_{P} \frac{\partial T}{\partial t}=-\rho C_{P}\left(\varepsilon_{d}\left\langle v_{d}^{\prime}\right\rangle^{d}\right) \frac{\partial T}{\partial y}+L_{f}\left(\Gamma_{s}+\Gamma_{e}\right)+\vec{\nabla} \cdot(\bar{K} \vec{\nabla} T)
$$

\subsection{Conservação das Espécies Químicas no Líquido Interdendrítico}

Para a equação de espécies químicas no líquido interdendrítico, a expressão geral com a hipótese geral 2, mais o acoplamento entre as fases (Eq. [B7], Apêndice B) é dada por:

$$
\frac{\partial\left(\varepsilon_{d}\left\langle C_{d}\right\rangle^{d}\right)}{\partial t}+\vec{\nabla} \cdot\left(\varepsilon_{d}\left\langle C_{d}\right\rangle^{d}\left\langle\vec{v}_{d}^{\prime}\right\rangle^{d}\right)=\vec{\nabla} \cdot\left(\varepsilon_{d} D_{d}^{*} \vec{\nabla}\left\langle C_{d}\right\rangle^{d}\right)-\frac{1}{\rho}\left(J_{s d}^{\Gamma}+J_{s d}^{D}\right)-\frac{1}{\rho}\left(J_{e, d}^{\Gamma}+J_{e, d}^{D}\right)
$$

Como a difusão nas fases sólidas é desprezada (hipótese geral 9), os termos interfaciais de difusão são nulos, desprezando os termos $J_{s, d}^{\Gamma}$ e $J_{e, d}^{\Gamma}$ :

$$
\frac{\partial\left(\varepsilon_{d}\left\langle C_{d}\right\rangle^{d}\right)}{\partial t}+\vec{\nabla} \cdot\left(\varepsilon_{d}\left\langle C_{d}\right\rangle^{d}\left\langle\vec{v}_{d}^{\prime}\right\rangle^{d}\right)=\vec{\nabla} \cdot\left(\varepsilon_{d} D_{d}^{*} \vec{\nabla}\left\langle C_{d}\right\rangle^{d}\right)-\frac{1}{\rho} J_{s d}^{\Gamma}-\frac{1}{\rho} J_{e, d}^{\Gamma}
$$

Com a definição dos termos interfaciais $J_{s d}^{\Gamma}$ e $J_{e, d}^{\Gamma}$ respectivamente:

$$
\begin{gathered}
J_{s d}^{\Gamma}=\frac{1}{V_{0}} \int_{A_{s d}} \rho_{s} C_{s}\left(\vec{w}_{s}^{\prime}-\vec{v}_{s}^{\prime}\right) \cdot \vec{n}_{s} d A \\
J_{e, d}^{\Gamma}=\frac{1}{V_{0}} \int_{A_{c d}} \rho_{e} C_{e}\left(\vec{w}_{e}^{\prime}-\vec{v}_{e}^{\prime}\right) \cdot \vec{n}_{e} d A
\end{gathered}
$$

mais a hipótese 10 do submodelo microscópico de equilíbrio termodinâmico na interface sólido-líquido em conjunto com a hipótese geral 2, a Eq. [C21] é modificada para: 


$$
J_{s d}^{\Gamma}=k\left\langle C_{d}\right\rangle^{d} \frac{1}{V_{0}} \int_{A_{s d}} \rho_{s}\left(\vec{w}_{s}^{\prime}-\vec{v}_{s}^{\prime}\right) \cdot \vec{n}_{s} d A=k\left\langle C_{d}\right\rangle^{d} \Gamma_{s}
$$

A concentração média na interface da fase eutética é constante e igual a concentração eutética (hipótese 9 do submodelo microscópico), obtendo:

$$
J_{e, d}^{\Gamma}=C_{e} \frac{1}{V_{0}} \int_{A_{e d}} \rho_{e}\left(\vec{w}_{e}^{\prime}-\vec{v}_{e}^{\prime}\right) \cdot \vec{n}_{e} d A=C_{e} \Gamma_{e}
$$

Substituindo as Eq. [C24] e [C25] na Eq. [C20]:

$$
\frac{\partial\left(\varepsilon_{d}\left\langle C_{d}\right\rangle^{d}\right)}{\partial t}+\vec{\nabla} \cdot\left(\varepsilon_{d}\left\langle C_{d}\right\rangle^{d}\left\langle\vec{v}_{d}^{\prime}\right\rangle^{d}\right)=\vec{\nabla} \cdot\left(\varepsilon_{d} D_{d}^{*} \vec{\nabla}\left\langle C_{d}\right\rangle^{d}\right)-\frac{k\left\langle C_{d}\right\rangle^{d}}{\rho} \Gamma_{s}-\frac{C_{e}}{\rho} \Gamma_{e}
$$

Aplicando as Eq. [C7] e Eq. [C9], e a hipótese geral 8, obtemos o formato final para a equação de conservação das espécies químicas para a fase líquida interdendrítica:

$$
\frac{\partial\left(\varepsilon_{d}\left\langle C_{d}\right\rangle^{d}\right)}{\partial t}+\varepsilon_{d}\left\langle v_{d}^{\prime}\right\rangle^{d} \frac{\partial\left\langle C_{d}\right\rangle^{d}}{\partial y}=\vec{\nabla} \cdot\left(\varepsilon_{d} D_{d} \vec{\nabla}\left\langle C_{d}\right\rangle^{d}\right)-\frac{k\left\langle C_{d}\right\rangle^{d}}{\rho} \Gamma_{s}-\frac{C_{e}}{\rho} \Gamma_{e}
$$

\subsection{Conservação das Espécies Químicas na Fase de Sólido Primário}

A equação de conservação de soluto na fase sólida é obtida utilizando as mesmas hipóteses utilizadas para a Eq. [C27]. A equação geral é dada por:

$$
\frac{\partial\left(\varepsilon_{s}\left\langle C_{s}\right\rangle^{s}\right)}{\partial t}+\vec{\nabla} \cdot\left(\varepsilon_{s}\left\langle C_{s}\right\rangle^{s}\left\langle\vec{v}_{s}^{\prime}\right\rangle^{s}\right)=\vec{\nabla} \cdot\left(\varepsilon_{s} D_{s}^{*} \vec{\nabla}\left\langle C_{s}\right\rangle^{s}\right)+\frac{1}{\rho}\left(J_{s d}^{\Gamma}+J_{s d}^{D}\right)+\frac{1}{\rho}\left(J_{s e}^{\Gamma}+J_{s e}^{D}\right)
$$

onde despreza-se os termos difusivos (hipótese geral 9 e $J_{s d}^{D}=J_{s e}^{D}=0$ ), anula-se o termo convectivo (hipótese 6 do submodelo microscópico), e despreza a transformação de fase da fase eutética sobre a fase sólida primária $\left(J_{s e}^{\Gamma}=0\right)$. Substituindo a Eq. [C22], é obtido o formato final: 


$$
\frac{\partial\left(\varepsilon_{s}\left\langle C_{s}\right\rangle^{s}\right)}{\partial t}=\frac{k\left\langle C_{d}\right\rangle^{d}}{\rho} \Gamma_{s}
$$

\section{Submodelo Macroscópico}

O submodelo macroscópico tem como domínio o molde (que é o próprio referencial das equações), e as equações da média são calculadas a partir da Eq. [C4], cujo volume representativo $V_{0_{M}}$ é dado segundo a discretização do domínio macroscópico (Apêndice D). As equações que serão tratadas para o modelo macroscópico são as de conservação de massa, energia e de espécies químicas no líquido extradendrítico. Detalhes sobre o acoplamento micro-macro também serão explicados neste item.

As hipóteses utilizadas por este submodelo são:

1. O domínio deste modelo corresponde ao molde de solidificação, sendo o seu volume representativo (VER) da ordem de escala entre um conjunto de grãos e o tamanho do molde.

2. Há as seguintes pseudofases: sólido primário (s), eutético (e), líquido interdendrítico (d) e líquido extradendrítico (I).

3. Utilizando a hipótese geral 7 , a fase eutética tem velocidade média igual a fase primária: $\left\langle\vec{v}_{e}\right\rangle_{M}^{e}=\left\langle\vec{v}_{s}\right\rangle_{M}^{s}$.

4. Com a hipótese geral 12 , as temperaturas médias das fases no volume representativo são iguais (equilíbrio térmico entre as fases): $\langle T\rangle_{M}=\left\langle T_{s}\right\rangle_{M}^{s}=\left\langle T_{e}\right\rangle_{M}^{e}=\left\langle T_{d}\right\rangle_{M}^{d}=\left\langle T_{l}\right\rangle_{M}^{l}$.

5. Pela hipótese geral 10 , não há área de contato entre a fase de líquido extradendrítico e as fases sólidas, logo: $A_{l s}=A_{l e}=0$ 


\subsection{Conservação de Massa}

Somando-se as equações da continuidade (Apêndice B, Eq. [B4]), com a hipóteses gerais 2 e 7 , obtém-se a conservação de massa da mistura das fases:

$$
\vec{\nabla} \cdot\left[\left(\varepsilon_{s}+\varepsilon_{e}\right)\left\langle\vec{v}_{s}\right\rangle_{M}^{s}+\varepsilon_{d}\left\langle\vec{v}_{d}\right\rangle_{M}^{d}+\varepsilon_{l}\left\langle\vec{v}_{l}\right\rangle_{M}^{l}\right]=0
$$

Com a hipótese de movimento unidirecional, utilizando a condição de contorno de velocidade nula na base do molde:

$$
\left[\left(\varepsilon_{s}+\varepsilon_{e}\right)\left\langle v_{s}\right\rangle_{M}^{s}+\varepsilon_{d}\left\langle v_{d}\right\rangle_{M}^{d}+\varepsilon_{l}\left\langle v_{l}\right\rangle_{M}^{l}\right]=0
$$

Definindo-se $\varepsilon_{f}=\varepsilon_{d}+\varepsilon_{l}$ como a fase líquida total, e $\varepsilon_{f}\left\langle\vec{v}_{f}\right\rangle_{M}^{f}=\varepsilon_{d}\left\langle\vec{v}_{d}\right\rangle_{M}^{d}+\varepsilon_{l}\left\langle\vec{v}_{l}\right\rangle_{M}^{l}$ a velocidade líquida média total, temos a partir da Eq. [C31]:

$$
\varepsilon_{f}\left\langle v_{f}\right\rangle_{M}^{f}=-\left(\varepsilon_{s}+\varepsilon_{e}\right)\left\langle v_{s}\right\rangle_{M}^{s}
$$

O modelo de Wang et al. (1995) tem a seguinte equação para calcular distintivamente a velocidade de cada fase líquida:

$$
\varepsilon_{d_{M}}\left\langle v_{f}\right\rangle_{M}^{f}=\varepsilon_{d_{M}}\left\langle v_{s}\right\rangle_{M}^{s}+\varepsilon_{f_{M}} \kappa_{v}\left(\left\langle v_{f}\right\rangle_{M}^{f}-\left\langle v_{s}\right\rangle_{M}^{s}\right)
$$

Substituindo a equação [C32] na [C33]:

$$
\varepsilon_{d_{M}}\left(\left\langle v_{f}\right\rangle_{M}^{f}-\left\langle v_{s}\right\rangle_{M}^{s}\right)=-\kappa_{v}\left\langle v_{s}\right\rangle_{M}^{s}
$$

que será reescrita em termos da velocidade relativa média:

$$
\varepsilon_{d_{M}}\left\langle v_{d}^{\prime}\right\rangle_{M}^{d}=-\kappa_{v}\left\langle v_{s}\right\rangle_{M}^{s}
$$

e sob a hipótese que a velocidade relativa média é aproximadamente igual a média das velocidades relativas: 


$$
\varepsilon_{d_{M}}\left\langle v_{d}^{\prime}\right\rangle_{M}^{d} \approx \frac{1}{V_{0_{M}}} \int_{V_{d_{M}}}\left(v_{d}-v_{s}\right) d V
$$

é possível acoplar os submodelos através da equação [C9] pela identidade:

$$
\varepsilon_{d_{M}}\left\langle v_{d}^{\prime}\right\rangle_{M}^{d} \approx \varepsilon_{g_{M}}\left(\varepsilon_{d}\left\langle v_{d}^{\prime}\right\rangle^{d}\right)
$$

\subsection{Conservação de Energia}

A equação geral para conservação de energia é expressa em termo das entalpias médias (Apêndice B, Eq. [B2]). Somando-se as equações de conservação de cada fase, obtemos a equação de conservação de energia de mistura dada por:

$$
\begin{aligned}
& \frac{\partial}{\partial t}\left(\rho_{s} \varepsilon_{s} h_{s}+\rho_{e} \varepsilon_{e} h_{e}+\rho_{d} \varepsilon_{d} h_{d}+\rho_{l} \varepsilon_{l} h_{l}\right)= \\
& -\vec{\nabla} \cdot\left(\rho_{s} \varepsilon_{s} h_{s}\left\langle\vec{v}_{s}\right\rangle^{s}+\rho_{e} \varepsilon_{e} h_{e}\left\langle\vec{v}_{e}\right\rangle^{e}+\rho_{d} \varepsilon_{d} h_{d}\left\langle\vec{v}_{d}\right\rangle^{d}+\rho_{l} \varepsilon_{l} h_{l}\left\langle\vec{v}_{l}\right\rangle^{l}\right) \\
& +\vec{\nabla} \cdot\left(\varepsilon_{s} K_{s}^{*} \vec{\nabla} T_{s}\right)+\vec{\nabla} \cdot\left(\varepsilon_{e} K_{e}^{*} \vec{\nabla} T_{e}\right)+\vec{\nabla} \cdot\left(\varepsilon_{d} K_{d}^{*} \vec{\nabla} T_{d}\right)+\vec{\nabla} \cdot\left(\varepsilon_{l} K_{l}^{*} \vec{\nabla} T_{l}\right)
\end{aligned}
$$

sendo as definições para a entalpia média de cada fase análogas a Eq. [C15], mas com a temperatura média macroscópica $\left(h_{l}=C_{P l}\left\langle T_{l}\right\rangle^{l}+L_{f}\right)$. As hipóteses gerais 2, 3 , 7, e 12 aplicadas, transformam a Eq. [C38] em:

$$
\begin{aligned}
& \rho C_{P} \frac{\partial\langle T\rangle_{M}}{\partial t}-\rho L_{f} \frac{\partial\left(\varepsilon_{s}+\varepsilon_{e}\right)}{\partial t}+\rho L_{f} \vec{\nabla} \cdot\left(\varepsilon_{f}\left\langle\vec{v}_{f}\right\rangle^{f}\right)= \\
& -\rho \vec{\nabla} \cdot\left\{C_{P}\langle T\rangle_{M}\left[\left(\varepsilon_{s_{M}}+\varepsilon_{e_{M}}\right)\left\langle\vec{v}_{s}\right\rangle^{s}+\varepsilon_{f}\left\langle\vec{v}_{f}\right\rangle^{f}\right]\right\}+\vec{\nabla} \cdot\left(\bar{K} \vec{\nabla}\langle T\rangle_{M}\right)
\end{aligned}
$$

onde $\bar{K}=\varepsilon_{s} K_{s}+\varepsilon_{e} K_{e}+\varepsilon_{d} K_{d}+\varepsilon_{l} K_{l}$.

Com a Eq. [C32], e a equação da continuidade para as fases sólidas (Apêndice B, [B4]), a equação tem o formato: 


$$
\rho C_{P} \frac{\partial\langle T\rangle_{M}}{\partial t}=L_{f}\left(\Gamma_{s_{M}}+\Gamma_{e_{M}}\right)+\vec{\nabla} \cdot\left(\bar{K} \vec{\nabla}\langle T\rangle_{M}\right)
$$

Como o transporte de calor neste trabalho foi calculado apenas em uma direção, a equação final é:

$$
\rho C_{P} \frac{\partial\langle T\rangle_{M}}{\partial t}=L_{f}\left(\Gamma_{s_{M}}+\Gamma_{e_{M}}\right)+\frac{\partial}{\partial y}\left(\bar{K} \frac{\partial\langle T\rangle_{M}}{\partial y}\right)
$$

\subsection{Conservação de Massa no Líquido Extradendrítico}

A equação de conservação de massa utilizada pelo modelo é deduzida a partir da equação diferencial da continuidade usual, e não multifásico como utilizada até então.

$$
\frac{\partial \rho_{l}}{\partial t}+\vec{\nabla} \cdot\left(\rho_{l} \vec{v}_{l}\right)=0
$$

Com a condição de densidade constante, a equação da continuidade toma a forma da equação para fluidos incompressíveis:

$$
\vec{\nabla} \cdot \vec{v}_{l}=0
$$

Aplicando a média do divergente (Whitaker, 1969):

$$
\left\langle\vec{\nabla} \cdot \vec{\psi}_{k}\right\rangle=\vec{\nabla} \cdot\left(\varepsilon_{k}\left\langle\vec{\psi}_{k}\right\rangle^{k}\right)+\sum_{j, j \neq k} \frac{1}{V_{0}} \int_{A_{k j}} \vec{\psi}_{k} \cdot \vec{n}_{k} d A
$$

sobre a Eq. [C43], assumindo que apenas a fase líquida extradendrítica tem apenas área de contato sobre a fase líquida interdendrítica:

$$
\left\langle\vec{\nabla} \cdot \vec{v}_{l}\right\rangle_{M}=\vec{\nabla} \cdot\left(\varepsilon_{l_{M}}\left\langle\vec{v}_{l}\right\rangle_{M}^{l}\right)+\frac{1}{V_{0_{M}}} \int_{A_{d d}} \vec{v}_{l} \cdot \vec{n}_{l} d A=0
$$


com a hipótese de movimento unidirecional, obtemos a equação para o cálculo do divergente da velocidade média do líquido extradendrítico:

$$
\frac{\partial}{\partial y}\left(\varepsilon_{l_{M}}\left\langle v_{l}\right\rangle_{M}^{l}\right)=-\frac{1}{V_{0_{M}}} \int_{A_{d d}} \vec{v}_{l} \cdot \vec{n}_{l} d A
$$

Como a velocidade do líquido na interface do grão deve ser igual à condição de contorno de $\varepsilon_{d}\left\langle v_{d}^{\prime}\right\rangle^{d}$ no outro referencial, podemos fazer uma substituição com:

$$
\vec{v}_{l}=\vec{v}_{l}^{\prime}+\vec{v}_{s}=\varepsilon_{d}\left\langle\vec{v}_{d}\right\rangle^{d}+\vec{v}_{s}=-\frac{\kappa_{v}\left\langle\vec{v}_{s}\right\rangle_{M}^{s}}{\varepsilon_{g_{M}}}+\vec{v}_{s}
$$

Portanto:

$$
\frac{\partial}{\partial y}\left(\varepsilon_{l_{M}}\left\langle v_{l}\right\rangle_{M}^{l}\right)=\frac{1}{V_{0_{M}}} \int_{A_{d d}}\left[\frac{\kappa_{v}\left\langle\vec{v}_{s}\right\rangle_{M}^{s}}{\varepsilon_{g_{M}}}-\vec{v}_{s}\right] \cdot \vec{n}_{l} d A
$$

Para auxiliar a dedução da equação de espécies químicas no próximo item, é utilizado o mesmo método para obter uma expressão para outros termos da equação da continuidade. Aplica-se a média (Whitaker, 1969) sobre o primeiro termo da Eq. [C42]:

$$
\left\langle\frac{\partial \rho_{l}}{\partial t}\right\rangle_{M}=\frac{\partial\left(\varepsilon_{l_{M}} \rho_{l}\right)}{\partial t}-\frac{1}{V_{0_{M}}} \int_{A_{d d}} \rho_{l} \vec{w}_{l} \cdot \vec{n}_{l} d A
$$

onde $\vec{w}_{l}$ é a velocidade total da interface:

$$
\vec{w}_{l}=\vec{w}_{g}^{\prime}+\vec{v}_{s}
$$

onde $\vec{v}_{s}$ é a velocidade do grão que a interface está contida e $\vec{w}_{g}^{\prime}$ a velocidade de crescimento do grão. Com densidade constante, a equação se torna: 


$$
\frac{\partial \varepsilon_{l_{M}}}{\partial t}=\frac{1}{V_{0_{M}}} \int_{A_{d d}}\left(\vec{w}_{g}^{\prime}+\vec{v}_{s}\right) \cdot \vec{n}_{l} d A
$$

\subsection{Conservação das Espécies Químicas no Líquido Extradendrítico}

A equação geral da média das espécies químicas (Apêndice B, Eq. [B3]) para a fase líquida extradendrítica com densidade constante e área interfacial apenas com a fase líquida interdendrítica:

$$
\frac{\partial}{\partial t}\left(\varepsilon_{l_{M}}\left\langle C_{l}\right\rangle_{M}^{l}\right)+\vec{\nabla} \cdot\left(\varepsilon_{l_{M}}\left\langle C_{l}\right\rangle_{M}^{l}\left\langle\vec{v}_{l}\right\rangle_{M}^{l}\right)=\vec{\nabla} \cdot\left(\varepsilon_{l_{M}} D_{l}^{*} \vec{\nabla}\left\langle C_{l}\right\rangle_{M}^{l}\right)+\frac{J_{l d}^{\Gamma}}{\rho}+\frac{J_{l d}^{D}}{\rho}
$$

Despreza-se o termo difusivo (macro-difusão) e no primeiro termo, se aplica a regra da cadeia:

$$
\left\langle C_{l}\right\rangle_{M}^{l} \frac{\partial \varepsilon_{l_{M}}}{\partial t}+\varepsilon_{l_{M}} \frac{\partial\left\langle C_{l}\right\rangle_{M}^{l}}{\partial t}+\vec{\nabla} \cdot\left(\varepsilon_{l_{M}}\left\langle C_{l}\right\rangle_{M}^{l}\left\langle\vec{v}_{l}\right\rangle_{M}^{l}\right)=\frac{J_{l d}^{\Gamma}}{\rho}+\frac{J_{l d}^{D}}{\rho}
$$

e subsititui os termos interfaciais pelas definições (Eq. [B9] e [B10]):

$$
\begin{aligned}
& \left\langle C_{l}\right\rangle_{M}^{l} \frac{\partial \varepsilon_{l_{M}}}{\partial t}+\varepsilon_{l_{M}} \frac{\partial\left\langle C_{l}\right\rangle_{M}^{l}}{\partial t}+\vec{\nabla} \cdot\left(\varepsilon_{l_{M}}\left\langle C_{l}\right\rangle_{M}^{l}\left\langle\vec{v}_{l}\right\rangle_{M}^{l}\right)= \\
& \frac{1}{V_{0_{M}}} \int_{A_{d d}} C_{l}\left(\vec{w}_{l}-\vec{v}_{l}\right) \cdot \vec{n}_{l} d A-\frac{1}{V_{0_{M}}} \int_{A_{d d}} \vec{j}_{l d} \cdot \vec{n}_{l} d A
\end{aligned}
$$

Substitui a Eq. [C51] na Eq. [C54]:

$$
\begin{aligned}
& \varepsilon_{l_{M}} \frac{\partial\left\langle C_{l}\right\rangle_{M}^{l}}{\partial t}+\vec{\nabla} \cdot\left(\varepsilon_{l_{M}}\left\langle C_{l}\right\rangle_{M}^{l}\left\langle\vec{v}_{l}\right\rangle_{M}^{l}\right)=\frac{1}{V_{0_{M}}} \int_{A_{d d}}\left(C_{l}-\left\langle C_{l}\right\rangle_{M}^{l}\right) \vec{w}_{l} \cdot \vec{n}_{l} d A+ \\
& -\frac{1}{V_{0_{M}}} \int_{A_{d}} C_{l} \vec{V}_{l} \cdot \vec{n}_{l} d A-\frac{1}{V_{0_{M}}} \int_{A_{d d}} \vec{j}_{l d} \cdot \vec{n}_{l} d A
\end{aligned}
$$

O fluxo difusivo entre a interface do grão e o líquido extradendrítico pode ser expresso em termos de uma espessura efetiva de difusão (Apêndice $E$ ): 


$$
\vec{j}_{l d}=-\frac{D_{l}}{\delta_{l d}}\left(C_{l}-\left\langle C_{l}\right\rangle_{M}^{l}\right) \vec{n}_{l}
$$

Substituindo a Eq. [C56] na [C55]:

$$
\begin{aligned}
& \varepsilon_{l_{M}} \frac{\partial\left\langle C_{l}\right\rangle_{M}^{l}}{\partial t}+\vec{\nabla} \cdot\left(\varepsilon_{l_{M}}\left\langle C_{l}\right\rangle_{M}^{l}\left\langle\vec{v}_{l}\right\rangle_{M}^{l}\right)= \\
& \frac{1}{V_{0_{M}}} \int_{A_{d}}\left(C_{l}-\left\langle C_{l}\right\rangle_{M}^{l}\right)\left(\vec{w}_{l}+\frac{D_{l}}{\delta_{l d}} \vec{n}_{l}\right) \cdot \vec{n}_{l} d A-\frac{1}{V_{0_{M}}} \int_{A_{l d}} C_{l} \vec{v}_{l} \cdot \vec{n}_{l} d A
\end{aligned}
$$

Os valores de $C_{l}$ na interface do grão serão aproximados pelo valor médio de concentração no líquido interdendrítico $\left\langle C_{d}\right\rangle^{d} \quad$ (calculado pelo submodelo microscópico):

$$
\begin{aligned}
& \varepsilon_{l_{M}} \frac{\partial\left\langle C_{l}\right\rangle_{M}^{l}}{\partial t}+\vec{\nabla} \cdot\left(\varepsilon_{l_{M}}\left\langle C_{l}\right\rangle_{M}^{l}\left\langle\vec{v}_{l}\right\rangle_{M}^{l}\right)= \\
& \frac{1}{V_{0_{M}}} \int_{A_{d d}}\left(\left\langle C_{d}\right\rangle^{d}-\left\langle C_{l}\right\rangle_{M}^{l}\right)\left(\vec{w}_{l}+\frac{D_{l}}{\delta_{l d}} \vec{n}_{l}\right) \cdot \vec{n}_{l} d A-\frac{1}{V_{0_{M}}} \int_{A_{d}}\left\langle C_{d}\right\rangle^{d} \vec{v}_{l} \cdot \vec{n}_{l} d A
\end{aligned}
$$

A velocidade do líquido na interface do grão é calculada através do modelo de partição de escoamento do trabalho de Wang et al. (1995), substituindo $\vec{v}_{l}$ na interface por:

$$
\vec{v}_{l}=\vec{v}_{l}^{\prime}+\vec{v}_{s}=\varepsilon_{d}\left\langle\vec{v}_{d}^{\prime}\right\rangle^{d}-\vec{v}_{s}=-\frac{\kappa_{v}\left\langle\vec{v}_{s}\right\rangle_{M}^{s}}{\varepsilon_{g_{M}}}+\vec{v}_{s}
$$

onde $\vec{v}_{s}$ é a velocidade de translação do grão que a interface pertence. Substituindo as Eq. [C59] e [C50] na Eq. [C58], e assumindo movimento unidirecional, é obtido o formato final da equação diferencial solucionada pelo modelo:

$$
\begin{aligned}
& \varepsilon_{l_{M}} \frac{\partial\left\langle C_{l}\right\rangle_{M}^{l}}{\partial t}+\frac{\partial}{\partial y}\left(\varepsilon_{l_{M}}\left\langle C_{l}\right\rangle_{M}^{l}\left\langle v_{l}\right\rangle_{M}^{l}\right)=\frac{1}{V_{0_{M}}} \int_{A_{d d}}\left\langle C_{d}\right\rangle^{d}\left[\frac{\kappa_{v}\left\langle\vec{v}_{s}\right\rangle_{M}^{s}}{\varepsilon_{g_{M}}}-\vec{v}_{s}\right] \cdot \vec{n}_{l} d A \\
& +\frac{1}{V_{0_{M}}} \int_{A_{A_{d}}}\left(\left\langle C_{d}\right\rangle^{d}-\left\langle C_{l}\right\rangle_{M}^{l}\right)\left(\vec{w}_{g}^{\prime}+\vec{v}_{s}+\frac{D_{l}}{\delta_{l d}} \vec{n}_{l}\right) \cdot \vec{n}_{l} d A
\end{aligned}
$$


Separando o termo convectivo (segundo termo), é possível obter uma restrição para a espessura de difusão:

$$
\begin{aligned}
& \varepsilon_{l_{M}} \frac{\partial\left\langle C_{l}\right\rangle_{M}^{l}}{\partial t}+\varepsilon_{l_{M}}\left\langle v_{l}\right\rangle_{M}^{l} \frac{\partial\left\langle C_{l}\right\rangle_{M}^{l}}{\partial y}=\frac{1}{V_{0_{M}}} \int_{A_{l_{d}}}\left(\left\langle C_{d}\right\rangle^{d}-\left\langle C_{l}\right\rangle_{M}^{l}\right)\left(\vec{w}_{g}^{\prime}+\vec{v}_{s}+\frac{D_{l}}{\delta_{l d}} \vec{n}_{l}\right) \cdot \vec{n}_{l} d A \\
& -\left\langle C_{l}\right\rangle_{M}^{l} \frac{\partial}{\partial y}\left(\varepsilon_{l_{M}}\left\langle v_{l}\right\rangle_{M}^{l}\right)+\frac{1}{V_{0_{M}}} \int_{A_{l d}}\left\langle C_{d}\right\rangle^{d}\left(\frac{\kappa_{v}\left\langle\vec{v}_{s}\right\rangle_{M}^{s}}{\varepsilon_{g_{M}}}-\vec{v}_{s}\right) \cdot \vec{n}_{l} d A
\end{aligned}
$$

e, enfim, substituindo a Eq. [C46] na Eq. [C60]:

$$
\begin{aligned}
& \varepsilon_{l_{M}} \frac{\partial\left\langle C_{l}\right\rangle_{M}^{l}}{\partial t}+\varepsilon_{l_{M}}\left\langle v_{l}\right\rangle_{M}^{l} \frac{\partial\left\langle C_{l}\right\rangle_{M}^{l}}{\partial y}= \\
& \frac{1}{V_{0_{M}}} \int_{A_{l d}}\left(\left\langle C_{d}\right\rangle^{d}-\left\langle C_{l}\right\rangle_{M}^{l}\right)\left(\vec{w}_{g}^{\prime}+\frac{D_{l}}{\delta_{l d}} \vec{n}_{l}+\frac{\kappa_{v}\left\langle\vec{v}_{s}\right\rangle_{M}^{s}}{\varepsilon_{g_{M}}}\right) \cdot \vec{n}_{l} d A
\end{aligned}
$$

Se a diferença $\left\langle C_{d}\right\rangle^{d}-\left\langle C_{l}\right\rangle_{M}^{l}$ for sempre positiva, sem gradiente de concentração, a variação de $\left\langle C_{l}\right\rangle_{M}^{l}$ no tempo deve ser sempre positiva (WANG; BECKERMANN, 1993). Portanto, deve ser sempre positivo o termo:

$$
\left(\vec{w}_{g}^{\prime}+\frac{D_{l}}{\delta_{l d}} \vec{n}_{l}+\frac{\kappa_{v}\left\langle\vec{v}_{s}\right\rangle_{M}^{s}}{\varepsilon_{g_{M}}}\right) \cdot \vec{n}_{l} \geq 0
$$

fornecendo uma nova restrição para a espessura de difusão:

$$
\delta_{l d} \leq \frac{D_{l}}{\left(\frac{\kappa_{v}\left\langle\vec{v}_{s}\right\rangle_{M}^{s}}{\varepsilon_{g_{M}}}+\vec{w}_{g}^{\prime}\right) \cdot\left(-\vec{n}_{l}\right)}
$$

calculado em cada ponto na interface de um grão. O critério mais restritivo é fornecido por: 


$$
\delta_{l d} \leq \frac{D_{l}}{\frac{\kappa_{v}\left|\left\langle\vec{v}_{s}\right\rangle_{M}^{s}\right|}{\varepsilon_{g_{M}}}+\left|\vec{w}_{g}^{\prime}\right|}
$$




\section{APÊNDICE D - DISCRETIZAÇÃO DAS EQUAÇÕES DE CONSERVAÇÃO}

Neste apêndice, são demonstradas as etapas de discretização de cada equação diferencial utilizada pelo modelo. A discretização das equações é feita através da técnica dos volumes finitos, onde a malha de volumes finitos do submodelo microscópico coincide com a malha de autômato celular, e a malha de volumes finitos do submodelo macroscópico contém um conjunto de células de CA (Figura D1).
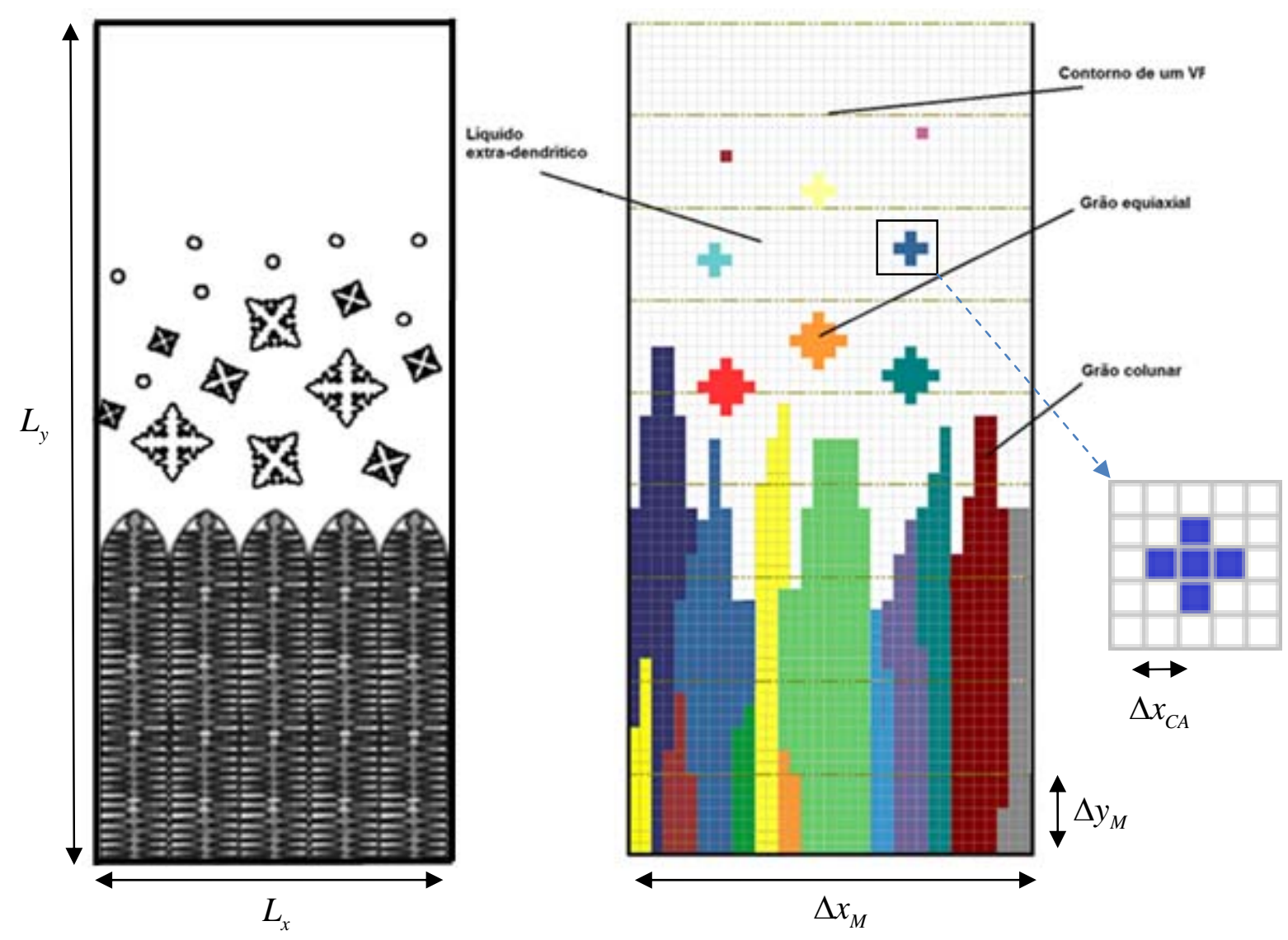

Figura D1 - Representação do domínio do molde e a malha de discretização dos submodelos micro e macroscópico, onde a malha de volumes finitos do submodelo microscópico (com dimensão

$\Delta x_{C A}$ ) coincide com a malha de CA e o volume finito macroscópico (com dimensões $\Delta x_{M}$ e $\Delta y_{M}$ ) contém um conjunto de células de CA. 


\section{Submodelo Microscópico}

O submodelo microscópico tem como domínio os cada grão definido pelo $\mathrm{CA}$, e sua malha de volumes finitos coincide com a malha de CA (Figura D1)

\subsection{Conservação de Massa}

A equação de conservação de massa para a fase líquida interdendrítica (Eq. [C11]) é discretizada integrando ambos os lados pela variável do tempo:

$$
\int_{t}^{t+\Delta t} \frac{\partial \varepsilon_{d}}{\partial t} d t=-\frac{1}{\rho} \int_{t}^{t+\Delta t}\left(\Gamma_{s}+\Gamma_{e}\right) d t
$$

Considerando as hipóteses para o método dos volumes na forma explícita, o termo do lado direito é considerado constante no intervalo de tempo integrado:

$$
\varepsilon_{d P}^{t+\Delta t}=\varepsilon_{d P}^{t}-\frac{1}{\rho}\left(\Gamma_{s P}^{t}+\Gamma_{e P}^{t}\right) \Delta t
$$

Analogamente, para aas equações de conservação de massa para a fase de sólido primário (Eq. [C12]) e eutético (Eq. [C13]):

$$
\begin{aligned}
& \int_{t}^{t+\Delta t} \frac{\partial \varepsilon_{s}}{\partial t} d t=\int_{t}^{t+\Delta t} \frac{1}{\rho} \Gamma_{s} d t \\
& \varepsilon_{s P}^{t+\Delta t}=\varepsilon_{s P}^{t+\Delta t}+\frac{\Gamma_{s P}^{t}}{\rho} \Delta t \\
& \int_{t}^{t+\Delta t} \frac{\partial \varepsilon_{e}}{\partial t} d t=\frac{1}{\rho} \int_{t}^{t+\Delta t} \Gamma_{e} d t \\
& \varepsilon_{e P}^{t+\Delta t}=\varepsilon_{e P}^{t}+\frac{1}{\rho} \Gamma_{e P}^{t} \Delta t
\end{aligned}
$$




\subsection{Conservação de Energia}

A equação de conservação de energia no modelo microscópico é discretizada integrando ambos os lados pelas variáveis de tempo "t" e espacial "y", devido ao termo convectivo:

$$
\begin{aligned}
& \rho C_{P} \int_{t}^{t+\Delta t} \int_{y_{s}}^{y_{p}}\left[\frac{\partial T}{\partial t}+\varepsilon_{d}\left\langle v_{d}^{\prime}\right\rangle^{d} \frac{\partial\langle T\rangle_{M}}{\partial y}\right] d y d t=L_{f} \int_{t}^{t+\Delta t} \int_{y_{s}}^{y_{s}}\left(\Gamma_{s}+\Gamma_{e}\right) d y d t \\
& +\int_{t}^{t+\Delta t} \int_{y_{s}}^{y_{s}}\left[\frac{\partial}{\partial y}\left(\bar{K} \frac{\partial\langle T\rangle_{M}}{\partial y}\right)\right] d y d t
\end{aligned}
$$

$\mathrm{Na}$ forma explícita, o método dos volumes finites conta com a aproximação das integrais considerando as variáveis da derivada temporal constantes no espaço integrado e as variáveis das derivadas espaciais constantes no intervalo de tempo integrado:

$$
\begin{aligned}
& \rho C_{P}\left(T_{P}^{t+\Delta t}-T_{P}^{t}\right) \Delta y_{C A}-\left[\frac{\kappa_{v}\left\langle v_{s}\right\rangle_{M}^{s}}{\varepsilon_{g_{M}}}\right]_{P}^{t}\left(\langle T\rangle_{M}\right)_{y_{s}}^{y_{n}} \Delta t= \\
& =L_{f}\left(\Gamma_{s P}^{t}+\Gamma_{e P}^{t}\right) \Delta t \Delta y_{C A}+\left[\frac{\partial}{\partial y}\left(\bar{K} \frac{\partial\langle T\rangle_{M}}{\partial y}\right)\right]_{P}^{t} \Delta t \Delta y_{C A}
\end{aligned}
$$

Assim, o termo convectivo se torna um produto entre a velocidade relativa da fase líquida e a diferença de temperatura em cada interface do volume, sendo esta temperatura $\langle T\rangle_{M}$ interpolado do submodelo macroscópico na respectiva interface do volume finito do submodelo microscópico. O termo de difusão de calor não é discretizado, pois é obtido através da interpolação do termo já discretizado no submodelo macroscópico, como no modelo de Gandin e Rappaz (1994). A temperatura no instante "t" dentro do volume finito também é interpolado do submodelo macroscópico como um acoplamento "extra". Isolando a temperatura no instante seguinte, obtemos: 


$$
\begin{aligned}
& T_{P}^{t+\Delta t}=\langle T\rangle_{M P}{ }^{t}+\left[\frac{\kappa_{v}\left\langle v_{s}\right\rangle_{M}^{s}}{\varepsilon_{g_{M}}}\right]_{P}^{t} \frac{\Delta t}{\Delta y_{C A}}\left(\langle T\rangle_{M y_{n}}{ }^{t}-\langle T\rangle_{M y_{n}}{ }^{t}\right) \\
& +\frac{L_{f} \Delta t}{\rho C_{P}}\left(\Gamma_{s P}{ }^{t}+\Gamma_{e P}^{t}\right)+\frac{\Delta t}{\rho C_{P}}\left[\frac{\partial}{\partial y}\left(\bar{K} \frac{\partial\langle T\rangle_{M}}{\partial y}\right)\right]_{P}^{t}
\end{aligned}
$$

A equação pode ser finalmente expressa da seguinte forma compacta:

$$
T_{P}^{t+\Delta t}=\langle T\rangle_{M P}{ }^{t}+a_{\Delta T}^{T} \Delta T_{y_{s}}^{y_{n}}+a_{\Gamma}^{T}\left(\Gamma_{s P}{ }^{t}+\Gamma_{e P}{ }^{t}\right)+\frac{\Delta H_{M P}{ }^{t}}{\rho C_{P}}
$$

onde, cada coeficiente e termo são definidos por:

$$
\begin{gathered}
a_{\Delta T}^{T}=\left[\frac{\kappa_{v}\left\langle v_{s}\right\rangle_{M}^{s}}{\varepsilon_{g_{M}}}\right]_{P}^{t} \frac{\Delta t}{\Delta y_{C A}} \\
\Delta T_{y_{s}}^{y_{n}}=\langle T\rangle_{M y_{n}}{ }^{t}-\langle T\rangle_{M y_{n}}{ }^{t} \\
a_{\Gamma}^{T}=\frac{L_{f} \Delta t}{\rho C_{P}} \\
\Delta H_{M P}{ }^{t}=\Delta t\left[\frac{\partial}{\partial y}\left(\bar{K} \frac{\partial\langle T\rangle_{M}}{\partial y}\right)\right]
\end{gathered}
$$

\subsection{Conservação de Soluto}

Para simplificação de notação, alguns termos serão escritos de maneira diferente do que estão na equação diferencial, sendo eles:

$$
\begin{gathered}
\left\langle C_{d}\right\rangle^{d}=C_{d} \\
D_{d}^{*}=D
\end{gathered}
$$


Aplica-se a técnica dos volumes finitos na forma explícita integrando cada termo nas variáveis "t", "y" e "x" (pois há difusão na direção horizontal):

$$
\begin{aligned}
& \int_{t}^{t+\Delta t} \int_{y_{s}}^{y_{n}} \int_{x_{w}}^{x_{e}} \frac{\partial\left(\varepsilon_{d} C_{d}\right)}{\partial t} d x d y d t+\int_{t}^{t+\Delta t} \int_{y_{s}}^{y_{n}} \int_{x_{w}}^{x_{e}}\left[\varepsilon_{d}\left\langle v_{d}^{\prime}\right\rangle^{d} \frac{\partial C_{d}}{\partial y}\right] d x d y d t= \\
& \int_{t}^{t+\Delta t} \int_{y_{s}}^{y_{n}} \int_{x_{w}}^{x_{e}} \frac{\partial}{\partial x}\left(\varepsilon_{d} D \frac{\partial C_{d}}{\partial x}\right) d x d y d t+\int_{t}^{t+\Delta t} \int_{y_{s}}^{y_{n}} \int_{x_{w}}^{x_{e}} \frac{\partial}{\partial y}\left(\varepsilon_{d} D \frac{\partial C_{d}}{\partial y}\right) d x d y d t \\
& -\frac{k}{\rho} \int_{t}^{t+\Delta t} \int_{y_{s}}^{y_{x_{n}}} \int_{x_{w}}^{x_{e}} C_{d} \Gamma_{s} d x d y d t-\frac{C_{e}}{\rho} \int_{t}^{t+\Delta t} \int_{y_{s}}^{y_{n}} \int_{x_{w}}^{x_{e}} \Gamma_{e} d x d y d t
\end{aligned}
$$

Com as mesmas considerações durante a integração para as equações anteriores, e substituindo a Eq. [D2] no termo $\varepsilon_{d P}^{t+\Delta t}$ :

$$
\begin{aligned}
& {\left[\varepsilon_{d P}^{t}-\frac{1}{\rho}\left(\Gamma_{s P}^{t}+\Gamma_{e P}^{t}\right) \Delta t\right] C_{d P}^{t+\Delta t}=\varepsilon_{d P}^{t} C_{d P}^{t}-\left[\frac{\kappa_{v}\left\langle v_{s}\right\rangle_{M}^{s}}{\varepsilon_{g_{M}}}\right]_{P}^{t}\left(C_{d y_{n}}^{t}-C_{d y_{s}}^{t}\right) \frac{\Delta t}{\Delta y_{C A}}=} \\
& {\left[\left(\varepsilon_{d} D \frac{\partial C_{d}}{\partial x}\right)_{x_{e}}^{t}-\left(\varepsilon_{d} D \frac{\partial C_{d}}{\partial x}\right)_{x_{w}}^{t}\right] \frac{\Delta t}{\Delta x_{C A}}+\left[\left(\varepsilon_{d} D \frac{\partial C_{d}}{\partial y}\right)_{y_{n}}^{t}-\left(\varepsilon_{d} D \frac{\partial C_{d}}{\partial y}\right)_{y_{s}}^{t}\right] \frac{\Delta t}{\Delta y_{C A}}-\frac{\Delta t}{\rho}\left(k C_{d P}^{t} \Gamma_{s P}^{t}-C_{e} \Gamma_{e P}^{t}\right)}
\end{aligned}
$$

Os fluxos difusivos para um nó central são calculados através da difusividade equivalente entre cada voluma finito, sendo em cada direção substituído por:

$$
\begin{aligned}
& \left(\varepsilon_{d} D \frac{\partial C_{d}}{\partial x}\right)_{x_{e}}^{t}=\frac{\left(C_{d E}^{t}-C_{d P}^{t}\right)}{\frac{\delta x_{e}^{+}}{\varepsilon_{d E}^{t} D_{E}}+\frac{\delta x_{e}^{-}}{\varepsilon_{d P}^{t} D_{P}}} \quad[\mathrm{D} 17] \quad\left(\varepsilon_{d} D \frac{\partial C_{d}}{\partial y}\right)_{y_{n}}^{t}=\frac{\left(C_{d N}^{t}-C_{d P}^{t}\right)}{\frac{\delta y_{n}^{+}}{\varepsilon_{d N}{ }^{t} D_{N}}+\frac{\delta y_{n}^{-}}{\varepsilon_{d P}^{t} D_{P}}} \\
& \left(\varepsilon_{d} D \frac{\partial C_{d}}{\partial x}\right)_{x_{w}}^{t}=\frac{\left(C_{d P}^{t}-C_{d W}^{t}\right)}{\frac{\delta x_{w}^{+}}{\varepsilon_{d W}^{t} D_{W}}+\frac{\delta x_{w}^{-}}{\varepsilon_{d P}^{t} D_{P}}} \quad[\mathrm{D} 19] \quad\left(\varepsilon_{d} D \frac{\partial C_{d}}{\partial y}\right)_{y_{s}}^{t}=\frac{\left(C_{d P}{ }^{t}-C_{d S}{ }^{t}\right)}{\frac{\delta y_{s}^{+}}{\varepsilon_{d S}^{t} D_{S}}+\frac{\delta y_{s}^{-}}{\varepsilon_{d P}^{t} D_{P}}}
\end{aligned}
$$

onde $\delta x_{e}^{+}$é a distância entre a interface $x_{e}$ e o ponto $\mathrm{E} ; \delta x_{e}^{-}$é a distância entre a interface $x_{e}$ e o ponto $\mathrm{P} ; \delta x_{w}^{-}$é a distância entre a interface $x_{w}$ e o ponto $\mathrm{P} ; \delta x_{w}^{+}$é a distância entre a interface $x_{w}$ e o ponto W; $\delta y_{n}^{+}$é a distância entre a interface $y_{n}$ e o ponto $\mathrm{N} ; \delta y_{n}^{-}$é a distância entre a interface $y_{n}$ e o ponto $\mathrm{P} ; \delta y_{s}^{+}$é a distância entre a interface $y_{s}$ e o ponto $\mathrm{S} ; \delta y_{s}^{-}$é a distância entre a interface $y_{s}$ e o ponto $\mathrm{P}$; e os 
coeficientes $D_{W}, D_{E}, D_{N}, D_{S}$ e $D_{P}$ são os coeficientes de difusão na fase líquida calculados nos pontes $\mathrm{W}, \mathrm{E}, \mathrm{N}, \mathrm{S}$ e $\mathrm{P}$ respectivamente.

No termo convectivo, a concentrações nas interfaces são aproximados pelas concentrações nos nós de cada volume finito, através da técnica de "up-wind". Como a velocidade relativa do líquido é sempre positiva:

$$
C_{d y_{n}}^{t}=C_{d P}^{t} \quad[\mathrm{D} 21] \quad C_{d y_{s}}^{t}=C_{d S}^{t}
$$

Para os volumes que estão tem alguma interface na borda do grão definido pelo CA, é necessária uma condição de contorno para calcular a concentração da interface $C_{d}^{*}$. Esta condição é dada pelo fluxo efetivo para fora do grão, calculado pela espessura efetiva de difusão $\delta_{l d}$ (Apêndice E); onde, na forma discretizada, será escrita como:

$$
\left(\varepsilon_{d} D \frac{\partial C_{d}}{\partial n}\right)_{l d}^{t}=\frac{D_{l}^{*}}{\delta_{l d}}\left(C_{d}^{*}-\left\langle C_{l}\right\rangle_{M}^{l}\right)=\frac{\varepsilon_{d P}^{t} D_{P}}{\delta n^{-}}\left(C_{d P}^{t}-C_{d}^{*}\right)
$$

Substituindo a concentração $C_{d}^{*}$, pela relação acima, o fluxo difusivo é calculado por:

$$
\left(\varepsilon_{d} D \frac{\partial C_{d}}{\partial n}\right)_{l d}^{t}=\frac{\left(C_{d P}^{t}-\left\langle C_{l}\right\rangle_{M}^{l}\right)}{\frac{\delta_{l d}}{D_{l}^{*}}+\frac{\delta n^{-}}{\varepsilon_{d P}^{t} D_{P}}}
$$

\subsection{Cálculo das Taxas de Transformação de Fases Sólidas}

Para calcular a taxa de transformação de fase para a fase de sólido primário e eutética ( $\Gamma_{s}$ e $\Gamma_{e}$, respectivamente), é necessária a equação de equilíbrio termodinâmico entre a concentração do líquido interdendrítico e a temperatura local. Para a solidificação eutética, são impostas as seguintes condições:

$$
T_{P}^{t+\Delta t}=T_{e}
$$




$$
C_{d P}^{t+\Delta t}=C_{e}
$$

onde $T_{e}$ é a temperatura eutética e $C_{e}$ a concentração eutética da liga no diagrama de equilíbrio. Substituindo [D25] na Eq. [D10], e isolando a soma das taxas:

$$
\left(\Gamma_{s P}^{t}+\Gamma_{e P}^{t}\right)=\frac{T_{e}-\langle T\rangle_{M P}{ }^{t}-a_{\Delta T}^{T} \Delta T_{y_{s}}^{y_{n}}-\frac{\Delta H_{M P}{ }^{t}}{\rho C_{P}}}{a_{\Gamma}^{T}}
$$

Antes de substituir a soma das taxas na equação de conservação de soluto, a equação será, antes, escrita de maneira compacta, reunindo todos os termos difusivos e convectivos em uma somatória (PATANKAR, 1981):

$$
\left[\varepsilon_{d P}^{t}-a_{\Gamma}^{\varepsilon_{d}}\left(\Gamma_{s P}^{t}+\Gamma_{e P}^{t}\right)\right] C_{d P}^{t+\Delta t}=\sum_{n b} a_{n b}^{C_{d}} \varepsilon_{d n b}^{t} C_{d n b}^{t}+a_{\Gamma_{s}}^{C_{d}} \Gamma_{s P}^{t}+a_{\Gamma_{e}}^{C_{d}} \Gamma_{e P}^{t}
$$

Para conseguir isolar $\Gamma_{e}$, é somado e subtraído o termo de transformação eutética $\Gamma_{e}$ multiplicado pelo coeficiente do termo de solidificação primária $a_{\Gamma_{s}}^{C_{d}}$ :

$$
\begin{aligned}
& {\left[\varepsilon_{d P}^{t}-a_{\Gamma}^{\varepsilon_{d}}\left(\Gamma_{s P}^{t}+\Gamma_{e P}^{t}\right)\right] C_{e}=\sum_{n b} a_{n b}^{C_{d}} \varepsilon_{d n b}^{t} C_{d n b}^{t}} \\
& +a_{\Gamma_{s}}^{C_{d}}\left(\Gamma_{s P}^{t}+\Gamma_{e P}^{t}\right)+\left(a_{\Gamma_{e}}^{C_{d}}-a_{\Gamma_{s}}^{C_{d}}\right) \Gamma_{e P}^{t}
\end{aligned}
$$

Enfim, é substituída a Eq. [D27] na Eq. [D29]:

$$
\begin{aligned}
& {\left[\varepsilon_{d P}^{t}-a_{\Gamma}^{\varepsilon_{d}} \frac{T_{e}-\langle T\rangle_{M P}{ }^{t}-a_{\Delta T}^{T} \Delta T_{y_{s}}^{y_{n}}-\frac{\Delta H_{M P}{ }^{t}}{\rho C_{P}}}{a_{\Gamma}^{T}}\right] C_{e}=\sum_{n b} a_{n b}^{C_{d}} \varepsilon_{d n b}^{t} C_{d n b}^{t}} \\
& +a_{\Gamma_{s}}^{C_{d}} \frac{T_{e}-T_{P}^{t}-a_{\Delta T}^{T} \Delta T_{y_{s}}^{y_{n}}-\frac{\Delta H_{M P}^{t}}{\rho C_{P}}}{a_{\Gamma}^{T}}+\left(a_{\Gamma_{e}}^{C_{d}}-a_{\Gamma_{s}}^{C_{d}}\right) \Gamma_{e}
\end{aligned}
$$

obtendo, uma expressão para $\Gamma_{e}$ : 


$$
\Gamma_{e P}^{t}=\frac{\varepsilon_{d P}^{t} C_{e}-\sum_{n b} a_{n b}^{C_{d}} \varepsilon_{d n b}^{t} C_{d n b}^{t}-\frac{\left(a_{\Gamma}^{\varepsilon_{d}}+a_{\Gamma_{s}}^{C_{d}}\right)}{a_{\Gamma}^{T}}\left[T_{e}-\langle T\rangle_{M P}{ }^{t}-a_{\Delta T}^{T} \Delta T_{y_{s}}^{y_{n}}-\frac{\Delta H_{M P}{ }^{t}}{\rho C_{P}}\right]}{\left(a_{\Gamma_{e}}^{C_{d}}-a_{\Gamma_{s}}^{C_{d}}\right)}
$$

Após o cálculo de $\Gamma_{e}$, este é substituído na equação de conservação de massa [D6], e verificado se a condição abaixo se verifica:

$$
\varepsilon_{e P}^{t+\Delta t} \in[0,1]
$$

Caso $\varepsilon_{e P}^{t+\Delta t}$ calculado esteja fora do intervalo, o valor deste é truncado, e $\Gamma_{e}$ é calculado através da equação da continuiade da fase eutética [D6], como mostrado abaixo:

$$
\Gamma_{e P}^{t}=\frac{\rho\left(\varepsilon_{e P}^{t+\Delta t}-\varepsilon_{e P}^{t}\right)}{\Delta t}
$$

Em outro caso, se $\varepsilon_{e P}^{t+\Delta t}$ pertencer ao intervalo, $\Gamma_{s}$ é calculado por:

$$
\Gamma_{s P}^{t}=T_{e}-\langle T\rangle_{M P}{ }^{t}-a_{\Delta T}^{T} \Delta T_{y_{s}}^{y_{n}}-\frac{\Delta H_{M P}{ }^{t}}{\rho C_{P}}-\Gamma_{e P}^{t}
$$

Quando $\Gamma_{e P}^{t}=0$ calculado pela equação [D10], é utilizada uma nova condição para o cálculo de $\Gamma_{s}$, que é a equação de equilíbrio termodinâmico entre a temperatura e a concentração de soluto, sobre a liquidus, fora do ponto de eutético:

$$
T_{P}^{t+\Delta t}=T_{f}+m_{l} C_{d P}^{t+\Delta t}
$$

Substituindo $C_{d P}^{t+\Delta t}$ na equação de conservação de soluto: 


$$
\begin{aligned}
& \frac{\left[\varepsilon_{d P}^{t}-a_{\Gamma}^{\varepsilon_{d}} \Gamma_{s P}^{t}\right]}{m_{l}}\left[\langle T\rangle_{M P}{ }^{t}+a_{\Delta T}^{T} \Delta T_{y_{s}}^{y_{n}}+a_{\Gamma}^{T} \Gamma_{s P}^{t}+\frac{\Delta H_{M P}{ }^{t}}{\rho C_{P}}-T_{f}\right]= \\
& =\varepsilon_{d P}^{t} C_{d P}^{t}+\sum_{n b} a_{n b}^{C_{d}} \varepsilon_{d n b}{ }^{t} C_{d n b}{ }^{t}+a_{\Gamma_{s}}^{C_{d}} \Gamma_{s P}^{t}
\end{aligned}
$$

é obtida uma equação de segundo grau para $\Gamma_{s}$ :

$$
\begin{aligned}
& \left(-\frac{a_{\Gamma}^{\varepsilon_{d}} a_{\Gamma}^{T}}{m_{l}}\right)\left[\Gamma_{s P}{ }^{t}\right]^{2}+\left[-\frac{a_{\Gamma}^{\varepsilon_{d}}}{m_{l}}\left(\langle T\rangle_{M P}{ }^{t}+a_{\Delta T}^{T} \Delta T_{y_{s}}^{y_{n}}+\frac{\Delta H_{M P}{ }^{t}}{\rho C_{P}}-T_{f}\right)+\frac{a_{\Gamma}^{T} \varepsilon_{d P}{ }^{t}}{m_{l}}-a_{\Gamma_{s}}^{C_{d}}\right] \Gamma_{s P}^{t} \\
& +\left[\frac{\varepsilon_{d P}^{t}}{m_{l}}\left(\langle T\rangle_{M P}{ }^{t}+a_{\Delta T}^{T} \Delta T_{y_{s}}^{y_{n}}+\frac{\Delta H_{M P}{ }^{t}}{\rho C_{P}}-T_{f}\right)-\varepsilon_{d P}{ }^{t} C_{d P}{ }^{t}+\sum_{n b} a_{n b}^{C_{d}} \varepsilon_{d n b}{ }^{t} C_{d n b}{ }^{t}\right]=0
\end{aligned}
$$

Como a equação fornece duas soluções, é verificada qual das soluções fornece, ao substituir o valor de $\Gamma_{s}$ na equação de conservação de soluto, um valor para a concentração no próximo instante entre:

$$
C_{d P}^{t+\Delta t} \in\left[0, C_{e}\right]
$$

O valor de $\Gamma_{s}$ que obedece ao critério [D38] é selecionado como solução.

\section{Submodelo Macroscópico}

O domínio do submodelo macroscópico (molde) é discretizado em volumes finitos retangulares dispostos verticalmente (Figura D1).

\subsection{Conservação de Energia}

A equação de conservação de energia do submodelo macroscópico [C41], é discretizada pelo método dos volumes finitos em sua forma explícita, integrando ambos os lados da equação pelas variáveis " $t$ " e " $y$ ": 


$$
\rho C_{P} \int_{t}^{t+\Delta t} \int_{y_{s}}^{y_{y_{n}}} \frac{\partial\langle T\rangle_{M}}{\partial t} d y d t=L_{f} \int_{t}^{t+\Delta t} \int_{y_{s}}^{y_{n}}\left(\Gamma_{s_{M}}+\Gamma_{e_{M}}\right) d y d t+\int_{t}^{t+\Delta t} \int_{y_{s}}^{t} \frac{\partial}{\partial y}\left(\bar{K} \frac{\partial\langle T\rangle_{M}}{\partial y}\right) d y d t
$$

Sob as hipóteses de aproximação da integral com os termos da derivada temporal constantes no espaço e os outros termos constantes no tempo:

$$
\rho C_{P}\left(\langle T\rangle_{M P}{ }^{t+\Delta t}-\langle T\rangle_{M P}{ }^{t}\right)=L_{f}\left(\Gamma_{s_{M} P}{ }^{t}+\Gamma_{e_{M} P}{ }^{t}\right) \Delta t+\left[\left(\bar{K} \frac{\partial\langle T\rangle_{M}}{\partial y}\right)_{y_{n}}^{t}-\left(\bar{K} \frac{\partial\langle T\rangle_{M}}{\partial y}\right)_{y_{s}}^{t}\right] \frac{\Delta t}{\Delta y}
$$

Para cálculo do fluxo difusivo de calor, para um nó central, o termo é aproximado pelo fluxo equivalente entre cada volume finito:

$$
\left(\bar{K} \frac{\partial\langle T\rangle_{M}}{\partial y}\right)_{y_{n}}^{t}=\frac{\left(\langle T\rangle_{M N}{ }^{t}-\langle T\rangle_{M P}{ }^{t}\right)}{\frac{\delta y_{M n}{ }^{+}}{\bar{K}_{N}}+\frac{\delta y_{M n}^{-}}{\bar{K}_{P}}} \quad[\mathrm{D} 41] \quad\left(\bar{K} \frac{\partial\langle T\rangle_{M}}{\partial y}\right)_{y_{s}}^{t}=\frac{\left(\langle T\rangle_{M P}{ }^{t}-\langle T\rangle_{M S}{ }^{t}\right)}{\frac{\delta y_{M S}{ }^{+}}{\bar{K}_{S}}+\frac{\delta y_{M S}{ }^{-}}{\bar{K}_{P}}}
$$

onde $\langle T\rangle_{M N}{ }^{t}$ é a temperatura do centro do VF superior, $\langle T\rangle_{M P}{ }^{t}$ a temperatura do centro do VF central, $\langle T\rangle_{M S}{ }^{t}$ a temperatura do centro do VF inferior, $\delta y_{M n}{ }^{+}$a distância entre a interface $y_{n}$ e o centro do VF superior, $\delta y_{M n}{ }^{-}$a distância entre a interface $y_{n}$ e o centro do VF central,$\delta y_{M s}^{+}$a distância entre a interface $y_{s}$ e o centro do VF inferior, $\delta y_{M s}^{-}$a distância entre a interface $y_{s}$ e o centro do VF central; e $\bar{K}_{N}, \bar{K}_{S}$ e $\bar{K}_{P}$ as condutividades térmicas médias de cada centro de VF.

Para os VFs com interface no molde, é necessária uma condição de contorno. A utilizada pelo modelo é de forma mista com um coeficiente de transporte de calor:

$$
\left(\bar{K} \frac{\partial\langle T\rangle_{M}}{\partial y}\right)_{y=L_{y}}^{t}=\frac{\left(T_{y=L_{y}}^{\infty}-\langle T\rangle_{M P}{ }^{t}\right)}{\frac{1}{h_{y=L_{y}}}+\frac{\delta y_{M n}{ }^{-}}{\bar{K}_{P}}} \quad[\mathrm{D} 43] \quad\left(\bar{K} \frac{\partial\langle T\rangle_{M}}{\partial y}\right)_{y=0}^{t}=\frac{\left(\langle T\rangle_{M P}{ }^{t}-T_{y=0}^{\infty}\right)}{\frac{1}{h_{y=0}}+\frac{\delta y_{M n}{ }^{-}}{\bar{K}_{P}}}
$$


onde $T_{y=L_{y}}^{\infty}$ é a temperatura ao longe da interface $y=L_{y}, h_{y=L_{y}}$ é o coeficiente de transporte de calor para a interface superior do molde, $T_{y=0}^{\infty}$ é a temperatura ao longe da interface inferior do molde, e $h_{y=0}$ o respectivo coeficiente de transporte de calor.

O termo do balanço de fluxo de calor por difusão é interpolado para o submodelo microscópico, e será definido por:

$$
\Delta H_{M}=\left[\left(\bar{K} \frac{\partial\langle T\rangle_{M}}{\partial y}\right)_{y_{n}}^{t}-\left(\bar{K} \frac{\partial\langle T\rangle_{M}}{\partial y}\right)_{y_{s}}^{t}\right] \frac{\Delta t}{\Delta y}
$$

As taxas de transformação de fases do submodelo macroscópico serão calculadas a partir da média das taxas do submodelo microscópico (acoplamento), e são definidas pelas equações:

$$
\begin{aligned}
& \Gamma_{s_{M}}=\frac{1}{V_{0_{M}}} \int_{V_{0_{M}}} \Gamma_{s} d V \\
& \Gamma_{e_{M}}=\frac{1}{V_{0_{M}}} \int_{V_{0_{M}}} \Gamma_{e} d V
\end{aligned}
$$

e em suas formas discretizadas por:

$$
\begin{gathered}
\Gamma_{S_{M} P}^{t}=\frac{1}{N_{C A}} \sum_{N_{C A}} \Gamma_{s P}^{t} \\
\Gamma_{e_{M} P}^{t}=\frac{1}{N_{C A}} \sum_{N_{C A}} \Gamma_{e P}^{t}
\end{gathered}
$$

onde $N_{C A}$ é a quantidade de células de CA dentro de um mesmo VF macroscópico. 


\subsection{Conservação de Massa}

A equação de conservação de massa para a fase líquida extradendrítica [C48] tem um termo de integral sobre superfície dos grãos. Como o movimento neste modelo é sempre unidirecional, os vetores velocidades serão iguais ao seu módulo multiplicado ao versor na direção "y" $\vec{e}_{y}$ :

$$
\frac{\partial}{\partial y}\left(\varepsilon_{l_{M}}\left\langle v_{l}\right\rangle_{M}^{l}\right)=\frac{1}{V_{0_{M}}} \int_{A_{d d}}\left[\frac{\kappa_{v}\left\langle v_{s}\right\rangle_{M}^{s}}{\varepsilon_{g_{M}}}-v_{s}\right]\left(\vec{e}_{y} \cdot \vec{n}_{l}\right) d A
$$

O termo da integral sobre superfície é aproximado pela somatória de cada interface entre os grãos de CA e o líquido extradendrítico (células inativas):

$$
\frac{1}{V_{0_{M}}} \int_{A_{A_{d}}}\left[\frac{\kappa_{v}\left\langle v_{s}\right\rangle_{M}^{s}}{\varepsilon_{g_{M}}}-v_{s}\right]\left(\vec{e}_{y} \cdot \vec{n}_{l}\right) d A \approx \frac{1}{\Delta x_{M} \Delta y_{M}} \sum_{i}^{N_{C A, d}}\left[\left(\frac{\kappa_{v}\left\langle v_{s}\right\rangle_{M}^{s}}{\varepsilon_{g_{M}}}\right)_{P}-v_{s_{i}}\right] n_{l, y_{i}}
$$

onde $\Delta x_{M}$ e $\Delta y_{M}$ são as dimensões do VF macroscópico, $\Delta x_{C A}$ é o tamanho do lado de uma célula de CA, $N_{C A, l d}$ é o número de lados de CA que definem a interface entre grãos e líquido extradendrítico, $v_{s_{i}}$ é a velocidade do grão que a interface pertence, $n_{l, y_{i}}$ é o versor em "y" orientado em cada interface para dentro dos grãos, sendo -1 para interfaces superiores e +1 para interfaces inferiores. Após a substituição pela Eq. [D51] e a discretização da derivada espacial na Eq. [D50] pelo método dos volumes finitos, é obtida a equação final discretizada:

$$
\left(\varepsilon_{l_{M}}\left\langle v_{l}\right\rangle_{M}^{l}\right)_{y_{n}}^{t}=\left(\varepsilon_{l_{M}}\left\langle v_{l}\right\rangle_{M}^{l}\right)_{y_{n}}^{t}+\frac{\Delta x_{C A}}{\Delta x_{M}} \sum_{i}^{N_{C, A, d}}\left[\left(\frac{\kappa_{v}\left\langle v_{s}\right\rangle_{M}^{s}}{\varepsilon_{g_{M}}}\right)_{P}-v_{s_{i}}\right] n_{l, y_{i}}
$$

É notado que esta integral aproximada terá valor nulo para cada grão completamente contido dentro do VF, ou seja, as velocidades da fase líquida na interface só terão valores diferentes de zero quando algum grão atravessar esta interface. 


\subsection{Conservação de Soluto}

Para simplificação de notação, na equação de conservação de soluto no líquido extradendrítico, será escrito $C_{l}$ no lugar de $\left\langle C_{l}\right\rangle_{M}^{l}$. A equação [C60] tem termo de integral sobre superfície de grãos, estes termos serão aproximado por somatórias sobre a malha de células de CA. Os termos que contém velocidade de convecção, terão apenas a componente " $y$ " integradas (movimento unidirecional). $O$ termo que contém a velocidade da fase líquida será aproximado por:

$$
\frac{1}{V_{0_{M}}} \int_{A_{A_{d}}}\left\langle C_{d}\right\rangle^{d}\left(\frac{\kappa_{v}\left\langle v_{s}\right\rangle_{M}^{s}}{\varepsilon_{g_{M}}}+v_{s}\right)\left(\vec{e}_{y} \cdot \vec{n}_{l}\right) d A \approx \frac{\Delta x_{C A}}{\Delta x_{M}} \sum_{i}^{N_{C A, d}}\left[C_{d_{i}}^{*}\left(\frac{\kappa_{v}\left\langle v_{s}\right\rangle_{M}^{s}}{\varepsilon_{g_{M}}}\right)_{P}-v_{s_{i}}\right] n_{l, y_{i}}
$$

onde $C_{d_{i}}^{*}$ é a concentração de soluto na interface calculada pelo submodelo microscópico (Eq. [D23]), $N_{C A, l d}$ é a quantidade de interfaces entre grãos e o líquido extradendrítico contidos no VF macroscópico, " $i$ " é o índice de cada interface e $n_{l, y_{i}}$ é o versor em "y" orientado em cada interface para dentro dos grãos, sendo -1 para interfaces superiores $\mathrm{e}+1$ para interfaces inferiores.

O termo que multiplica a diferença de concentração entre as duas fases líquidas e a velocidade de crescimento do grão $\vec{w}_{g}^{\prime}$ é aproximado pela somatória de células de CA capturadas (recém-ativadas) vezes a concentração de soluto na interface da célula que as capturou menos a concentração de soluto no líquido extradendrítico do VF correspondente:

$$
\frac{1}{V_{0_{M}}} \int_{A_{d d}}\left(\left\langle C_{d}\right\rangle^{d}-\left\langle C_{l}\right\rangle_{M}^{l}\right) \vec{w}_{g}^{\prime} \cdot \vec{n}_{l} d A \approx-\frac{\Delta x_{C A}^{2}}{\Delta t} \sum_{i}^{N_{C A \text { anow }}}\left(C_{d_{i}}^{*}-C_{l P}^{t}\right)
$$

onde $N_{C A, n o v o}$ é o número de células recém-ativadas no determinado intervalo de tempo $\Delta t, e$ " $i$ " é o índice de cada célula recém-ativada. O termo que multiplica a diferença de concentração entre as duas fases líquidas e a velocidade da fase sólida tem o mesmo tratamento das duas aproximações anteriores (Eq. [D53] e [D54]): 


$$
\frac{1}{V_{0_{M}}} \int_{A_{d d}}\left(\left\langle C_{d}\right\rangle^{d}-\left\langle C_{l}\right\rangle_{M}^{l}\right) v_{s}\left(\vec{e}_{y} \cdot \vec{n}_{l}\right) d A \approx \frac{\Delta x_{C A}}{\Delta x_{M}} \sum_{i}^{N_{C A, d}}\left[\left(C_{d_{i}}^{*}-C_{l P}^{t}\right) v_{s_{i}} n_{l, y_{i}}\right]
$$

O termo de difusão entre a fase líquida interdendrítica e a fase líquida extradendrítica é aproximada de forma análoga os termos anteriores, com o detalhe do cálculo de $\delta_{l d}$ calculado em cada interface pelo submodelo microscópico:

$$
\frac{1}{V_{0_{M}}} \int_{A_{l d}}\left(\left\langle C_{d}\right\rangle^{d}-\left\langle C_{l}\right\rangle_{M}^{l}\right) \frac{D_{l}}{\delta_{l d}} d A \approx \frac{D_{l} \Delta x_{C A}}{\Delta x_{M} \Delta y_{M}} \sum_{i}^{N_{C A, l d}} \frac{\left(C_{d_{i}}^{*}-C_{l P}^{t}\right)}{\delta_{l d_{i}}}
$$

onde $\delta_{I d_{i}}$ é a espessura efetiva de difusão calculada pelo submodelo microscópico para cada interface " $i$ " pela Eq. [75]. Durante a etapa de integração pelo método dos volumes finito, os termos aproximados tratados até então são considerados constantes neste intervalo de tempo de integração numérica e no VF calculado. Todos os outros termos são tratados da forma explícita do método dos volumes finitos:

$$
\begin{aligned}
& \int_{t}^{t+\Delta t} \int_{y_{s}}^{y_{n}} \varepsilon_{l_{M}} \frac{\partial\left\langle C_{l}\right\rangle_{M}^{l}}{\partial t} d y d t+\int_{t}^{t+\Delta t} \int_{y_{s}}^{y_{n}} \frac{\partial}{\partial y}\left(\varepsilon_{l_{M}}\left\langle C_{l}\right\rangle_{M}^{l}\left\langle v_{l}\right\rangle_{M}^{l}\right) d y d t= \\
& -\int_{t}^{t+\Delta t} \int_{y_{s}}^{y_{n}}\left[\frac{1}{V_{0_{M}}} \int_{A_{l d}}\left\langle C_{d}\right\rangle^{d}\left(\frac{\kappa_{v}\left\langle\vec{v}_{s}\right\rangle_{M}^{s}}{\varepsilon_{g_{M}}}+\vec{v}_{s}\right) \cdot \vec{n}_{l} d A\right] d y d t \\
& +\int_{t}^{t+\Delta t} \int_{y_{s}}^{y_{n}}\left[\frac{1}{V_{0_{M}}} \int_{A_{d d}}\left(\left\langle C_{d}\right\rangle^{d}-\left\langle C_{l}\right\rangle_{M}^{l}\right)\left(\vec{w}_{g}^{\prime}+\vec{v}_{s}+\frac{D_{l}}{\delta_{l d}} \vec{n}_{l}\right) \cdot \vec{n}_{l} d A\right] d y d t
\end{aligned}
$$

O termo convectivo integrado se torna a diferença entre as concentrações na interface multiplicadas às respectivas velocidades da fase líquida em cada interface. 


$$
\begin{aligned}
& \varepsilon_{l P}^{t}\left(C_{l P}^{t+\Delta t}-C_{l P}^{t}\right) \Delta y_{M}+\left[\left(\varepsilon_{l} C_{l} v_{l}\right)_{y_{n}}^{t}-\left(\varepsilon_{l} C_{l} v_{l}\right)_{y_{s}}^{t}\right]= \\
& -\frac{\Delta t \Delta x_{C A}}{\Delta x_{M}} \sum_{N_{C A . l d}}\left[C_{d_{i}}^{*}\left(\frac{\kappa_{v}\left\langle v_{s}\right\rangle_{M}^{s}}{\varepsilon_{g_{M}}}+v_{s_{i}}\right) n_{l, y_{i}}\right]-\frac{\Delta x_{C A}^{2}}{\Delta y_{M} \Delta x_{M}} \sum_{i}^{N_{C A, \text { novo }}}\left(C_{d_{i}}^{*}-C_{l P}^{t}\right) \\
& \frac{\Delta t \Delta x_{C A}}{\Delta x_{M}} \sum_{i}^{N_{C A, l d}}\left[\left(C_{d_{i}}^{*}-C_{l P}^{t}\right) v_{s_{i}} n_{l, y_{i}}\right]+\frac{\Delta t D_{l} \Delta x_{C A}}{\Delta x_{M} \Delta y_{M}} \sum_{i}^{N_{C A, l d}} \frac{\left(C_{d_{i}}^{*}-C_{l P}^{t}\right)}{\delta_{l d_{i}}}
\end{aligned}
$$

As concentrações de cada interface são aproximadas pelas concentrações nos centros dos VFs utilizando a técnica do "up-wind". Como a velocidade da fase líquida extradentrítica é sempre maior ou igual a zero:

$$
\begin{aligned}
& \varepsilon_{l P}^{t}\left(C_{l P}^{t+\Delta t}-C_{l P}^{t}\right) \Delta y_{M}+\left[C_{l P}^{t}\left(\varepsilon_{l} v_{l}\right)_{y_{n}}^{t}-C_{l S}^{t}\left(\varepsilon_{l} v_{l}\right)_{y_{s}}^{t}\right] \frac{\Delta t}{\Delta y_{M}}= \\
& -\frac{\Delta t \Delta x_{C A}}{\Delta x_{M}} \sum_{N_{C A . l d}}\left[C_{d_{i}}^{*}\left(\frac{\kappa_{v}\left\langle v_{s}\right\rangle_{M}^{s}}{\varepsilon_{g_{M}}}+v_{s_{i}}\right) n_{l, y_{i}}\right]-\frac{\Delta x_{C A}^{2}}{\Delta y_{M} \Delta x_{M}} \sum_{i}^{N_{C A, \text { novo }}}\left(C_{d_{i}}^{*}-C_{l P}^{t}\right) \\
& \frac{\Delta t \Delta x_{C A}}{\Delta x_{M}} \sum_{i}^{N_{C A, l d}}\left[\left(C_{d_{i}}^{*}-C_{l P}^{t}\right) v_{s_{i}} n_{l, y_{i}}\right]+\frac{\Delta t D_{l} \Delta x_{C A}}{\Delta x_{M} \Delta y_{M}} \sum_{i}^{N_{C A, l d}} \frac{\left(C_{d_{i}}^{*}-C_{l P}^{t}\right)}{\delta_{l d_{i}}}
\end{aligned}
$$

Finalmente, substituindo a expressão calculada em [D52], obtemos a equação discretizada no seu formato final:

$$
\begin{aligned}
& \varepsilon_{l P}^{t}\left(C_{l P}^{t+\Delta t}-C_{l P}^{t}\right) \Delta y_{M}=-\left(C_{l P}^{t}-C_{l S}^{t}\right) \frac{\Delta t\left(\varepsilon_{l} v_{l}\right)_{y_{s}}^{t}}{\Delta y_{M}}-\frac{\Delta x_{C A}}{\Delta x_{M}} \sum_{N_{C A, l d}}\left[\left(C_{d_{i}}^{*}-C_{l P}^{t}\right)\left(\frac{\kappa_{v}\left\langle v_{s}\right\rangle_{M}^{s}}{\left(1-\varepsilon_{l_{M}}\right)}+v_{s_{i}}\right) n_{l, y_{i}}\right] \\
& -\frac{\Delta x_{C A}^{2}}{\Delta t} \sum_{i}^{N_{C A, \text { nowo }}}\left(C_{d_{i}}^{*}-C_{l P}^{t}\right)+\frac{\Delta x_{C A}}{\Delta x_{M}} \sum_{i}^{N_{C A, l d}}\left[\left(C_{d_{i}}^{*}-C_{l P}^{t}\right) v_{s_{i}} n_{l, y_{i}}\right]+\frac{D_{l} \Delta x_{C A}}{\Delta x_{M} \Delta y_{M}} \sum_{i}^{N_{C A, l d}} \frac{\left(C_{d_{i}}^{*}-C_{l P}^{t}\right)}{\delta_{l d_{i}}}
\end{aligned}
$$




\section{APÊNDICE E - CÁLCULO DA ESPESSURA EFETIVA DE DIFUSÃO COM CONVECÇÃO}

O cálculo de espessura de difusão efetiva sobre uma esfera ativa (com reação química) é obtido através da solução do perfil de concentração de soluto ao redor da mesma. Utiliza-se este perfil para calcular o fluxo médio
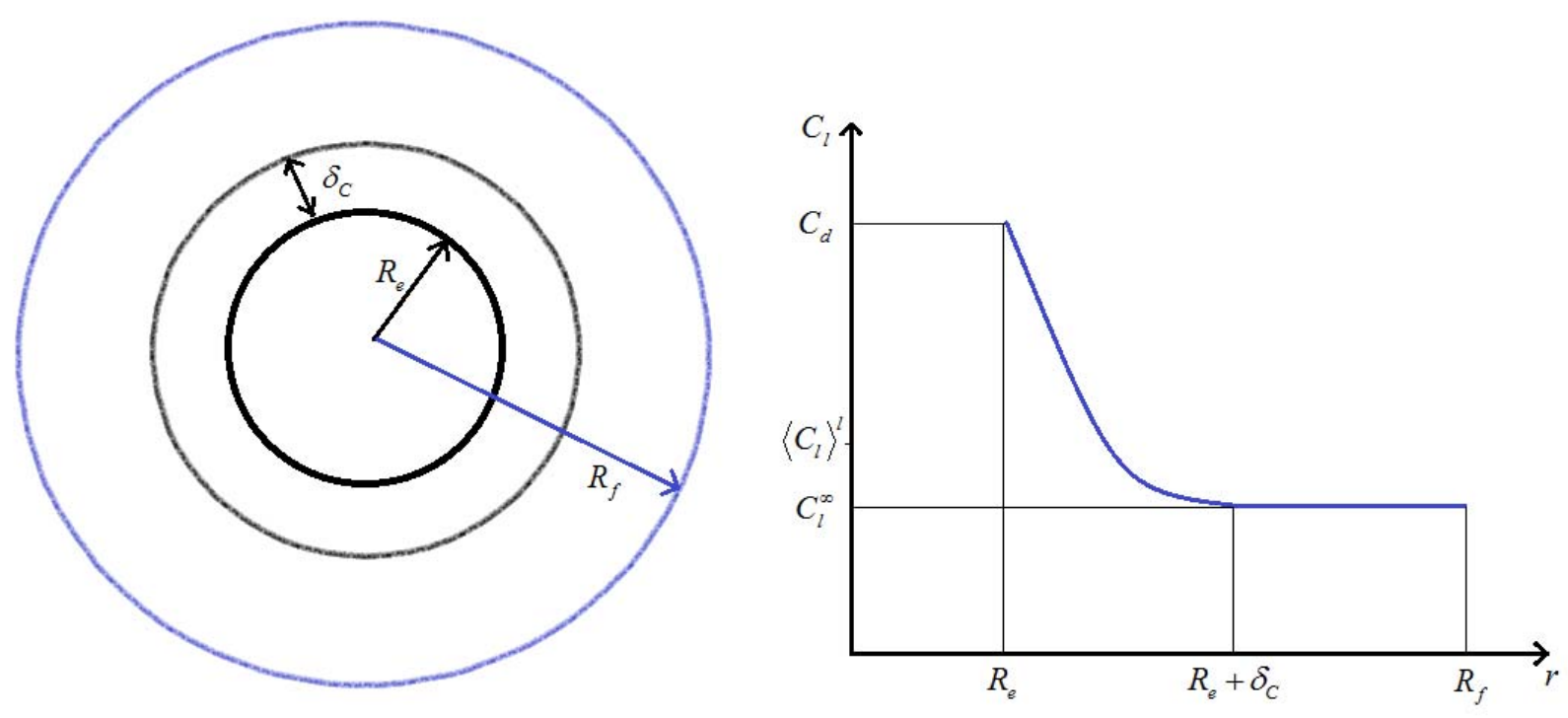

Figura E1 - Esquematização do perfil de concentração $C_{l}$ ao redor da uma esfera de raio $R_{e}$ com camada de estagnação $\delta_{C}$, raio de referência $R_{f}$.

\section{Equação Diferencial}

Utilizando a equação de conservação das espécies químicas em coordenadas esféricas, e assumindo a hipótese de coeficiente de difusão $D_{l}$ constante, obtemos a expressão:

$$
\frac{\partial C_{l}}{\partial t}=D_{l} \frac{1}{r^{2}} \frac{\partial}{\partial r}\left(r \frac{\partial C_{l}}{\partial r}\right)
$$

As coordenadas esféricas são transformadas para o sistema de coordenadas com referencial na interface esférica móvel, para assim, aplicar a condição de estado 
quasi-estacionário. Sendo assim, a posição radial da interface é dada pela coordenada $r^{\prime}$ pela equação:

$$
r^{\prime}=r-w_{e} t
$$

e a coordenada temporal $t^{\prime}$ igual à própria coordenada temporal do sistema anterior:

$$
t^{\prime}=t
$$

sendo assim, a equação diferencial em ambos os sistemas devem ser iguais.

$$
C_{l}(r, t)=C_{l}\left(r^{\prime}(r, t), t^{\prime}(r, t)\right)
$$

Para obter esta identidade, cada termo da equação diferencial será reescrito em função das novas coordenadas:

$$
\begin{gathered}
\frac{\partial C_{l}}{\partial t}=\frac{\partial C_{l}}{\partial r^{\prime}} \frac{\partial r^{\prime}}{\partial t}+\frac{\partial C_{l}}{\partial t^{\prime}} \frac{\partial t^{\prime}}{\partial t} \Rightarrow \frac{\partial C_{l}}{\partial t}=-w_{e} \frac{\partial C_{l}}{\partial r^{\prime}}+\frac{\partial C_{l}}{\partial t^{\prime}} \\
\frac{\partial C_{l}}{\partial r}=\frac{\partial C_{l}}{\partial r^{\prime}} \frac{\partial r^{\prime}}{\partial r}+\frac{\partial C_{l}}{\partial t^{\prime}} \frac{\partial t^{\prime}}{\partial r} \Rightarrow \frac{\partial C_{l}}{\partial r}=\frac{\partial C_{l}}{\partial r^{\prime}} \\
\frac{1}{r^{2}} \frac{\partial}{\partial r}\left(r^{2} \frac{\partial C_{l}}{\partial r}\right)=\frac{\partial^{2} C_{l}}{\partial r^{2}}+\frac{2}{r} \frac{\partial C_{l}}{\partial r} \\
\frac{\partial^{2} C_{l}}{\partial r^{2}}=\frac{\partial}{\partial r}\left(\frac{\partial C_{l}}{\partial r}\right)=\frac{\partial}{\partial r^{\prime}}\left(\frac{\partial C_{l}}{\partial r}\right) \frac{\partial r^{\prime}}{\partial r}+\frac{\partial}{\partial t^{\prime}}\left(\frac{\partial C_{l}}{\partial r}\right) \frac{\partial t^{\prime}}{\partial r}=\frac{\partial^{2} C_{l}}{\partial r^{\prime 2}} \Rightarrow \frac{\partial^{2} C_{l}}{\partial r^{2}}=\frac{\partial^{2} C_{l}}{\partial r^{\prime 2}} \\
\frac{1}{r^{2}} \frac{\partial}{\partial r}\left(r^{2} \frac{\partial C_{l}}{\partial r}\right)=\frac{\partial^{2} C_{l}}{\partial r^{\prime 2}}+\frac{2}{r} \frac{\partial C_{l}}{\partial r^{\prime}}
\end{gathered}
$$

Substituindo as equações acima na Eq. [E1], a equação diferencial no novo sistema de coordenadas é escrita da forma:

$$
\frac{\partial C_{l}}{\partial t^{\prime}}-w_{e} \frac{\partial C_{l}}{\partial r^{\prime}}=D_{l}\left(\frac{\partial^{2} C_{l}}{\partial r^{\prime 2}}+\frac{2}{r} \frac{\partial C_{l}}{\partial r^{\prime}}\right)
$$


Impondo a condição de estado quase-estacionário é considerada na equação, retirando o termo transiente:

$$
\frac{\partial C_{l}}{\partial t^{\prime}}=0
$$

e a equação diferencial final do problema se torna:

$$
\frac{\partial^{2} C_{l}}{\partial r^{\prime 2}}+\left(\frac{w_{e}}{D_{l}}+\frac{2}{r}\right) \frac{\partial C_{l}}{\partial r^{\prime}}=0
$$

Como as derivadas espaciais do sistema de coordenadas $\left(r^{\prime}, t^{\prime}\right)$ são iguais às do sistema de coordenadas $(r, t)$, e há apenas a variável $r$, a equação diferencial se torna:

$$
\frac{d^{2} C_{l}}{d r^{2}}+\left(\frac{w_{e}}{D_{l}}+\frac{2}{r}\right) \frac{d C_{l}}{d r}=0
$$

\section{Solução Analítica da Equação Diferencial}

Utilizando uma variável $X$ igual a:

$$
X=\frac{d C_{l}}{d r}
$$

a equação diferencial se torna:

$$
\frac{d X}{d r}+\left(\frac{w_{e}}{D_{l}}+\frac{2}{r}\right) X=0
$$

e isolando cada variável para integrar a expressão, a solução para $X$ é dada por: 


$$
X=A \frac{\exp \left(-\frac{w_{e}}{D_{l}} r\right)}{r^{2}}
$$

onde $A^{\prime}$ é uma constante de integração. Substituindo a variável $X$ pela derivada de $C_{l}$ (Eq. [E14]):

$$
\frac{d C_{l}}{d r}=A \frac{\exp \left(-\frac{w_{e}}{D_{l}} r\right)}{r^{2}}
$$

para integrar a expressão novamente:

$$
\int_{C_{d}}^{C_{l}} d C_{l}=A \int_{R_{e}}^{r} \frac{\exp \left(-\frac{w_{e}}{D_{l}} r^{\prime}\right)}{r^{\prime 2}} d r^{\prime}
$$

temos a solução para o perfil de concentração (Figura E1) dada por:

$$
C_{l}(r)=C_{d}+A \int_{R_{e}}^{r} \frac{\exp \left(-\frac{w_{e}}{D_{l}} r^{\prime}\right)}{r^{\prime 2}} d r^{\prime}
$$

Como condição de contorno, assume-se que na posição da camada de estagnação, a concentração de soluto é a concentração de soluto no infinito.

$$
r=R_{e}+\delta_{C} \Rightarrow C_{l}=C_{l}^{\infty}
$$

Substituindo a condição de contorno na solução da Eq. [E19]:

$$
C_{l}^{\infty}=C_{d}+A \int_{R_{e}}^{R_{e}+\delta_{C}} \frac{\exp \left(-\frac{w_{e}}{D_{l}} r^{\prime}\right)}{r^{\prime 2}} d r^{\prime}
$$

obtendo-se, assim, um valor para a constante de integração $A$ : 


$$
A=\frac{\left(C_{l}^{\infty}-C_{d}\right)}{\int_{R_{e}}^{R_{e}+\delta_{C}} \frac{\exp \left(-\frac{w_{e}}{D_{l}} r^{\prime}\right)}{r^{\prime 2}} d r^{\prime}}
$$

Desta forma, a solução final com a condição de contorno é expressa por:

$$
C_{l}(r)=C_{d}+\left(C_{l}^{\infty}-C_{d}\right) \frac{\int_{R_{e}}^{r} \frac{\exp \left(-\frac{w_{e}}{D_{l}} r^{\prime}\right)}{r^{\prime 2}} d r^{\prime}}{\int_{R_{e}}^{R_{e}+\delta_{C}} \frac{\exp \left(-\frac{w_{e}}{D_{l}} r^{\prime}\right)}{r^{\prime 2}} d r^{\prime}}
$$

A integral que aparece na equação acima não tem solução analítica, mas pode ser expressa por combinação de funções aproximadas numericamente conhecidas como a função exponencial integral.

Utilizando a definição do adimensional de Peclet $(P e)$ :

$$
P e=\frac{R_{e} w_{e}}{D_{l}}
$$

e modificando a variável de integração por:

$$
y=\frac{P e}{R_{e}} r^{\prime}
$$

a integral é expressa por:

$$
\int_{R_{e}}^{r} \frac{\exp \left(-\frac{P e}{R_{e}} r^{\prime}\right)}{r^{\prime 2}} d r^{\prime}=\frac{P e}{R_{e}} \int_{P e}^{P e} \frac{r}{R_{e}} \frac{\exp (-y)}{y^{2}} d y
$$


Utilizando a técnica de integral por partes, a integral pode ser calculada por:

$$
\frac{P e}{R_{e}} \int_{P e}^{P e \frac{r}{R_{e}}} \frac{\exp (-y)}{y^{2}} d y=\frac{P e}{R_{e}}\left\{\left[-\frac{\exp (-y)}{y}\right]_{P e}^{P e \frac{r}{R_{e}}}+\int_{P e}^{P e \frac{r}{R_{e}}} \frac{\exp (-y)}{y} d y\right\}
$$

Sendo que o segundo termo pode ser expresso através da função exponencial integral definida por:

$$
E_{1}(x)=\int_{x}^{\infty} \frac{\exp (-y)}{y} d y
$$

e substituída na expressão [E27]:

$$
\int_{P e}^{P e \frac{r}{R_{e}}} \frac{\exp (-y)}{y} d y=E_{1}\left(P e \frac{r}{R_{e}}\right)-E_{1}(P e)
$$

Portanto, a integral pode ser calculada por:

$$
\int_{R_{e}}^{r} \frac{\exp \left(-\frac{P e}{R_{e}} r^{\prime}\right)}{r^{\prime 2}} d r^{\prime}=\frac{P e}{R_{e}}\left\{E_{1}\left(P e \frac{r}{R_{e}}\right)-E_{1}(P e)-\frac{\exp \left(-P e \frac{r}{R_{e}}\right)}{P e \frac{r}{R_{e}}}+-\frac{\exp (-P e)}{P e}\right\}
$$

No modelo, a função $E_{1}$ será calculada a partir da aproximação numérica da função de Ivantsov ( $I v)$ :

$$
I v(x)=x \exp (x) E_{1}(x)
$$

que substituindo na integral a ser solucionada, se torna: 


$$
\int_{R_{e}}^{r} \frac{\exp \left(-\frac{P e}{R_{e}} r^{\prime}\right)}{r^{\prime 2}} d r^{\prime}=\frac{I v\left(P e \frac{r}{R_{e}}\right)-1}{r \exp \left(P e \frac{r}{R_{e}}\right)}-\frac{1-I v(P e)}{R_{e} \exp (P e)}
$$

Substituindo a Eq. [E32] no cálculo da integral a ser solucionada, é obtida a solução final expressa por funções com aproximações conhecidas na literatura:

$$
C_{l}(r)=C_{d}+\left\{\frac{\frac{I v\left(P e \frac{r}{R_{e}}\right)-1}{r \exp \left(P e \frac{r}{R_{e}}\right)}+\frac{1-I v(P e)}{R_{e} \exp (P e)}}{\frac{I v\left(P e \frac{R_{e}+\delta_{C}}{R_{e}}\right)-1}{\left(R_{e}+\delta_{C}\right) \exp \left(P e \frac{R_{e}+\delta_{C}}{R_{e}}\right)}+\frac{1-I v(P e)}{R_{e} \exp (P e)}}\right\}\left(C_{l}^{\infty}-C_{d}\right)
$$

\section{Espessura Efeitva de Difusão}

A definição desta espessura efetiva de difusão ( $\delta_{l d}^{*}$, que ainda não é a utilizada pelo modelo) é dada por uma diferença de concentração vezes a difusividade de massa, sobre o fluxo médio sobre a interface do corpo:

$$
\delta_{l d}^{*}=\frac{\left(C_{d}-C_{l}^{\infty}\right)}{-\left.\left(\frac{\partial C_{l}}{\partial r}\right)\right|_{r=R_{e}}}
$$

Pela solução do perfil de concentrações [E23], se obtém a derivada do perfil sobre a interface da esfera $\left(r=R_{e}\right)$ : 


$$
\frac{\partial C_{l}}{\partial r}=\left(C_{l}^{\infty}-C_{d}\right) \frac{\frac{\exp (-P e)}{R_{e}^{2}}}{\int_{R_{e}}^{R_{e}+\delta_{C}} \frac{\exp \left(-\frac{P e}{R_{e}} r^{\prime}\right)}{r^{\prime 2}} d r^{\prime}}
$$

substituindo na expressão da espessura $\delta_{l d}^{*}$ (Eq. [E34]), obtemos:

$$
\delta_{l d}^{*}=R_{e}^{2} \exp (P e) \int_{R_{e}}^{R_{e}+\delta_{C}} \frac{\exp \left(-\frac{P e}{R_{e}} r^{\prime}\right)}{r^{\prime 2}} d r^{\prime}
$$

cujo valor para a integral expresso em [E32] é substituído para obter a expressão final para $\delta_{l d}^{*}$ :

$$
\delta_{l d}^{*}=R_{e}^{2} \exp (P e)\left[\frac{I v\left(P e \frac{R_{e}+\delta_{C}}{R_{e}}\right)-1}{\left(R_{e}+\delta_{C}\right) \exp \left(P e \frac{R_{e}+\delta_{C}}{R_{e}}\right)}+\frac{1-I v(P e)}{R_{e} \exp (P e)}\right]
$$

\section{Cálculo da Concentração de Soluto na Espessura de Estagnação}

Para o cálculo de $C_{l}^{\infty}$ dado uma concentração média $\left\langle C_{l}\right\rangle^{l}$ é necessário calcular este valor pela integral do perfil de concentração dado pela solução. A definição de $\left\langle C_{l}\right\rangle^{l}$ é dada pela equação:

$$
\left\langle C_{l}\right\rangle^{l}=\frac{1}{V_{l}} \iiint_{V_{l}} C_{l} d V
$$

Em coordenadas esféricas, e assumindo simetria radial do perfil, da integral tripla resta apenas a integral do perfil em $r$ : 


$$
\left\langle C_{l}\right\rangle^{l}=\frac{3}{4 \pi\left(R_{f}^{3}-R_{e}^{3}\right)} \int_{R_{e}}^{R_{f}} C_{l} 4 \pi r^{2} d r
$$

Como para valores de $r \geq R_{e}+\delta_{C}$ o perfil é assumido constante e igual a $C_{l}^{\infty}$, a integral total é calculada em cada trecho distinto:

$$
\left\langle C_{l}\right\rangle^{l}=\frac{3}{4 \pi\left(R_{f}^{3}-R_{e}^{3}\right)}\left[\int_{R_{e}}^{R_{e}+\delta_{C}} C_{l} 4 \pi r^{2} d r+\int_{R_{e}+\delta_{C}}^{R_{f}} C_{l}^{\infty} 4 \pi r^{2} d r\right]
$$

resultando em:

$$
\left\langle C_{l}\right\rangle^{l}=\frac{3}{4 \pi\left(R_{f}^{3}-R_{e}^{3}\right)} \int_{R_{e}}^{R_{e}+\delta_{C}} C_{l} 4 \pi r^{2} d r+\frac{R_{f}^{3}-\left(R_{e}+\delta_{C}\right)^{3}}{\left(R_{f}^{3}-R_{e}^{3}\right)} C_{l}^{\infty}
$$

Substituindo $C_{l}$ pela solução obtida na Eq. [E23]:

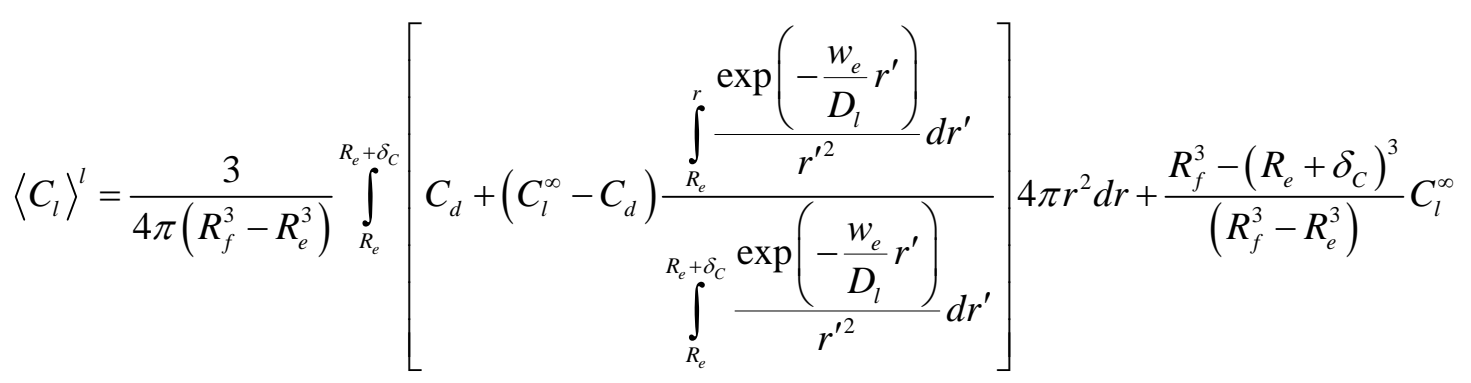

e extraindo as constantes de dentro da integral resulta em:

$$
\left\langle C_{l}\right\rangle^{l}=\frac{\left(R_{e}+\delta_{C}\right)^{3}-R_{e}^{3}}{\left(R_{f}^{3}-R_{e}^{3}\right)} C_{d}+\frac{3\left(C_{l}^{\infty}-C_{d}\right)}{4 \pi\left(R_{f}^{3}-R_{e}^{3}\right)} \frac{\int_{R_{e}}^{R_{e}+\delta_{C}}\left[\int_{R_{e}}^{r} \frac{\exp \left(-\frac{w_{e}}{D_{l}} r^{\prime}\right)}{r^{\prime 2}} d r^{\prime}\right] 4 \pi r^{2} d r}{\int_{R_{e}}^{R_{e}+\delta_{C}} \frac{\exp \left(-\frac{w_{e}}{D_{l}} r^{\prime}\right)}{r^{\prime 2}} d r^{\prime}}+\frac{R_{f}^{3}-\left(R_{e}+\delta_{C}\right)^{3}}{\left(R_{f}^{3}-R_{e}^{3}\right)} C_{l}^{\infty}
$$

Isolando $C_{l}^{\infty}$, obtemos a expressão final para esta constant em função do perfil e da concentração média $\left\langle C_{l}\right\rangle^{l}$ : 


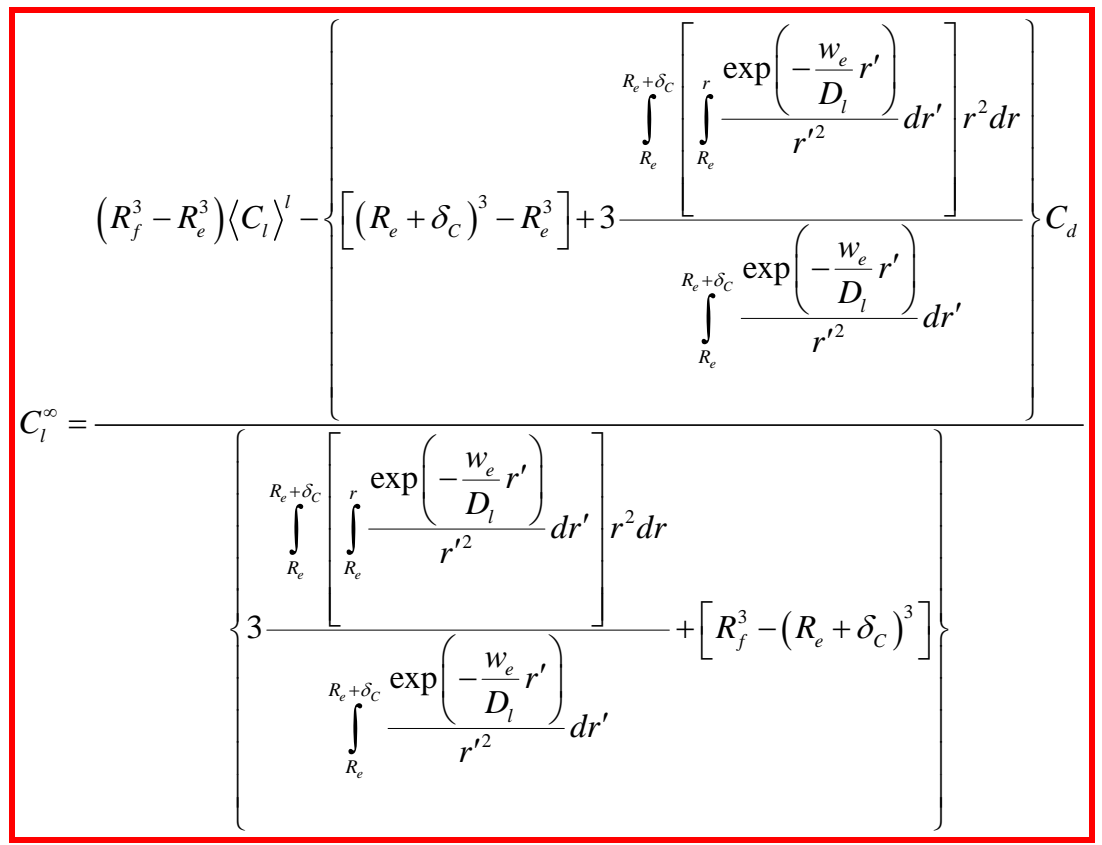

[E44]

O valor da integral dupla da expressão é calculada através da Eq. [E30]:

$$
\int_{R_{e}}^{R_{e}+\delta_{C}}\left[\int_{R_{e}}^{r} \frac{\exp \left(-\frac{w_{e}}{D_{l}} r^{\prime}\right)}{r^{\prime 2}} d r^{\prime}\right] r^{2} d r=\int_{R_{e}}^{R_{e}+\delta_{C}} \frac{P e}{R_{e}}\left\{E_{1}\left(P e \frac{r}{R_{e}}\right)-E_{1}(P e)-\frac{\exp \left(-P e \frac{r}{R_{e}}\right)}{P e \frac{r}{R_{e}}}+\frac{\exp (-P e)}{P e}\right\} r^{2} d r
$$

que, após o cálculo da integral de cada termo, se obtém a expressão final para esta integral dupla:

$$
\begin{array}{|l}
\int_{R_{e}}^{R_{e}+\delta_{C}}\left[\int_{R_{e}}^{r} \frac{\exp \left(-\frac{w_{e}}{D_{l}} r^{\prime}\right)}{r^{\prime 2}} d r^{\prime}\right] r^{2} d r=\frac{1}{3}\left\{\exp (-P e)\left[\frac{1-I v(P e)}{R_{e}}\left(R_{e}+\delta_{C}\right)^{3}-\frac{R_{e}^{2}}{P e}-\frac{R_{e}^{2}}{P e^{2}}\right]\right. \\
\left.+\exp \left(-P e \frac{R_{e}+\delta_{C}}{R_{e}}\right)\left(R_{e}+\delta_{C}\right)^{2}\left[I v\left(P e \frac{R_{e}+\delta_{C}}{R_{e}}\right)-1+\frac{R_{e}}{P e\left(R_{e}+\delta_{C}\right)}+\frac{R_{e}^{2}}{P e^{2}\left(R_{e}+\delta_{C}\right)^{2}}\right]\right\}
\end{array}
$$

Substituindo esta integral dupla na expressão de $C_{l}^{\infty}$ (Eq. [E44]): 


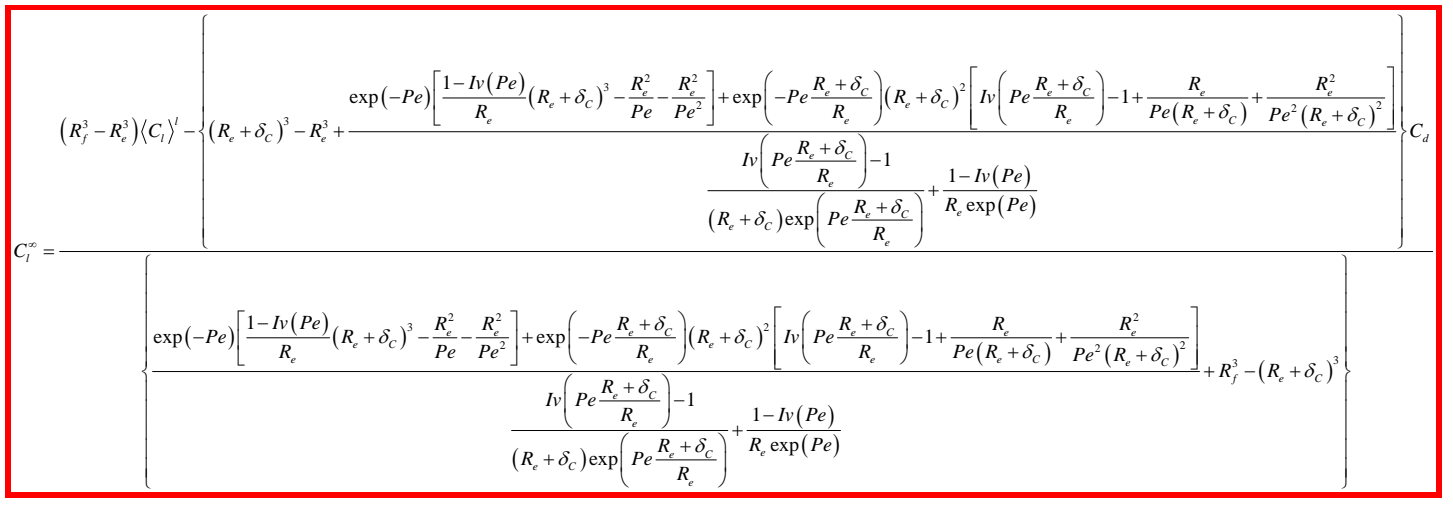

\section{Cálculo da Espessura Efetiva de Difusão do Modelo}

Utilizando uma espessura efetiva de difusão definida como no artigo Martorano et al (2003)

$$
\delta_{l d}=\frac{\left(C_{d}-\left\langle C_{l}\right\rangle^{l}\right)}{-\left.\left(\frac{\partial C_{l}}{\partial r}\right)\right|_{r=R_{e}}}
$$

é possível obter uma relação entre as duas espessuras:

$$
\delta_{l d}=\frac{C_{d}-\left\langle C_{l}\right\rangle^{l}}{C_{d}-C_{l}^{\infty}} \delta_{l d}^{*}
$$

Esta definição para a espessura efetiva de difusão é vantajosa para o modelo, pois este fornece os valores de $C_{d}$ e $\left\langle C_{l}\right\rangle^{l}$ para o cálculo do fluxo difusivo. Portanto, eliminando $C_{l}^{\infty}$ da equação substituindo a Eq. [E44], a expressão se torna: 


$$
\delta_{l d}=\left\{\frac{R_{f}^{3}-\left(R_{e}+\delta_{C}\right)^{3}}{R_{f}^{3}-R_{e}^{3}}+\frac{3}{R_{f}^{3}-R_{e}^{3}} \frac{\int_{R_{e}}^{R_{e}+\delta_{C}}\left[\int_{R_{e}}^{r} \frac{\exp \left(-\frac{P e}{R_{e}} r^{\prime}\right)}{r^{\prime 2}} d r^{\prime}\right] r^{2} d r}{\int_{R_{e}}^{R_{e}+\delta_{C}} \frac{\exp \left(-\frac{P e}{R_{e}} r^{\prime}\right)}{r^{\prime 2}} d r^{\prime}}\right\} \delta_{l d}^{*}
$$

e, finalmente, substituindo a equação para $\delta_{l d}^{*}$ (Eq. [E36]):

$$
\delta_{l d}=R_{e}^{2} \exp (P e)\left\{\frac{R_{f}^{3}-\left(R_{e}+\delta_{c}\right)^{3}}{R_{f}^{3}-R_{e}^{3}} \int_{R_{e}}^{R_{e}+\delta_{c}} \frac{\exp \left(-\frac{P e}{R_{e}} r^{\prime}\right)}{r^{\prime 2}} d r^{\prime}+\frac{3}{R_{f}^{3}-R_{e}^{3}} \int_{R_{e}}^{R_{e}+\delta_{c}}\left[\int_{R_{e}}^{r} \frac{\exp \left(-\frac{P e}{R_{e}} r^{\prime}\right)}{r^{\prime 2}} d r^{\prime}\right] r^{2} d r\right\}
$$

Substituindo as integrais pelas suas expressões calculadas em [E32] e [E46]:

$$
\begin{aligned}
& \delta_{l d}=\frac{R_{e}^{2}}{R_{f}^{3}-R_{e}^{3}}\left\{\left[R_{f}^{3}-\left(R_{e}+\delta_{C}\right)^{3}\right]\right] e^{\left.-P e\left(\frac{\left.R_{t}+\delta_{e}-1\right)}{R_{e}}\right) \frac{I V\left(P e \frac{R_{e}+\delta_{C}}{R_{e}}\right)-1}{\left(R_{e}+\delta_{C}\right)}+\frac{1-I V(P e)}{R_{e}}\right]+} \\
& \left.\left[\frac{1-I v(P e)}{R_{e}}\left(R_{e}+\delta_{C}\right)^{3}-\frac{R_{e}^{2}}{P e}-\frac{R_{e}^{2}}{P e^{2}}\right]+e^{-P e\left(\frac{R_{e}+\delta_{C}}{\left.R_{e}-1\right)}\left(R_{e}+\delta_{C}\right)^{2}\right.}\left[I v\left(P e \frac{R_{e}+\delta_{C}}{R_{e}}\right)-1+\frac{R_{e}}{P e\left(R_{e}+\delta_{C}\right)}+\frac{R_{e}^{2}}{P e^{2}\left(R_{e}+\delta_{C}\right)^{2}}\right]\right\}
\end{aligned}
$$

e rearranjando os termos, se obtém a expressão final para a espessura efetiva de difusão utilizada pelo modelo:

$$
\begin{aligned}
& \frac{\delta_{l d}}{R_{e}}=\frac{R_{e}}{R_{f}^{3}-R_{e}^{3}}\left\{\left[R_{f}^{3}-\left(R_{e}+\delta_{C}\right)^{3}\right]\left[e^{-P e\left(\frac{R_{e}+\delta_{C}}{R_{e}}-1\right)} \frac{I v\left(P e \frac{R_{e}+\delta_{C}}{R_{e}}\right)-1}{\left(R_{e}+\delta_{C}\right)}+\frac{1-I v(P e)}{R_{e}}\right]+\left[\frac{\left(R_{e}+\delta_{C}\right) R_{e}}{P e}+\frac{R_{e}^{2}}{P e^{2}}-\left(R_{e}+\delta_{C}\right)^{2}\right] e^{-P e\left(\frac{R_{e}+\delta_{C}}{R_{e}}-1\right)}\right. \\
& \left.-\left[\frac{R_{e}^{2}}{P e}+\frac{R_{e}^{2}}{P e^{2}}-\frac{\left(R_{e}+\delta_{C}\right)^{3}}{R_{e}}\right]+P e \frac{\left(R_{e}+\delta_{C}\right)^{3}}{R_{e}}\left[\frac{I v\left(P e \frac{R_{e}+\delta_{C}}{R_{e}}\right) e^{-P e\left(\frac{R_{e}+\delta_{C}}{R_{e}}-1\right)}}{P e \frac{\left(R_{e}+\delta_{C}\right)}{R_{e}}}-\frac{I v(P e)}{P e}\right]\right\}
\end{aligned}
$$

Para verificar se o caso se reduz à espessura efetiva de difusão calculada por Martorano et al (2003), utiliza-se a expressão $\delta_{C}=R_{f}-R_{e}$ : 


$$
\begin{aligned}
& \frac{\delta_{l d}}{R_{e}}=\frac{R_{e}}{R_{f}^{3}-R_{e}^{3}}\left\{\left[\frac{R_{f} R_{e}}{P e}+\frac{R_{e}^{2}}{P e^{2}}-R_{f}^{2}\right] e^{-P e\left(\frac{R_{f}}{R_{e}}-1\right)}-\left[\frac{R_{e}^{2}}{P e}+\frac{R_{e}^{2}}{P e^{2}}-\frac{R_{f}^{3}}{R_{e}}\right]\right. \\
& \left.+P e \frac{R_{f}^{3}}{R_{e}}\left[\frac{I v\left(P e \frac{R_{f}}{R_{e}}\right) e^{-P e\left(\frac{R_{f}}{R_{e}}-1\right)}}{P e \frac{R_{f}}{R_{e}}}-\frac{I v(P e)}{P e}\right]\right\}
\end{aligned}
$$

que é exatamente a expressão escrita em Martorano et al. (2003).

\section{Cálculo da Espessura de Estagnação}

Para o cálculo da espessura de estagnação $\delta_{C}$, é necessário que a função desta espessura, substituída na Eq. [E37], garanta que a espessura efetiva de difusão $\delta_{l d}^{*}$ convirja para os casos limites conhecidos (os casos limites tem espessura efetiva de difusão com a mesma definição que $\delta_{l d}^{*}$ ). O primeiro limite é o de velocidade de crescimento de interface nula, ou seja, para valor de $P e=0$. Substituindo o valor nulo para o Peclet na expressão de $\delta_{l d}^{*}$ :

$$
\delta_{l d}^{*}=R_{e}^{2}\left[\frac{1}{R_{e}}-\frac{1}{\left(R_{e}+\delta_{C}\right)}\right]
$$

resultando na média harmônica entre $R_{e}$ e $\delta_{C}$ :

$$
\delta_{l d}^{*}=\frac{R_{e} \delta_{C}}{R_{e}+\delta_{C}}
$$

Portanto, isolando $\delta_{C}$, obtemos uma expressão que deve ser sempre obedecida para casos com $P e=0$ : 


$$
\delta_{C}=\frac{R_{e} \delta_{l d}^{*}}{R_{e}-\delta_{l d}^{*}}
$$

Se posicionarmos a espessura de estagnação sobre o raio de referencia $R_{f}$, a solução obtida é igual a equação de Martorano et al. (2003) para o valor de Peclet nulo, que deve ser igual a solução de um modelo para a espessura efetiva de difusão só considerando a convecção, para o valor de Reynolds nulo. Assim, garantindo que ambos os modelos convirjam para o mesmo valor quando os valores de Peclet e Reynolds tenderem a zero. Substituindo $\delta_{C}$ por $R_{f}-R_{e}$ :

$$
\delta_{l d}^{*}=\frac{R_{e}\left(R_{f}-R_{e}\right)}{R_{f}}
$$

$\mathrm{Na}$ literatura, foi encontrada uma equação para a espessura efetiva de difusão que tende a este limite no trabalho de Rowe e Claxton (1965), que é dada pela relação abaixo:

$$
S h=\frac{2}{1-(1-\varepsilon)^{1 / 3}}+\frac{2}{3 \varepsilon} \operatorname{Re}^{n} S c^{1 / 3}
$$

com $\varepsilon$ igual a fração de volume livre no leito fluidizado de esferas empacotadas (em diferentes arranjos), que neste modelo será igual à própria fração de líquido extradendrítico $\varepsilon_{l}$; e $n$ igual a:

$$
n=\frac{2+4,65 \mathrm{Re}^{-0,28}}{3\left(1+4,65 \mathrm{Re}^{-0,28}\right)}
$$

podemos verificar que, com a expressão que correlaciona $R_{f}$ e $R_{e}$ no artigo de Wang e Beckermann (1993):

$$
\frac{R_{e}}{R_{f}}=\left(1-\varepsilon_{l}\right)^{1 / 3}
$$


verifica-se que para $\operatorname{Re}=0$, a expressão apresenta o mesmo limite que a espessura do modelo para valor de $P e=0$ e para qualquer valor de $R_{f}$ :

$$
S h \equiv \frac{2 R_{e}}{l_{l d}}=\frac{2}{1-\frac{R_{e}}{R_{f}}} \Rightarrow l_{l d}=\frac{R_{e}\left(R_{f}-R_{e}\right)}{R_{f}}
$$

Para garantir que o número de Sherwood seja equivalente ao calculado pela relação de Ranz-Marshall (caso de uma esfera isolada, ou seja, $R_{f} \rightarrow \infty$ ), o valor de $n$ deve ser constante e igual a 0,5 . Como $n$ varia num intervalo próximo de 0,5 para os valores de Reynolds do modelo, este assumirá este valor constante nos cálculos do modelo.

Para obter a expressão final, é feita a hipótese de que a espessura de estagnação não é função do número de Peclet (ou seja, do crescimento da esfera), sendo apenas função do adimensional de Reynolds ( $\mathrm{Re}$ ). Portanto, com a expressão para o adimensional de Sherwood (Sh) do trabalho de Rowe e Claxton (1967), a expressão para a espessura de estagnação é dada por:

$$
\delta_{C}=\frac{R_{e} \frac{2 R_{e}}{S h}}{R_{e}-\frac{2 R_{e}}{S h}} \Rightarrow \delta_{C}=\frac{2 R_{e}}{(S h-2)}
$$

e, finalmente, substituindo as expresses, a equação final para $\delta_{C}$ é dada por:

$$
\delta_{C}=\frac{R_{e}}{\frac{R_{f}}{R_{f}-R_{e}}+\frac{\operatorname{Re}^{n} S c^{1 / 3}}{3-3\left(R_{e} / R_{f}\right)^{3}}-1}
$$

\section{Gráficos para Espessura Efetiva de Difusão}

Foram feitos dois gráficos para ilustrar o comportamento da função para a espessura efetiva de difusão. O primeiro ilustra a espessura em função dos 
adimensionais de Reynolds e Peclet para valores de $R_{e}=10^{-4} \mathrm{~m}$ e $R_{f}=4 \times 10^{-4} \mathrm{~m}$ constantes. No plano em que o valor de Reynolds é igual a zero, temos a solução do artigo de Martorano et al. (2003), enquanto no plano para Peclet igual a zero, é exibida a solução para a espessura efeitva de difusão de Rowe e Claxton (1967).

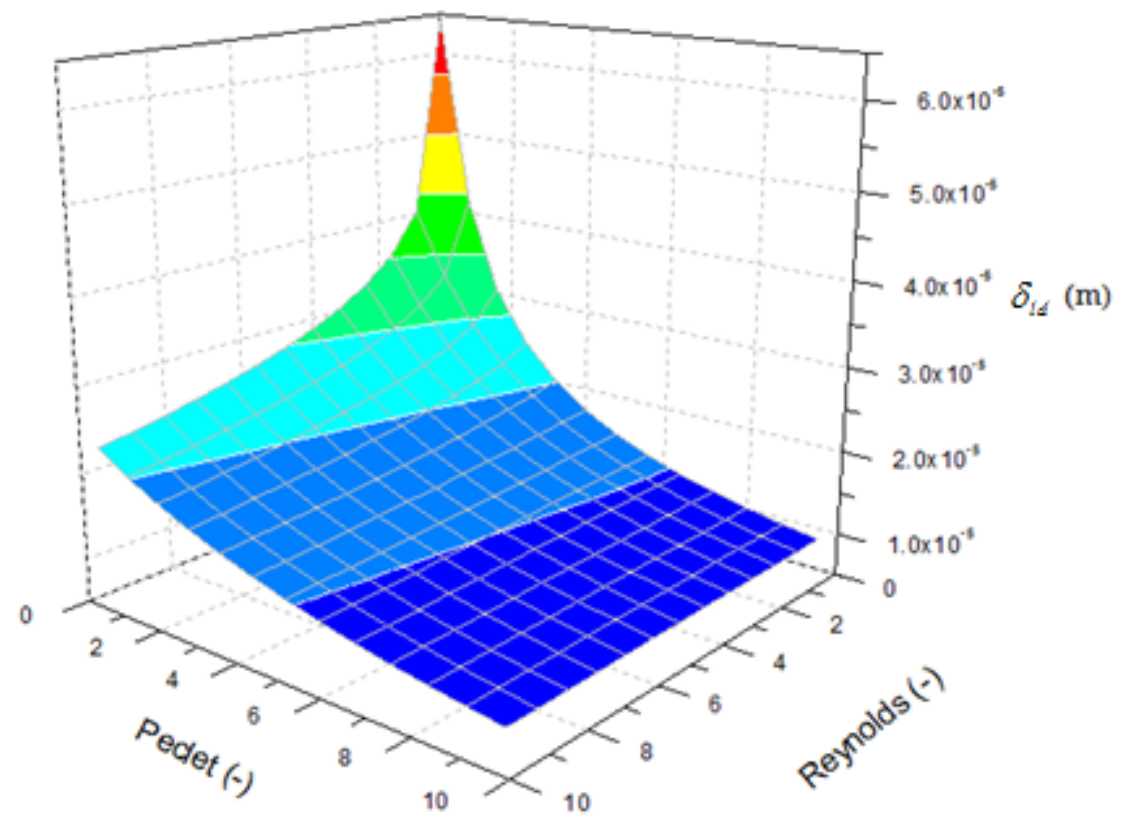

Figura E2 - Espessura efetiva de difusão $\delta_{l d}$ em função dos adimensionais de Reynolds e de Peclet e com $R_{e}=10^{-4} \mathrm{~m}$ e $R_{f}=4 \times 10^{-4} \mathrm{~m}$ constantes

No segundo gráfico, é ilustrada a espessura efetiva de difusão em função do raio de referência $R_{f}$ e o adimensional de Reynolds para valor de Peclet constante e igual a 0,02. No plano de Reynolds igual a zero, temos a solução do artigo de Martorano et al. (2003) e no plano para $1 / R_{f}$ igual a zero $\left(R_{f} \rightarrow \infty\right)$, temos a solução de Ranz-Marshall (1952). 


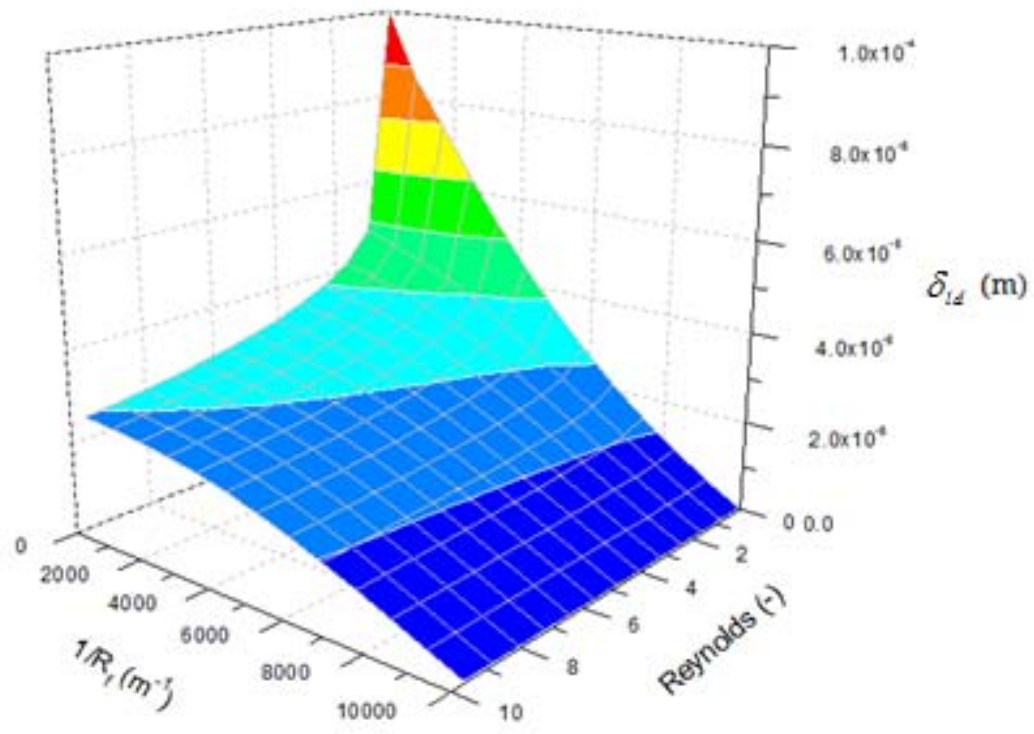

Figura E3 - Espessura efetiva de difusão $\delta_{l d}$ em função do raio de referência $R_{f}$ e do adimensional de Reynolds com Peclet constante igual a 0,02. 